\title{
Technical Program Plan for the Transitioning, Decommissioning, and Final Disposition Focus Area
}

Office of Technology Development

Office of Environmental Restoration and Waste Management

Prepared by the D\&D Integrated Demonstration Technical Support Group

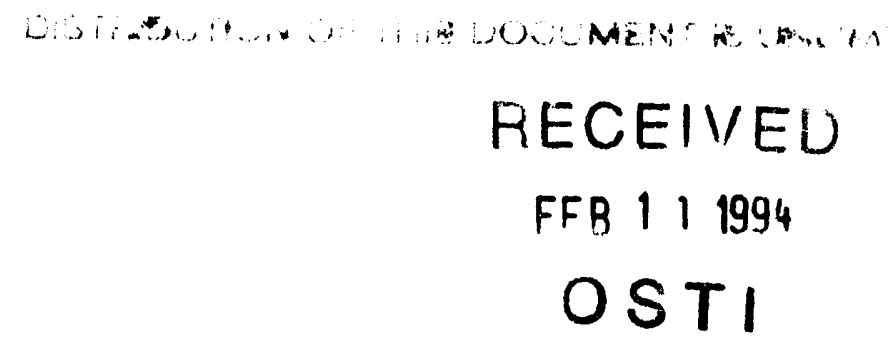




\section{Disclaimer}

This report was prepared as an account of work sponsored by an agency of the United States Government. Neither the United States Government nor any agency thereof, nor any of their employees, makes any warranty, express or implied, or assumes legal liability or responsibility for the accuracy, completeness, or usefulness of any information, apparatus, produce, or process disclosed, or represents that its use would not infringe privately owned rights. Reference herein to any specific commercial product, process, or service by trade name, trademark, manufacturer, or otherwise, does not necessarily constitute or imply its endorsement, recommendation, or favoring by the United States Government or arly agency thereof. The views and opinions of authors expressed herein do not necessarily state or reflect those of the United States Government or any agency thereof.

This document has been reproduced directly from the best available copy.

This document is available to DOE and DOE contractors through the Office of Scientific and Technical Information, P.O. Box 62, Oak Ridge, TN 37831. For price information, call (615) 576-8401.

This document is available to the public through the National Technical Information Service, U.S. Department of Commerce, 5285 Port Royal Road, Springfield, VA 22161. For price information, call (703) 487-4650. 


\title{
Technical Program Plan for the Transitioning, Decommissioning, and Final Disposition Focus Area
}

\author{
Office of Technology Development \\ Office of Environmental Restoration \\ and Waste Management
}

\section{Prepared by}

D\&D Integrated Demonstration

Technical Support Group 


\section{Acknowledgments}

This program plan was developed under the nianagement and leadership of Jerry $M$. Hyde, DOE-HQ Program Manager for the Office of Technology Development, ard Johnny O. Moore, Technical Program Officer, DOE Oak Ridge Operations Office. They were assisted in overall planning and strategy development for this endeavor by R. Keith Kibbe, D\&D Integrated Demonstration Coordinator (D\&D IDC), Martin Marietta Energy Systems.

The detailed planning and analysis reflected in this document was conducted by the D\&D ID Technical Support Group, a group of individuals selected by the EM-30, -40, and -60 field organizations for their knowledge of specific problems and/or their technical expertise (see page 48 for a list of the members of each planning team).

Bill Austin, WSRC (EM-40)

R.W. Bailey, WHC (EM-60)

Charles Baldwin, EG\&G-RFP (EM-30, $-40,-50)$

G.E. Bingham, WINCO (EM-30)

Bill Boettinger, WSRC-WMER (EM-50)

Roy Bundy, MMES (EM-40)

Keith Cavin, EG\&G-RFP (EM-60)

Yolanda Childs, MMES (EM-40)

Todd Clark, FERMCO (EM-40)

Mike Coffey, ANL (EM-40)

Jeff Colson, WINCO (EM-40, -60)

Martin Edelson, Ames (EM-50)

Brad Frazee, WINCO (EM-30)

Sue Garrett, PNL (EM-40)

Bill Hamel, MMES (EM-50)

Wayne Hayden, MMES (EM-50)

Frank Heckendorn, WSRC (EM-30)

Bill Heine, WHC (EM-40)
Don Henley, ANL (EM-40, 60)

Charles Hensley, MMES (EM-40)

Don Herman, FERMCO (EM-40)

Doug Hoffmann, MMES (EM-40, -50)

Susan Howell, MMES (EM-40)

Jim Johnessee, WPI (EM-50)

Duncan MacArthur, LANL (EM-50)

Mark McKay, WINCO (EM-30, -50)

Ken Merrill, EG\&G-ID (EM-40, -50, -60)

Dick Meservey, EG\&G-ID (EM-40, -50, $-60)$

Rod Meyer, ETEC (EM-30, -40, -50)

Louise O'Brien, LANL (EM-40, -60)

Blynn Prince, MMES (EM-40)

Miguel Salazar, LANL (EM-40, -60)

Pete Sanford, KMI-RFP (EM-40)

Gary Street, WSRC-SRS (EM-60)

Andre Williams, WHC (EM-30)

Planning and development strategy assistance was also provided by Rodney Grubb, former Deputy Integrated Demonstration Coordinator, Martin Marietta Energy Systems (through August 1993), Daniel Phifer, K-25 Site Technical Division, Martin Marietta Energy Systems, and Kristen Clark, Martin Marietta Energy Systems.

The FY93 meetings of the Technical Support Group that resulted in the preparation of this document were facilitated by Ware Hartwell, Los Alamos National Laboratory, and Ladonna Robson, Lawrence Livermore National Laboratory.

Documentation and editing were performed by James McDonald, Los Alamos National Laboratory.

Martin Marietta Energy Systems K-25 Site Central Printing and Linda Amburn, Martin Marietta Energy Systems, were responsible for final printing and distribution. 


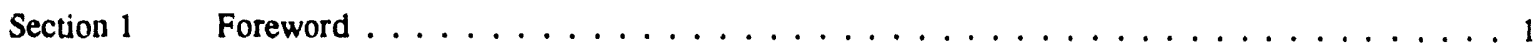

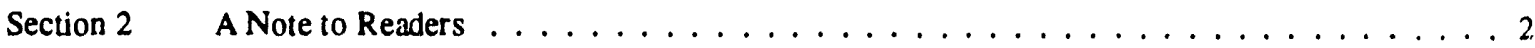

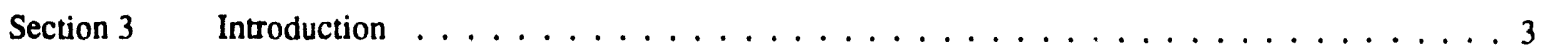

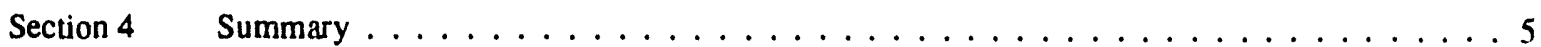

Section 5 Recommendations $\ldots \ldots \ldots \ldots \ldots \ldots \ldots \ldots \ldots \ldots \ldots$

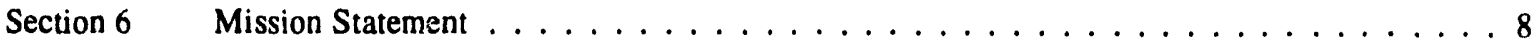

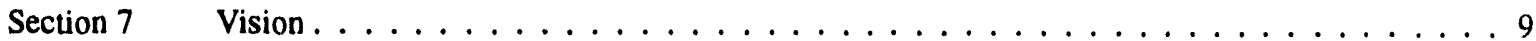

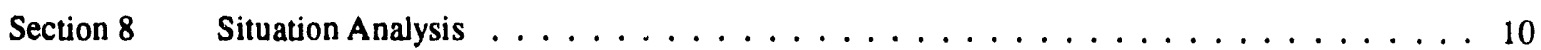

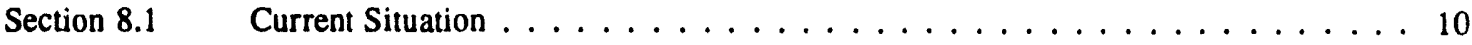

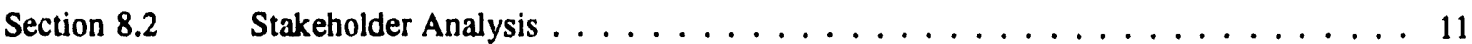

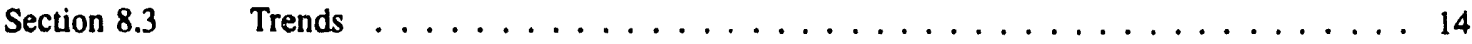

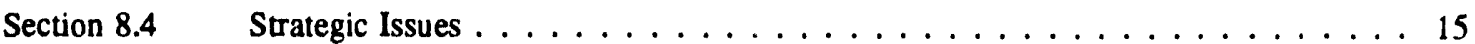

Section 9 Benefits/Strengths of the ID Strategy $\ldots \ldots \ldots \ldots \ldots \ldots \ldots \ldots \ldots \ldots$

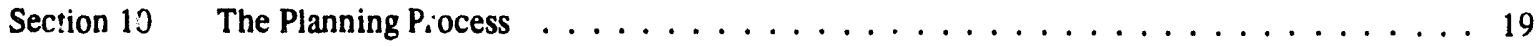

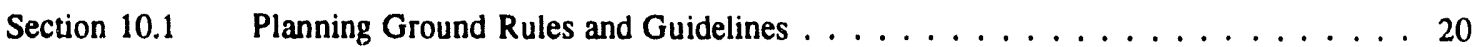

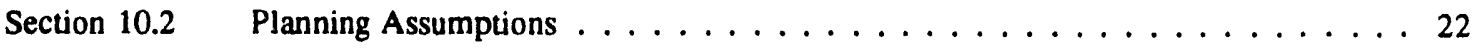

Section 11 The Recommended IDs $\ldots \ldots \ldots \ldots \ldots \ldots \ldots \ldots \ldots \ldots \ldots$

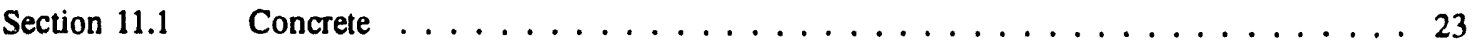

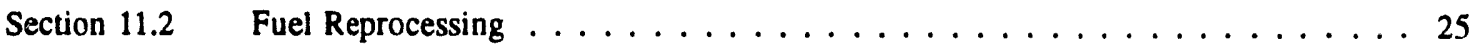

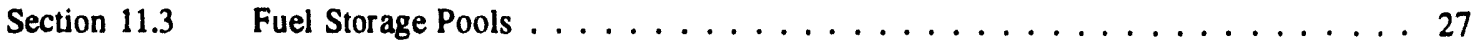

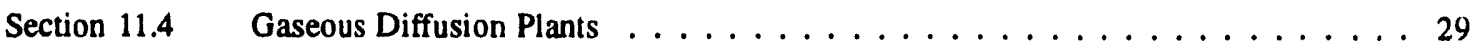

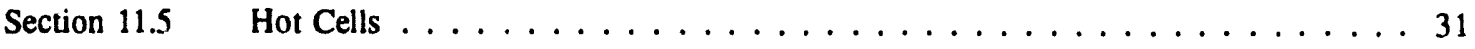

Section $11.6 \quad$ Lithium-processing Facilities $\ldots \ldots \ldots \ldots \ldots \ldots \ldots \ldots \ldots \ldots$

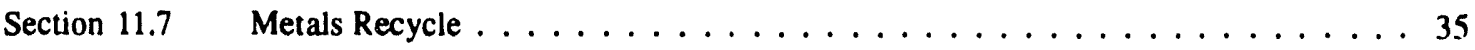

Section $11.8 \quad$ Plutonium-processing Facilities: De-inventory and Deactivation $\ldots \ldots \ldots \ldots$

Section 11.9 Plutonium-processing Facilities: Equipment $\ldots \ldots \ldots \ldots \ldots \ldots$

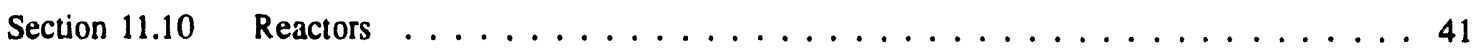

Section 11.11 Uranium-processing Facilities: Process Systems $\ldots \ldots \ldots \ldots \ldots \ldots \ldots$

Section 11.12 Uranium-processing Facilities: Asbestos/Transite . . . . . . . . . . . . . 44

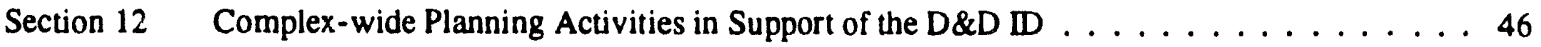

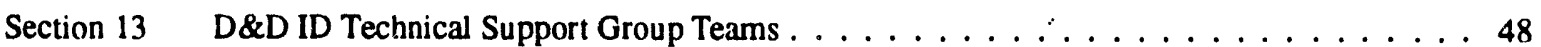

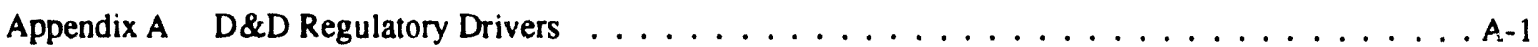

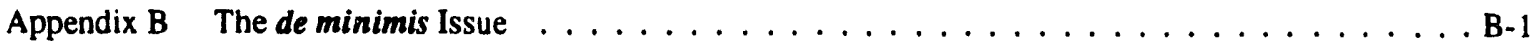

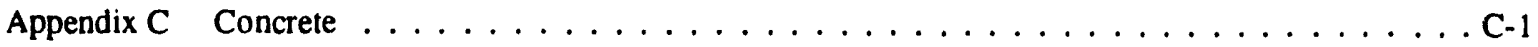

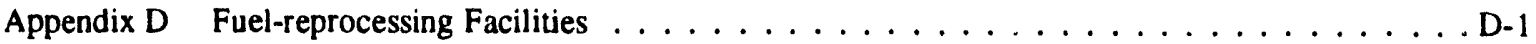


Appendix E Fuel Storage Pools $\ldots \ldots \ldots \ldots \ldots \ldots \ldots \ldots \ldots \ldots \ldots \ldots$

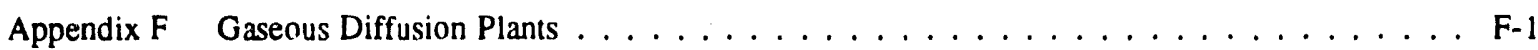

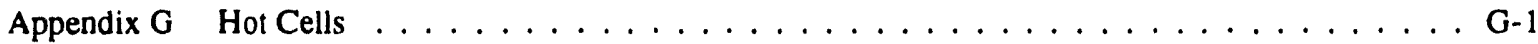

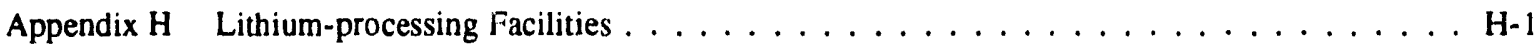

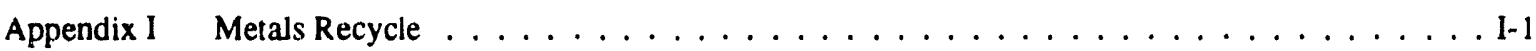

Appendix $\mathrm{J}$ Plutonium-processing Facilities $\ldots \ldots \ldots \ldots \ldots \ldots \ldots \ldots \ldots \ldots \ldots$

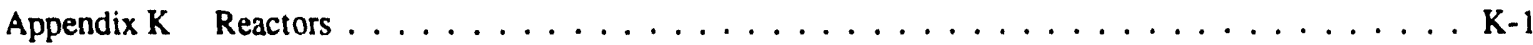

Appendix $\mathrm{L}$ Uranium-processing Facilities $\ldots \ldots \ldots \ldots \ldots \ldots \ldots \ldots \ldots \ldots \ldots$

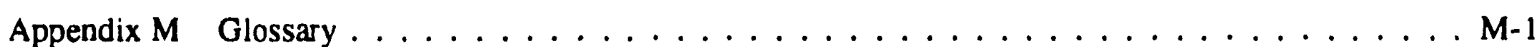


Section $1 \quad$ Foreword

Hundreds of aging nuclear materials processing facilities within the Deparment of Energy's (DOE) Weapons Complex are now being shut down and deactivated. These facilities, situated throughout the United States, will require a monumental effort to clean up safely and with minimal environmental insult.

Current cleanup technologies tend to be labor intensive and expensive, they produce an unacceptably large volume of waste, and they expose workers to radioactive and other hazardous substances.

This document describes an emerging program designed to develop and demonstrate new technical approaches to the decontamination and decommissioning (D\&D) program for DOE's nuclear materials processing facilities. Sponsored by the DOE Office of Technology Development within the Office of Environmental Restoration and Waste Management (EM), the program seeks to integrate the strengths of DOE's technical, managerial, and systems engineering capabilities with those of industry, universities, and other government agencies. Once developed, these technologies will help to provide U.S. industry with a competitive edge in the worldwide market that exists for improved environmental restoration and D\&D services. 
Section 2

\section{A Note to Readers}

This document begins with approximately twenty pages of overview and background information, followed by a series of one-page, summary descriptions of the twelve proposed demonstrations. The balance of the document consists of appendices that contain detailed descriptions of the proposed demonstrations.

A detailed reading of the appendices will reveal some duplication of technologies for the various demonstrations. This was done in order to provide the reader with a complete description of the technology needs of each problem area. This program has a unique opportunity to identify and eliminate such duplication, when DOE decides which demonstrations will be conducted.

Although not precise calculations, the cost estimates contained in this document were provided by the technical professionals familiar with current project costs. These estimates are sufficient in many instances to support a decision to pursue the development of new technical approaches on the basis of cost payback.

DOE is committed to providing the public with opportunities to participate meaningfully in decisions that affect their communities. Involving the public will help DOE make better decisions that incorporate legal, technical, economic, environmental, and social factors and that respect public values and concerns. If, after technical and economic analysis, DOE decides that it would be beneficial to conduct a demonstration in a particular location, the affected community will be asked to participate in a review of the technical merits of the plan and to communicate any concerns its members might have relative to the plan. 


\section{Section 3 . Introduction}

The end of the Cold War and the decision to reduce the size of the nuclear weapons production complex have created a need for DOE to deactivate, decontaminate, and decomznission (D\&D) a large number of aging, surplus facilities. The nature and magnitude of the facility $D \& D$ problems require EM to facilitate the development and application of technologies that will address these problems quickly and cost-effectively. The needed technologies can best be provided by integrating the strengths of DOE's national laboratories with those of industry, universities, and other government agencies. To help focus and direct these activities toward achieving DOE's goals, the EM Office of Technology Development (OTD) devised the strategic concept of an Integrated Demonstration (ID), which involves selecting, demonstrating, testing, and evaluating an integrated set of technologies tailored to provide a complete solution to specific EM problems, such as those posed by D\&D.

The ID approach allows optimal use of DOE's resources by avoiding duplication of effort and ensuring rapid demonstration of applicable technologies. Many technologies, including both the commercially mature and the innovative, are combined and evaluated for a cradle-to-grave solution to specific EM problems in areas such as D\&D. The process will involve transforming an existing problem condition to a desired end state, recycling waste materials generated, wherever feasible, and minimizing requirements for waste disposal.

The D\&D ID Strategic Plan has been prepared by a Technical Support Group (TSG) assembled from various sites within the DOE Complex and intended to identify cross-cutting problem areas amenable to applications of the D\&D ID concept and to develop specific ID proposals for these problem areas. The primary focus is technology demonstration activities that can be initiated and completed during the next five years (1994-99). The proposed IDs, however, are part of a broader, long-range effort to provide improved technologies for effecting the transition and D\&D of all surplus DOE facilities. 
In this document, the term integrate will be used according to its dictionary definition: "to form into a whole," or "to incorporate into a larger unit." We have chosen a systems approach which involves integration through several different dimensions or levels: the integration of technologies to form complete solutions to key D\&D problem areas; the integration of problem areas, needs, and implementation approaches across the DOE Complex; and the integration of development resources (i.e., institutions, personnel, facilities, and equipment to meet these needs). Therefore, while the total plan refers to a D\&D Integrated Demonstration, we have also referred to IDs that are components of this total plan and that are directed at specific D\&D problem areas. 


\section{Section $4 \quad$ Summary}

The D\&D ID Strategic Plan outlines and recommends a structured approach to dispositioning DOE's equipment and facilities that have become surplus as a result of recent Complex-wide mission decisions.

The Strategic Plan identifies a functional facility approach to D\&D that, when viewed as a whole

- effectively encompasses all existing DOE equipment and facilities;

- identifies IDs to be performed;

- identifies facilities at which the recommended IDs could be performed effectively;

- provides level-one schedules and rough order of magnitude cost estimates for each ID;

- identifies needed technology developments essential to each ID; and

- identifies unique needs (e.g., human skills) essential to the success of the proposal.

The IDs identified and recommended in the Strategic Plan include concrete, fuel-processing facilities, fuel storage facilities, gaseous diffusion plant equipment, hot cells, lithium-processing facilities, metals recycle, plutonium-processing facilities, reactors, and uranium-processing facilities. These IDs were selected and recommended in order to

- optimize the use of DOE resources through integrated planning and avoidance of duplication;

- demonstrate cradle-to-grave methods and solutions;

- effect desired facility end use;

- maximize reuse/recycle of materials and equipment;

- minimize waste types and volumes; and

- ensure adequate protection to workers, the public, and the environment. 
Several assumptions are basic to the D\&D ID philosophy, approach, and potential success, including:

- DOE top management support;

- adequate funding;

- continuous interfacing and communications;

- formation of a Complex-wide planning and analysis group;

- efficient stakeholder interface program;

- development and implementation of de minimis standards; and

- appropriate involvement of industry and academia. 


\section{Section $5 \quad$ Recommendations}

The following recommendations are basic to the success of the D\&D ID concept.

1. Obtain a commitment of support and involvement from EM-20, -30, -40, -50, and -60 .

2. Use this Strategic Plan to organize and support Complex- and site-specific planning and analysis efforts for D\&D.

3. Evaluate and select specific IDs to be funded and pursued.

4. Initiate selected technical development efforts.

5. Organize stakeholder, industry, and academia involvement and input into this Strategic Plan.

6. Resolve de minimis standards issues.

7. Execute the strategic planning studies identified in Section 12.

8. Obtain feedback from the field and update the D\&D ID Strategic Plan annually.

The TSG believes that each of the IDs identified in this document have technical merit and recommends that each be considered by the Planning Review Group for possible funding. No recommendations are included herein with respect to timing and prioritization of individual demonstrations.

These recommendations need to be evaluated as soon as possible, and decisions made and actions initiated to ensure a viable D\&D ID effort that will provide a solid basis upon which to plan, organize, and actively pursue effective and efficient Complex-wide D\&D programs.

Support of the D\&D ID concept will provide significant benefits to DOE, including technology developments, proven solutions, and public support, all of which will lend support to a credible, cost-effective D\&D approach. 


\section{Section $6 \quad$ Mission Statement}

The mission of the TSG is to develop and implement the strategy for an ID of D\&D for inactive facilities and sites across the DOE Complex that uses the best technological approaches in terms of cost-effectiveness and risk reduction. This will be accomplished by

- identifying certain key problem areas in D\&D (some of which are common to a number of sites in the Complex, others of which are more site-specific), which collectively make up the most significant technical challenges and offer specific opportunities for significant benefits from an improved technological approach to D\&D;

- selecting a set of appropriate technologies, each of which is either sufficiently mature in development or can be brought to the necessary stage for field demonstration of a complete, technically integrated solution for the identified problem area, within a specified time period (e.g., five to seven years);

- selecting an appropriate scope for the demonstrations as well as suitable locations within the DOE Complex where specific steps of the demonstrations can be performed to best advantage; and

- performing the technology demonstrations and testing, evaluating, and reporting the results. 


\section{Section $7 \quad$ Vision}

The results from the D\&D ID will provide a solid basis for selecting improved technical approaches to D\&D and related activities and will be used as reference bases and models to assist other DOE/EM Offices in planning future, large-scale tasks involving Facilities Transition (EM-60), D\&D (EM-40), and associated Waste Management (EM-30). Many of these tasks must be undertaken during the next two decades so as to support the current EM Program mission oi ensuring that risks to human health and safety and to the environment posed by the inactive and surplus facilities are either eliminated or reduced to publicly acceptable levels. The results of the IDs developed and implemented during the next five to seven years can optimize the technical approaches used to complete these tasks. Moreover, the results of the ID process will serve to guide future technology development by identifying any significant technology needs and gaps in the current programs.

A fundamental goal of D\&D must be to avoid or minimize the chances that future generations will be required to correct the situations remaining after D\&D has been juclged completed by the agencies currently responsible for these actions. The ideal model of true D\&D supporting this goal improves the separation of all hazardous components from benign or economically recyclable materials, treatment, and concentration of the former into small volumes, stabilization of these volumes against future environmental dispersal, and placement in engineered long-term repositories. This ideal depends upon technological knowledge and engineering capabilities in specific problem areas. However, adhering to the ideal as a guiding principle implies that true $D \& D$ is not merely a reverse line-item construction activity (i.e., takedown and burial of contaminated equipment and structures), carried out simply because it is not currently cost-effective to do otherwise. Instead, a range of strategies need to be employed to meet the needs of both the present and the future. 


\section{Section $8 \quad$ Situation Analysis}

Section 8.1 Current Situation

DOE is going through dramatic changes: it is moving from a mission of producing nuclear weapons to increased emphasis on Complex-wide safety, cleanup, and mitigation of environmental risks and concerns. The resulting reconfiguration of the DOE Complex will profoundly affect the EM program, especially the increasing number of surplus defense program facilities that will require shutdown, deactivation, and, eventually, D\&D. Methods and technologies used in past D\&D efforts were adequate on a small scale and may still be appropriate for some tasks; however, exclusive reliance on these technologies could result in serious deficiencies in the rapidly expanding D\&D program. Current technology tends to be labor intensive and expensive, it produces an unacceptably large volume of waste, and it exposes workers to radioactivity and hazardous substances unnecessarily. These facts point to a need for increased emphasis on improving the technologies.

The types of facilities to be included in the D\&D program span a broad range of past production and research and development support functions. For example:

- uranium-processing facilities (feed materials preparation, uranium enrichment, fuel fabrication);

- reactors (materials production, research);

- irradiated fuels storage facilities (basins);

- fuel-reprocessing facilities (remotely operated canyons);

- hot cells;

- plutonium-processing facilities; and

- $\quad$ special materials processing facilities (e.g., lithium).

A large number of support and adjunct facilities associated with these major facility types are also included in the scope of D\&D requirements.

The appendices to this document contain descriptions of the proposed D\&D IDs, the magnitude of the requirements for specific problem areas, and the problem attributes common to several major functional areas. The process for identifying and selecting the problems provided a basis for developing proposals for specific D\&D IDs that address the identified problems.

The D\&D of these surplus facilities is expected to generate very large quantities of waste materials, including large amounts of secondary wastes. Wastes will include the primary materials generated from decontamination 
and dismantlement/demolition and also secondary wastes from processes used to accomplish these tasks. The potential for economic benefits to the U.S. taxpayer from recovery and recycle of some of these materials is correspondingly large. Initially, the focus should be on materials with highest recovery values (e.g., metals such as nickel, stainless steel, mercury, aluminum, copper); however, all waste material streams generated should be considered for reuse/recycle intil analysis shows that this is infeasible. Appropriate separation and treatment of hazardous components of these material streams will be needed. There is significant interest in developing materials disposition strategies that optimize recovery of economically valuable materials and thereby reduce requirements and problems associated with future disposal in landfills. Thus, technologies that enhance material recovery potential are an important component of the D\&D ID strategy.

\section{Section $8.2 \quad$ Stakeholder Analysis}

A large number of organizations and individual stakeholders will be involved, either directly or indirectly, in the outcome of the D\&D ID. These include the DOE as a primary stakeholder, various government regulatory agencies, commercial enterprises, local communities in the vicinity of DOE sites, and the general public. The following is an analysis of stakeholder interests.

\section{DOE}

The charter for DOE/EM programs includes the treatment and disposal of radioactive and chemical waste generated by DOE operations, minimizing the generation of additional waste, cleaning up contaminated sites, and developing the necessary supporting technology to achieve these ends. Current DOE policy relating to the Decommissioning of Radioactively Contaminated Facilities (DOE Order 5820.2A, Chapter V, 1988) states:

Radioactively contaminated facilities for which DOE is responsible shall be managed in a safe, cost-effective manner to assure that release of, and exposure to, radioactivity and other hazardous materials comply with Federal and State standards.

Facilities, equipment, and valuable materials shall be recovered and reused when practical. 
In defining requirements for developing programs that implement this policy, the DOE Order also states:

DOE Program organizations shall identify contaminated facilities under their jurisdiction, document the potential for reuse and recovery of materials and equipment, and develop sciuedules for decommissioning them. Projects consisting of one or more facilities shall be identified as appropriate, and priorities shall be developed based on:

(a) Maintaining employee and public health and safety,

(b) Protection of the environment,

(c) Compliance with the National Environmental Policy Act (NEPA), the Resource Conservation and Recovery Act (RCRA), the Comprehensive Environmental Response, Compensation, and Liability Act (CERCLA), the Superfund Amendments and Reauthorization Act (SARA), and other contractual and legal requirements,

(d) Cost-effective program management (e.g., maintaining manpower pools, selecting economical decommissioning alternatives), and

(e) Future site plans.

These post-operational requirements and criteria will form the background for all decommissioning projects and activities at DOE sites, including the D\&D ID.

\section{Regulatory Agencies}

The regulatory framework applicable to all EM activities will be an important consideration in planning and implementing the D\&DID. In addition to DOE, the Environmental Protection Agency (EPA) and other federal and state regulatory agencies will be directly involved in these activities.

See Appendix A, "Regulatory Drivers," for a brief summary of the principal health, safety, and environmental laws and regulations affecting all D\&D activities that will be undertaken in the near future. These regulatory stakeholder interests will be served by ensuring that the D\&D ID projects comply with these laws and regulations and that these compliance benefits can be extended to larger-scale tasks to be undertaken later. Also, as indicated in the situation analysis described above, regulatory stakeholder interests need to extend beyond the present to recognize the possibility that future generations may establish more stringent regulatory standards than those applicable under current environmental laws. The -3monstration of innovative and more efficient technological approaches for \lrcorner $\& D$ would support these interests. 


\section{Public Involvement}

DOE is committed to providing the public with opportunities to participate meaningfully in decisions that affect their communities. Involving the public will help DOE make better decisions that incorporate legal, technical, economic, environmental, and social factors and that respect public values and concerns. If, after technical and economic analysis, DOE decides that it would be beneficial to conduct a demonstration in a particular location, the affected community will be asked to participate in a review of the technical merits of the plan and to communicate any concerns its members might have relative to the plan.

Each DOE operations office has an EM community relations representative charged with the responsibility of maintaining an ongoing relationship with the local community. These representatives would be the point of contact when specific sites are identified as technically desirable for demonstrating technologies. Through the local EM community relations representatives, information would be shared with the public about the technical and economic reasons the site was identified as the preferred location to test the technology. Public meetings would be publicized through mass mailings to existing mailing lists and through local advertisements, and provisions wouta be made for gathering public comments and concerns as well as dispersing information about the technology demonstration.

The local governmental, economic, and environmental agencies would also be informed by direct mailings of the proposed demonstration, and opportunities would be made available to meet and discuss the idea. No action would be taken on any proposed demonstration without rigorous efforts to inform and involve the public.

\section{Other Stakeholders}

Stakeholder input in D\&D and other EM activities at DOE sites comes from local communities, state environmental organizations, tribal governments, operations contractors, local businesses, and special interest groups. These stakeholders will benefit from the D\&D ID through mitigation of public concerns over future health risks and through potential conversions of these sites to productive uses. Some commercial and industrial organizations also have an important stake in the $\mathrm{ID}$, as major suppliers of the technologies and commercial services ultimately involved in future D\&D applications, both in the U.S. and abroad. Finally, the U.S. taxpayer is the ultimate funding source for cleanup of inactive defense facilities; hence, there should be general incentives for demonstrating improved and more cost-effective methods for accomplishing these tasks, in a time when there are many competing demands on all public funds. 


\section{Section $8.3 \quad$ Trends}

Developments are now occurring within the Facilities Transition Program (EM-60) that will result in a large legacy of radioactive and chemical waste materials requiring disposal.

Regulatory requirements continue to become both more complex and more restrictive, with an increasing role for regulators and state and local governments in all EM activities.

Decision-making in DOE/EM programs is becoming more decentralized, with increasing public involvement in evaluating all EM activities, including D\&D.

There is increasing emphasis on preventing pollution by minimizing waste generation at the source points and by maximizing recycling/reuse of materials wherever feasible.

Partnerships between DOE, contractors, EPA, academia, and industry are increasingly useful for bringing expanded expertise to technology development problems. These partnerships will help promote the transfer and diffusion of innovative technologies and methods for application to environmental problems in both the U.S. and other nations.

- The necessary human resources, including the appropriate skill mix, needed to perform the IDs will be available as needed.

- Funding for all EM programs, including technology development, will be limited; therefore, an emphasis will be placed on technologies with potentially high cost payback.

- Recycling of equipment, metals, and other materials generated by $D \& D$ activities will be performed in accordance with existing regulations and DOE/nuclear industry needs. 


\section{Section 8.4 Strategic Issues}

Certain unresolved issues associated with the general situation in which D\&D activities will be undertaken need to be recognized, since they could influence the selection and scheduling priorities for implementing specific IDs:

- Budgetary Constraints and Resource Planning The DOE/EM programs will be conducted under increasing budgetary constraints which are likely to influence the scope of efforts undertaken in the Technology Development Program and the D\&D IDs. Therefore, it is important that each element of the demonstrations make the most effective use of resources from a Complex-wide perspective.

- Transition and D\&D Strategic Plans

Various DOE sites are at different stages in defining the magnitude, diversity, scope, and costs associated with facilities transition and D\&D programs. This results from the recent rapid changes that have occurred in DOE missions and priorities for these sites. Comprehensive strategic plans for facilities transition and D\&D have not been developed for all DOE sites. These site-specific plans are needed to help further identify and prioritize technology demonstrations considered in this D\&D ID Strategic Plan.

- Risk Evaluation and Management Optimal D\&D strategies for some sites and facilities could involve a risk management approach in which some actions are taken early while others are deferred until a more permanent and effective solution could be implemented. However, difficulties in applying this approach arise from the lack of consensus on how to evaluate relative risks or determine acceptable risks, the tendencies for facilities to degrade over time, and the lack of public trust in interim risk management versus final resolutions. 
- de minimis and Below Regulatory Concern (BRC)

\section{Standards}

The lack of accepted de minimus standards for unrestricted release of materials bulk-contaminated with very low levels of radioactivity was identified as a key generic issue affecting nearly all D\&D activities. An analysis of various aspects of this issue was conducted during the TSG meeting and is recorded here in Appendix $\mathrm{B}$, "The de minimis Issue. Also, the lack of an accepted BRC standard is a significant related issue. The concept of a BRC limit is distinct from that of a de minimis standard and applies specifically to local effects of disposal of some low-level radioactive wastes. Lack of resolution of these issues has the potential for significantly increasing D\&D waste disposal quantities and costs.

\section{- Land/Facility End State}

The need for developing comprehensive strategic plans for facilities transition and D\&D for major DOE sites must include the evaluation of end-state alternatives. This will involve consideration of future land uses, issues of acceptable risks, potential for reuse of facilities for other purposes, and regulatory acceptability of these options. Pending the resolution of these issues, D\&D technology development and demonstration activities must be guided by general principles that can broaden the range of options. These principles include increasing the cost-effectiveness of specific tasks, improving worker health and safety, optimizing materials recycle options, and minimizing secondary waste generation.

\section{- Existing Knowledge Base}

There are advantages in establishing D\&D strategies and plans, including technology demonstrations, while Defense Program personnel familiar with past operations of the surplus facilities are still assigned to the facilities and available to participate. In other words, there is a window of opportunity for using the memory and skills of these personnel that will be rapidly closing because of retirements, reductions in work forces, etc. Certain deactivation and D\&D steps could prove to be less costly and risky now than later, while advantage can be taken of this corporate knowledge. 


\section{Section 9 Benefits/Strengths of the ID Strategy}

The D\&D ID Strategy described in this document will address many, but not all, of the issues identified above. The following are some specific benefits associated with implementing this strategy.

- Efficient use of resources

The D\&D ID efforts will be subject to resource limitations. Combining several D\&D activities having common problem elements will lead to efficient use of people, money, time, equipment, and facilities. This avoids duplication of effort while achieving basic objectives through economies of scale and scope.

- Effective use of special skills and knowledge base

The D\&D IDs must be accomplished with minimum numbers of skilled, knowledgeable, and trained personnel; therefore, effective use of these personnel will be required. For example, many of the proposed D\&D IDs intend extensive use of robotics and other remote technologies. Were each D\&D effort to proceed independently, the requirements for personnel having special knowledge and skills in these areas could exceed their availability. By organizing and performing the D\&D efforts as IDs, groups of core personnel perform many tasks, thereby maximizing their effectiveness and efficiency.

- Cradle-to-grave solutions

A major objective of the D\&D ID will be to demonstrate complete solutions to specific D\&D core problems, which do not leave a legacy of subsidiary problems remaining for others to resolve. Achieving this objective will require the integration of technologies for addressing all steps in D\&D from characterization to wastes disposal. Even though each ID may not actually perform all of these steps, collectively, the demonstrations would provide the bases for a complete solution for each problem area. For example, the systems engineering criteria and issues that must be addressed will be representative of those to be encountered in large-scale D\&D operations. Implementing these solutions on bite-sized IDs should maximize benefits from learning-by-doing before larger tasks are undertaken.

- Public perception and support

The general public is intensely interested and will be deeply involved in decisions relating to D\&D of DOE facilities. An ID of a cradle-to-grave solution to specific D\&D problems is more apt to gain early visibility and generate public interest and support than a fractured approach involving numerous applications of specific technologies. 
- Communication and reporting

Assimilation of information from the large amount of documentation is a continuing problem to those involved in DOE programs. Communicating the results of the IDs should be easier and more effective than reporting numerous,

smaller-scale accomplishments. Effective communication will be important, since the D\&D program will be heavily

dependent on political support at all levels of government: national, state, and local. Therefore, accomplishments that are more comprehensive, visible, and communicable to the general public should help maintain political support.

- Early identification of needs for long-term technology developments

The IDs should help to disclose significant gaps in the current Technology Development Program by measuring and evaluating the performance of the technologies selected and their potential for continued development and application. 
Section 10 The Planning Process

At the request of the DOE/EM-50 D\&D ID coordinator, staff from LANL and LLNL facilitated and coordinated the development of a strategic plan for D\&D. The process encompassed three week-long meetings - one a month from May through July - followed by a three-month review and revision cycle. The participants in the planning process were selected from active DOE-EM waste remediation and environmental restoration programs, based on their expertise and familiarity with key D\&D technologies and potential D\&D sites.

For background information, this group was provided with the results of a workshop sponsored by EM-50 and held in Knoxville, Tenn. during August of 1991, to develop a D\&D needs assessment (some members of the TSG participated in this workshop). For review before their first meeting, the TSG was also provided with documentation from an information exchange meeting held in March 1992 at Charleston, S.C., with industrial participants, to discuss the state of D\&D technologies.

During the first meeting, representatives from various DOE sites presented detailed information about the extent of the D\&D problems at their sites, an overview of D\&D efforts currently underway, and a wish list of technologies that would help solve their D\&D problems. After the presentations, the participants identified the critical D\&D issues that affect the entire DOE Complex (e.g., the lack of a de minimis standard) and divided the major local and national D\&D problems into ten categories:

- hot cells,

- reactors,

- plutonium-processing facilities,

- fuel storage pools,

- gaseous diffusion plants,

- tritium-processing facilities,

- lithium-processing facilities,

- fuel reprocessing,

- metals recycle, and

- uranium-processing facilities. 
The participants formed teams to analyze and document the status of D\&D in each of these categories and to identify specific problems within each category. Each of the teams was made up of ten or so participants who represented either relevant expertise or ownership of the problem. The document that was produced after the first meeting (D\&D ID Technical Support Group: Meeting One Summary) contains summaries of the site presentations, brief descriptions of the identified categories, and the first draft of the strategic plan outline.

During the second meeting, the teams identified specific D\&D problems for each category and prepared detailed situation analyses of each of these problems (see D\&D ID Technical Support Group: Meeting Two Summary). As a result of the analysis of these problems, the team members created a new category for the Complex-wide problem of contaminated concrete and eliminated the tritium-processing facilities category and realigned themselves accordingly. The problems associated with tritium-processing facilities were redistributed as follows: the tritiated concrete problem was assigned to the new contaminated concrete category and the tritiated metals problem was assigned to the metals recycle category.

During the third meeting, the teams convened to propose IDs for each problem identified in each category. The proposals addressed the desired solutions to what the team members considered to be the top problem areas, based on fiscal feasibility and the magnitude of the problems. The team members were asked to develop five-year plans, focusing on accomplishments that would demonstrate to the public DOE's commitment to D\&D and ensure a successful beginning to a monumental task.

This document is the result of this exhaustive process to identify and propose solutions for the problems related to D\&D. The plans contained in this document will be updated and refined to keep pace with technological advancements and changing national priorities.

\section{Section 10.1 Planning Ground Rules and Guidelines}

- The IDs should be planned and implemented as consolidated efforts, even where activities at more than one site are involved for a specific problem. The IDs should be managed, in so far as possible, as single projects according to guidelines and principles given in DOE 4700.1.

- The IDs should be conducted throughout the DOE Complex wherever specific problems exist and maximum benefits can be gained. This includes identifying ongoing D\&D program activities that provide opportunities for synergisms or piggy-backing of projects to accomplish technology demonstrations at reduced total costs. 
- An adequate support infrastructure should be available at each site selected for the IDs.

- A systems approach should be applied to ID project planning and management that integrates the solutions of six major technical areas of D\&D: facilities characterization; decontamination; dismantlement; materials disposition (including recycling and waste treatment and disposal); robotics and automation applications; and regulatory compliance considerations.

- Specific ID projects may involve testing a combination of existing technologies (i.e., accepted for specific D\&D applications based upon past experience) and new or enhanced technologies. Strong emphasis should be placed on the latter as a means of remediating deficiencies in available techniques.

- The D\&D ID projects should demonstrate a complete cradle-to-grave solution for the specific problem area considered.

- Justification should be provided to demonstrate that both site-specific and complex-wide benefits would ensue from these IDs. This should include estimates or indicators of early cost payback potentials, reduction in worker exposure, transfer of benefits across sites, or accelerated resolution of specific issues.

- The approaches selected for the IDs should be capable of ultimately providing cost savings to the DOE, combined witi profit-making potentials for commercial industries involved in environmental restoration activities.

- Emphasis should be placed on demonstrating technologies which can be implemented within five to seven years; however, longer-term technology needs for D\&D should also be identified to help guide the Technology Development Programs.

The scope of the efforts planned for the IDs should be compatible with the general funding levels projected to be available during this period. Also, maximum advantage should be taken of opportunities for joint funding with EM-60, EM-40, and EM-30. 


\section{Section 10.2 Planning Assumptions}

The ID proposals developed in this planning document are based on several fundamental assumptions concerning future directions, requirements, and use of resources for DOE/EM programs.

- EM will continue to place the highest priority on protecting the safety and health of occupational workers and the general public.

- Large D\&D problems/issues can be approached by breaking them down into specific problem areas to help identify technology development and demonstration needs.

- The development, demonstration, testing, and evaluation of new or enhanced technologies for D\&D are necessary elements in achieving a successful outcome of the DOE/EM program; however, existing (mature) technologies will also be used, where appropriate, and will be an integral part of the overall D\&D strategy.

- Industrial and academic involvement in EM technology developments and demonstrations (e.g., through PRDAs, CRADAs, and ROAs) is essential. 


\section{Section 11 The Recommended IDs}

\section{Section 11.1 Concrete}

Problem Concrete is a common material that is widely used in the construction of floors, foundations, walls, shielding, and roads for DOE facilities. Because it was exposed to contamination sources, this somewhat porous material has been contaminated extensively. Types of contaminants include PCBs and hazardous chemicals, as well as radionuclides. The extent of contamination ranges from loose surface contamination to contamination that has permeated throughout the concrete. Radiation fields vary from none to extremely high levels. Types of contamination include uranium, plutonium, fission products, miscellaneous hazardous chemicals (e.g., corrosives, organics, heavy metals). and PCBs. The concrete surfaces may be bare, painted, or coated. In a small number of cases, concrete and rebar have been activated by radiation.

Some is in the form of concrete block. Most of the contamination is near-surface contamination; in other words, the contaminants have penetrated into the concrete to varying depths, but generally have remained near the surface. However, some contaminants, principally tritium, PCBs, and mercury, have penetrated throughout the concrete.

The major challenge in decommissioning contaminated concrete is to segregate the clean material from the contaminated. This will allow a high percentage of the rubble resulting form decommissioning to be reused. If this is not done, the vast quantities of potential waste resulting from concrete structure decommissioning could easily choke all available low-level waste burial volume.

Proposed The contaminated concrete ID will develop new and improved technologies Demonstration for characterization, decontamination, dismantlement, and material handling of contaminated concrete materials within the DOE complex. The characterization demonstrations will emphasize in situ techniques with real time feedback, including characterization of RCRA hazardous materials. The decontamination demonstrations will use both in situ and ex situ techniques for near surface and volumetrically contaminated concrete. Efficient techniques for separating contaminated and non-contaminated materials to minimize wastes and enable beneficial ruse of materials will be demonstrated. 
The component sub-demonstrations will be brought together into two integrated demonstrations. The first is a remote characterization and decontamination demonstration that involves the use of a small characterization vehicle and a larger decontamination vehicle which will operate autonomously in a coordinated manner. The other integrated demonstration encompasses an automated production line which reduces rubble size, performs real-time characterization, and segregates the clean rubble from contaminated.

Sites It appears that the Oak Ridge K25 installation is the prime candidate for the "small robot/big robot" integrated demonstration because of the vast amount of relatively unobstructed floor area. LANL is the prime candidate for the production line ex situ decontamination demonstration because of the considerable amount of soil-washing development that has occurred there. However, should there be another site with a near-term requirement to demolish a large concrete structure, it should probably receive priority for this demo.

Cost Estimated total cost for this demonstration will be $\$ 18.6$ million over five years.

Benefits The anticipated benefits of the contaminated concrete ID are:

- reduced volume of contaminated materials;

- potential for materials recycle/reuse;

- development of new businesses specializing in these activities; and

- efficient segregation of contaminated or suspect contaminated material from non-contaminated.

See Appendix $C$ for a detailed description of the proposed demonstration. 


\section{Section 11.2 Fuel Reprocessing}

Problem Hanford, INEL, and Savannah River have several inactive spent fuel reprocessing facilities. The facilities have well over two million square feet of floor space containing thousands of tons of highly contaminated equipment. Using existing proven technologies for decontaminating and decommissioning these facilities would generate millions of gallons of high-level decontamination waste and millions of tons of low-level solid waste for burial or subsequent treatment.

Proposed The proposed fuel reprocessing ID focuses on the characterization, Demonstration decontamination, dismantlement, and disposition/reuse of highly contaminated fuel reprocessing equipment. Initial characterization activities will focus on establishing detailed contamination status of facilities and the demonstration of radiological sensor devices. Decontamination activities will test the effectiveness of internal and external flushing of facilities and developing effective, in situ decontamination solutions which also minimize secondary wastes. Dismantlement activities include development and demonstration of remote/robotic techniques, and comparative analysis with manual dismantlement methods. The remote/robotic techniques will be used in limited-access, confined space, high-radiation environments. Material disposition activities will be determined based upon results obtained from these demonstrations. This $\mathbb{I D}$ will involve a variety of DOE contractors, instrumental in developing the dismantlement and disposition techniques, while private industry will contribute to development of the decontamination methods.

Sites $\quad$ NEL and the Hanford PUREX plant are suitable sites for the proposed demonstration because of the existence of current inactive facilities undergoing deactivation activities and because of the availability of resources. These facilities are complex in operation and contain high radiation fields.

Cost The estimated total cost for this demonstration is $\$ 9.05$ million over six years. 
Benefits The anticipated benefits of the fuel-reprocessing equipment ID are:

- reduced radiation levels and overall reductions in facilities transition and D\&D project costs (by conducting this rad level reducing demonstration soon after facility shutdown will operating and auxiliary systems still operate);

- shared costs with existing programs (e.g., robotics development, industry decontamination, EM-60 deactivation);

- immediate use of operations personnel and equipment while available;

- demonstration of robotic dismantlement of complex items;

- potential for materials recycle/reuse; and

- potential savings of $\$ 30$ million per deactivated facility.

See Appendix $D$ for a detailed description of the proposed demonstration. 


\section{Section 11.3 Fuel Storage Pools}

Problem Several sites identified future planıs that would require the deactivation and decommissioning of reactor fuel storage pools. These fuel storage pools contain about one million gallons of contaminated liquids, and some contain as much as one million pounds of metals. Moreover, the D\&D of fuel storage pools is considered a high- to medium-risk activity because of two facts: first, there is a possibility of contaminated liquids leaking into the ground water through cracks in the concrete; second, there are broken fuel elements in some of the pool sludges.

Using current processes, decontamination of these fuel storage pools would require thousands of man-hours.

Proposed The proposed fuel storage pool ID focuses on improving and adapting current Demonstration processes, developing new processes, and demonstrating packages of these improved, adapted, and newly developed processes. Decontamination activities (concrete) will include processes that are able to bulk/volume decontaminate the vertical and horizontal surfaces of the wetted areas. Dismantlement activities (equipment, sludge) will include processes that can be used with remote tooling such as the current long-handled tools and overhead cranes as well as future articulated arms. Characterization activities (concrete and sludge) will include instruments that can be used with remote tooling and that will reduce the sampling and analysis times, and produce more representative results. Decontamination activities (sludge) will include processes that can be used with remote tooling. Disposition activities (sludge and water) will include processes that separate the broken fuel elements, the sludge and the water, and then treat each of the streams individually.

Sites Industrial facilities are the recommended sites for the improvement, adaptations, and development of processes and instruments. The Hanford $\mathrm{N}$ Reactor is the recommended site for this demonstration because:

- the current deactivation schedule will support a FY 95 start;

- the examination and segregation pits can be isolated from the rest of the pool; and

- this reactor fuel storage pool contains about one million pounds of metals.

Costs The estimated total cost for this demonstration is $\$ 15.3$ million over four years. 
Benefits The anticipated benefits of the fuel storage pools ID are:

- significant reduction in worker, public, and environmental risks;

- reduced volume of contaminated materials in each category; and

- the potential for materials recycle/reuse.

See Appendix E for a detailed description of the proposed demonstration. 


\section{Secion 11.4 Gaseous Diffusion Plants}

Problem The process used in the United States for enriched uranium production involves repetitive stages of gaseous diffusion of uranium hexafluoride (UF6), in cascade, to achieve isotopic enrichment. There are three Gaseous Diffusion Plants in the US: Oak Ridge, TN, K-25 Site; Portsmouth (Ohio); and Paducah (Kentucky). These three plants contains large amounts of equipment (over 10,000 highly repetitive stages, which represent over 750,000 tons of metal). The process equipment (compressors, converters, control valves, and piping), by nature of the process, has been internally contaminated with radioactive materials. In addition to the known internal contamination, the external surfaces may be contaminated with radiological and/or hazardous (RCRA, TSCA) materials. The challenge is to define technologies to characterize, decontaminate, and dismantle the equipment which takes advantage of the repetitive nature of the equipment but does not become burdened by labor needs or secondary waste generation.

Proposed The focus of the integrated technology demonstration will address the Demonstration characterization, decontamination, dismantlement and management of the gaseous diffusion plant process equipment. The proposed demonstration will be a synergistic combination of EM-50 and EM-40 technology development activities that will provide in situ and remote techniques to fully support the D\&D needs for removing the process equipment and allowing the resources (e.g. stainless steel, nickel, enriched uranium) to be recovered/recycled. Proposals for technology demonstrations were divided into 3 possible scope levels, with the base program (level $A$ ) including the following elements:

- internal radiological characterization of process equipment;

- automated system to deploy end-effectors over the exterior surface of the process equipment. End-effectors would allow

- characterization and mapping of the radiological contaminants

- decontamination of the contaminated (mapped) areas

- cutting in support of dismantling the process equipment

- advanced containment and protective systems to reduce worker exposure, protective clothing requirements, and minimize the spread of contamination;

- decontamination of internal process equipment surfaces utilizing either long-term, low-temperature (LTLT) gas-phase treatment or a vendor demonstrated technology. This element is an ongoing EM-40 sponsored activity; and

- real-time detection ( $\mathrm{min}$ ) of polychlorinated biphenyls (PCBs) and minimization of secondary waste generation (also an ongoing EM-40 sponsored activity). 
Site

The Oak Ridge K-25 Site (formerly the Oak Ridge Gaseous Diffusion Plant) is recommended for this demonstration. This site is the only shutdown GDP and D\&D activities for the equipment is in early stages of planning. Utilizing this site would allow coordination with EM-40 D\&D technology development activities and the reuse of the process buildings (post decontamination) is desired for future waste management activities.

Cost The estimated total cost for this demonstration (Level A, see Appendix $F$ ) will be approximately $\$ 25$ million over a five year period. Of this cost, approximately $\$ 15$ million would be EM-50 funding and $\$ 10$ million would be EM-40 funding.

Benefits The proposed technology development activities will provide a complete system which will address the D\&D needs of GDP process equipment. The primary benefits associated with this ID are:

- reduced worker exposure and minimization of the spread of contamination;

- minimization of secondary waste generation;

- minimization of industrial safety concerns;

- optimized recovery and reuse of valuable resources:

- stainless steel

- strategic materials (e.g. nickel)

- enriched uranium

- technologies to address the characterization, decontamination, dismantlement, and automation of processes for the D\&D of the GDP equipment;

- technologies will be applicable to other DOE complex (e.g. Portsmouth and Paducah GDPs) and private sector needs; and

- potential cost reductions estimated between $\$ 1.3$ to $\$ 1.6$ billion, compared to existing estimates for D\&D for the K-25 Site. These cost reductions will also translate to other sites as these technologies can be directly applied, in the future, to the two existing GDPs.

See Appendix $F$ for a detailed description of the proposed demonstration. 


\section{Section 11.5 Hot Cells}

Problem Hotcells are found throughout the DOE complex and represent a significant problem for D\&D. Hot cells have a high-radiation environment with highly-contaminated equipment. The cells are generally packed with equipment, resulting in limited space for movement, and generally have limited access. Techniques available for hot cell D\&D are cumbersome and time consuming and are unreliable because of the high radiation fields.

Description The primary objective of this demonstration is to demonstrate improved technologies for performing D\&D in a highly radioactive environment. In this demonstration, improved technologies will be demonstrated for characterization, decontamination, dismantling and waste disposal. Recycling will not be addressed in this ID because the Fuel Reprocessing ID is addressing the recycling of highly contaminated equipment. A secondary objective of this ID is to provide the D\&D ID Program with a success early in the program to promote the usefulness of the ID approach.

Improved technologies, which will all require remote capabilities, to be demonstrated in this ID include:

- improved hazardous and radiological sensors to provide better discrimination and real-time capabilities;

- 3-D mapping capabilities for D\&D planning and waste reduction;

- improved cryogenics decontamination to provide faster and better coverage and small diameter cleaning capabilities;

- improved dust and debris removal techniques with integrated modular filtration to provide faster capabilities, access to limited space areas, and reduced airborne dust;

- improved wet decontamination to provide a non-hazardous solution, reduce secondary waste generation, and faster capabilities;

- modified BWID dismantling system with integrated modular filtration to provide limited access capabilities with reduced airborne materials;

- improved segregation techniques to provide faster capabilities; and

- improved volume reduction techniques to reduce secondary waste generation.

Results of this demonstration are applicable to other high-radiation environments, such as canyons. However, the limited access and confined spaces of hot cells provide unique challenges for D\&D. 
Sites INEL and PNL are the recommended sites for the demonstration, with support from other laboratories (e.g., SNL, SRTC) which have expertise in robotics and sensors. PNL is recommended because of ongoing D\&D which allows for shared cost savings, a basis for consistent cost/benefit analyses, trained personnel availability, and use of work performed by EM-30 and -40 (e.g., definition of the technology improvements needed). INEL is recommended because of the availability of top-hatch hot cells.

Cost The total estimated cost for this demonstration is $\$ 10.25$ million over three years.

Benefits The anticipated benefits of the hot cells ID are:

- improved techniques in characterization, debris removal, dry/wet decontamination, segregation volume reduction, and remote/robotic dismantlement;

- a short duration demonstration allowing the D\&D ID to benefit from an early victory demonstrating $D \& D$ techniques;

- early spin-off of techniques to other related applications; and

- potential cost savings of $\$ 10$ million - per hot cell - from accelerated and more effective future D\&D tasks.

See Appendix $G$ for a detailed description of the proposed demonstration. 


\section{Section 11.6 Lithium-processing Facilities}

Problem Mercury-contaminated process equipment can be found in lithium processing facilities at the DOE's Y-12 Plant and poses certain unique D\&D challenges. Mercury is a highly toxic substance which, with excessive exposure, can lead to human and animal symptoms of heavy metal poisoning. Significant environmental damage can also potentially occur through air emissions and releases of mercury to soils and water systems. Although relatively minor levels of mercury contamination exist at several sites within the DOE complex, addressing mercury contamination issues is a major task for the lithium processing facilities at the Y-12 Plant. There is an estimated 7,000 tons of mercury-contaminated equipment at one Y-12 facility alone. Mercury contamination is a near-term issue for the Y-12 Plant facility $9201-4$, currently in the EM-40 Program, in that D\&D planning activities for this facility are underway.

Description The Lithium-Processing Facilities ID will address pre- and post-characterization of the lithium-processing equipment for mercury contamination, removal of the mercury, removal of the processing equipment, and disposition of the recovered mercury and processing equipment. The demonstration will utilize existing technologies available through commercial vendors, where applicable, and will involve commercial entities to insure commercialization of emerging technologies.

- Characterization activities will address identification of a viable method for real time, certifiable, field characterization. Decontamination activities will address potential methods for in situ decontamination of process equipment.

- Dismantlement activities will focus on the application of modular, automated equipment in dismantling large pieces of equipment.

- In the area of material disposition, the goal of the demonstration is to identify decontamination and dismantlement methods that will allow recycle of recovered mercury and process equipment metals.

- This demonstration will also address utilization of robotics and automation in characterization, decontamination, and dismantlement.

Sites The Y-12 Plant at Oak Ridge is the recommended site for this demonstration; specifically, it is proposed that the demonstration be conducted at the 9201-4 facility. Since the majority of the mercury contamination issues in the DOE complex reside at the Y-12 Plant facilities, the utilization of 9201-4 will provide an optimum demonstration of the technologies. 
Costs

Benefits

The estimated total cost for this demonstration is $\$ 16$ million over five years.

The anticipated benefits from the lithium-processing facilities ID are:

- projected cost savings of $\$ 80$ million in the D\&D of the 9201-4 facility based on projected 50\% reductions in PPE utilization, lab analysis for characterization, and metal processing equipment requiring $e x$ situ treatment (thermal desorption);

- reduced risk of toxic mercury vapor exposure to workers during D\&D operations;

- reduced risk of mercury releases to the environment during D\&D operations;

- development of new mercury characterization and decontamination techniques for both DOE and industrial (chlor-alkali and mercury mining facilities) including technologies for measuring and removing mercury from equipment interiors; and

- recovery of metals for recycle/reuse.

See Appendix $H$ for a detailed description of the proposed demonstration. 


\section{Section 11.7 Metals Recycle}

Problem Many DOE Sites have accumulated large quantities of radiologically contaminated scrap metal (RSM). Because of regulatory restrictions on the release of RSM, the lack of demonstrated decontamination technologies, and the lack of a licensed commercial infrastructure for processing contaminstid scrap, most of this material is not being recycled for beneficial reuse. W/itr: the projected D\&D activities at many Sites, massive additional quantities of $\mathrm{K} . \mathrm{SM}$ will be generated. The lack of commercial technologies for reprocessing RSM for beneficial reuse is a major roadblock to increased levels of $D \& D$ activities.

Proposed The proposed metals recycle ID will focus on the demonstration of Demonstration technologies for recycle of RSM within the constraints of present regulatory drivers. Efforts will concentrate on demonstrations involving materials that can be processed for controlled beneficial reuse by the DOE (and other federal) Sites. Because of its high potential for reuse, the first demonstration will be the recycle of contaminated stainless steel. Deliverables will include the demonstration of a workable process for the production of limited quantities of items such as stainless steel containers for use by the DOE facilities. RSM feed-to-recycle will include various forms of available stainless steel scrap, as well as scrap materials which can combined to produce stainless steel (mild steel scrap, nickel scrap and purchased chromium). The ID will involve the establishment of commercial consortia to partner with the DOE in melting RSM from various sites and fabricating containers for DOE use. Parallel efforts will be devoted to laboratory-scale development/demonstration testing of new technologies for RSM decon'amination. The work will provide a database to support long-term de minimis initiatives for free release for non-DOE uses. The ID supports and augments efforts supported by three PRDAs in related development/demonstration areas.

Sites The ID is directed to the long-term development of regional commercial RSM recycle industries for handling the needs of DOE. Because of its wide applicability, work on this ID has been initiated for processing slug buckets, heat exchangers, and other items at the Savannah River Site. Laboratory-scale efforts in FY 94 at ORNL will be directed to advanced process development for decontamination of nickel scrap. Continuing efforts in FY 95 and beyond will also include processing stainless steel scrap items from INEL, melting mild steel and nickel scrap from Oak Ridge, and other forms of stainless steel scrap from other DOE Sites.

Cost The estimated total cost for the proposed ID is $\$ 16$ million over five years. 
Benefits

The anticipated benefits from the metals recycle ID are:

- reuse of valuable materials, some of which (such as nickel) are strategic materials for which there are inadequate domestic resources;

- minimizes future risks for remediation of waste burial sites resulting from future regulatory changes;

- demonstrates waste minimization through recycle/reuse;

- develops DOE/industrial partnership in reprocessing and recycling of stainless steel and other valuable RSM materials;

- develops methods applicable to numerous DOE sites/regions;

- demonstrates resource conservation and environmental consciousness by reducing the net amount of additional clean metal which can potentially become contaminated; and

- establishes a useful controlled reuse model which functions within the current regulatory restrictions (in spite of the lack of a de minimis free release criterion).

See Appendix I for a detailed description of the proposed demonstration. 
Section 11.8 Plutonium-processing Facilities: De-inventory and Deactivation

Problem With the reduction of the weapons mission, virtually all of the plutonium-processing facilities throughout the DOE Complex (primarily Rocky Flats, Savannah River, Hanford, LANL, and LLNL) will require de-inventory and deactivation activities; the magnitude has yet to be determined. There are few, if any, domestic industrial sites with significant plutonium inventories; however, there are several potential overseas applications. Because of heir construction and functions, plutonium-processing facilities tend to be more difficult to retire. As a result of this, delays to D\&D represent a significant ongoing surveillance and maintenance cost. Furthermore, at sites with such facilities, they are generally considered the major contributor to off-site risk.

Proposed This ID will focus on technologies for the deactivation of Demonstration plutonium-processing facilities. They are broken down, below, by technology category.

- Characterization activities cover the development of real-time instrumentation for alpha contamination analysis in the appropriate ranges for surface, air, and liquid media. Also, substantial effort will be focused on improvement of non-destructive analysis techniques for qualification of SNM levels within gloveboxes and process equipment. Finally, the development of non-destructive methods to evaluate packaged residue conditions will be supported.

- Decontamination activities cover improvements in flushing and liquid decontamination techniques for piping, process equipment, and tankage.

- Dismantlement activities cover glovebag enhancement and approaches to resolve SNM holdup in ductwork.

- Robotics and automation activities support application of duct crawlers as platforms for removal of SNM holdup in ducts.

- Materials disposition activities support the development of a long-term container for residue storage.

- Systems analysis activities will provide studies for evaluation of the deactivation/D\&D interface, approaches for safety-system reduction in deactivation, and residue package life-cycle cost.

Sites

The preferred sites for field activities associated with this ID include Savannah River, Hanford, and Rocky Flats because they have active transition programs involving their plutonium-processing facilities. 
Cost

The estimated total cost for this demonstration is $\$ 16.5$ million over five years.

Benefits The anticipated benefits of the plutonium-processing facilities de-inventory and deactivation ID are:

- reduced costs for surveillance and maintenance;

- reduced off-site risk; and

- reduced porsibility of SNM diversion or nuclear criticality during D\&L.

See Appendix $J$ for a detailed description of the proposed demonstration. 


\section{Section 11.9 Plutonium-processing Facilities: Equipment}

Problem

Proposed Demonstration

Facilities throughout the DOE Complex contain what amounts to tens of thousands of tons of plutonium-contaminated equipment, principally at Rocky Flats, Savannah River, Hanford, LANL, and LLNL. Plutonium-processing facilities present relatively high public risk in the event of release; at sites with plutonium-processing facilities, those facilities are generally considered the major contributor to off-site risk. These also tend to be difficult to retire. Thus, delays to $D \& D$ represent a significant ongoing surveillance and maintenance cost. The cost of actual D\&D is expected to be in the range of several billion dollars. Much of the resultant waste will be classified as transuranic, for which there is no permanent means of disposal at this time; intermediate or long-term waste storage costs will continue after D\&D is completed.

The proposed ID focuses on technologies for the D\&D of process equipment in plutonium-processing facilities. The scope includes all equipment that makes up or is within the primary containment: gloveboxes, tanks, ducts, filter plenums (Zone I only), process piping, etc. The ID supports all D\&D activities involved in removal and disposition of the contaminated equipment. Two areas have been emphasized: reducing labor costs and improving worker productivity, and reducing waste volumes in categories of waste which are more difficult to handle. Thus, TRU materials would be decontaminated to LLW, TRU-mixed to TRU, etc. Approaches include earlier and more accurate characterization of contamination conditions, improved decontamination methods to clean items prior to breaching systems boundaries, and improved methods of waste minimization and certification.

Activities covered under the proposed ID are broken down by technology category.

- Categorization activities cover development of real-time instrumentation for alpha contamination analysis for surface, airborne, and liquid media in the appropriate ranges.

- Decontamination activities cover development of better low-liquid and dry decontamination methods, and apply them to piping and gloveboxes, both in situ and after sectioning.

- Dismantlement activities cover development of lighter, more flexible tooling both for dismantling glovebox equipment and for the size reduction of the gloveboxes themselves. Additional activities cover development of better means of operating local and central size reduction facilities: modular or improved reuse configurations, better pressure/air flow control, real-time evaluation of enclosure conditions, and better personnel and equipment egress. 
- Robotics and automation covers activities to improve central size reduction facility equipment, develop mobile transport equipment to transfer between local sectioning and central size reduction facilities, and adaptation of robots developed elsewhere for D\&D enclosure work.

- Work in materials disposition covers development of an interface and criteria to allow for acceptance of plutonium facility D\&D-generated materials by outside recycle programs.

- Systems analysis activities would support decisions for activity prioritization, regulatory requirements, and segregation and waste packaging approaches.

Sites

The preferred sites for field activities associated with this ID include Savannah River, Hanford, and Rocky Flats because of active, ongoing plutonium-processing facility D\&D programs which will support the baseline D\&D facility costs to provide a platform for demonstration activities.

Cost The total estimated cost for this demonstration is $\$ 16.7$ million over five years.

Benefits The anticipated benefits of the plutonium-processing facilities equipment ID are:

- reduced costs of D\&D and continued operations and surveillance and maintenance costs;

- reduced possibility of SNM diversion or nuclear criticality during D\&D;

- reduced internal exposures to workers during D\&D; and

- reduced generation of high-level TRU wastes and increased assurance that those wastes that are generated are in a compact, transportable form.

See Appendix $J$ for a detailed description of the proposed demonstration. 


\section{Section 11.10 Reactors}

Problem There are many formerly acive nuclear research reactors located throughout the DOE Complex and at universities in the U.S. and abroad. Many of these have irradiated core components and reactor vessels that will require remote size reduction, packaging, and disposal at a suitable site. There is currently no common approach to reactor dismantlement and no standard size-reduction dismantlement systems are currently available.

Proposed The proposed reactors ID focuses on the D\&D of research reactor vessels and Demonstration internals by size reduction and packaging; applications of remote/robotic technologies for characterization, dismantlement, and disassembly; and re-designed containment and filtration systems for air, water, and particulates. This effort includes the evaluation of existing delivery systems with a telescoping mast and end effectors, for a range of possible applications to reactors and fuel facilities.

This ID will involve laboratory and field development of new technologies, modification and adaptation of existing technologies, system integration, demonstration testing, and implementation as part of the CP-5 reactor D\&D at ANL-E, scheduled for FY 97-98 and funded by EM-40.

Sites Several DOE sites have inactive reactors and these sites include ANL, Hanford, Savannah Kiver, INEL, and Oak Ridge. In addition, other DOE sites will be involved in fabricating or testing component parts of the system developed to dismantle core internals and metal vessels. ANL-E is recommended because it has scheduled D\&D in its EM-40 planning.

Cost The estimated total cost for this demonstration is $\$ 16$ million over five years.

Benefits The anticipated benefits of the reactors ID are:

- reduction in D\&D worker exposure and secondary waste;

- enhanced DOE technology transfer and involvement with industry;

- reduced environmental threats and improved public perception;

- applicability to problems at other DOE sites, including non-reactor systems; and

- jobs for industry and cost savings for dismantlement system users.

See Appendix $K$ for a detailed description of the proposed demonstration. 


\section{Section 11.11 Uranium-processing Facilities: Process Systems}

Problem The scope of the uranium process systems includes equipment, piping, control systems, ducts, vessels, utilities, and related components used in processing uranium-containing materials. The scope does not include irradiated fuels or TRU-contaminated systems. Only depleted and low enrichment uranium-contaminated systems are included

Within the DOE Complex, uranium-processing facilities represent approximately 4.5 million square feet of floor space, with miles of process piping and ductwork, as well as numerous process components. Most major DOE sites contain some ur u ium-processing facilities. The cost to D\&D these facilities using current baseline technologies will exceed $\$ 5$ billion.

Proposed The proposed ID focuses on developing an effective approach to the D\&D of Demonstration uranium-processing facilities. This involves the selection and integration of a system of preferred technologies for characterization, decontamination, dismantlement, and materials disposition, with appropriate applications of robotics and automation.

- Characterization emphasizes real-time analyses and include radiological and hazardous components.

- Decontamination includes improvements to in situ and ex situ decontamination methods, as well as decontamination via metal remelt.

- Dismantlement demonstrates tele-operated robots to improve labor efficiency, industrial safety, and ALARA. Other aspects include improvements to large component dismantlement and portable, reusable containment systems.

- Materials disposition focuses on maximizing recycle and reuse. Data will be developed to support inclusion of material release criteria in a CERCLA Record of Decision.

- A systems approach will be applied to planning, analysis, and integration of the demonstration components.

Site

The recommended facility for this ID is Fernald. A Fernald demonstration would support the EM-40 customers' 1997 Record of Decision. At Fernald, the ID could take advantage of EM-40 treatability testing, permit exclusions, and early D\&D activities. Alternatively, characterization and $e x$ situ decontamination demonstrations could include Rocky Flats, to support near-term D\&D plans at that site.

This ID would need to be funded in FY 95 to ensure them improved technologies can be included in the 1997 Record of Decision and to complement planned EM-40 treatability studies.

$424 \begin{gathered}\text { January } 1994 \\ \text { Revision } 0\end{gathered} \begin{gathered}\text { Technical Program Plan for the Transitioning. } \\ \text { Decommissioning, and Final Disposition Focus Area }\end{gathered}$


Cost The estimated total cost for this $\mathrm{ID}$ is $\$ 19$ million over four years.

Benefits The anticipated benefits of the uranium process systems ID are:

- increased use of recycle and reuse options;

- reduced exposures to D\&D workers;

- improved job productivity and accelerated schedules due to minimizing tasks requiring PPE (i.e., more remote operations);

- reduction in industrial accidents involving D\&D workers;

- improved public perception resulting from visible progress;

- broad applicability of results across DOE and spin-off to commercial industry;

- improved data is support of EM-40 Record of Decision in 1997;

- demonstrated viability of remote robotic operations; and

- potential cost savings of $\$ 500$ million, compared to present estimates.

See Appendix L for a detailed description of the proposed demonstration. 


\section{Section 11.12 Uranium-processing Facilities: Asbestos/Transite}

Problem The scope of the asbestos/transite problem includes asbestos insulation, transite ${ }^{1}$ and other asbestos-containing materials.

This problem is particularly pervasive in DOE buildings that were built before 1970. All DOE sites of this vintage have asbestos- and transite-containing materials.

Proposed The objective of the proposed ID is to develop the most effective approach for Demonstration the D\&D of asbestos-containing and transite materials through the systematic integration of the D\&D technologies selected from the six technology areas. The preferred and proven technologies will be selected through a comparative technical and economic evaluation of viable alternative processes and concepts.

- Characterization focuses on real-time, in situ analysis for asbestos fiber content to avoid operational delays.

- Decontamination technologies support evaluation for less restricted and less costly disposal options.

- Dismantlement technology improvements form the major focus for this ID. Automated systems for containment and dismantlemunt will remove the workers from the hazards of hands-on operations.

- Materials disposition demonstrates options for asbestos fiber destruction, followed by decontamination. A proposal to recycle the resultant materials will be included in a CERCLA Record of Decision.

- A systems approach will be applied to planning, analysis, and integration of the demonstration components.

Site A specific site for this ID has not been selected. It is recommended that the following attributes be considered in selecting a site: advanced stage of planning for D\&D; suitable facilities for testing; and personnel available to plan and administer the field work.

Cost The estimated total cost for this ID is $\$ 10.2$ million over three years.

1 Transite is a mixture of cement and asbestos materials and was used as a siding for many DOE facilities. 
Benefits The anticipated benefits of the asbestos and transite ID are:

- improved techniques for asbestos/transite removal;

- reduced exposures for asbestos workers;

- broad applicability of results across DOE and spin-off to commercial industry; and

- significant potential cost savings resulting from increased labor efficiency for dismantlement, reduced schedule durations, and possible lower disposal costs.

See Appendix $L$ for a detailed description of the proposed demonstration. 


\section{Section 12 Complex-wide Planning Activities in Support of the D\&D ID}

The effectiveness of the D\&D ID Strategy could be enhanced by concurrently carrying out certain complex-wide planning and technical support studies, perhaps as a joint effort between EM-30, $-40,-50$, and -60 . The need for an integrated systems approach to planning for surplus facilities transition, $D \& D$, and waste management and disposal is emphasized. For example, the EM-60 programs for transition of facilities from DP to EM will benefit significantly from the technologies developed and experience gained in the D\&D ID. Transition requires many of the same steps for deactivation as will be encountered later in D\&D (a primary responsibility of EM-40), namely characterization, decontamination, recycle/reuse of materials, and waste disposal processes. The deactivation step will occur prior to D\&D, so certain technologies may actually be needed and demonstrated first in the transition program. At that stage, the surplus facilities will be in the most highly contaminated condition that will be encountered. Remote techniques for characterization (e.g., sensors, cameras, robotics) and other steps could be essential for these activities.

Deactivation and D\&D of surplus facilities could generate more material that has to be disposed of than was generated from all previous DOE operations. This will include both solid and liquid wastes. The type, quantity, and treatment requirements of this material are not firmly established. There will also be a need for interim storage facilities which may not already exist The development of a Complex-wide database that documents the size and scale of these problems would foster greater understanding of the scope of future tasks.

There is a need for technical support studies on a range of broad issues in the regulatory acceptability of various material recycle and facility end-state options. These include the establishment of U.S. de minimis standards for unrestricted release of materials after decontamination and the need for appropriate regulatory guidelines and criteria for controlled use of these materials within the DOE Complex or the nuclear industry.

To obtain maximum value from the limited technology development funds available, economic evaluations of the effectiveness of specific technologies on actual deactivation/D\&D operations are needed. To achieve this, methods and models for determining life cycle cost/benefits of various options must be available. In so far as possible, the end-state or end-use alternatives for these surplus facilities need to be considered as parameters within the scope of evaluations. This could greatly assist in prioritizing and time-phasing of the technology development and demonstrations processes. 
Perhaps the most important of all is the need for comprehensive strategic plans for facilities transition and D\&D for each major DOE site and for the integrated DOE Complex, to guide in detailed planning and implementation of the D\&D Program. This planning process must take maximum advantage of the individual and corporate knowledge of personnel experienced in past operations at various sites. A D\&D ID strategy must emphasize integrating these programmatic concerns into technology development activities so that maximum payback is realized from these investments. It must be ensured that the technology is being developed for realistic and achievable D\&D options. Close coordination of technology needs, schedules, and resources is required between EM-50 and its customers.

The following is an example of how the Complex-wide planning studies might be implemented.

- Teams would be formed at each major DOE site to produce a comprehensive, site-specific strategic plan for transition and D\&D of all site facilities from their present status to their recommended end states. This would include considerations of costs, risks, and waste generation estimates based on analysis of the options available. These teams would consist of an experienced cross-section of personnel representing programs in DP, EM-60, EM-40, and EM-30. Appropriate specialists in safety, environmental requirements, and cost analysis would be included.

- Existing plans and studies would be reviewed and used to the extent possible.

- A Complex-wide team should be formed under the leadership of DOE-HQ, comprised of the team leaders from each site. This team would coordinate and integrate the activities and ensure that all sites produce studies on the same basis so they can be compared.

- The studies from each site should be combined by the DOE-HQ team into one Complex-wide document.

- An annual update of site and HQ plans would be provided.

A key advantage of this technique is that it combines top-level management and integration with bottom-up input from some of the more involved and knowledgeable personnel from each site.

The plan/study should result in a document that provides very usable information that was not previously available and that can be used by all DOE organizations and sites to plan and optimize their programs. 


\section{Section 13 D\&D ID Technical Support Group Teams}

\begin{tabular}{|c|c|c|}
\hline Team & Team Members & Affillation \\
\hline \multirow{10}{*}{$\begin{array}{l}\text { Contaminated } \\
\text { Concrete }\end{array}$} & Bill Austin (Team Leader) & WSRC (EM-40) \\
\hline & Roy Bundy & MMES (EM-40) \\
\hline & Duncan MacArthur & LANL (EM-50) \\
\hline & R. W. Bailey & WHC (EM-60) \\
\hline & Frank Heckendorn & WSRC (EM-30) \\
\hline & Wayne Hayden & MMES (EM-50) \\
\hline & Don Herman & FERMCO (EM-40) \\
\hline & Charles Baldwin & EG\&G-RFP (EM-30, -40, -50$)$ \\
\hline & Brad Frazee & WINCO (EM-30) \\
\hline & Todd Clark & FERMCO (EM-40) \\
\hline \multirow[t]{7}{*}{ Fuel Reprocessing } & Jeff Colson (Team Leader) & WINCO (EM-40, -60) \\
\hline & R. W. Bailey & WHC (EM-60) \\
\hline & Sue Garrett & PNL (EM-40) \\
\hline & Mark McKay & WINCO (EM-30, -50) \\
\hline & Gary Street & WSRC-SRS (EM-60) \\
\hline & Keith Cavin & EG\&G-RFP (EM-60) \\
\hline & Bill Austin & WSRC-SRS (EM-40) \\
\hline \multirow[t]{7}{*}{ Fuel Storage Pools } & Jim Johnesee (Team Leader) & Waste Policy Institute (EM-50) \\
\hline & Bill Heine & WHC (EM-40) \\
\hline & Dick Messervey & EG\&G-ID (EM-40, -50, -60) \\
\hline & Andre Williams & WHC (EM-30) \\
\hline & Duncan MacArthur & LANL (EM-50) \\
\hline & Ken Merrill & EG\&G-ID (EM-40, -50, -60) \\
\hline & Mike Coffey & ANL (EM-40) \\
\hline
\end{tabular}




\begin{tabular}{|c|c|c|}
\hline Team & Team Members & Afflliation \\
\hline \multirow{6}{*}{$\begin{array}{l}\text { Gaseous Diffusion } \\
\text { Plants }\end{array}$} & Doug Hoffmann (Team Leader) & MMES (EM-40, -50) \\
\hline & Roy Bundy & MMES (EM-40) \\
\hline & Blynn Prince & MMES (EM-40) \\
\hline & Charlie Hensley & MMES (EM-40) \\
\hline & Bill Hamel & MMES (EM-50) \\
\hline & Martin Edelson & Ames Laboratory (EM-50) \\
\hline \multirow[t]{8}{*}{ Hot Cells } & Jeff Colson (Team Leader) & WINCO (EM-40, -60) \\
\hline & Sue Garrett & PNL (EM-40) \\
\hline & Blynn Prince & MMES (EM-40) \\
\hline & Mark McKay & WINCO (EM-30, -50) \\
\hline & Ken Merrill & EG\&G-ID (EM-40, -50, -60) \\
\hline & Dick Meservey & EG\&G-ID (EM-40, $-50,-60)$ \\
\hline & Rod Meyer & ETEC (EM30, -40, -50) \\
\hline & Don Henley & ANL (EM-40, -60) \\
\hline \multirow{5}{*}{$\begin{array}{l}\text { Lithlum-processing } \\
\text { Facllities }\end{array}$} & Yolanda Childs (Team Leader) & MMES (EM-40) \\
\hline & Bill Hamel & MMES (EM-50) \\
\hline & Doug Hoffmann & MMES (EM-40, -50) \\
\hline & Roy Bundy & MMES (EM-40) \\
\hline & Susan Howell & MMES (EM-40) \\
\hline \multirow[t]{8}{*}{ Metals Recycling } & Wayne Hayden (Team Leader) & MMES (EM-50) \\
\hline & Brad Frazee & WINCO (EM-30) \\
\hline & Bill Boettinger & WSRC-WMER (EM-50) \\
\hline & G.E. Bingham & WINCO (EM-30) \\
\hline & Blynn Prince & MMES (EM-40) \\
\hline & Yolanda Childs & MMES (EM-40) \\
\hline & Charles Baldwin & EG\&G-RFP (EM-30, -40, -50) \\
\hline & Martin Edeison & Ames Laboratory (EM-50) \\
\hline
\end{tabular}




\begin{tabular}{|c|c|c|}
\hline Team & Team Members & Affiliation \\
\hline \multirow{11}{*}{$\begin{array}{l}\text { Plutonium-processing } \\
\text { Facilities }\end{array}$} & Pete Sanford (Team Leader) & KMI-RFP (EM-40) \\
\hline & Miguel Salazar & LANL (EM-40, -60) \\
\hline & Yolanda Childs & MMES (EM-40) \\
\hline & Ken Merrill & EG\&G-ID (EM-40, -50, -60) \\
\hline & Keith Cavin & EG\&G-RFP (EM-60) \\
\hline & Bill Hamel & MMES (EM-50) \\
\hline & Bill Boettinger & WSRC-WMER (EM-50) \\
\hline & R. W. Bailey & WHC (EM-60) \\
\hline & Gary Street & WSRC-SRS (EM-60) \\
\hline & Jim Johnnesee & WPI (EM-50) \\
\hline & Mike Coffey & ANL (EM-40) \\
\hline \multirow[t]{9}{*}{ Reactors } & Rod Meyer (Team Leader) & ETEC (EM-30, -40,-50) \\
\hline & Bill Heine & WHC (EM-40) \\
\hline & Andre Williams & WHC (EM-30) \\
\hline & Charlie Hensley & MMES (EM-40) \\
\hline & G.E. Bingham & WINCO (EM-30) \\
\hline & Doug Hoffmann & MMES (EM-40, -50) \\
\hline & Dick Meservey & EG\&G-ID (EM-40, -50,-60) \\
\hline & Don Henly & ANL (EM-40, -60) \\
\hline & Mike Cotfey & ANL (EM-40) \\
\hline \multirow{6}{*}{$\begin{array}{l}\text { Uranium-processing } \\
\text { Facilltles }\end{array}$} & Don Herman (Team Leader) & FERMCO (EM-40) \\
\hline & Miguel Salazar & LANL (EM-40, -60) \\
\hline & Todd Clark & FERMCO (EM-40) \\
\hline & Rod Meyer & ETEC (EM-30, $-40,-50)$ \\
\hline & Frank Heckendorn & WSRC (EM-30) \\
\hline & Pete Sanford & KMI-RFP (EM-40) \\
\hline
\end{tabular}




\section{D\&D Regulatory Drivers}




\section{Introduction}

The following paragraphs briefly describe the principle federal regulations governing all D\&D activities. They are not intended to be complete descriptions of all aspects of this regulatory framework. For more details concerning these areas, other sources should be consulted. Note also that the term "regulatory drivers" used as the title of this appendix needs to be interpreted carefully when applied to D\&D activities. Strictly interpreted, regulatory drivers establish explicit timetables and procedures for achieving compliance with current environmental laws and health and safety regulations. These may be applicable to certain tasks involved in the deactivation of facilities to achieve permanent safe shutdown conditions, such as managing and disposing of hazardous materials generated in the process. Once these conditions are attained and the facilities are accepted into D\&D programs, more appropriate terminology may be "regulatory rules or controls" rather than "regulatory drivers". Currently, most DOE sites lack explicit regulatory drivers for D\&D. The relevant laws and regulations are documented here since they must be considered in planning these projects.

At an early stage in the implementation of any of the D\&D IDs described in this document, it will be necessary to develop a plan to ensure the feasibility of compliance with the regulations, procedures, and any special environmental regulations specific to the state or region in which a demonstration is conducted. This may require early contacts with appropriate federal and state regulatory officials to enlist their support in preventing any unnecessary delays in accomplishing these projects. 


\section{Atomic Energy Act of 1954, as Amended}

The Atomic Energy Act of 1954, as amended, provides for DOE jurisdiction in management and control of all radionuclide source material, special nuclear materials, and by-product materials in DOE-owned facilities; also provides the basis for DOE responsibilities for complying with other regulatory criteria, defined in a number of specific DOE Orders (internal department requirements establishing policy and procedures for complying with applicable laws and regulations).

\section{National Environmental Policy Act (NEPA)}

This act established national environmental policy and goals for protecting the environment and provided a process for implementing these goals within federal agencies. The act requires an Environmental Impact Statement (EIS) for every proposed major federal action "significantly affecting the quality of the human environment." The EIS is made available for public review and comment and includes evaluations of alternatives to the proposed actions. Certain project activities of a more limited scope may comply with NEPA through a simpler documentation/review process called an Environmental Assessment (EA) and, in certain cases, through a Categorical Exclusion (CX).

\section{RCRA and the Toxic Substances Control Act (TSCA)}

The Resource Conservation and Recovery Act (RCRA) of 1976, as amended in 1984 by the Hazardous Solid Waste Amendments, sets standards for managing hazardous waste facilities and for dealing with hazardous waste releases. The Toxic Substances Control Act (TSCA) of 1990 regulates the manufacture, distribution, use, and disposal of toxic chemical substances, with special emphasis on polychlorinated byphenyls (PCBs). Both acts are administered by the EPA, acting in concert with state regulatory agencies. Through the mechanism of a permit system, RCRA regulations require that safe and secure procedures be used in treating, storing, transporting, and disposing of hazardous wastes. Corrective actions may be required for continuing releases and releases beyond a waste management facility's boundary. The significance of theses laws for D\&D lies in the fact that hazardous materials may be generated from these projects as primary or secondary wastes. DOE has traditionally operated under legal immunity in dealing with risks associated with non-radioactive hazardous materials management. In recent years, acceptance of EPA regulatory criteria for the treatment, storage, and disposal of materials subject to RCRA and TSCA has occurred through the mechanism of site-specific Federal Facility Compliance Agreements involving the DOE, EPA and state regulatory agencies. The Federal Facilities Compliance Act (1992) formally commits the DOE to 
legally enforceable acceptance of RCRA criteria for hazardous waste management at all DOE-owned facilities. For mixed wastes (containing both hazardous and radioactive components and therefore regulated under both RCRA and the Atomic Energy Act) a three-year period of immunity is granted for the DOE to achieve compliance with RCRA criteria for waste storage. Afterward, enforcement actions can be initiated by the EPA unless specific compliance agreements are in place with affected states. Significant quantities of mixed and/or hazardous wastes will be generated by D\&D activities, and there is a need to demonstrate technologies which can minimize the generation and effectively treat, store, and recycle or dispose of these wastes.

\section{CERCLA/SARA}

The Comprehensive Environmental Response, Compensation, and Liability Act (CERCLA) of 1980, as amended in 1986 by the Superfund Amendments Reauthorization Act (SARA), requires investigation and remediation of abandoned or uncontrolled hazardous waste sites where a release has occurred or a substantial threat or release exists. The law, administered by the EPA, specifies a process for performing site investigations and characterizations, evaluating alternatives for remediation, and documenting results and recommendations to the EPA and state regulators. A public forum is held and comments are solicited on these documents. Final selections of remedial alternatives are documented in a legally binding Record of Decision. A number of DOE sites are on the National Priorities List for remedial action (RA) under CERCLA.

As presently defined, the law is not a direct regulatory driver for D\&D in all cases. However, at some DOE sites D\&D facilities either occupy or are immediately adjacent to operable units for RA. In these cases, D\&D and RA activities may have to be coordinated with the D\&D activities or incorporated under the CERCLA regulatory framework. This framework would then become the primary regulatory driver for establishing schedules and priorities for specific cleanup activities, iricluding technology demonstrations which might influence these activities. 


\section{The Clean Air Act and the Clean Water Act}

The Clean Air Act and the Clean Water Act set national emission standards for hazardous air pollutants (NESHAP) and national pollutant discharge effluent standards (NPDES). State regulatory agencies generally have the responsibilities for administering and enforcing these regulations with oversight by the EPA. In some cases, states have established standards more stringent than the national criteria which can further influence the technologies and approaches to be used for D\&D.

\section{Occupational Health and Safety Act and Administration (OSHA)}

The Occupational Health and Safety Administration sets standards for protecting occupational workers from various work place hazards. These standards, in conjunction with DOE policy and procedures for ALARA control of worker radiological exposures, will provide significant challenges in performing $\mathrm{D} \& \mathrm{D}$ tasks.

\section{Department of Transportation (DOT) Regulations}

Through the Hazardous Materials Transportation Act (1975) and Amendments, the U.S. Department of Transportation has regulatory authority for the packaging and transport of hazardous materials. These regulations, in conjunction with internal DOE Orders establishing standards for packaging and transport of radioactive and other hazardous materials, must be considered for both off-site and on-site movements of these materials. 

Decommissioning, and Final Disposition Focus Area 


\section{Section 1 The Current Situation - Summary}

DOE surface decontamination guidelines allow for the general release of process-contaminated metal scrap meeting certain criteria.

There are no DOE guidelines for the release of materials with volumetric or bulk contamination.

\section{Section 2 Objectives}

To support the objectives in this Strategic Plan and the full benefits of materials recycling, we strive for the adoption of a de minimis standard permitting general release. In addition, we need to educate the public about, encourage the public to participate in, and make the public aware of the benefits of recycling for beneficial reuse.

These objectives can be achieved in a graded manner:

1. Release material for unrestricted use under the current DOE surface criteria.

2. Release material for restricted use within the DOE Complex under current DOE standards.

3. Release material for controlled use within the DOE Complex under new DOE standards.

4. Release material for restricted use outside the DOE Complex (e.g., commercial nuclear power plants, roadbed) under new state and DOE standards.

5. Release material for unrestricted use outside the DOE Complex under new DOE standards.

The effect on the IDs of not meeting these objectives would be that a larger quantity of materials would be buried instead of reused. 
The road to this graded approach is full of barriers.

- There is a need for the regulatory agencies to establish a de minimis level for the unrestricted release of bulk- and volumetric-contaminated materials (as has been done in Europe and Asia). In fact, the United States imports from Europe and Asia products that meet their established de minimis criteria for bulk and volumetric contamination. This tends to put U.S. industry at a competitive disadvantage. As a starting point, it is recommended that the regulatory agencies consider adopting proposed International Atomic Energy Agency standards.

- There is a need to deal with changing regulations and regulatory climates.

- There is a need to establish materials release standards for hazardous constituents (e.g., mercury).

- There is a need to better define recyclable materials and waste materials.

- There is a need to address the public reaction to BRC wastes.

The demonstrations can make a start on these objectives by:

- working with the EPA liaison (EM-20), the NRC liaison (EH-20), and the OSHA liaison (EH-30) in standards development;

- working with professional society committees (e.g., American Society for Testing and Materials, American Nuclear Society, American Society for Mechanical Engineers) in standards development; and

- collecting data from, and documenting the results of, tests of bulk and volumetric contaminated media. 


\begin{tabular}{|c|c|c|}
\hline Leval & Description & Standard \\
\hline & Froo release & DOE surface decontamination criteria \\
\hline 10 & Restricted use within DOE Complex & DOT standards (no DOE standarc) \\
\hline ree & Controlled use within DOE Complex & Now DOE standard \\
\hline ur & Restricted use outside of DOE Complex & New state standards and new DOE standard \\
\hline & Unrestricted use outside of DOE Complex & Now DOE standard \\
\hline
\end{tabular}




\section{Contaminated Concrete}

\section{Section $1 \quad$ Situation Analysis}

\section{Section 1.1 Problem Definition}

Description of Concrete is a common material that is widely used in the construction of the Problem floors, foundations, walls, shielding, and roads for DOE facilities. Because it was exposed to contamination sources, this somewhat porous material has been contaminated extensively. Types of contaminants include PCBs and hazardous chemicals, as well as radionuclides. The extent of contamination ranges from loose surface contamination to contamination that has permeated throughout the concrete. Radiation fields vary from none to extremely high levels. Types of contamination include uranium, plutonium, fission products, miscellaneous hazardous chemicals (e.g., corrosives, organics, heavy metals). and PCBs. The concrete surfaces may be bare, painted, or coated. In a small number of cases, concrete and rebar have been activated by radiation.

Most of the concrete is bare concrete; however, some of the contaminated concrete has been painted or covered with tile or epoxy. Some is in the form of concrete block. Most of the contamination is near-surface contamination; in other words, the contaminants have penetrated into the concrete to varying depths, but generally have remained near the surface. However, some contaminants, principally tritium, PCBs, and mercury, have penetrated throughout the concrete.

The most significant examples of contaminated concrete throughout the DOE Complex include:

- concrete in fuel-reprocessing facilities

- Hanford

- Savannah River

- INEL

- ORNL

- concrete in hot cells

- Hanford

- Savannah River

- INEL

- ORNL 
- tritiated concrete

- Savannah River

- Mound Laboratories

- LANL

- INEL

- Princeton University Tokamak

- ORNL

- concrete in fuel storage pools and solar ponds

- Hanford

- INEL

- Savannah River

- LANL

- concrete in uranium-processing facilities

- Fernald

- Oak Ridge, Y- 12

- Hanford

- INEL

- Rocky Flats

- LANL

- concrete in gaseous diffusion plants

- Oak Ridge.

- Paducah

- Portsmouth

- activated concrete in the biological shield around reactors

- INEL

- Savannah River

- Oak Ridge

- plutonium-processing facilities

- Rocky Flats

- Lawrence Livermore

- LANL

- Hanford

- Savannah River

Numerous examples of commercial facilities in the U.S. and abroad exhibit similarly contaminated concrete. 


\section{Section 1.2 Characterization}

Baseline Current baseline technologies for characterization of contaminated concrete Technologies include:

- interviews and analysis of plant records and documentation

- physical and remote video inspection

- gas analysis, non-invasive measurements

- active and passive scanning

- core sampling and remote analysis

- smears and wipes and remote analysis

- chemical and biological surveys

There has been little change in any of these techniques in recent years.

Deficiencies The deficiencies associated with using current baseline technologies for characterization include the following:

- questionable completeness and accuracy of existing plant records and results of personal interviews

- coatings cause distortion of results with current measurement technology

- inspections are limited by the risk of exposure and physical accessibility

- sampling limitations

- lack of physical access

- not always representative

- not real time

- long count time required for accuracy

- transportation hazards

- volatility of samples

- lack of analysis capability and capacity

- low analysis methods

- inadequate three-dimensional analysis

- limited automated/remote capabilities

- lack of adequate sampling devices

- lack of in situ measurement capabilities 
- probes suitable for field use are non-discriminating, insensitive, and often fragile and delicate

- potential health risks

- worker exposure

- public exposure

- undefined contaminants

- detection limits

- lowering of standards

- state versus federal standards vary widely

Solutions The best solution to the problems associated with using current baseline technologies for characterization should provide

- in situ characterization

- real-time characterization

- ability to discriminate between nuclides

- ability to see through coatings

- 3-D mapping (with a database)

- improved access to remote locations

- faster results

- better sensitivity

- EPA-approved methods

- means to interview human resources now (before records are lost)

- rugged, real-time analysis, suitable for field use

- better remote deployment technology

\section{Section 1.3 Decontamination}

Baseline Current baseline technologies for concrete decontamination include shot Technologies blasting, mechanical scabbling, detergent scrubbing (nand mops and riding scrubbers), high-pressure washing, chemical and electrochemical treatments, strippable coatings, clamshell scrapers, brushing, vacuuming, and attacking cracks with jack hammers. For tritiated concrete, wet outgassing and high-temperature dry air treatments are used in addition to standard methods. Wet blasting and wet vacuuming are used to decontaminate concrete fuel storage pools. Innovative new technologies have been introduced slowly. 
Deficiencies Several deficiencies characterize current baseline technologies for decontamination. Available methods are labor intensive, time consuming, costly, and generate a large amount of secondary waste. Furthermore, concrete may be deeply contaminated because of joints, cracks, and diffusion permitted by the porous nature of concrete. Current technologies clean only the surface and, thus, are not effective for in-depth contamination. Many of these techniques are difficult or impossible to apply to restricted access areas like hot cells. Outgassing may pose a cleanup problem for tritiated concrete. Many of the baseline technologies are not effective for concrete with painted or epoxy liners, like fuel storage pools; the less aggressive techniques are not effective unless the coating is removed first.

Iterative cycles of characterization, decontamination, re-characterization, and additional decontamination are often needed. The primary risks associated with current baseline technologies for decontamination are worker exposure to radiation and radioactive and hazardous materials, and large amounts of secondary waste.

Solutions The most meaningful solutions to concrete decontamination problems are technologies that are quick, automated, that generate little or no secondary waste, and that minimize worker exposure to radioactive and hazardous materials. A viable in situ method is needed for decontamination of massive concrete structures (surface decontamination, surface removal, and decontamination of cracks and other areas where contamination has penetrated the concrete), including floors, walls, roofs, and ceilings.

In addition, a solution that allows contaminated concrete to be identified, segregated, and cleaned during dismantlement is needed. Without this solution, it will be impossible to segregate the massive clean concrete structures from the small volume of contaminated surfaces.

Decontamination of mercury and tritium-contaminated concrete may require decontamination of the entire volume of the concrete plus better off gas treatments with a means to recover tritium for beneficial reuse. Remote operation may be required for highly radioactive areas.

\section{Section 1.4 Dismantlement}

Baseline Current baseline technologies for dismantlement of concrete structures focus Technologies on conventional demolition techniques. These include wrecking balls, expansive grout, diamond saws, high-pressure water jets (with and without abrasive grit), laser cutting, jack hammers, and blasting. These technologies are well accepted in the commercial world for non-contaminated facilities and have also been used in the nuclear industry (e.g., Shippingport Nuclear Station).

\begin{tabular}{ccc}
\hline C-6 & $\begin{array}{c}\text { January } 1994 \\
\text { Revision } 0\end{array}$ & $\begin{array}{c}\text { Technical Program Plan for the Transitioning. } \\
\text { Decommissioning, and Final Disposition Focus Area }\end{array}$
\end{tabular}


Deficiencies The primary deficiency for dismantlement using conventional techniques is the difficulty of confining and segregating the contaminated portion of the concrete rubble and the resulting dust. Additional deficiencies include worker exposure to high radiation fields and to industrial safety hazards and generation of secondary waste. Moreover, the volume of material to be handled is staggering.

Solutions One desired solution would be to decontaminate the concrete structure to a releasable limit prior to dismantlement. This would enable the use of hands-on, currently available, dismantlement technology. In cases where this is not practical or achievable due to access limitations, solutions must be reached that dismantle these structures remotely with minimal exposure to workers, or that segregate the rubble into clean and contaminated streams. Under this latter case, an ex situ decontamination of the concrete should be considered before final disposition.

\section{Section 1.5 Materials Disposition}

Baseline Current baseline technologies include entombment, reducing concrete Technologies structures to segments and rubble, boxing, and burial. Entombment or burial requires continuous surveillance and maintenance and their viability under current and future regulations is questionable. The current low-level waste burial costs range from $\$ 5.00$ to $\$ 300.00$ per cubic foot and are expected to steadily increase. Those sites with currently low cost per cubic foot have little incentive for volume reduction or decontamination.

Deficiencies Current baseline technologies for materials disposition have several deficiencies. They are limited by diminishing landfill space, increasingly restrictive environmental regulations, the inability to recycle or reuse buried or entombed waste, and the specter of materials resurrection. Size reduction is expensive and labor intensive, and it produces secondary waste; even after size reduction, contaminated materials must still be disposed of.

Solutions The most meaningful solution to the problems of materials disposition would include viable means to:

- characterize existing structures;

- separate the concrete from the rebar;

- segregate the contaminated concrete from the "clean" concrete;

- crush the "clean" concrete into aggregate suitable for reuse (e.g., roadbed, landfill, mine fill). 


\section{Section 1.6 Robotics and Automation}

Baseline Technologies

The baseline technologies for the decontamination and dismantlement of concrete are limited to crawlers, cranes, master/slave manipulators, electro-mechanical manipulators, and remote delivery of tooling (e.g., remote cranes in canyons). Limited versions of mobile floor-survey units, and remote decontamination equipment are available.

Deficiencies The deficiencies associated with current robotics and automation technologies include suitability for hazardous environments, large size or weight, limited access capabilities, limited range and sensor capabilities, and limited load capabilities. Additionally, there is a lack of technologies for in situ characterization.

Solutions

Sophisticated robotics and automation could solve many problems with current baseline technologies for characterization, decontamination, and dismantlement of massive concrete structures. The development of new D\&D robotic end-effectors will benefit all those technologies.

Characterization will require robust and remotely operated devices that can completely characterize large concrete surfaces, both walls and floors, and map the resulting data into meaningful databases or models.

Decontamination needs will require robust and remotely operated surface cleaning, scabbling, etc., devices capable of minimizing secondary waste and radioactive waste dispersion (e.g., splattering, over spray).

The dismantlement solution requires a remote system of compatible, robust robotics and/or automated equipment to permit remote cutting, scabbling, drilling, crushing, and lifting of sections of highly radioactive, massive concrete structures in a contained environment.

\section{Section 1.7 Management and Systems}

Baseline The developmental work in concrete technologies is advancing on a number Technologies of fronts. There is a large body of established lore relating to the decontamination and decommissioning of contaminated concrete, based on the previous commercial nuclear power experience. Additional research and development is underway, both at government laboratories and at commercial establishments. Most of this development is ad hoc, with little or no coordination, and no top-level management. 
Deficiencies Because of the lack of coordination of research and development, there are frequent examples of duplication of efforts. An integrated program that systematically addresses problem areas and marshals the needed resources has been lacking.

Solutions An integrated program recognizes the many variables to the problem, encourages the development of techniques that address one or more of the variables, and then brings the pieces together into a unified whole. A systems approach to the concrete problem recognizes that the variables are:

- Coating - bare concrete or coated

- Orientation - horizontal, vertical, or overhead surfaces

- Composition - reinforced, monolithic, concrete block, or precast panel

- Contaminants - heavy metals (U, Pu, TRU), fission products, chemicals, fissile, tritium, mercury

The first three variables affect the efficiency of each given technique and how it is applied in practice, while the last two variables can serve as a basis for selecting a location for the demonstration.

It is the responsibility of the Integrated Demonstration program to coordinate the development of the appropriate techniques without unnecessary duplication, and to bring them together, using a systems approach, into a unified program. 


\section{Section 2 Description of the Proposed Integrated Demonstration}

The concrete ID contains sub-tasks in all six of the technical areas, with the eventual goal of providing a "womb-to-tomb" demonstration at a chosen site.

The proposed ID considers the following task areas for new and improved characterization. In addition to the requirements listed below, it is highly desirable that the characterization devices be miniaturized to the maximum extent possible, so that it can be delivered via remote technology in the field.

- Development of characterization technologies that provide real-time feedback, in situ, and including characterization of both radioactive and RCRA hazardous materials. This is to be a two-stage development effort, with laboratory development of a number of diverse detection techniques, followed by field testing of a few of those techniques that show promise.

- Development of improved data-collection and display systems that can map the collected characterization data in the physical space of the facility. This is to include data logging, chain-of custody records for samples, spatial location determination, physical marking of the hot spots encountered, and 3-D mapping capabilities.

The proposed ID considers the following areas for new and improved technologies for decontamination. At least some of the techniques for decontamination will also need to be miniaturized to the maximum extent possible, for remote deployment.

- Improved, in situ decontamination techniques for surface and volumetric decontamination of massive concrete volumes will be demonstrated. Demonstrations are proposed for the following technologies:

- Chemical cleaning by a vendor using vendor's selected technology.

- Microwave decontamination

- $\mathrm{CO}_{2}$ blasting using centrifugal-accelerated $\mathrm{CO}_{2}$ particles. These particles will have velocities of 4000 $\mathrm{ft} / \mathrm{sec}$, which is 4 to 16 times that of commercial $\mathrm{CO}_{2}$ machines. Some support will be needed to complete the development of a mobile machine.

- Supercritical $\mathrm{CO}_{2}$ blaster under development by a vendor. This technique uses ultra-high pressure to turn $\mathrm{CO}_{2}$ into a supercritical fluid, which is then sprayed against the surface, where it flashes to a gas. ?Tovide any funding needed to complete development and field test. 
- Electrokinetic decontamination will be tested in situ. This technique uses an electrolyte that is forced into the concrete matrix by an electric voltage, then removed by reversing the voltage. The contaminant ions are also moved in the direction of the voltage, and collected by processing the electrolyte. This technique was independently developed by a group at ORNL and by a vendor who developed it as an adaptation of a soil cleaning process, via a PRDA. The existing PRDA may be extended to include joint field testing by ORNL and the vendor at a solar pond at the Hanford site.

- Laser hydraulic cutting has been developed by a mining concern. This technology will be adapted for concrete decontamination. It may also be a suitable technique for segmentation during dismantlement.

These technologies will be carried from the laboratory tests through field tests to the ultimate demonstration in contaminated facilities. Not all of these phases may be needed, depending on the present state of maturity of the technology.

In the technical area of dismantlement, several advancements in technology are desired. At least some of the techniques for dismantlement will also need to be miniaturized if possible, for remote deployment. The need for remote technology during dismantlement is likely to be relatively low, since most of the high radiation sources will have been removed by the time demolition takes place. Demonstrations of the following are included:

- Laser cutting

- Water jet cutting (abrasive jet or cavitating jet)

- Controlled explosives (shaped charge cutting)

- Remotely operated expansive grout fracturing

- Liquefied gas cutting

In the technical area of materials disposition, several advancements in technology are desired. Demonstrations of the following are included:

- In "ex situ" decontamination, the concrete is decontaminated after it has been removed from the building or structure. Innovative technologies are needed for:

- concrete size reduction

- production-line characterization of concrete rubble streams to segregate clean rubble from contaminated.

- "washing" of concrete to remove contaminants. 
- Improved methods for handling the secondary waste from decontamination will also be demonstrated. These include:

- Vacuum collection systems will be developed for blasting-type decontamination systems

- Off-gas filtration systems will be demonstrated for gaseous systems

- A treatment system that will permit recycling/reuse of water will be demonstrated for water-based decontamination systems

These treatment systems will probably need to be tailored to the specific contaminants at each site.

- Decontaminated concrete could also be used to entomb contaminated areas within the DOE Complex to prevent short and long-term contaminant migration. As an example, contaminated canyons could be filled with decontaminated, reformed concrete. In this manner, the decontaminated concrete could replace more expensive grout for entumbment of canyons and similar areas, as well as provide shielding.

In the technical area of robotics and automation, several advancements in technology are desired. Demonstrations of the following are included:

- Development of a remote delivery vehicle to deploy the characterization devices that are also a part of this integrated demonstration. The vehicle needed will have the following features:

- It needs to be as small as possible, consistent with the other requirements, in order to have maximum capability for entering confined areas of facilities

- It needs to operate autonomously, i.e., without constant attendance by operators, to minimize personnel radiation and contamination exposure

- It needs to have a position locating feature, so that it knows the exact location of each measurement it takes within the facility

- It needs to have a data-logging capability, either onboard or via telemetry, so that it can take multiple measurements without having to be retrieved or handled each time to get the data

- It would be a desirable feature for it to have the ability to mark any "hot spot." This could be done by applying paint or perhaps a bar-code label to the surface at the point of interest. 
- Development of a second remote vehicle to deploy decontamination equipment to deal with the "hot spots" discovered by the characterization vehicle. This vehicle will need to have the following features:

- It needs to be able to deliver a variety of different devices for decontamination, to have maximum flexibility in how it is used

- It needs to be designed to accommodate any specific requirements of the decontamination device, such as fluid delivery, electric power, reaction forces, etc.

- It needs to have knowledge of the same spatial information and coordinate system used by the characterization vehicle, so that it can find the particular "hot spot" location by itself.

- It needs the ability to confine, collect, and remove any secondary waste generated by the decontamination devices onboard

- It would be a desirable feature for it to have onboard lights and video cameras, to observe and record the decontamination process, so that effectiveness can be judged, problems encountered can be understood, and a permanent record of the action can be generated

In the technical area of management and systems, the administrative requirements associated with managing this integrated demonstration, and the integration of the sub-demos will be accomplished. The schedule sheets at the end of this appendix show some of the demo program activities, such as writing plans and reports, calls for TTPs, selecting sites, and public participation. In addition, the following items encompassing multiple technical areas of this demonstration are proposed to be brought together:

- (Characterization, decontamination, robotics) A facility with large expanses of potentially contaminated floor area will be chosen to demonstrate an integrated solution to characterization and in situ decontamination in the following manner:

- A remotely operated characterization vehicle will be used to survey a large floor area and to identify spot contamination

- A CAD map of the facility will be prepared, and the hot spot(s) located on the map

- A second remote vehicle will find the spot identified by the first vehicle, drill and remove a core sample from within the hot spot, and then apply one of the candidate decontamination techniques to the hot spot

- A second core sample will be taken by the remote vehicle after the decontamination is completed 
- The two samples will be analyzed and a report of the decontamination factor achieved will be prepared

- Characterization, dismantlement, materials handling, robotics

A pilot scale concrete rubble handling system will be demonstrated at a site with sufficient volumetrically contaminated concrete. This integrated demonstration will be accomplished as follows:

- A sufficient amount of the contaminated concrete will be removed from the facility using one of the dismantlement candidate techniques

- The concrete will be placed into the first section of the demonstration system, where it will be reduced in size

- The concrete will then move along a conveyor, where the clean rubble will be separated from the contaminated

- The clean rubble will continue to a packaging facility suitable for landfill disposal

- The contaminated rubble will be cleaned via a candidate decontamination technology

- The resulting cleaned rubble will be further characterized, and released to the clean stream for disposal, if appropriate

- Any rubble which was not releasable will be segregated and packaged for disposal as appropriate

- All secondary waste will be treated and packaged for appropriate disposal

\section{Section 2.1 Deliverables}

- Enabling technologies for real-time, in situ characterization of concrete from pre-characterization through verification of decontamination.

- Technologies for both in situ and ex situ decontamination of near-surface and volumetrically contaminated concrete.

- Efficient technologies for separation of contaminated and non-contaminated materials to minimize waste. System for beneficial reuse of slightly contaminated materials within the DOE complex.

- Cost/benefit of the technologies tested under the integrated demo and subsequent recommendation for use by DOE and industry. 


\section{Section 2.2 Reasons for Pursuing the Proposed ID Now (versus Later)}

- A strong case can be made for performing this demonstration for concrete now rather than in the future. Several DOE sites must D\&D concrete structures in the near future to meet regulatory mandates. Using conventional methods to perform this D\&D would use up limited burial space and require significant expenditures because of rising burial costs. The sooner this ID can be performed, the sooner new technologies can be applied to D\&D to reduce volumes of concrete going to landfills. Facilities are currently available to house the ID. Experienced personnel are also available at the facilities.

- The only significant driver to delay the performance of the ID would be lack of funding. However, the funding used for the ID would be offset by accelerating D\&D activity which, in turn, will eliminate excessive surveillance and maintenance costs associated with the facilities. Delay will only increase the ultimate cost of D\&D, as well as providing fuel for public dissatisfaction with the DOE Complex. 


\section{Section $3 \quad$ Benefits}

Direct benefits of the ID are as follows.

- Potential to free release concrete.

- Potential to reuse/recycle concrete.

- Potential for waste minimization.

- Potential for "no further action" at some facilities.

- Potential for lower exposure to workers.

Values EM will gain from the results of the ID are as follows.

- Spin-off of decontamination to commercial industry.

- Improved image of DOE for advancing technology in cleanup.

- New and improved technologies to clean up sites.

- Successful DOE/industry collaboration.

Industry or the DOE Complex might benefit from the ID in the following

- New jobs for private sector.

- New private companies in D\&D business.

- New and improved technologies directly applicable for the commercial utility industry.

Cost savings to DOE will be realized through large volume reductions in contaminated concrete and associated wastes, potential beneficial reuse of some of these materials, and reduced labor costs through robotics and automation and isolation of contaminated concrete from uncontaminated concrete. 
Section 4 What Cannot Be Done Between FY-94 and FY.99

Use of contaminated concrete rubble as fill for entombment of a canyon or other large contaminated structure is discussed as a long-term goal. However, there are two main reasons why no demonstration actions will be possible in the near future:

- Acceptance of this mode of decommissioning is a question which would need to be settled first; thi i to predict how long this would take or whether it is $:$ ' possible.

- The idea would be most likely applied to the entombment of a large facility, like a processing canyon or a production reactor. There is not likely to be any such facility decommissioning in the FY-94 to FY-99 period, because of fiscal constraints.

\section{Section $5 \quad$ Locations}

The selection of sites will depend on the specific sub-demo technology and the nature of the contamination at the proposed site. The overall integrated demos should be done at sites chosen on the following criteria.

- The coating, orientation, and composition of the concrete must be representati bulk of concrete in the complex.

- The contaminar: proposed site should be representative of the range of contaminants for which the characterization techniques in the integrated demo are suitable.

- The proposed site must be available for ease of access (security); have reasonable cost; use trained personnel; be within regulatory guidelines.

The selection will be based on the above criteria and the advantages of each site for the various characterization and decontamination techniques for in situ operations. It appears that the Oak Ridge K25 installation is the prime candidate for the "small robot/big robot" integrated demonstration because of the vast amount of relatively unobstructed floor area.

LANL is the prime candidate for the production line ex situ decontamination demonstration because of the considerable amount of soil-washing development that has occurred there. However, should there be another site with a near-term requirement to demolish a large concrete structure, it should probably receive priority for this demo. 
The table below lists the DOE and commercial sites with facilities with contaminated concrete, their relationships to each other, and the current justification for a D\&D ID.

\begin{tabular}{|c|c|c|c|c|}
\hline DOE Sltes & $\begin{array}{c}\text { Why Use this } \\
\text { Stie }\end{array}$ & $\begin{array}{l}\text { Relationships } \\
\text { between Sites }\end{array}$ & $\begin{array}{l}\text { Technical } \\
\text { Justiflcation }\end{array}$ & $\begin{array}{c}\text { Financial } \\
\text { (or other) } \\
\text { Justification }\end{array}$ \\
\hline Oak Ridge (GDP) & $\begin{array}{l}\text { Good for } \\
\text { characterization . } \\
\text { and } \\
\text { decontamination }\end{array}$ & \multirow{9}{*}{$\begin{array}{l}\mathrm{Hg} \text { and tritiated } \\
\text { concrete similar to } \\
\text { Savannah River } \\
\text { Concrete problems } \\
\text { related across site } \\
\text { Activated concrete is } \\
\text { similar only at sites } \\
\text { with concrete } \\
\text { biological shields } \\
\text { around reactors }\end{array}$} & $\begin{array}{l}\text { Low contamination; } \\
\text { low radiation; U. TC }\end{array}$ & Available today \\
\hline $\begin{array}{l}\text { Savannah River } \\
\text { (R-Reactor) }\end{array}$ & $\begin{array}{l}\text { Probably best for } \\
\text { characterization } \\
\text { only }\end{array}$ & & $\begin{array}{l}\text { Low contamination; } \\
\text { low radiation; very } \\
\text { large; potential for } \\
\text { free release; potential } \\
\text { tritium contamination }\end{array}$ & $\begin{array}{l}\text { Available today; no } \\
\text { security requirement; } \\
\text { representative of a } \\
\text { very large percentage } \\
\text { of total concrete } \\
\text { across complex }\end{array}$ \\
\hline LANL (TA-21) & $\begin{array}{l}\text { Available for all } \\
\text { technology areas }\end{array}$ & & $\begin{array}{l}\text { U, Pu; heavily } \\
\text { contaminated }\end{array}$ & $\begin{array}{l}\text { Available today; } \\
\text { actively being D\&D } \\
\text { today; cost-sharing } \\
\text { opportunities; soil- } \\
\text { washing experience }\end{array}$ \\
\hline $\begin{array}{l}\text { Rocky Flats (371. } \\
771)\end{array}$ & $\begin{array}{l}\text { Best for } \\
\text { characterization } \\
\text { only }\end{array}$ & & $\begin{array}{l}\mathrm{Pu}, \mathrm{PCB}, \mathrm{U} \text {; solvents, } \\
\text { organic; Am, Tritium }\end{array}$ & $\begin{array}{l}\text { Available today; no } \\
\text { disposal of waste } \\
\text { available today }\end{array}$ \\
\hline $\begin{array}{l}\text { Hanford (REDOX, } \\
\cup_{3} \text { ) }\end{array}$ & $\begin{array}{l}\text { Best for } \\
\text { characterization } \\
\text { and } \\
\text { decontamination }\end{array}$ & & U, Pu, fission products & $\begin{array}{l}\text { Available today; } \\
\text { representative of a } \\
\text { very large percentage } \\
\text { of concrete }\end{array}$ \\
\hline Hanford Solar Ponds & $\begin{array}{l}\text { Good for } \\
\text { decontamination; } \\
\text { piggy-back with } \\
\text { ongoing EM-40 } \\
\text { D\&D project }\end{array}$ & & $U$, solvents, organics & $\begin{array}{l}\text { Available today; EM- } \\
40 \text { wants cooperative } \\
\text { demonstration }\end{array}$ \\
\hline Fornald (Plant 6) & $\begin{array}{l}\text { Available for all } \\
\text { technology areas }\end{array}$ & & $\begin{array}{l}U, \text { machining oils. } \\
\text { heavy metals }\end{array}$ & $\begin{array}{l}\text { Available today: NEPA } \\
\text { and EPA permitting } \\
\text { complete }\end{array}$ \\
\hline RMI & $\begin{array}{l}\text { Available for all } \\
\text { technology areas }\end{array}$ & & $\begin{array}{l}\text { U, machining oils, } \\
\text { heavy metals, TCE }\end{array}$ & $\begin{array}{l}\text { Pseudo-DOE site; } \\
\text { available today; } \\
\text { performed under NRC } \\
\text { jurisdiction }\end{array}$ \\
\hline INEL (ICPP) & $\begin{array}{l}\text { Characterization } \\
\text { and surface } \\
\text { decontamination }\end{array}$ & & Fission products & Available today \\
\hline
\end{tabular}




\section{Section 6 ID Schedule and Costs}

The following table summarizes the costs (in millions) of this ID over its entire lifespan.

\begin{tabular}{|l|c|c|c|c|c|c|c|}
\hline & Year 1 & Year 2 & Year 3 & Year 4 & Year 5 & Year 6 & Total \\
\hline Characterization & 4.000 & 0.650 & & & & & 4.650 \\
\hline Decontamination & 1.700 & 1.840 & 0.660 & & & & 4.200 \\
\hline Dismantlement & & 1.075 & 0.050 & & & & 1.125 \\
\hline Materials Disp. & & & 0.750 & 1.750 & 1.185 & 0.315 & 4.000 \\
\hline Robotics \& Auto. & & 0.670 & 2.597 & 0.133 & & & 3.400 \\
\hline Mgmt. \& Sys. & 0.100 & 0.120 & 0.313 & 0.467 & 0.100 & 0.100 & 1.200 \\
\hline Total & 5.800 & 4.355 & 4.370 & 2.350 & 1.285 & $\mathbf{0 . 4 1 5}$ & $\mathbf{\$ 1 8 . 5 7 5}$ \\
\hline
\end{tabular}


Contaminated Concrete Demonstration Path

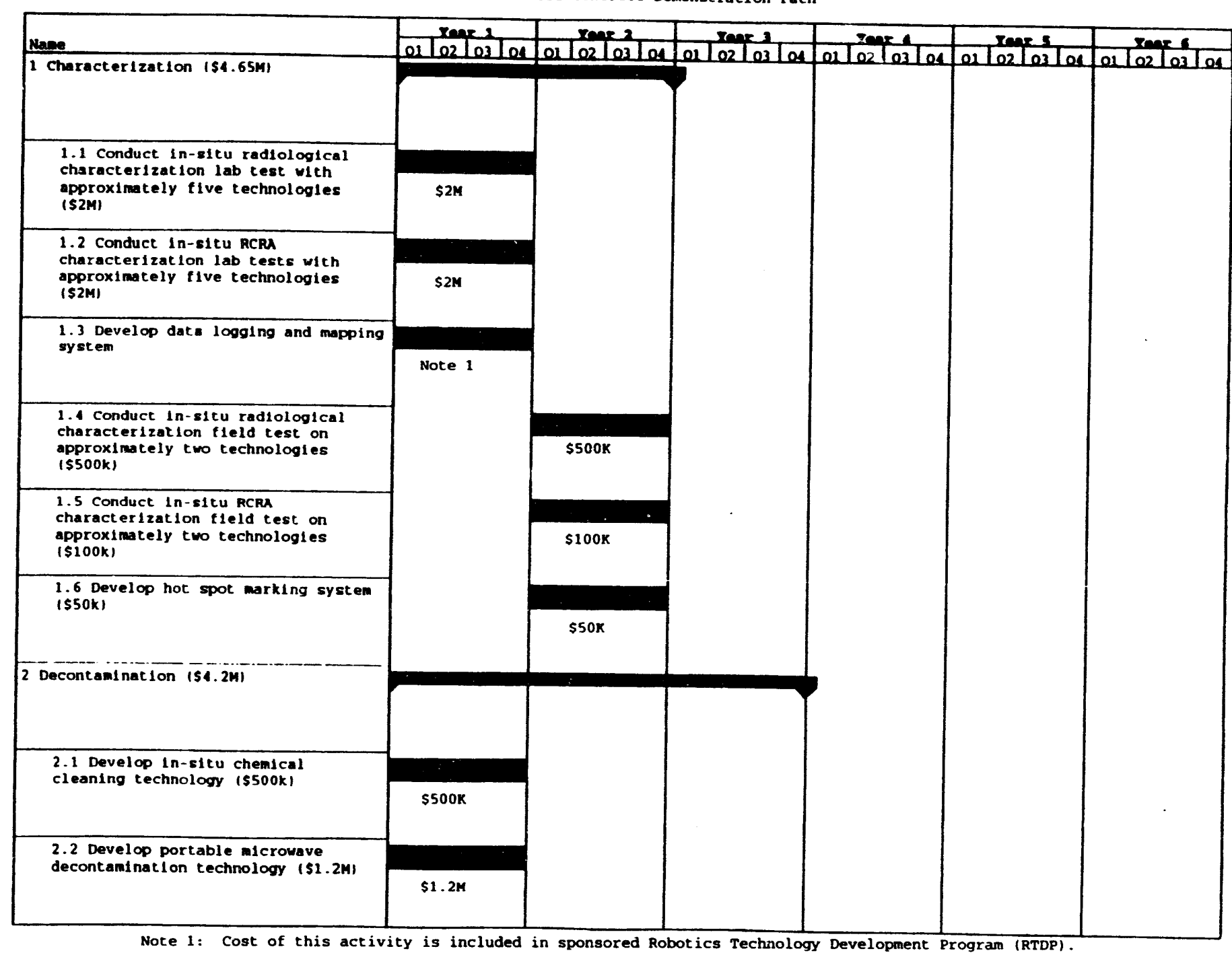


Contaminated Concrete Demonstration Pach

\begin{tabular}{|c|c|c|c|c|c|c|}
\hline Name & 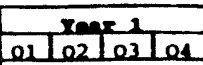 & $0102 \log _{03}^{2}$ & 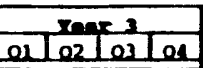 & 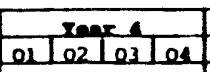 & 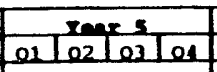 & 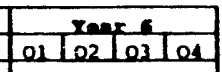 \\
\hline $\begin{array}{l}2.3 \text { Field tests of electromanget ic } \\
\text { decon }\end{array}$ & 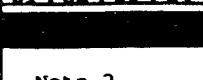 & & & & & \\
\hline $\begin{array}{l}2.1 \text { Develop centrifugal accelerated } \\
\mathrm{co2} \text { blaster and field test (sim) }\end{array}$ & & s670k & $\$ 330 \mathrm{~K}$ & & & \\
\hline $\begin{array}{l}2.5 \text { Develop supereritical co2 fluld } \\
\text { biaster and theld test (siM) }\end{array}$ & & $\$ 670 \mathrm{~K}$ & $5330 \mathrm{x}$ & & & \\
\hline $\begin{array}{l}2.6 \text { Adapp laser hydraulic cutt ing } \\
\text { techn1 que for decontaminat ion } \\
\text { (5500k) }\end{array}$ & & $\$ 500 \mathrm{~K}$ & & & & \\
\hline 3 D1 emant lement $151.1 \mathrm{H}$ tota 11 & & & & & & \\
\hline $\begin{array}{l}3.1 \text { Develop portable laser cutter } \\
\text { for concrete (5500k) }\end{array}$ & & \$500R & & & & \\
\hline $\begin{array}{l}3.2 \text { water yet cutting field demo } \\
\text { (550k) }\end{array}$ & & $550 \mathrm{~K}$ & & & & \\
\hline $\begin{array}{l}3.3 \text { control ied explosive cutting } \\
\text { ileld demonst ration (575k) }\end{array}$ & & $575 k$ & & & & \\
\hline $\begin{array}{l}\text { 3.4 Develop expansive grout } \\
\text { segment ing system sultable for } \\
\text { remote deployment }(5200 k)\end{array}$ & & \$200k & & & & \\
\hline $\begin{array}{l}\text { 3.5 Liquefled gas cutLing lab scale } \\
\text { development (5250k) }\end{array}$ & & \$250K & & & & \\
\hline
\end{tabular}




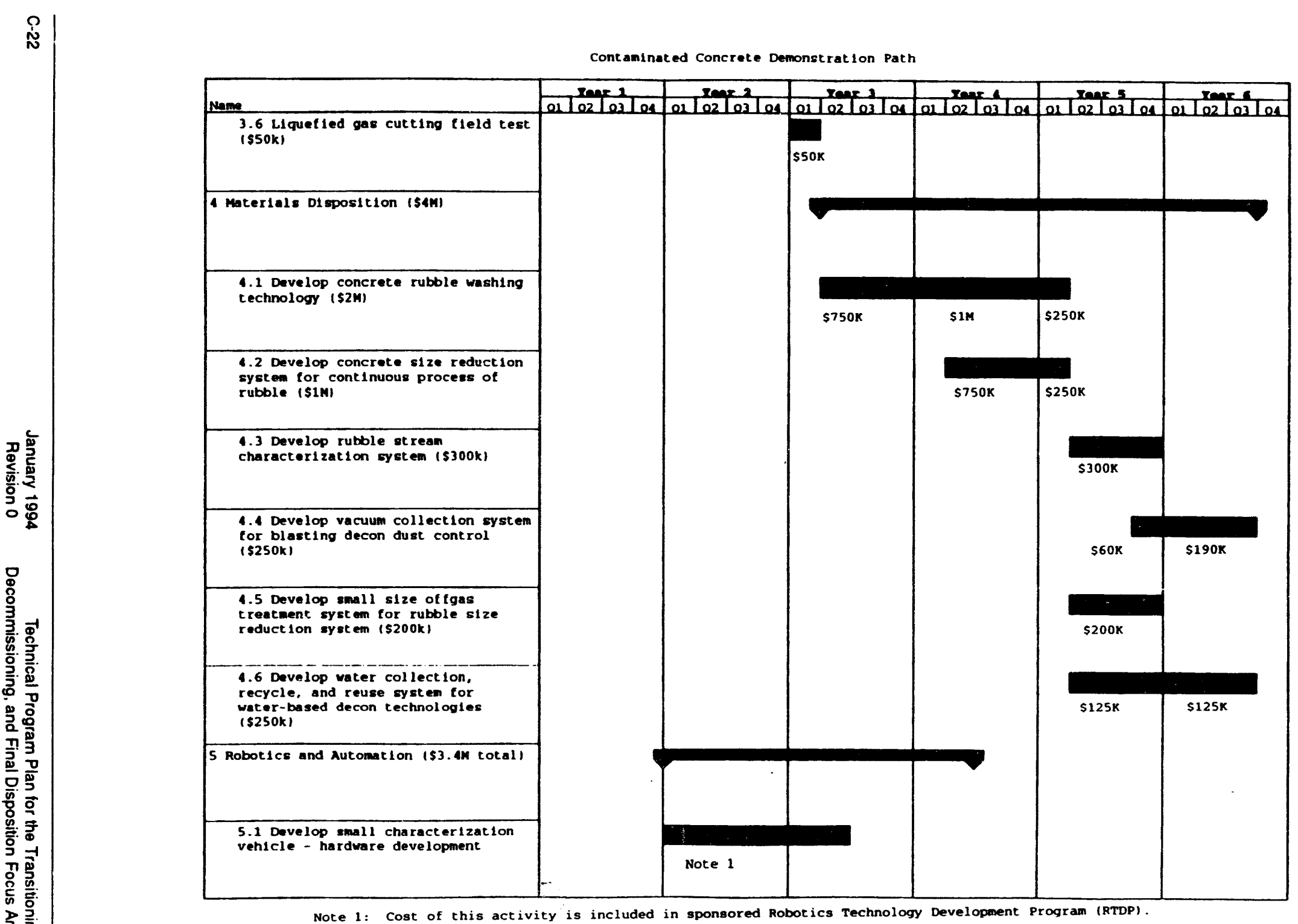


Contaminated Cencrete Demonstration Path

\begin{tabular}{|c|c|c|c|c|c|c|}
\hline Name & \begin{tabular}{|l|l|l|}
\multicolumn{3}{|c|}{ xear 1} \\
01 & 02 & 03 \\
\end{tabular} & 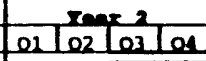 & 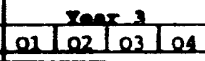 & 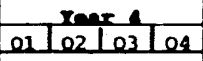 & 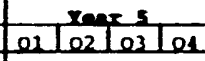 & \begin{tabular}{|l|l|l|l|}
\multicolumn{3}{|c|}{$x_{0}$} & \\
01 & 02 & 03 & 02 \\
\end{tabular} \\
\hline $\begin{array}{l}5.2 \text { Develop small characterlzation } \\
\text { vehicle - data logglng software }\end{array}$ & & Note 1 & & & & \\
\hline $\begin{array}{l}5.3 \text { Develop small characterization } \\
\text { vehicle - autonomous operation } \\
\text { softuare }\end{array}$ & & Note 1 & & & & \\
\hline $\begin{array}{l}5.4 \text { Develop large decontamination } \\
\text { vehicle ihardwarel i } 52 \mathrm{MI}\end{array}$ & & $\$ 670 x$ & $\$ 1.33 \mathrm{M}$ & & & \\
\hline $\begin{array}{l}\text { 5.5 Develop large decontamination } \\
\text { vehicle / sensing/monitoringl } 15500 \mathrm{k} \text { ) }\end{array}$ & & & $\$ 500 \pi$ & & & \\
\hline $\begin{array}{l}5.6 \text { Devel op large decontamination } \\
\text { vehicle lautonomous operation } \\
\text { softwarel }(\$ 500 \mathrm{k})\end{array}$ & & & $\$ 500 \pi$ & & & \\
\hline $\begin{array}{l}5.7 \text { Develop secondary waste handling } \\
\text { subsystem for large decon vehicle } \\
\text { (5400k) }\end{array}$ & & & $\$ 267 \pi$ & $\$ 133 \mathrm{~K}$ & & \\
\hline 6 Management and systems $(51.2 \mathrm{M}$ total & & & & & & \\
\hline $\begin{array}{l}6.1 \text { conduct regulatory revieus, call } \\
\text { tor TTPs. ete. and manage ef frits } \\
\text { (5600k) }\end{array}$ & $\$ 100 \pi$ & $\$ 100 x$ & $\$ 100 \mathrm{x}$ & $\$ 100 x$ & $\$ 100 x$ & \$100x \\
\hline 6.2 select demonstrat 1 ins and sit $\cdots s$ & & & & & & \\
\hline 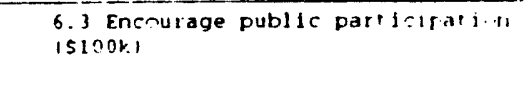 & & $\$ 20 \mathrm{R}$ & \$80K & & & \\
\hline
\end{tabular}

wote 1 : cost of this activity is included in sponsored Robotice Technology Developent Progren (RTDP). 


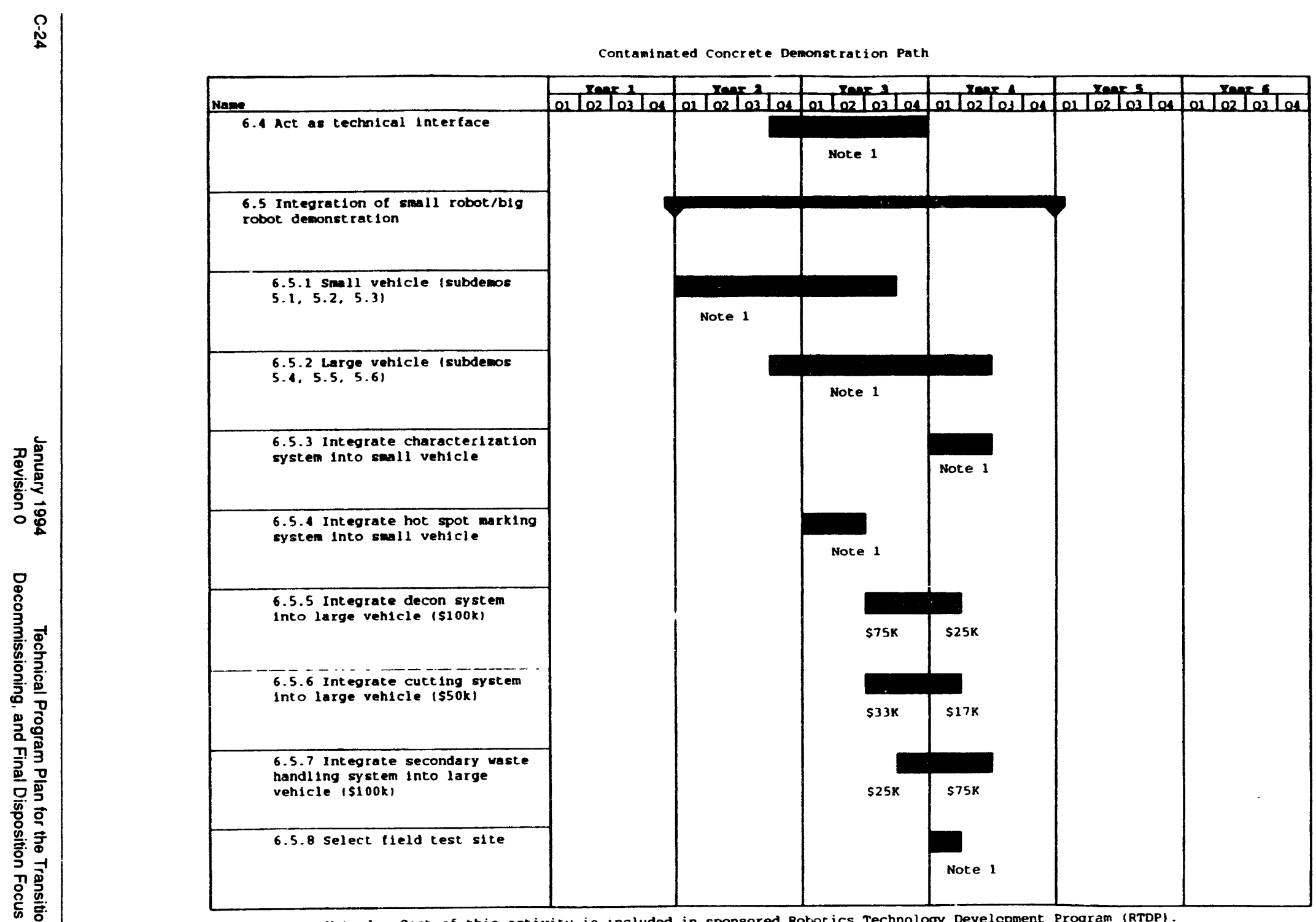

Cost this activity is included in sponsored Robotics Technology Development Program (RTDP). 
Contaminated Concrete Demonstration Path

\begin{tabular}{|c|c|c|c|c|c|c|}
\hline \multirow{2}{*}{ Nane } & & & & & rears & \\
\hline & (0) 102 (0) & 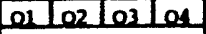 & 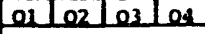 & 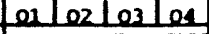 & $02 \mathrm{~L}_{02} \mathrm{~L}_{03} \mathrm{~L}_{01}$ & Les lo2 lou los \\
\hline $\begin{array}{l}\text { Hame } \\
6.5 .9 \text { conduct field test of } \\
\text { entire gystem (integrated demol } \\
(5250 \mathrm{k})\end{array}$ & & & & $\$ 250 K$ & & \\
\hline $\begin{array}{l}6.6 \text { Integration of rubble processin } \\
\text { demonstration }\end{array}$ & & & & & & \\
\hline $\begin{array}{l}6.6 .1 \text { cutting system (subdemo } \\
3.1 \text { through } 3.61\end{array}$ & & & & & & \\
\hline $\begin{array}{l}6.6 .2 \text { Rubble size reduction } \\
\text { sy stem (subdemo } 4.2 \text { ) }\end{array}$ & & & & 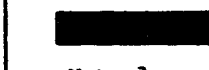 & & \\
\hline $\begin{array}{l}\text { 6.6.3 Characterization system } \\
\text { (subdemo } 4.31\end{array}$ & & & & & Note 3 & \\
\hline $\begin{array}{l}6.6 .1 \text { Dust/of fgas collection } \\
\text { system (subdemo } 4.4,4.5 \text { ) }\end{array}$ & & & & & Note 3 & \\
\hline $\begin{array}{l}6.6 .5 \text { Develop hardware for } \\
\text { rubble handling, transport, and } \\
\text { segregation loccurs after year }\end{array}$ & & & & & & \\
\hline $\begin{array}{l}\text { 6.6.6 Integrate systems loccurs } \\
\text { after Year } 61\end{array}$ & & & & & & \\
\hline $\begin{array}{l}6.6 .7 \text { choose site loceurs after } \\
\text { year } 61\end{array}$ & & & & & & \\
\hline $\begin{array}{l}\text { 6.6.8 Fleld test of system as } \\
\text { an Integrated Demonstration } \\
\text { loccurs after Year } 61\end{array}$ & & & & & & \\
\hline
\end{tabular}

Note 3: Cost of this activity is included in indicated subdemos. 

Fuel-reprocessing Facilities 


\section{Highly Contaminated Equipment}

\section{Section $1 \quad$ Situation Analysis}

\section{Section 1.1 Problem Definition}

Although fuel-reprocessing equipment is similar throughout the complex, the canyons and accessibility to the equipment differ from site to site. For example, Hanford and Savannah River canyons are large and accessible while many of the INEL facilities are not accessible by overhead crane. The INEL facilities, if decontaminated with current baseline technologies, would require a great deal of human exposure.

\section{Section $1.2 \quad$ Characterization}

Baseline Technologies

Current baseline technologies include standard characterization methods: analysis of plant records and documentation; physical and remote video inspection; sampling and laboratory analysis of radioactive/hazardous materials; and nondestructive assay and measurement using assay meters and counters. Because these methods have been adequate for small jobs to date, there has been little change in the technology over the last few years.

Deficiencies Several deficiencies are associated with current baseline technologies for characterization. The accuracy of plant records and documentation varies. Inspections are limited by the risk of exposure and restricted access to equipment; moreover, video capabilities are also limited by restricted access to equipment. Surveying is nondiscriminatory, is limited by restricted access and the risk of worker exposure, and creates secondary waste. Because samples cannot be characterized in real time, we need to deal with the hazards and risks associated with the transportation of contaminated materials. The capacity of laboratories where the samples are analyzed is limited, and the analytic methods are slow and cumbersome.

The risks associated with current baseline technologies for characterization include worker exposure and industrial safety issues. There are also some risks with transporting samples.

Solutions A solution to the problems associated with using current baseline technology for characterization is a viable method for a real time, in situ characterization. The tools and methods should include mapping and discrimination capabilities and improved access capabilities for video. 


\section{Section 1.3 Decontamination}

Deficiencies Several deficiencies characterize currert baseline technologies for decontamination. The methods available are labor intensive, time consuming, and costly; and they generate secondary waste. The efficiency of these methods is questionable.

The risks associated with current baseline technologies for decontamination include worker exposure and excess waste.

Solutions A solution to the problems associated with baseline technologies for decontamination is a viable method for inexpensive, in situ decontamination that generates little or no secondary waste.

\section{Section 1.4 Dismantlement}

Baseline Current baseline technologies for dismantlement include rotary saws, Technologies jaws-of-life, plasma arc torches, and manual removal (standard demolition techniques).

Deficiencies The primary deficiencies associated with the current baseline technologies for dismantlement of fuel-reprocessing facilities are potentially high exposure levels, safety hazards, secondary waste, and a labor-intensive process.

The risks associated with current baseline technologies for dismantlement include worker exposure and industrial/radiological hazards.

Solutions If we cannot attain lower radiation levels, then an automated mechanism that performs repetitive tasks while generating little or no secondary waste, manual removal (when justified by lower radiation levels), and entombment without dismantlement are options. 


\section{Section 1.5 Materials Disposition}

Baseline Current baseline technologies include entombment, burial, and size reduction.

Technologies However, entombment and burial require continuous surveillance and maintenance.

Deficiencies Several deficiencies characterize current baseline technologies for materials disposition. We are limited by diminishing landfill space, increasingly restrictive environmental regulations, and the inability to recycle or reuse buried waste. Size reduction is expensive, is labor intensive, and produces secondary waste; even after size reduction, contaminated materials must still be disposed of.

Solutions Possible solutions to the problems associated with using current baseline technologies for materials disposition include effective volume reduction techniques and reuse of metals and entombment.

\section{Section 1.6 Robotics and Automation}

Baseline Currently, the baseline technologies for the D\&D of equipment in highTechnologies radiation, high-contamination areas are limited to master-slave manipulators, cranes, crawlers, and remote monitoring and surveillance.

Deficiencies The deficiencies associated with current robotics and automation baseline technologies are the lack of technologies needed to perform in situ characterization, decontamination, and dismantlement of high-volume, highly contaminated equipment in fuel-reprocessing facilities. The current technologies and equipment are either archaic, unreliable, or have limited access capabilities.

Solutions Reliable robotics and automation (e.g., smaller pipe crawlers, micro robotics) would solve many of the problems associated with usirg current baseline technologies for characterization, decontamination, and dismantlement of high-volume, highly contaminated equipment in fuel-reprocessing facilities. The systems must also be able to handle large pieces of equipment as well as be mobile and modular.

\section{Section 1.7 Regulation}

There are no unique regulatory issues; however, there is a chance that future regulations may require the treatment of buried waste. 


\section{Section 2 Description of Proposed Integrated Demonstration}

We propose an integrated demonstration of D\&D techniques and innovative technologies for highly contaminated equipment while ensuring regulatory acceptance of demonstrated technologies. The proposed ID integrates demonstrated activities in five technological areas: characterization, decontamination, dismantlement, materials disposition, and robotics/automation. Characterization activities will address the status of facilities and the development and demonstration of radiological sensor devices. Decontamination activities will include demonstrations of internal and external facility flushing and development of innovative decontamination solutions. Dismantlement of equipment activities include development and demonstration of remote/robotic activities as well as a comparative analysis to manual dismantlement techniques. Materials disposition activities depend on results from the decontamination activities and future recycle/reuse issues. The remote/robotic activities include development and demonstration of dismantlement equipment for limited-access, confined-space, high-radiation field environments.

The D\&D ID of highly contaminated equipment in fuel-reprocessing facilities involves a variety of DOE contractors, DOE sites, and private industry. Each of the players is important to the success of the proposed demonstration. DC F contractors will be instrumental in developing innovative dismantlement and disposition techniques while private industry will contribute to the development of the decontamination solution.

These activities are scheduled to begin in FY 94 and extend to FY 99. The Fuel Reprocessing team believes this is a realistic schedule.

\section{Activities}

Activities related to the ID will begin with an expert workshop made up of participants representing the private sector, the federal government, and contractors. We have recommended the Hanford and INEL facilities as the site locations for demonstrations of the integrated demonstrations because of the existence of current inactive facilities undergoing deactivation activities and because of available resources. Laboratory sites have been selected for specific remote/robotic tasks and decontamination tasks.

At both facilities, characterization activities will begin with documenting the status of the physical plants. SRTC and SNL will begin developing radiological sensor technology in FY 94, and the sensors will be demonstrated at Hanford and INEL beginning in FY 95. Reports on the development and the demonstration findings will be written in late FY 95. 
Decontamination activities begin with the development of decontamination solutions in accordance with specifications for low secondary waste and effective radiation reduction. Beginning in FY 94. development of these solutions will include private industry and coordination with the national laboratories.

Internal line-flushing techniques will be demonstrated at Hanford beginning FY 95 and external flushing techniques will be developed at Hanford and NEL beginning in FY 96. The external flushing will be demonstrated at INEL beginning in mid FY 96; the results of this demonstration will be used by Hanford, and an analysis will be performed to determine the effectiveness of the flushing methods. With this analysis, we will be able to determine fiture activities for the removal of highly contaminated equipment. If radiation levels can be effectively reduced, manual removal methods can be used, thereby reducing the costs associated with remote applications.

Equipment removed during this demonstration will undergo extensive laboraiory analysis of the decontamination solution to determine if the equipment can be cleaned for release. If the material cannot be cleaned for release, options for materials disposition (e.g., entombment) must be reviewed and demonstrated. This alternative will result in a different path of activities for D\&D of facilities with highly contaminated equipment in high-radiation environments. PNL has been recommended as the laboratory to perform the decontamination solution analysis, beginning in mid-FY 96 .

Dismantlement activities begin with development of remote dismantlement applications at INEL, beginning in FY 94. Beginning in FY 96, the applications and manual removal techniques will be demonstrated at INEL. The results of these demonstrations will be documented in progress reports, and a comparative analysis of the two demonstrations will qualify their effectiveness and identify cost savings.

Materials disposition activities will rely on the results of the decontamination demonstrations. If the equipment cannot be cleaned to a level suitable for release, we will investigate options other than recycle/reuse. Two options for consideration are burial of equipment and entombment of the facilities. Both options offer diverse activity paths. Cleaning methods for the equipment will be developed at the national laboratories and private industry sites beginning in FY 96. Equipment cleaning methods will be demonstrated at Hanford and INEL beginning in FY 97.

Remote/robotic activities include the development of remote dismantlement applications and modifications to the buried waste ID. Development will occur at the many different laboratory sites, beginning now and again in FY 94. 
Management systems activities include all progress reports and the cost/benefit analysis of decontamination and dismantlement. A final report is expected by FY 99.

The proposed ID provides a solution that integrates the five technology areas (characterization, decontamination, dismantlement, materials disposition, and robotics/automation). This ID does not address regulatory issues.

Industry involvement is key to the success of the proposed demonstration of internal flushing decortamination. Various commercial vendors have demonstrated techniques for cleaning steam generators in the utilities industry. This experience would be the baseline for Jeveloping internal flushing techniques for fuel-reprocessing facilities.

The potential exists for high payback and cost savings within the DOE Complex. If radiation levels can be reduced through internal cleaning of highly contaminated systems, the remainder of the D\&D would be less expensive. Disassembly could be performed manually if we succeed in lowering the radiation levels. Moreover, using existing operations personnel in plants that have not been abandoned will enable us to flush the plant systems internally. This is the key to successful deactivation and to placing the plant in a SAFSTOR condition. This does not apply, however, to abandoned surplus facilities.

We have identified Hanford and INEL as candidate host sites for this demonstration. Hanford would provide the facility for the internal flushing demonstration. INEL, would host the external decontamination demonstration. Other sites will play roles in characterization: sensor development at Savannah River and Sandia, robotics at Savannah River and Oak Ridge, and materials disposition at Savannah River and Oak Ridge.

The emphasis on innovative technologies stems primarily from the application of a new chemical decontamination solution. Other opportunities for innovation exist in sensor development and in the development of robots to work in hard-to-reach, highly radioactive facilities.

With this demonstration, we propose achievable, short-term goals for demonstrating internal flushing techniques to lower radiation levels in the canyons and for solving remote application problems at the waste-calcining facility. Long-term goals include determining the suitability of the decontamination techniques that will enable the recycle of materials from the fuel-reprocessing facilities. 
The proposed demonstration applies primarily to the fuel-reprocessing facilities; however, if the demonstration is successful, it could be expanded to encompass many other sites throughout the DOE Complex. Such an expansion would provide a tremendous cost savings to DOE during the deactivation stage of decommissioning. Moreover, successful demonstrations will provide more opportunities for private industry in the decontamination field.

If this equipment can be successfully decontaminated, there is the potential for recycling and beneficial reuse of highly contaminated metals. 


\section{Section $2.1 \quad$ Deliverables}

- Expert Workshop Documentation

- document the results of the workshop

- ID of key industries and potential commercial technologies for radiation sensors. robotics and automation, dismantling tools and technologies, and metals recycle technologies

- Conditional Assessment of the Facility

- Characterization Progress Report

- document the results of characterization

- radiation levels of equipment

- isotopes found

- document success of characterization

- improvements over current techniques

- time, costs, exposure, accuracy, discrimination, etc.

- recommendations

- Decontamination Progress Report

- results of decontamination

- degree of cleanliness

- time

- waste generated

- costs

- exposures

- results of laboratory cleaning

- initial state

- degree of cleanliness

- time

- waste generated

- costs

- exposures

- cost/benefit analysis

- comparison of decontamination and laboratory's cleaning results to expected results using current technologies

- projection of comparison to a larger-scale project 
- recommendations

- future developments

- improvements to operations

- technology selections

- disposition of equipment (entomb or bury versus recycle)

- Dismantlement Progress Report

- results

- cost/benefit analysis

- recommendations

- Materials Disposition Progress Report

- results

- cost/benefit analysis

- recommendations

- Other Progress Reports

- results of pilot tests

- characterization

- cleaning solutions

- mobile robotics/manipulators

- dismantling tools

- method for cleaning for recycle

- definition of techniques

- definition of test

- results of test (e.g., speed, accuracy, secondary waste, reliability)

- projections of expected results for full-scale applications

- recommendations, selection of technologies

- Final Report

- objectives of the ID

- methods

- definition of players

- combined results (e.g., overall time, secondary waste)

- cost/benefit analysis

- recommendations 


\section{Section 2.2 Reasons for Pursuing the Proposed ID Now}

- Demonstrations of D\&D of highly contaminated equipment at fuel-reprocessing facilities can best be accomplished while the facilities are still staffed with personnel knowledgeable about the processes and the facility itself and while the necessary equipment is still operable. Delaying this activity will result in much higher costs.

- The facilities at Hanford and INEL that have been identified for this ID are either deactivated or soon-to-be deactivated. Characterization and decontamination are the required steps for the final deactivation of these facilities.

- Recycling of decontaminated material is a high priority for DOE. Decontaminating highly contaminated fuel-reprocessing equipment to make it suitable for recycle will be one of the toughest challenges of the program. An early demonstration and analysis of this capability is needed for planning the deactivation/D\&D programs for these facilities. 


\section{Section $3 \quad$ Benefits}

Potential benefits will be derived from successful flushing during the decontamination activities and reducing radiation levels. These activities will reduce overall project costs by using manual removal methods and by reducing disposal costs. Using existing personnel and available operational facilities will enhance the success of the $\mathrm{ID}$, primarily because these resources will not be available in the future.

The potential for coordination with other programs exists, and the results from this ID will be used by other facilities preparing for the deactivation and D\&D phase. That this is also an opportunity for technology transfer between the DOE and private industry is also beneficial.

The anticipated benefits of the proposed ID are:

- use of existing operational personnel and equipment;

- potential for greatly reduced radiation fields and personnel exposure levels;

- shared costs with existing programs (e.g., robotics development, industry decontamination, EM-60 deactivation);

- determination whether recycle/reuse is viable for this specific environment; and

- determination of the viability of remote robotic dismantlement.

The direct benefits to EM are:

- demonstration of non-remedial action activities;

- integration of EM-30, -40, -50, and -60 offices;

- making the most of ex-defense plant operating personnel while they are still available;

- completion at about the same time as Savannah River is ready for deactivation;

- completion in a relatively short time period; and

- reduction of the amount of waste storage sent to tank storage and vitrification. 
The economic impact of this ID includes the following:

- providing more "bang for the buck" because the work will begin soon rather than ten years from now;

- improving deactivation initiation times for a cost savings of approximately $\$ 40$ million per year, per plant;

- determination whether highly contaminated materials will be available for recycle/reuse; and

- reducing waste-processing costs.

This ID will be applicable to other problems in the DOE Complex:

- closed-loop, non-breach systems;

- waste generation forecasting; and

- immediate dismantlement of abandoned facilities (instead of waiting for detailed integrity assessments before decontamination).

\section{Section 4 What Cannot be Done in the FY 94 to FY 99 Time Frame}

- Entombment will have a low priority until the feasibility of recycle/reuse has been determined.

- Conditional assessment, physical structure characterization, and facility configuration all have low priority and, therefore, are excluded from the ID. 


\section{Section $5 \quad$ Locations}

The table below lists DOE fuel-reprocessing facilities with highly contaminated equipment, their relationships to each other, and the current justification for a D\&D ID.

\begin{tabular}{|c|c|c|c|c|}
\hline DOE Sltes & $\begin{array}{l}\text { Potentlal } \\
\text { Commerclal } \\
\text { Sites }\end{array}$ & $\begin{array}{c}\text { Relationships } \\
\text { between } \\
\text { Sites/Functions }\end{array}$ & $\begin{array}{l}\text { Technical } \\
\text { Justlfication }\end{array}$ & $\begin{array}{l}\text { Financlal } \\
\text { (or other) } \\
\text { Justlication }\end{array}$ \\
\hline Hanford & \multirow{4}{*}{$\begin{array}{l}\text { industrial } \\
\text { partners }\end{array}$} & $\begin{array}{l}\text { Hanford to perform } \\
\text { internal flushing of } \\
\text { vessels; transfer } \\
\text { lessons learned to } \\
\text { INEL and Savannah } \\
\text { River facilities that } \\
\text { have remaining } \\
\text { operations }\end{array}$ & $\begin{array}{l}\text { 1) equipment is still in } \\
\text { operating condition } \\
\text { 2) trained personnel } \\
\text { available at plant } \\
\text { 3) facility available }\end{array}$ & $\begin{array}{l}\text { can be piggy-backed } \\
\text { on deactivation } \\
\text { funded by EM- } 60\end{array}$ \\
\hline INEL & & $\begin{array}{l}\text { INEL to perform } \\
\text { remote } \\
\text { dismantlementfflushing: } \\
\text { transfer lessons } \\
\text { learned to Hanford and } \\
\text { Savannah River }\end{array}$ & $\begin{array}{l}\text { 1) unique situation in } \\
\text { abandoned facility } \\
\text { 2) little or no access } \\
\text { 3) ideal for robotic } \\
\text { demonstration for } \\
\text { dismantlement } \\
\text { 4) also applicable to } \\
\text { Hanford }\end{array}$ & $\begin{array}{l}\text { robotics development } \\
\text { currently funded }\end{array}$ \\
\hline $\begin{array}{l}\text { National laboratories } \\
\text { and SRTC }\end{array}$ & & $\begin{array}{l}\text { development of } \\
\text { cleaning solution (with } \\
\text { industry); development } \\
\text { of sensurs for } \\
\text { characterization before } \\
\text { flushing; documentation }\end{array}$ & $\begin{array}{l}\text { 1) sensor develop. } \\
\text { ment ongoing at } \\
\text { laboratories } \\
\text { 2) industry has } \\
\text { cleaning expertise } \\
\text { 3) joint venture for } \\
\text { application to large- } \\
\text { scale operations }\end{array}$ & \\
\hline Hanford (PNL) & & $\begin{array}{l}\text { analysis of } \\
\text { decontamination } \\
\text { effectiveness; } \\
\text { equipment from earlier } \\
\text { decontamination } \\
\text { efforts currently } \\
\text { available at Hanford }\end{array}$ & $\begin{array}{l}\text { 1) no shipping } \\
\text { restrictions } \\
\text { 2) PNL able to have } \\
\text { on-site presence }\end{array}$ & \\
\hline
\end{tabular}




\section{Section 6 ID Schedule and Costs}

The following table summarizes the costs (in millions) of this ID over its entire lifespan.

\begin{tabular}{|l|c|c|c|c|c|c|c|}
\hline & Year 1 & Year 2 & Year 3 & Year 4 & Year 5 & Year 6 & Total \\
\hline Characterization & 1.250 & 0.250 & 0.125 & & & & 1.625 \\
\hline Decontamination & 1.000 & 0.416 & 1.209 & 0.500 & & & 3.125 \\
\hline Dismantlement & & & 0.500 & 0.125 & & & 0.625 \\
\hline Materials Disp. & & & & 0.750 & 0.250 & & 1.000 \\
\hline Robotics \& Auto. & & 0.625 & 0.625 & & & & 1.250 \\
\hline Migmt. \& Sys. & 0.250 & & & & & 1.175 & 1.425 \\
\hline Total & 2.500 & 1.291 & 2.459 & $\mathbf{1 . 3 7 5}$ & $\mathbf{0 . 2 5 0}$ & $\mathbf{1 . 1 7 5}$ & $\mathbf{\$ 9 . 0 5 0}$ \\
\hline
\end{tabular}


Fuel Repiccessing Demenstration fath

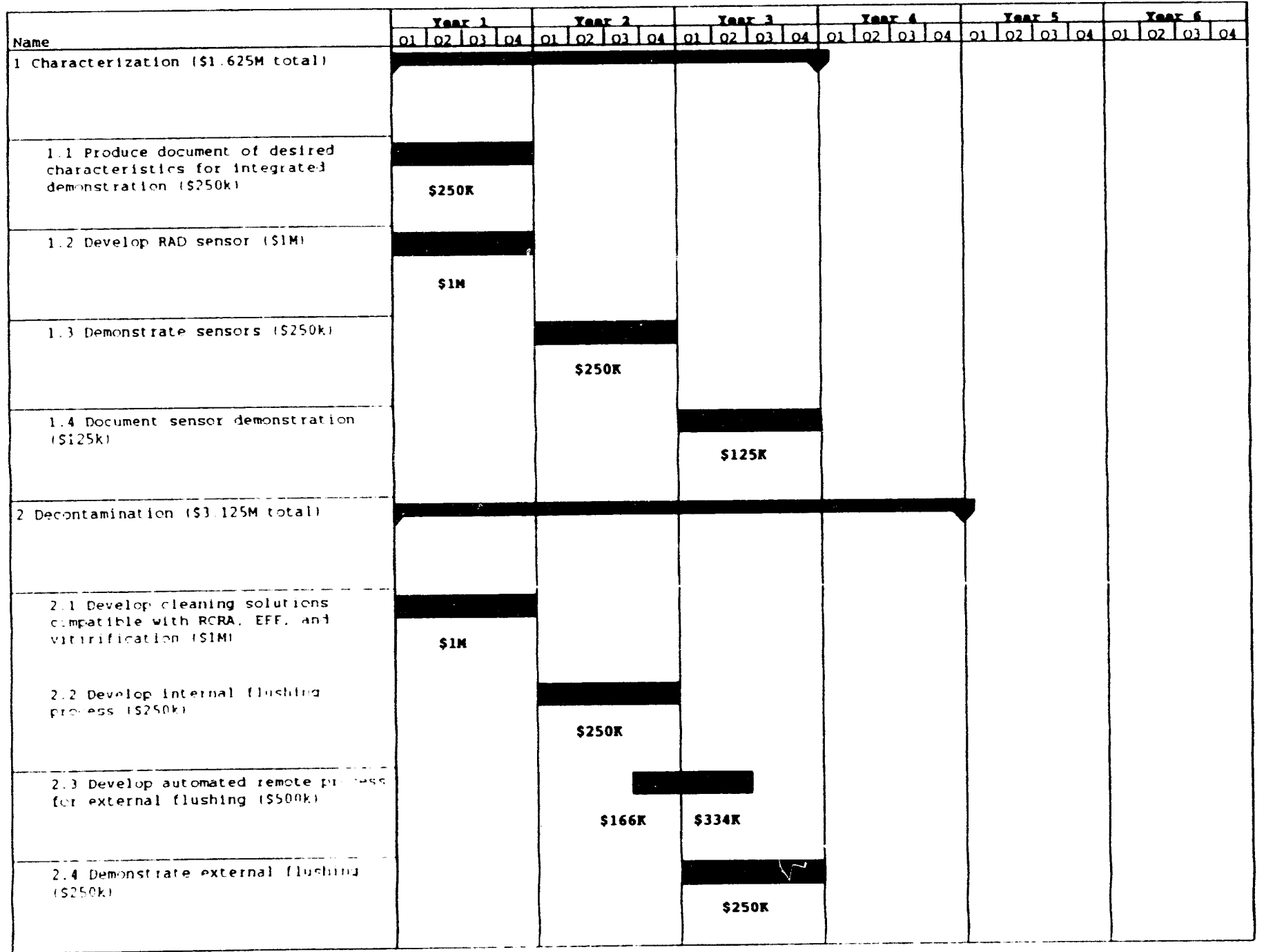


Fuel Refrocessing Demonstrarion path

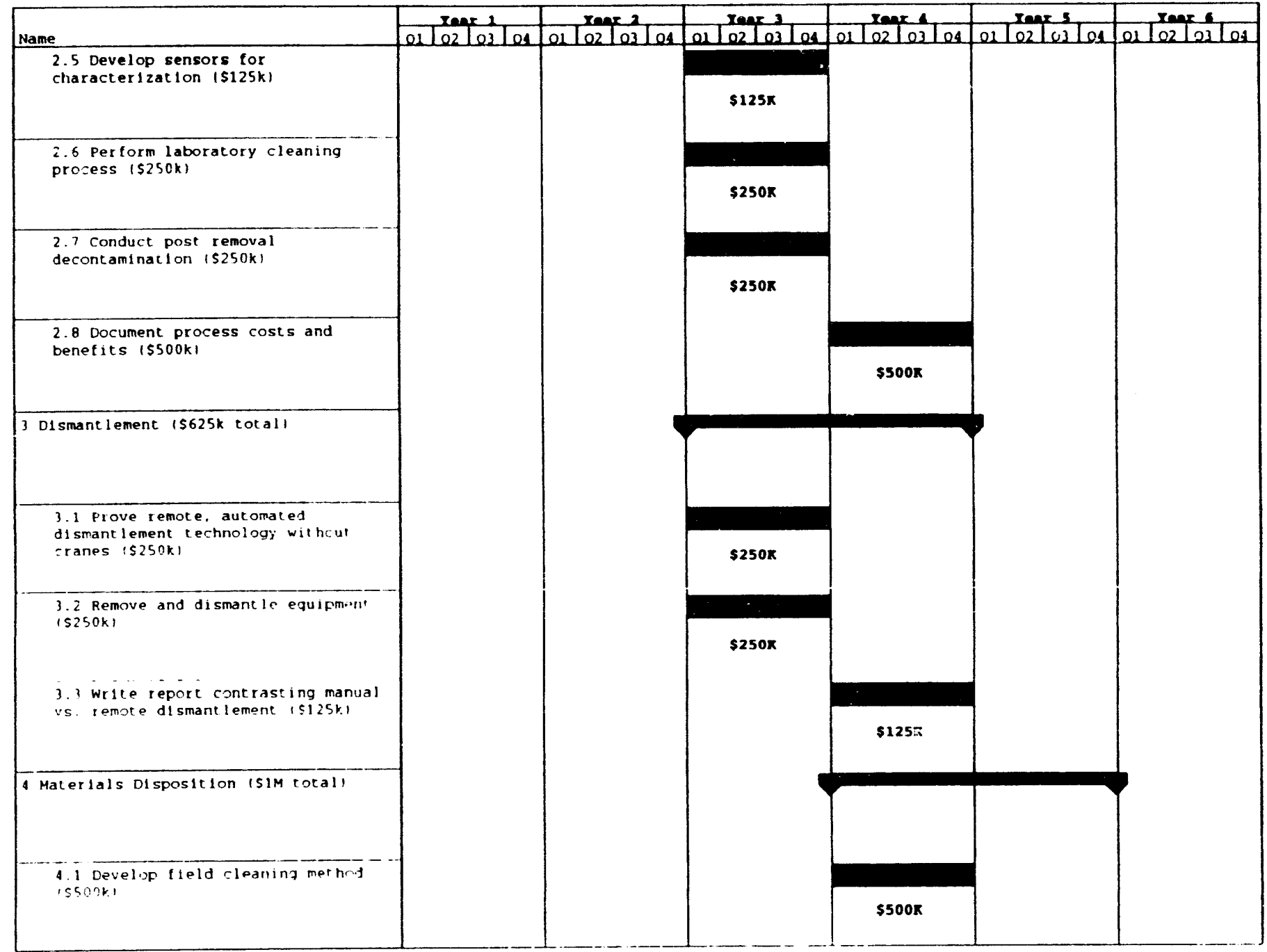




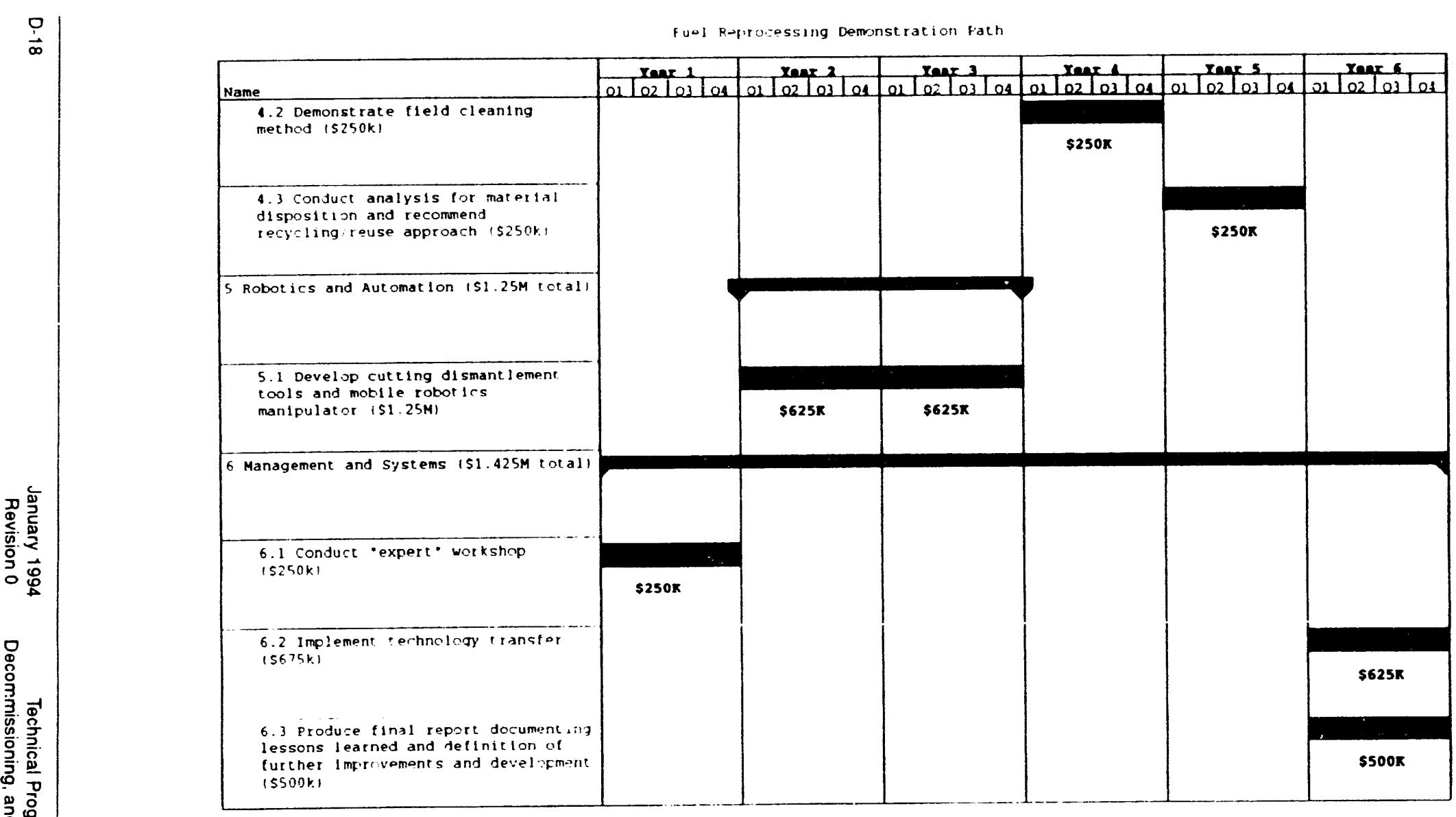



Fuel Storage Pools 


\section{Sludge and Equipment}

\section{Section $1 \quad$ Situation Analysis}

\section{Section 1.1 Problem Definition}

Size of the Each fuel storage pool can contain millions of gallons of contaminated liquids Problem and requires thousands of man hours to decontaminate using current baseline technologies. The sludge in the fuel storage pools is heterogeneous (including broken fuel elements and biologicals) and ranges in composition from the simple to the unknown. It costs approximately $\$ 120,000.00$ to decontaminate each pool using current baseline technologies.

Problem Several DOE installations that have reactors (e.g., Hanford, INEL, Savannah Locations River, and LANL), 111 commercial power reactor sites, and 360 foreign power reactor sites have reactor fuel pools.

\section{Section 1.2 Characterization}

Baseline Current baseline technologies include sampling, hazardous work analysis, Technologies radiolugical measurements, visual inspections of the pools, analysis of historical inventory and design records, and photography. The costs can be relatively large and are site specific.

Deficiencies The deficiencies associated with current baseline technologies for characterization and the methods available to us are laborious and time consuming; the results are often misleading because records are inaccurate or insufficient. It is often impossible to determine the contents of a pool with remote inspection and instrument survey, which is often limited to the surface of the pool. With current technologies, accurate, real-time, in situ characterization and real-time analysis of chemical components are out of the question, primarily because of the heterogeneous nature of the contaminants and the difficulties associated with using survey equipment underwater. Sampling often requires time-consuming and expensive offline analysis. 
Solutions A realistic solution to the problems associated with using current technology for characterization is remote sampling and a non-intrusive method for real-time analysis. In situ evaluation should include biological, chemical, physical (e.g., SONAR, ultrasonics, green laser), and radiological elements. Once the water is removed, workers can locate fuel elements using alpha detectors and passive/active ne 'tron interrogators.

\section{Section 1.3 Decontamination}

Baseline

Technologies Current baseline technologies include

- decanting water;

- vacuuming and pumping soft sludge; and

- removing hard sludge by sluicing/sparging, or physical removal.

Deficiencies Current baseline technologies require a large amount of water and, therefore, produce a large amount of secondary waste. The decontamination process is time consuming, and burial is not a long-term solution.

Solutions A solution to the problems associated with current baseline technology for decontamination should be one that generates no secondary waste and reduces worker exposure. To accomplish this, the tools or methods should allow workers to filter the contaminated water while pumping and to remove, reduce, and concentrate the contaminated sludge from a remote location. The solution would use robotics/automation to address

- decanting water;

- vacuuming and pumping soft sludge; and

- removing hard sludge by sluicing/sparging, or physical removal.

\section{Section 1.4 Dismantlement}

Dismantlement is included in the Concrete Situation Analysis (Appendix $C$, page $(-I)$ 


\section{Section 1.5 Materials Disposition}

Baseline

Technologies Current baseline technologies include the following:

- treating water by evaporation, filtration, or solidification;

- drying sludge in barrels for burial;

- solidifying, boxing (in barrels), and burying sludge;

- cleaning, filtering water for reuse; and

- releasing water vapor to the atmosphere and condensed/treated water to the ground.

Deficiencies The current decontamination process requires massive amounts of clean water, thereby increasing the volume of contaminated materials and complicating treatability and affecting long-term treatability. Hazardous and radioactive waste must be separated from bulk material. The condensation process is further complicated by permits, tritium standards, drinking water standiards, and volatiles mixed with condensate.

Solutions A solution to the problems associated with using current technology for materials dispositi 1 of the sludge in fuel storage pools should be one that produces clean water and clean dirt as end products with minimal contaminated material. The methods and tools proposed should reduce the volume and toxicity concentrations of the waste produced and should break down hazardous materials to hydrogen and carbon.

\section{Section 1.6 Robotics and Automation}

Baseline Currently, there are no robotic or automated baseline technologies for Technologies characterization, removal, or storage of contaminated sludge from fuel storage pools.

Deficiencies The deficiencies associated with current robotics and automation baseline technologies are the lack of such technologies needed to perform in situ characterization, decontamination, and removal of sludge from fuel storage pools.

Solutions Robotics and automation would solve many of the problems associated with using current baseline technologies for characterization, decontamination, and removal of sludge from fuel storage pools.

January 1994
Revision 0




\section{Section 2 Description of the Proposed Integrated Demonstration}

The proposed ID addresses the removal and cleanup of contaminated water/sludge and contaminated equipment from fuel storage pools. The process will result in the following:

- clean water

- clean material (sludge and equipment)

- a small volume of material (in an acceptable waste form) segregated for interim storage

- in situ decontamination of concrete (encompasses any technology that is used while the contents of the ponds are cleaned)

Qualifications

- proposal incorporates all six technology areas (characterization, decontamination, dismantlement, materials disposition, robotics/automation, and regulation)

- characterization technology is divided between DOE and private industry

- physical: mostly private industry

- radiological: divided equally between DOE and private industry

- chemical: approximately $90 \%$ private industry

- mapping: commercial, academic, and international

- dismantlemerit technology is divided equally between DOE and private industry

- shears

- cutters

- adaptable robotic equipment readily available from many commercial sources

- we need enhanced automated/remote tooling

- cost effectiveness will have to be demonstrated

- commercial technology needs to be adapted to the current waste processing situation 


\section{Section 2.1 Deliverables}

- delivery of a suite of characterization systems (FY-96-97)

- demonstration of applicability of filtration and separation technologies (pre-treatment)

- demonstration of treatment technologies emerging from other IDs and IPS, the private sector, or academia

- yearly progress reports (e.g., accomplishments, status)

- other reports (e.g., strategic plan, update, demonstration plan)

\section{Section 2.2 Reasons for Pursuing the Proposed ID Now (versus Later)}

Now

- momentum

- potential for leaks

- technological advancements are achievable now

- short-term potential hazards

- likely quick resolution with $\mathrm{N}$-reactor at Hanford

\section{Later}

- fuel will have to be removed from many operational reactors

- more difficult 


\section{Section $3 \quad$ Benefits}

- Characterization

- improved planning

- improved worker safety

- reduction in unknowns

- better characterization of waste stream for treatment

- helps establish regulatory requirements

- Separation

- enabling technologies for disposal of components (i.e., no mixed waste)

- reduced waste volume

- Value to EM

- improved EM-30, -40, -60 leveraging

- new technologies for D\&D

- improved public perception of EM programs

- Economic Impact

- industry benefits in other hazardous waste, sludge, and chemical waste markets

- more jobs for scientists

- 14 DOE reactors (each with approximately 200,000 cubic feet of sludge) will save $\$ 22$ million each for radioactive waste and $\$ 60$ million each for mixed waste

- Overall

- reduced risks

- faster: characterization 10 time faster, separation 2 times faster

- better: improved separation, more sensitive characterization to meet regulatory requirements

- cheaper: more knowledge, reduced cost of waste disposal

- safer: improved worker and public safety

- DOE can remove fuel storage pools throughout the Complex

- addresses common problems with buried waste: characterization, separation, treatment, and robotics/automation 


\section{Section 4 What Cannot Be Done between FY-94 and FY-99}

The compacting of waste and the transition to the concrete ID currently have a lower priority than what has already been included in the proposed ID and, therefore, will not be included. Moreover, as long as we lack a de minimis standard, recycling for beneficial reuse is not possible.

\section{Section $5 \quad$ Locations}

The table below lists DOE and commercial sites with contaminated fuel storage pools, their relationships to each other, and the current justification for a D\&D ID.

\begin{tabular}{|c|c|c|c|c|}
\hline DOE Sltes & $\begin{array}{l}\text { Potential } \\
\text { Commerclal } \\
\text { Sites }\end{array}$ & $\begin{array}{c}\text { Relatlonships } \\
\text { between } \\
\text { Sltes }\end{array}$ & $\begin{array}{l}\text { Technical } \\
\text { Justiflcation }\end{array}$ & $\begin{array}{c}\text { Financial } \\
\text { (or Other) } \\
\text { Justification }\end{array}$ \\
\hline Hanford & \multirow{4}{*}{ 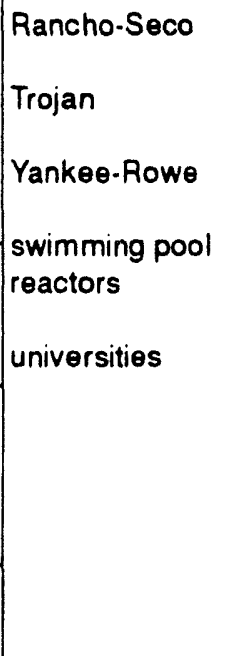 } & $\begin{array}{l}\text { much in common with } \\
\text { other DOE sites }\end{array}$ & $\begin{array}{l}\text { 1) solar pond } \\
\text { 2) basins are more } \\
\text { typical of DOE sites } \\
\text { 3) has all of the traits } \\
\text { we want to demon- } \\
\text { strate }\end{array}$ & $\begin{array}{l}\mathrm{N} \text {-reactor time scale } \\
\text { is correct with current } \\
\text { operations }\end{array}$ \\
\hline $\begin{array}{l}\text { INEL } \\
\text { (decontamination } \\
\text { processing) }\end{array}$ & & $\begin{array}{l}\text { more specialized to } \\
\text { high enrichment }\end{array}$ & special case only & longer time line \\
\hline Savannah River & & $\begin{array}{l}\text { much in common with } \\
\text { other DOE sites }\end{array}$ & 30-year shutdown & $\begin{array}{l}\text { R-reactor time scale } \\
\text { is correct with current } \\
\text { operations: fuel } \\
\text { removal in } 4.5 \text { years }\end{array}$ \\
\hline $\begin{array}{l}\text { Hanford and } \\
\text { Savannah River }\end{array}$ & & & & \\
\hline
\end{tabular}




\section{Section $6 \quad$ Assumptions}

- fuel basins contain no fuel

- contains fluid as well as soft and hard sludge

- ID will cover cleaning the basin to leave a clean, concrete basin for the concrete ID

- concerned orily with contaminated fuel ponds (concrete, sludge, and w'ater)

- ponds contain contaminated equipment and parts or pieces of fuel

\section{Section $7 \quad$ ID Schedule and Costs}

The following table summarizes the costs (in nillions) of this ID over its entire lifespan.

\begin{tabular}{|l|c|c|c|c|c|c|c|}
\hline & Year 1 & Year 2 & Year 3 & Year 4 & Year 5 & Year 6 & Total \\
\hline Decontamination & & & & & & & 0.0 \\
\hline Wet Concrete & 1.4 & 2.1 & 0.4 & & & & 3.9 \\
\hline End Effectors/P & 1.7 & 2.5 & 0.6 & & & & 4.8 \\
\hline Sludge & 1.4 & 1.7 & 1.1 & 0.1 & & & 4.3 \\
\hline Materlals Disp. & & & 0.5 & 0.5 & & & 1.0 \\
\hline Mgmt. \& Sys. & 0.4 & 0.4 & 0.4 & 0.1 & & & 1.3 \\
\hline Total & 4.9 & 6.7 & 3.0 & $\mathbf{0 . 7}$ & 0.0 & 0.0 & $\mathbf{\$ 1 5 . 3}$ \\
\hline
\end{tabular}


Faating Fupl Storage Fools Demonstration Farh

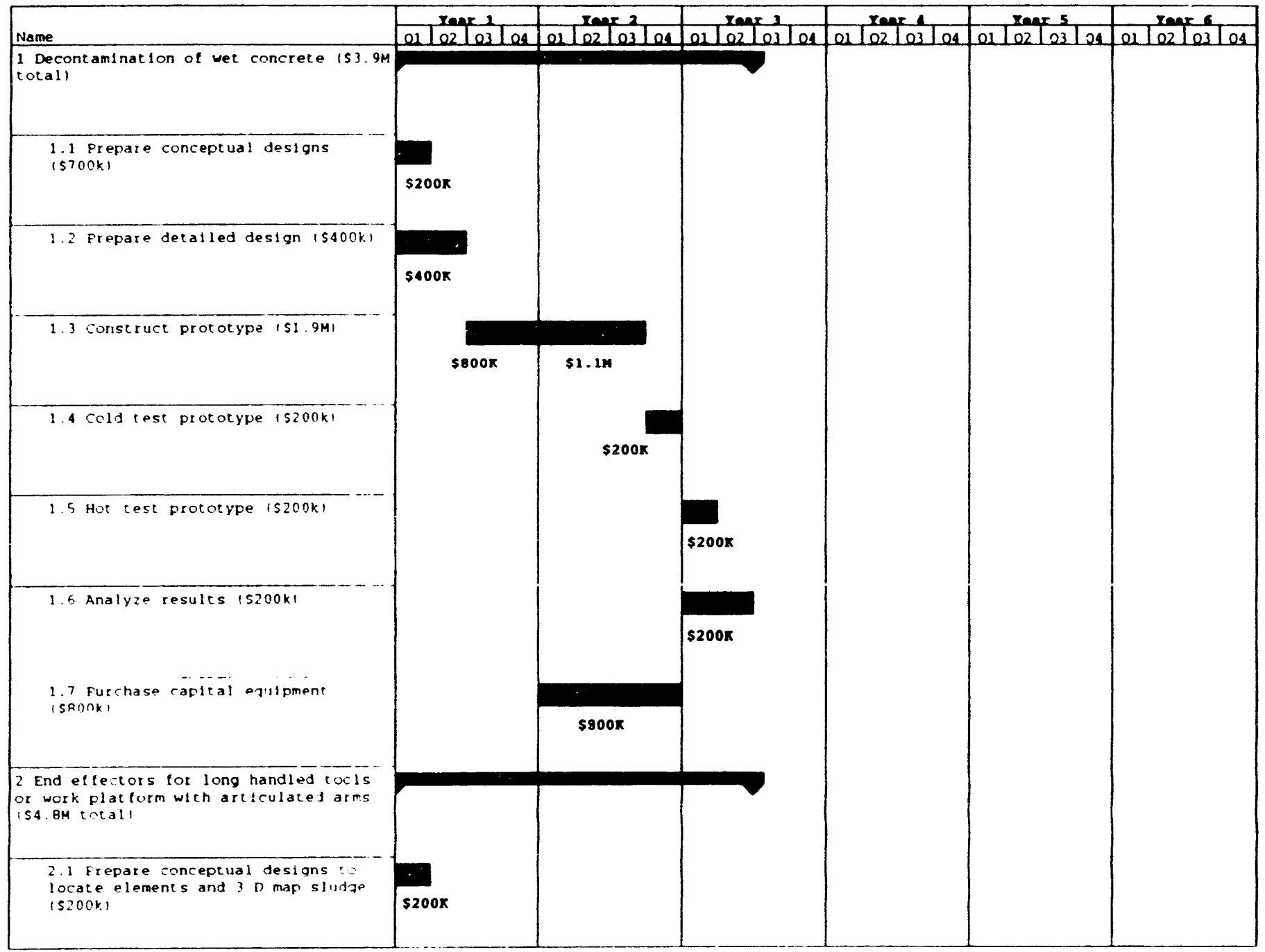


Reator fuel steraze fouls themenstiation fath

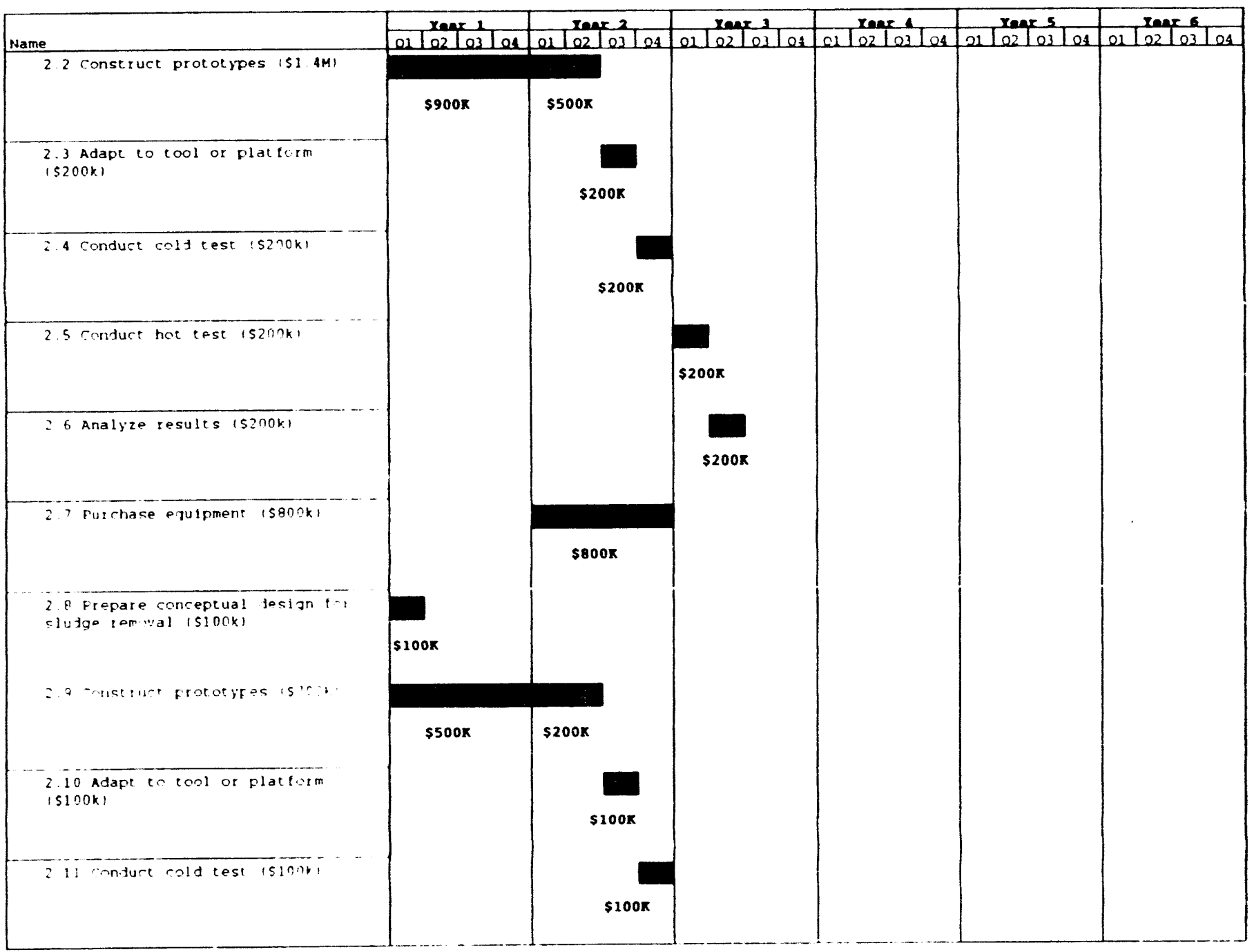




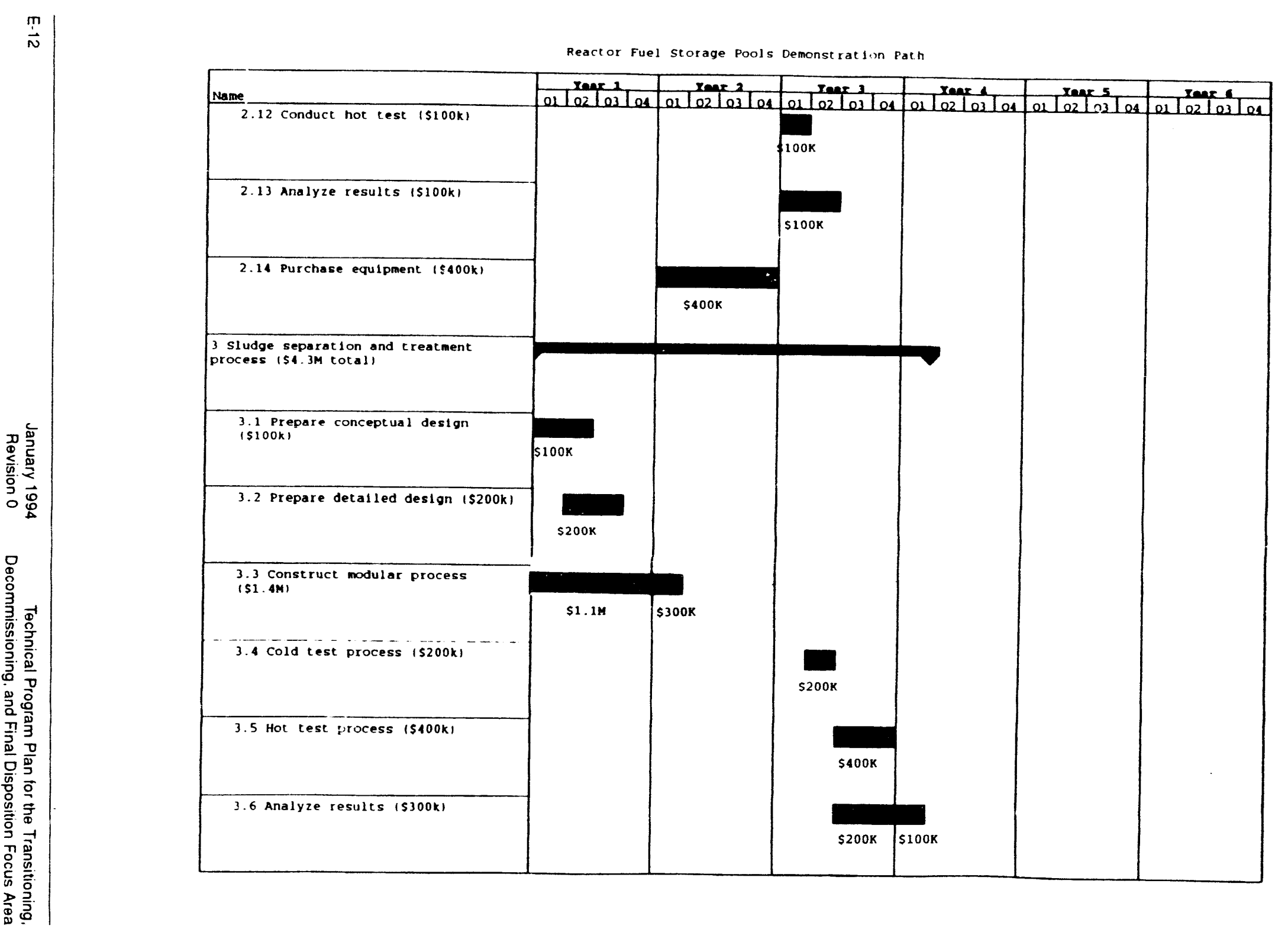




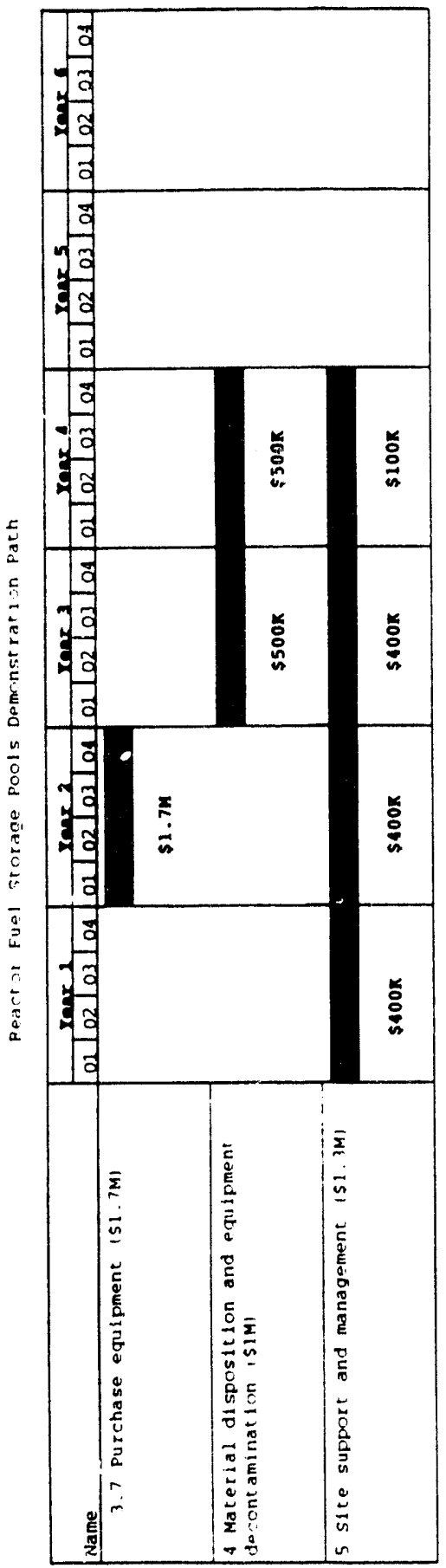




\section{Process Equipment}

\section{Section $1 \quad$ Situation Analysis}

\section{Section 1.1 Problem Definition}

Description of The process equipment at gaseous diffusion plants (GDPs) throughout the the Problem DOE Complex includes the major systems components (e.g., axial and centrifugal compressors, converters, control valves, pipes) that have had long-term exposures to uranium hexaflouride $\left(\mathrm{UF}_{6}\right)$ at elevated temperatures during the uranium enrichment process. The major radiological contaminant is uranium ( $\mathrm{U}$ ) and a minor amount of technetium $(\mathrm{Tc})$. Exterior surfaces may also be contaminated with PCBs (regulated by the Toxic Substances Control Act) and by RCRA-listed hazardous materials. This creates a situation where the internal surfaces of the process equipment are known to be contaminated, but to an unknown extent, and the external surfaces are suspected to have contaminated areas, but with contaminants in addition to the radiological components.

Size of the

GDPs are, by nature, large facilities which utilize repetitive stages of Problem equipment in a cascade to achieve enrichment. The three DOE GDPs have over 10,000 stages, with equipment in excess of 750,000 tons total weight. The combined footprint of the five GDP process buildings of the K-25 site alone is approximately 100 acres, with each building typically having three levels. The amount of contaminated equipment is truly massive. Using current baseline technology, we would need decades to characterize and decontaminate the equipment at the three DOE GDP sites. Currently, the Oak Ridge K-25 Site (formerly the Oak Ridge Gaseous Diffusion Plant) is the only permanently shut down GDP site, but the two other GDP sites at Paducah, KY, and Portsmouth, $\mathrm{OH}$, will also require D\&D. The total cost for D\&D of GDP facilities at the K-25 Site has been estimated at $\$ 7.5$ billion, using 1992 dollars (preliminary cost estimates by Ebasco Services, October 1991). This total included costs for constructing and operating two large-scale decontamination support facilities, estimated at $\$ 2.9$ billion. These facilities would be used for post-removal decontamination, disassembly of equipment, materials handling, packaging, and wastes certification. Dismantlement, removal, and transport of all equipment and internal structures to these facilities was estimated to cost $\$ 2.65$ billion, of which roughly one-half was associated with major process equipment and piping (the problem area addressed in this ID). These latter operations are expected to be highly labor intensive. 
Problem Locations
The DOE GDP sites that have contaminated equipment are Oak Ridge, TN, K-25 Site; Portsmouth, OH; and Paducah, KY. In addition, smaller UF6-handling facilities (e.g., fuel-handling, feed production) are located throughout the DOE Complex and private industry. Many of the characterization, dismantlement, and robotic technologies will be applicable to a wide variety of D\&D and environmental remediation scenarios.

\section{Section $1.2 \quad$ Characterization}

Baseline Current baseline field technologies include counting technologies to measure Technologies alpha, beta, and gamma radiation; passive gamma and neutron detection to measure uranium holdup; portable X-ray fluorescence; and immunoassay for PCBs. Classical EPA laboratory methods are used in support of various sampling protocols.

Deficiencies Field methods for characterization are time consuming and labor intensive; moreover, it is difficult to sample bulky equipment and internal surfaces. This increases worker exposure, the use of protective clothing, and the production of secondary waste. Also, these methods are used primarily for single-point analysis and do not really provide mapping information.

The EPA laboratory methods for characterizing organic contaminants involve an extensive chain of custody and intensive quality assurance procedures that increase cost and limit timeliness. There are currently no approved characterization methods for mixed organic wastes.

The major difficulty is the characterization of internal surfaces, odd shapes, and large items with intricate internal and external structures. The primary risk associated with current baseline technologies for characterization is imperfectly characterized process equipment that is released for recycle and/or reuse. The organic contaminants known to exist in the GDPs (e.g., PCBs) are carcinogenic, and there are radioactive contaminants (e.g., U, Tc) that pose long-term environmental hazards. The major deficiency with existing characterization techniques is the lack of instrumentation capable of real-time, in situ field measurements., particularly on the inside of the process equipment.

The cost of characterization using current baseline technologies is, for the most part, incalculable. 
Solutions Solutions to the problem associated with using current baseline technologies for characterization include

- robotic delivery systems to permit mapping of external structures;

- improved methods for holistic radiation measurements (e.g., long-range alpha detection (LRAD), improved non-destructive assay (NDA);

- ultra-sensitive organic analysis (PCB) to permit characterization of equipment surfaces in real-time (<10 $\mathrm{min})$;

- enhanced methods of detection of weak beta-emitters (e.g., Tc);

- fiber optic-based laser emission spectroscopy to determine Tc, RCRA, and actinide materials on internal pipe surfaces; and

- automated laboratory analysis to speed up results and reduce chain-of-custody requirements.

\section{Section 1.3 Decontamination}

Baseline Current baseline technologies include wiping, washing, blasting, chemical Technologies cleaning, scarification, vacuuming, etc. Surface decontamination is effective for simple geometric shapes and can be redone if necessary; however, it is less effective for complex shapes, is extremely labor intensive, and generates a substantial amount of secondary waste. This waste is not only expensive to dispose of but poses serious environmental hazards and substantial risks for worker exposure.

Deficiencies Current baseline technologies for decontamination are labor intensive, only partially effective, and generate a tremendous amount of secondary waste.

The risks associated with current baseline technologies for decontamination include worker exposure (direct and airborne) and excess secondary waste.

The estimated costs associated with decontamination of GDP equipment may be as high as $60 \%$ of the entire D\&D cost. Using only baseline technologies, we may never have enough money to perform all of the required work.

Solutions The best solutions for decontaminating UF6 process equipment are in situ decontamination of the inside of the process equipment with the equipment still assembled and in situ decontamination of the outside of the equipment to the greatest extent possible using robotics, automation, and modular containment. Adequate characterization is expected to reveal that much of the equipment will meet release standards without decontamination of the 
external surfaces. A method for melting the metal process equipment is needed for those cases in which the in situ decontamination is not adequate. Because of the lack of a de minimis limit for release of bulk contaminated materials, we should avoid melting and instead release metals based on surface standards, when possible. This combination of approaches provides the best solutions because it will reduce costs, waste, worker exposure to hazardous and radioactive materials, and risks of environmental insult.

\section{Section 1.4 Dismantlement}

Baseline

Technologies

Current baseline technologies include large and small, manual and hydraulic tools used to cut and shear process equipment: high-pressure water jets, saws, grinders, laser cutters, remote and manual shears, and plasma and acetylene torches. Because the efficacy of these methods has been proven, there has been little change or innovation in several years. Versatile and easy to control, these methods have a substantial knowledge base to support them.

Deficiencies Several deficiencies characterize current baseline technolog . " for dismantlement. The methods available are labor intensive and subject workers to the risk of exposure to contaminants and industrial hazards. There is, of course, the possibility of accidental releases, which could endanger both the public and the environment. These methods generate secondary wastes, require manual intervention/operation, and expose workers to mechanical hazards as well as to airborne and volatile contaminants

Solutions The most meaningful solution to the problems associated with using current baseline technologies for dismantlement is a viable method for in situ decontamination followed by dismantlement using robotics and automation. Of particular interest are tools/robotics that will handle massive equipment. This is the best solution because it improves worker safety, incre : :s productive work hours, and reduces the chance of exposure/release.

Note: There are fewer restrictions on the dismantlement of equipment that has been decontaminated than on equipment that has not been decontaminated. 


\section{Section 1.5 Materials Disposition}

Baseline Current baseline technologies include on-site storage, decontamination for Technologies controlled recycle and reuse, and decontamination for free release (non-porous materials).

Deficiencies There are several deficiencies associated with current baseline technologies for materials disposition. We are limited by diminishing storage space and increasingly restrictive environmental regulations. The risks associated with current materials disposition technologies include environmental impact, worker exposure, and regulatory compliance. It is also recognized that the GDP equipment contains large quantities of valuable nickel $(\mathrm{Ni})$, which could be recovered.

On-site storage requires continuous surveillance and maintenance, and their viability under current and future regulations is questionable. Finally, cross-country transportation of wastes is neither reasonable nor politically acceptable.

Solutions The most desirable solution to the problems associated with using current technologies for materials disposition is a viable means to turn scrap into products for controlled beneficial reuse. This is the best solution because it is cost effective, environmentally sound, and energy- and resource- efficient.. This solution depends on the committed investment of funds from private industry and is contingent upon DOE's commitment to ensure a market for recycled materials.

\section{Section 1.6 Robotics and Automation}

Baseline Currently, there are few - if any - baseline technologies for D\&D of Technologies uranium process systems and equipment that include robotics and automation. Semi-automated laboratory systems exist to assist characterization activities.

Deficiencies The deficiencies associated with current GDP baseline technologies are the lack of robotics and automation technologies needed to assist in situ/ex situ characterization, decontamination, and dismantlement of contaminated uranium process systems and equipment. Increased throughput of laboratory sample analyses are required to support characterization activities. 
Solutions Robotics and automation would solve many of the problems associated with using current baseline technologies for characterization, decontamination, and dismantlement of contaminated uranium process systems and equipment. Robotics and automation would eliminate the need for personnel to perform hazardous duties and would increase productivity because of the repetitive nature of D\&D activities in GDP facilities. Highly automated analytical chemistry laboratory operations and rield analysis capabilities will eliminate a major characterization bottleneck.

\section{Section $1.7 \quad$ Regulation}

All of the approaches and solutions that we have recommended can work under existing regulations. However, actions by regulators to facilitate and permit small-scale testing of innovative technologies and procedures with potential benefits for D\&D could be helpful. Establishment of a de minimis limit to permit the free release of slightly bulk-contaminated materials is critical for the reuse of the valuable metals in the GDPs and the consequent minimization of the waste from the D\&D of these plants. Acceptance of statistical sampling and field screening in support of laboratory analysis is also needed.

\section{Section 1.8 Management and Systems}

The technologies and approaches selected for D\&D of the GDPs need to take maximum advantage of the large-scale, repetitive configurations involved in various tasks. System models and databases for configuration management would help in estimating the costs and benefits associated with application of specific technologies.

Note: An integrated demonstration of automated equipment and devices for D\&D of the GDPs would enhance their usefulness for other problems in the DOE Complex. After successful debugging, these devices could be further "remotized" for applications in higher-radiation and/or hazardous environments. 


\section{Section 2 Description of the Proposed Integrated Demonstration}

This ID addresses the sub-problem of the decontamination and decommissioning (for recycle) of the gaseous diffusion process equipment that was directly in contact with UF$_{6}$ during the enrichment process. This contamination scenario is an ideal test bed for D\&D development within DOE for three major reasons: first, the huge volume of GDP equipment is a series of repetitive components; second, the contamination scenar os are expected to be repetitive throughout the equipment (e.g., thousands of similar process equipment components in series); and, third, the range in complexity and size (e.g., simple piping to large, internallv complex, equipment) is comparative to equipment used throughout the DOE and DoD complexes. These three factors all support a demonstration that is able to develop technologies which can utilize automated or remote methods (repetitive scenarios and internal surfaces), demonstrate the processes on a statistical number of components (i.e., availability of repetitive and semi-uniform contaminated components), and be transferrable to a wide variety of similar DOE and industrial D\&D scenarios.

In addition to providing support to D\&D operations, the ID will focus on providing a clean product that will be supportive of reuse/recycle of our resources. This is important, since the GDP equipment represents not only a large volume of equipment, but also large amounts of valuable resources.

- Within the gaseous diffusion complex there is approximately 750,000 tons of process and auxiliary equipment, including 633 converters (each weighing approximately 35 tons) in one building (K-33). This equipment includes significant amounts of nickel, aluminum, monel, and steel in an enclosed, interconnected piping network.

- The current market value of the nickel is approximately $\$ 350 \mathrm{M}$, assuming realistic de minimis limits are established.

- Recovery of enriched uranium for future use will provide significant payback (e.g., reactor fuel) at all sites.

This ID would be a field-scale demonstration. Some lab-scale work may be performed to assist in defining the parameters required for the field-scale demonstration. Section 5 of this Appendix indicates that the recommended site for this demonstration is the Oak Ridge K-25 Site. One of the main drivers for the choice of this location is to take advantage of, and coordinate activities with, the efforts of EM-40. EM-40 is funding a D\&D Technology Implementation Project (formerly Pilot Project) which is funding the development of complimentary technologies to those being suggested by the GDP D\&D ID. The combination of these two programs would allow not only the integration of the various technology areas (i.e., characterization, 
robotics/automation, decontamination, dismantlement, and systems management) but also the integration of EM-50 and EM-40 activities. The following items will be central to the development efforts being proposed by the GDP D\&D ID.

Items important to the demonstration include the following.

- Demonstrate (prove the predictions of) "production rate" benefits.

- Provide cost estimate information for labor needs and secondary waste generation.

- Demonstrate all technology tools (characterization, dismantlement, decontamination, material disposal, robotics) on all equipment types (converters, compressors, valves, piping).

- Perform secondary decontamination of difficult contamination scenarios in support of free release.

- Demonstrate capabilities for a total information management system.

- De minimis standards are needed to permit reuse/recycle of bulk contaminated materials, but the necessary regulations are lacking.

This ID is based upon development of technologies within the six major technical thrust areas (characterization, decontamination, dismantlement, robotics, materials disposition, and systems management) by both EM-50 and EM-40. Although each of the individual technologies provide a useful stand-alone tool in assisting the D\&D process, it is through their combination that the job of decontaminating, removing, recycling, and disposing of process equipment can be accomplished in a safe and cost-effective manner. This synergistic alliance of technologies can be used to provide a variety of D\&D support activities that are needed at the GDP plants as well as throughout the DOE complex.

In determining the various technical needs for the D\&D of GDP process equipment, a wide variety of technologies were considered. Those technologies that were selected were ranked and placed into one of three levels. The three levels represent the extent to which the technologies directly relate to GDP process equipment and DOE Complex D\&D needs. The following is a listing of the breakdown of the proposed technologies by their various levels. 
LevelA: Level A technologies directly relate to GDP issues and to other DOE Complex needs and will

- characterize the radionuclides inside process equipment using advanced NDA and alpha detection (e.g., long-range alpha detection, LRAD) methodologies.

- use an automated system capable of deploying a variety of end-effectors over the exterior surface of the process equipment. End-effectors would be developed to allow

- characterization and mapping of the radiological contaminants

- decontamination of the contaminated (mapped) areas

- cutting in support of dismantlement of the process equipment

- provide advanced containment and protective systems to reduce worker exposure, protective clothing requirements, and minimize the spread of contamination

- decontaminate the inside of the process equipment using either long-term, low-temperature (LTLT) gas-phase treatment or a vendor-demonstrated technology. Both systems will use materials recycle and secondary waste minimization. These technologies are funded by EM-40.

- characterize the exterior surface of the GDP equipment for the presence of PCBs using a real-time $(<10 \mathrm{~min})$ sensor that is designed to greatly reduce the amount of secondary waste generated per analysis. This technology is funded by EM-40.

Level B: Level B technologies relate to a portion of the GDP equipment issues in addition to other DOE Complex needs. Level B technologies will enhance the Level A technologies and will

- provide a means of characterizing for weak beta emitters, particularly Tc, in both internal and external equipment surfaces.

- remove Tc from the interior surfaces using an advanced gas-phase treatment technology.

- use remote systems to provide dismantlement, removal, and transport of process equipment segments to a disassembly area.

- provide an operator console to combine the various automated characterization, decontamination, and dismantlement controls and management. 
Level C: Level C technologies are applicable to "generic"GDP and DOE needs for process equipment. Level $C$ technologies will enhance the Level $A$ and Level B technologies and will

- characterize the internal and external surface of the process equipment using a fiber-optic-based laser spectroscopy.

- decontaminate large areas of process equipment that have either been removed during disassembly or found to be consistently contaminated throughout the repetitive stages of equipment.

- provide remote and automated disassembly of the process equipment in a specially designed cell.

- provide a 3-D mapping interface for the automated processes that are being used to support the D\&D process (Levels A, B, and $\mathrm{C}$ ).

- automate laboratory analysis which is required to provide regulatory analysis in support of the D\&D activities and waste generation and treatment.

It is envisioned that the Level A technologies, which represent the combined effort of EM-50 and EM-40, are the main technologies that need to be developed at this time. As additional technical support is needed, and as the developed technologies are applied to other D\&D problems throughout the DOD Complex, it is envisioned that the Level $B$ and Level $C$ technologies could be developed to provide additional technical support and cost savings.

The primary focus of the GDP D\&D ID is to decontaminate the process equipment and provide a means by which the material can be reused or recycled. Hence, in conjunction with the metals recycle $\mathrm{ID}$, this $\mathrm{ID}$ will demonstrate technologies for the D\&D of gaseous diffusion process equipment and provide for the recycle/reuse of the metal either in the general economy, in DOE, or in both. The majority of the metal - except for the nickel barrier, which is inherently bulk contaminated and, for security reasons, also must be reprocessed by smelting or some similar method - will be decontaminated to satisfy current release standards. 


\section{Section 2.1 Qualifications}

This ID will not only integrate various fields.of technology (characterization, dismantlement, decontamination, robotics, and program management) but also D\&D technology development and D\&D operations. This combined EM-50 and EM-40 program will use various partners (DOE, EPA, industrial vendors, academia, and federal facility resources) to ensure the success and applicability of the proposed program. Emphasis will be placed on ensuring that the technologies developed provide a complete solution to the D\&D challenges that exist for GDP process equipment. Issues of reducing worker exposure, reducing secondary waste generation, and minimizing industrial hazards will also be addressed.

If fully funded and completely successful, this ID will provide integrated technologies to sub-problems of GDP process equipment D\&D and involve the following elements:

- industry-academia-DOE involvement

- process equipment manufacturers; D\&D service contractors; universities; instrument manufacturers; industrial vendors; tooling design specialists; robotic vendors; engineering subcontractors; other DOE facilities; multi-site robotics program

- CRADA, TTP, PRDA, ROA, and subcontracts

- coordination of EM-50 and EM-40 activities

- not only an integrated technical solution through the development of the technologies in Section 2, but also an integrated work plan solution

- potentially large costs savings because of the large-scale and highly repetitive nature of the D\&D operation required for GDP process equipment

- all D\&D goals addressed in five-year program 


\section{Section $2.2 \quad$ Deliverables}

This ID will demonstrate, evaluate, and test several in situ and remote technologies for the characterization, decontamination, and dismantlement of GDP equipment. By teaming EM-50 and EM-50 and using industrial parci:ss, DOE will advance the technology baseline, and the hardware required to perform the scope of the D\&D work will be more accessible tivough commercial channels.

The following are the specific deliverables for this ID.

- optimized characterization techniques for in situ and ex situ characterization of GDP equipment

- decontamination of the interior and exterior of up to one cell of gaseous diffusion equipment

- dismantlement of GDP equipment

- automation of repetitive characterization, external decontamination, and dismantlement tasks

- recovered metals that meet surface release criteria for recycle/reuse

- techniques for recycle of secondary waste streams 


\section{Section 2.3 Reasons for Pursuing the Proposed ID Now (versus Later)}

This ID should begin in FY 94 to FY 95 to allow full integration with the EM-40 activities (D\&D Technologies Implementation Project). The EM-40 project is a three-year development plan and the proposed EM-50 demonstration is a four-year plan. This would allow the technologies to be developed by the FY 97-FY 98 time frame. This will allow full technical support of the planning process for the D\&D of the K-25 Site, which is expected to begin soon after the year 2000 .

The technology developed in this $\mathrm{ID}$ (Level A) will have direct applicability to other DOE and industrial sites. These technologies can then be implemented in other D\&D programs and allow other programs to benefit from their development and availability. The following are some of the advantages of pursuing the proposed ID.

- leveraged financial technical opportunities with the deposit removal program (EM-40)

- technical development and possible cooperative financing with the EM-40 D\&D Technologies Implementation Project.

- reduced surveillance maintenance (S/M) cost for special nuclear materials (SNM) and facilities

- possible reuse of facilities for interim storage of mixed and low-level radioactive waste and D\&D operations

\section{Section $3 \quad$ Benefits}

The direct benefits of completing the ID include the following:

- demonstration of characterization systems that will permit. internal surveys of pipes and equipment

- improved in situ methods for measuring radiation and organics to permit release of equipment

- effective, early demonstration of removal of uranium deposits (a high-risk problem because an earthquake or tornado could trigger the release of uranium - some of it highly enriched into the environment)

$\begin{array}{ccc}\text { F-14 January } 1994 & \begin{array}{c}\text { Technical Program Plan for the Transitioning, } \\ \text { Revision } 0\end{array} & \text { Decommissioning, and Final Disposition Focus Area }\end{array}$


- reduced risks of worker exposure, industrial hazards, and environmental release of hazardous and toxic materials (possible through in situ decontamination of the inside of the equipment without disassembly and in situ decontamination of the outside of the equipment [to the greatest extent possible] using robotics, automation, and modular containment, followeḍ by dismantlement using robotics and automation)

- enhanced positive public , rception of DOE/ERWM efforts

- recycled/reused metals

EM would benefit from the ID in the following ways:

- having a well-defined, expanded baseline criteria for future D\&D

- having demonstrated D\&D methods that minimize secondary waste production

Industry and the DOE Complex would benefit from the ID in the following ways:

- successful technology transfer

- new technology for commercialization

- digital RTR; improved LRAD and NDA

- fiber optic-based laser emission spectroscopy to determine Tc, RCRA, and actinide materials

- additional automated laboratory analyses

- LTLT gas-phase decontamination

- a D\&D infrastructure for other technology demonstrations (e.g., DOE, private sector)

- engineered systems (characterization, dismantlement, decontamination, robotics) for full-scale implementation. 


\section{Section 3.1 Cost Benefits}

Major cost savings are expected from the set of technologies that are being proposed for the GDP D\&D ID. Automated characterization (mapping) is expected to show that much of the exterior surfaces of the process equipment does not need to be decontaminated. The automated processes and the in situ decontamination are expected to reduce the amount of labor along with reducing the amount of worker exposure, secondary waste generation, and industrial safety risks.

The current baseline for costs of $\$ 7.5$ billion for the Oak Ridge K-25 Site are based on the 1991 report by Ebasco Services ("Environmental Restoration of the Gaseous Diffusion Plants"). This study detailed two major cost areas which the technologies of the GDP D\&D ID can help to reduce.

First, the report stated that $\$ 2.9$ billion would be required to build two new decontamination facilities. Of this $\$ 2.9$ billion, almost $\$ 1.0$ billion was for high-temperature fluorination cells and almost $\$ 0.28$ billion was for high-pressure water spray equipment. It is felt that the technologies proposed will not require the two new facilities to be built and the fluorination cells and the water spray equipment will not be required. This will lead to a cost reduction of $\$ 1.0$ to $\$ 1.3$ billion. Second, the report estimated that the decontamination and dismantlement activities would cost $\$ 2.65$ billion, with labor (approximately 63\%) and materials in direct support of labor activities (approximately $30 \%$ ) representing the majority of this cost. It is felt that the automated and in situ technologies will lead to a cost reduction of about $\$ 0.30$ billion. It should be noted that there is no direct estimate for the cost savings due to the reduction in the requirements for protective clothing or the treatment of secondary wastes. Thus, it is believed that a cost saving of $\$ 1.3$ to $\$ 1.6$ billion is a conservative estimate with respect to the stated baseline cost estimate. These estimates will continue to evolve as more detailed cost analyses are made available and as the ID plan evolves.

The economic impact of the GDP D\&D ID plan can be calculated for the various levels of development. The Level A cost of development is a total of $\$ 25.25$ million (EM-50: $\$ 15.25$ million; EM-40: \$10.0 million). The Level B cost of development is $\$ 11.2$ million. The Level $C$ cost of development is $\$ 14.30$ million. Thus, the total cost of development for Levels $\mathrm{A}, \mathrm{B}$, and $\mathrm{C}$ is $\$ 50.75$ million. The cost payback of the development costs with respect to the estimated savings is

- Cost payback for Level A:

$\$ 1.3$ to $\$ 1.6$ billion $\$ 0.025$ billion $=52 \mathrm{x}$ to $64 \mathrm{x}$

- Cost payback for Levels A, B, and C:

$\$ 1.3$ to $\$ 1.6$ billion $/ \$ 0.057$ billion $=25 \mathrm{x}$ to $31 \mathrm{x}$ 
In addition to the cost from the reduction of capital facilities and reduction of labor costs, it is expected that cost savings and resource recovery will also effect the economics of the GDP D\&D ID. Examples of specific cost benefits include:

- reduction of waste, protective clothing, waste storage/treatment, labor, dedicated decontamination facilities, surveillance and maintenance costs, safeguards, and security

- recycle/reuse of strategic materials (e.g., $\mathrm{Ni}$ ), SNMs, and recyclable metals

- potential recovery and reuse of enriched uranium

\section{Section $4 \quad$ What Cannot Be Done Between FY 94 and FY 99}

All D\&D goals are addressed in a five-year program, from FY 94 to FY 98. Additional goals may develop during the course of the proposed ID. 


\section{Section $5 \quad$ Locations}

The table below lists the DOE and commercial sites with gaseous diffusion plant equipment, their relationships to each other, and the current justification for a D\&D ID.

\begin{tabular}{|c|c|c|c|c|}
\hline DOE Sites & $\begin{array}{c}\text { Potential } \\
\text { Commerclal } \\
\text { Sites }\end{array}$ & $\begin{array}{l}\text { Relationships } \\
\text { between Sltes }\end{array}$ & $\begin{array}{l}\text { Technical } \\
\text { Justiflcation }\end{array}$ & $\begin{array}{l}\text { Financial } \\
\text { (or other) } \\
\text { Justiflcation }\end{array}$ \\
\hline \multirow[t]{3}{*}{ Oak Ridge (K-25) } & & $\begin{array}{l}\text { GDP equipment, not } \\
\text { operating }\end{array}$ & $\begin{array}{l}\text { Shutdown GDP site; } \\
\text { readily accessible } \\
\text { equipment; more } \\
\text { technical expertise } \\
\text { available }\end{array}$ & $\begin{array}{l}\text { In ERWM control: } \\
\text { possible FFCA drivers }\end{array}$ \\
\hline & $\begin{array}{l}\text { Portsmouth } \\
\text { USEC }\end{array}$ & $\begin{array}{l}\text { GDP equipment, } \\
\text { operating }\end{array}$ & $\begin{array}{l}\text { facilities are operable } \\
\text { and operating }\end{array}$ & \\
\hline & $\begin{array}{l}\text { Paducah } \\
\text { USEC }\end{array}$ & $\begin{array}{l}\text { GDP equipment, } \\
\text { operating }\end{array}$ & $\begin{array}{l}\text { facilities are operable } \\
\text { and operating }\end{array}$ & \\
\hline FERMCO & & $\begin{array}{l}\text { Limited application; } \\
\text { CERCLA drivers }\end{array}$ & & \\
\hline
\end{tabular}

Section 6

\section{Links and Dependencies}

This ID will interact with the metals recycle ID (see Appendix I) to demonstrate materials disposition methods for the decontaminated and dismantled equipment.

In addition to interacting with the D\&D integrated demonstrations for the development of complimentary technologies, other EM-50 programs (Office of Technology Development) will serve as a source for technology development cost savings. It is believed that the Characterization, Monitoring and Sensor Technology program (CMST) and the Robotics Technology Development Program (RTDP) will continue to provide needed portions of the overall technology development needs. This in turn will reduce the overall cost for the technology development for the GDP D\&D ID. 


\section{Section $7 \quad$ Assumptions}

- Cost estimates for existing technology are based on the 1991 Ebasco Services report, "Environmental Restoration of the Gaseous Diffusion Plants."

- Cost savings assume that proposed new technologies are completely successful.

- The schedule assumes

- funding at the beginning of FY 1995;

- continuous funding; and

- no major developmental or other problems.

- Costs reflect realistic estimates of doing business under modern DOE regulations.

- Cost savings do not claim credit for reused materials, enriched $\mathrm{UF}_{6}$, or reusable space.

\section{Section $8 \quad$ Issues}

A de minimis limit (see Appendix B) will be needed to recycle/reuse nickel barriers because this material is inherently bulk contaminated. 


\section{Section 9 ID Schedule and Costs}

The following table summarizes the Level A costs (in millions) of this ID over its entire lifespan.

\begin{tabular}{|l|c|c|c|c|c|c|c|}
\hline & Year 1 & Year 2 & Year 3 & Year 4 & Year 5 & Year 6 & Total \\
\hline Characterization & 1.30 & 2.05 & 1.50 & 0.50 & & & 5.35 \\
\hline Decontamination & & 1.00 & 1.00 & 1.00 & & & 3.00 \\
\hline Dismantlement & 0.30 & 0.80 & 0.30 & & & & 1.40 \\
\hline Materials Disp. & & & & & & & 0.00 \\
\hline Robotics \& Auto. & 0.45 & 1.75 & 1.85 & & & & 4.05 \\
\hline Mgmt. \& Sys. & & 0.20 & 0.95 & 0.30 & & & 1.45 \\
\hline Total & 2.05 & 5.80 & $\mathbf{5 . 6 0}$ & $\mathbf{1 . 8 0}$ & $\mathbf{0 . 0 0}$ & $\mathbf{0 . 0 0}$ & $\mathbf{\$ 1 5 . 2 5}$ \\
\hline
\end{tabular}


Gaseous Olfusion flant: Lavel A Technolingies tomonstratton path

\begin{tabular}{|c|c|c|c|c|c|c|}
\hline Name & 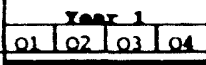 & $01 \mathrm{Cog}_{03}^{2}$ & 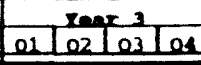 & O21 & 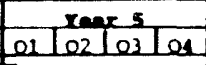 & 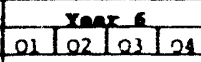 \\
\hline 1 Charactertzat ion $155.350 \mathrm{M}$ totall & & & & & & \\
\hline $\begin{array}{l}\text { 1.1 Select and procure external } \\
\text { radiation detector }(5500 k)\end{array}$ & $\$ 500 R$ & & & & & \\
\hline $\begin{array}{l}1.2 \text { conduct parameter selection and } \\
\text { modeling tor Improved NDA techniques } \\
15500 \mathrm{k} 1\end{array}$ & \$500x & & & & & \\
\hline $\begin{array}{l}1.3 \text { Configure and evaluate LRAD } \\
\text { system for Dak Ridge GDP systems } \\
15300 \mathrm{k},\end{array}$ & $\$ 300 \pi$ & & & & & \\
\hline $\begin{array}{l}\text { 1.4 Conduct fleld testing of } \\
\text { saw based pra senser unit }\end{array}$ & Mote 1 & & & & & \\
\hline 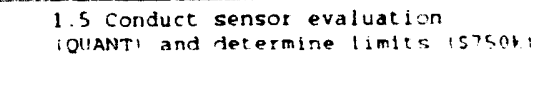 & & 5750 & & & & \\
\hline 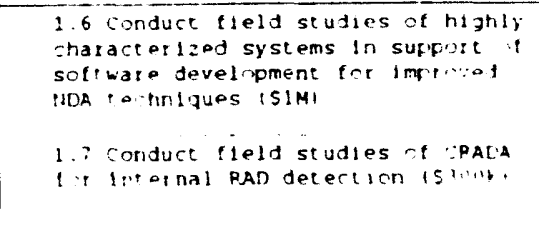 & & sim & & & & \\
\hline $\begin{array}{l}\text { 1.8 Demonstrate and feploy final F.A } \\
\text { sense: syscem }\end{array}$ & & Note 1 & & & & \\
\hline 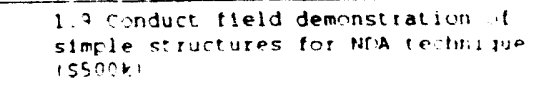 & & & $\$ 500 \mathrm{R}$ & & & \\
\hline
\end{tabular}

Note 1: Cost of this ectivity is included in sponeored projects by a technology uear organizetion (m-10). 


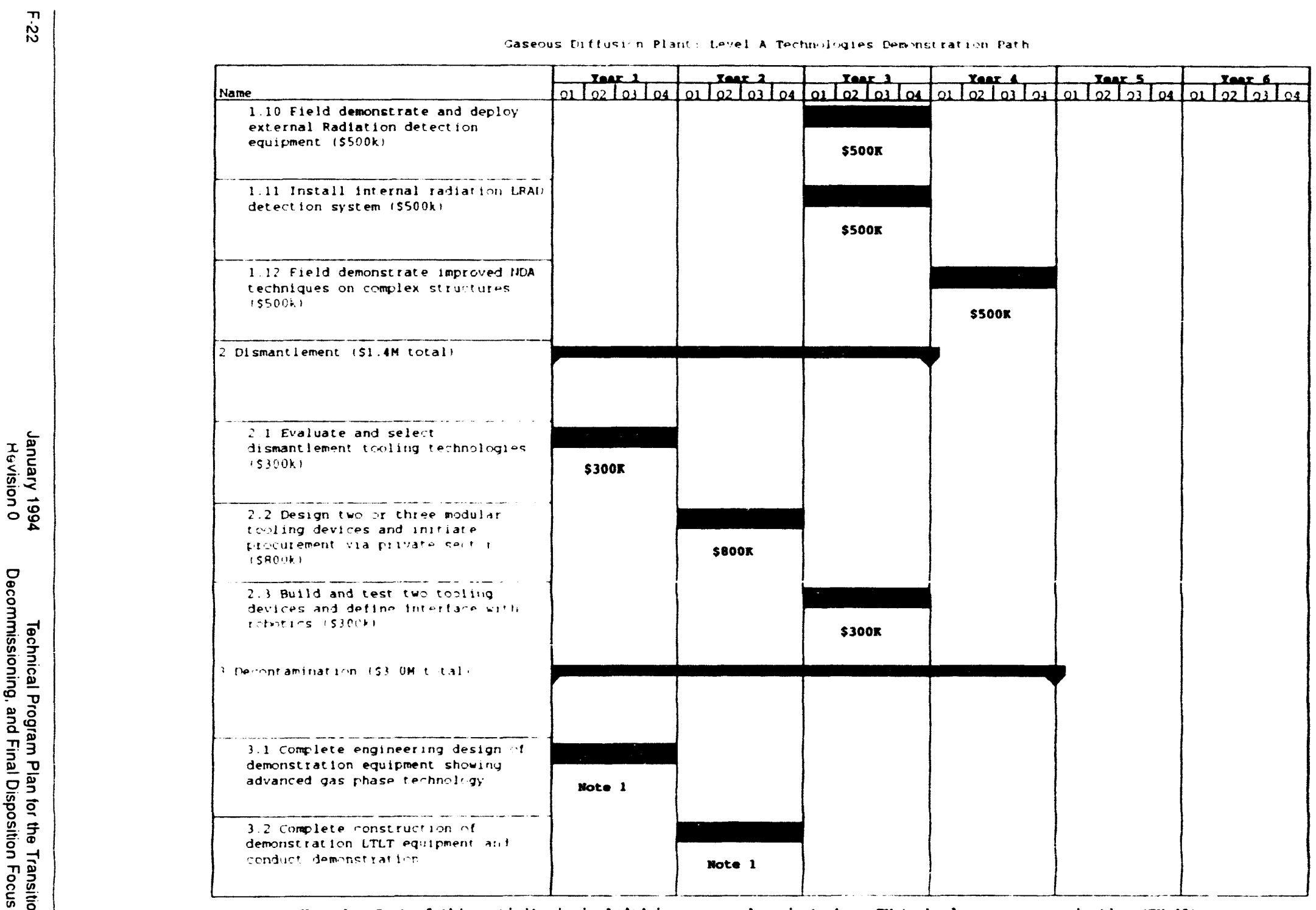

Wo.e 1: coet of this activity is included in aponeored projects by a en technology user organization (zm-10). 


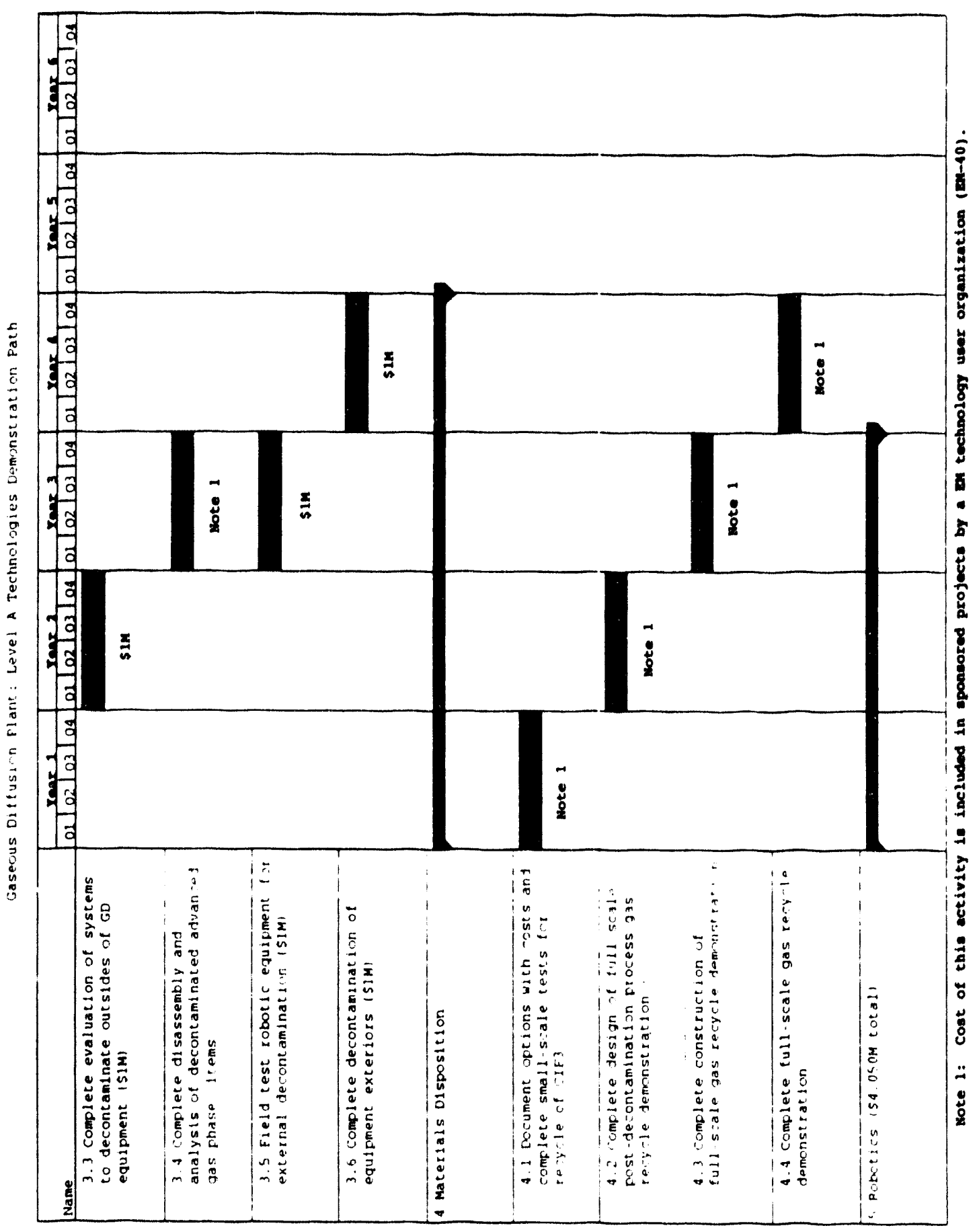




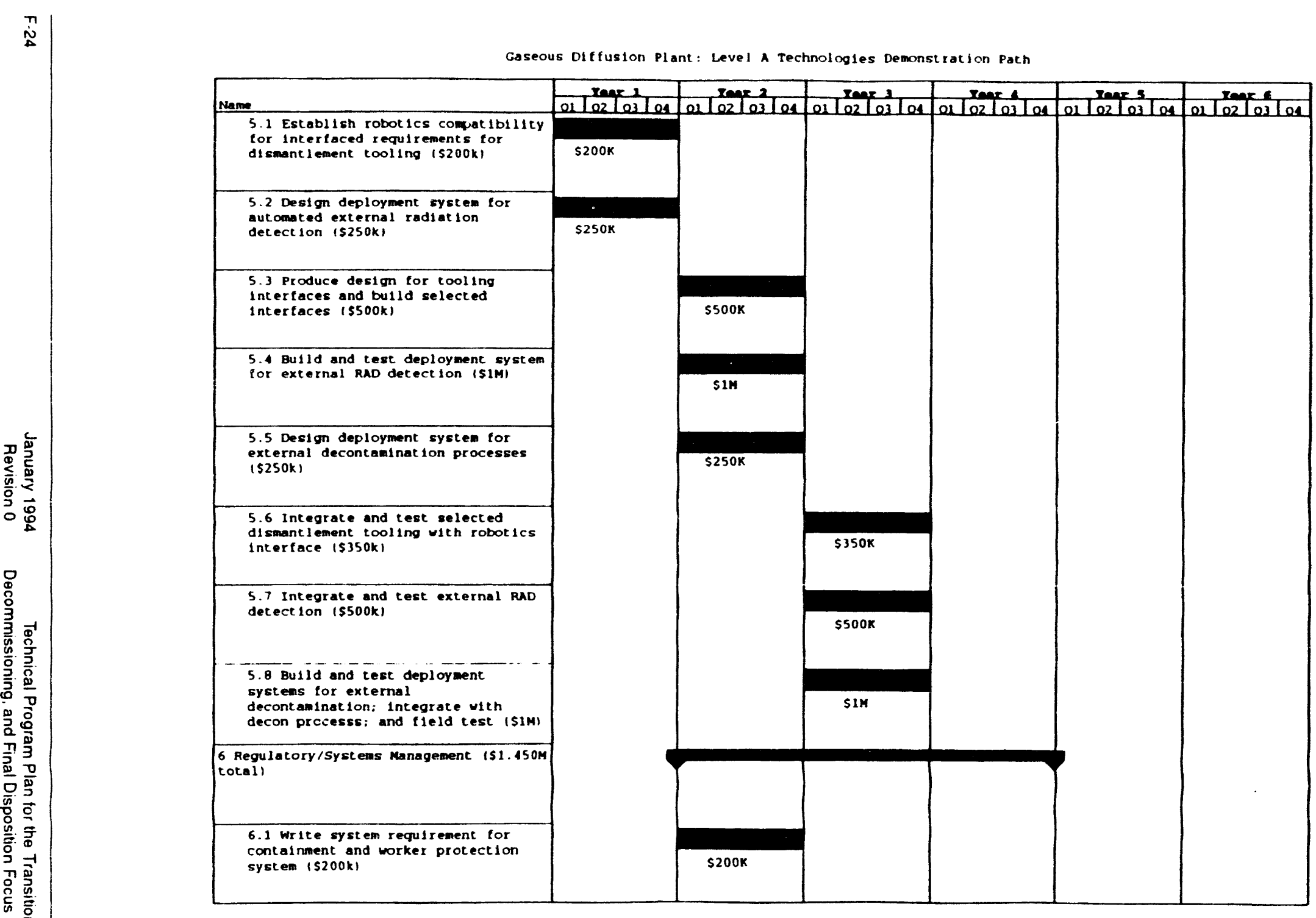




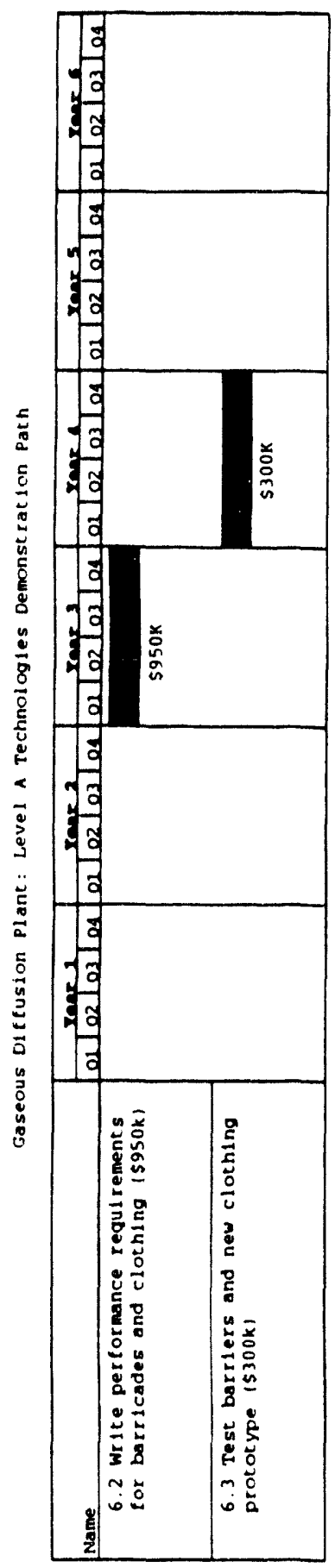




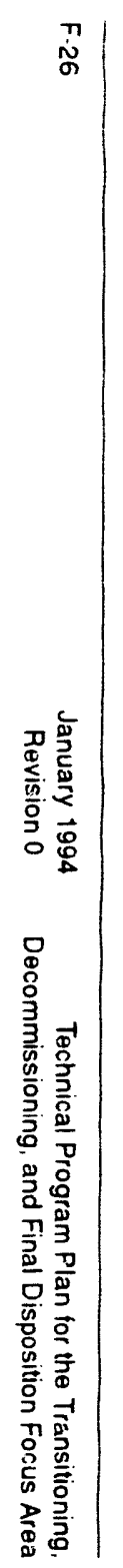

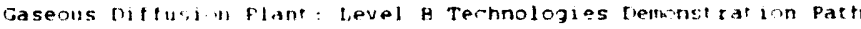

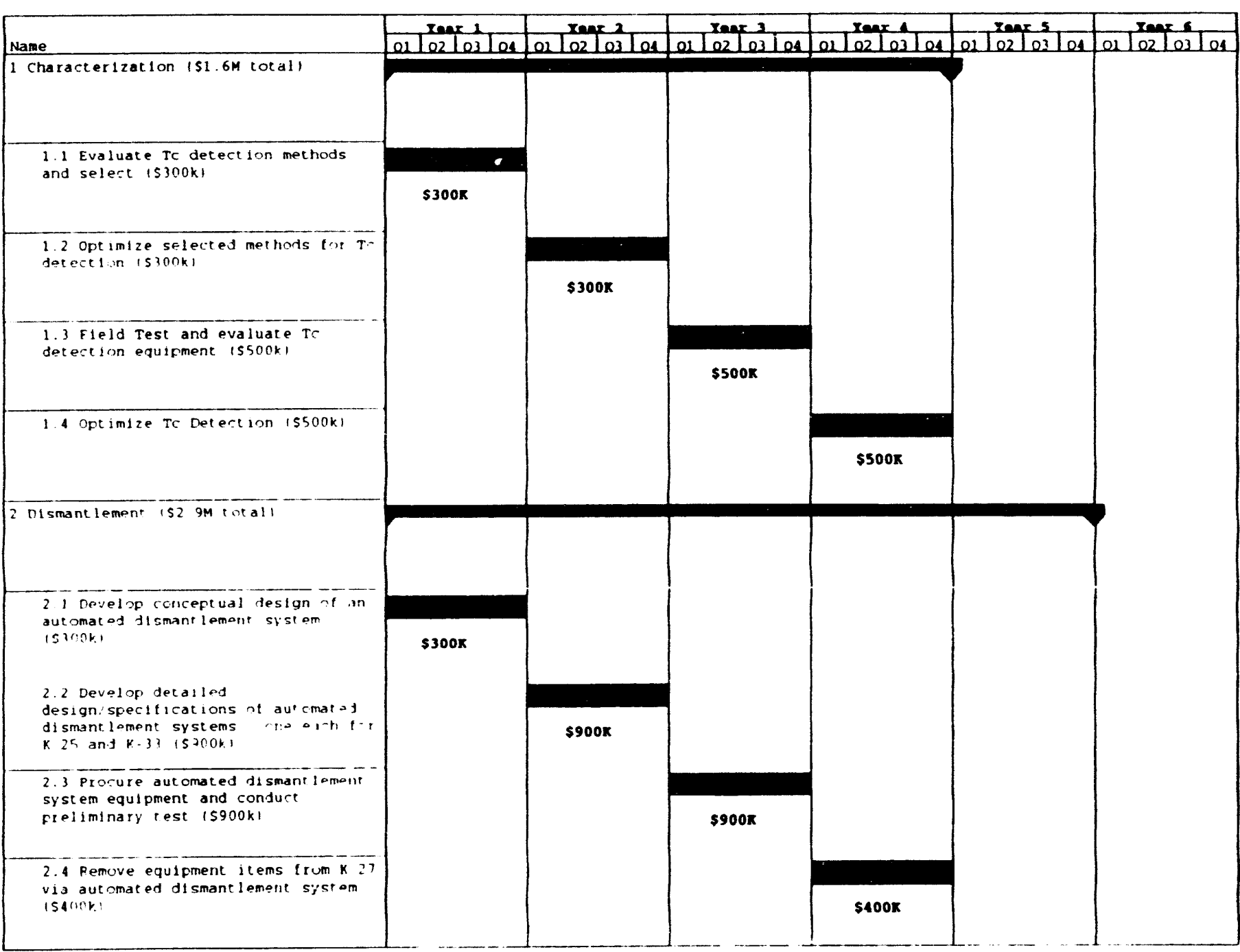


Gaseous Diffusion Plant: Level a Technologies Demonstration Path

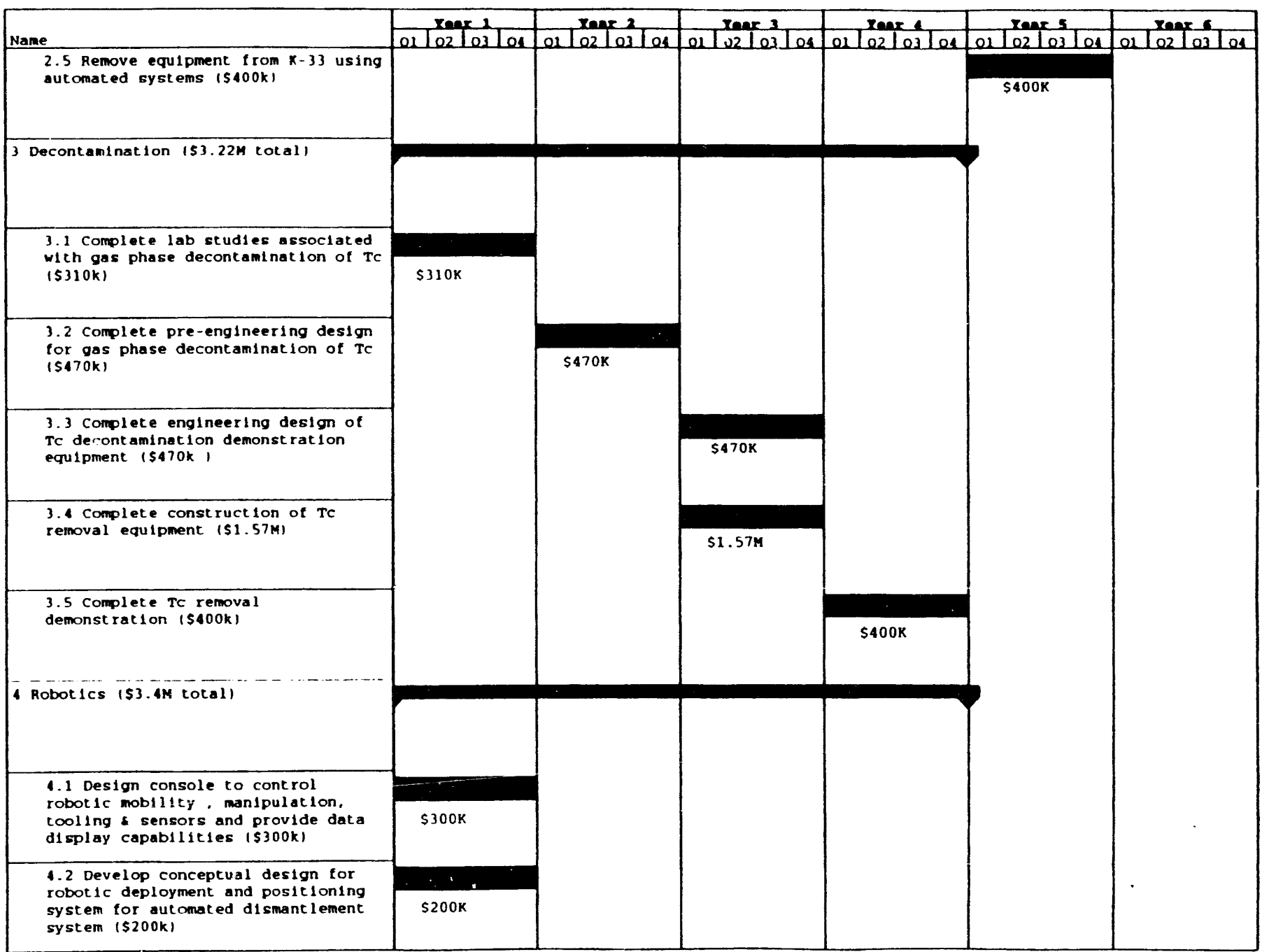


Gaseous Diffu:1" "Plant: Level B Technologies Dem nnstratich Path

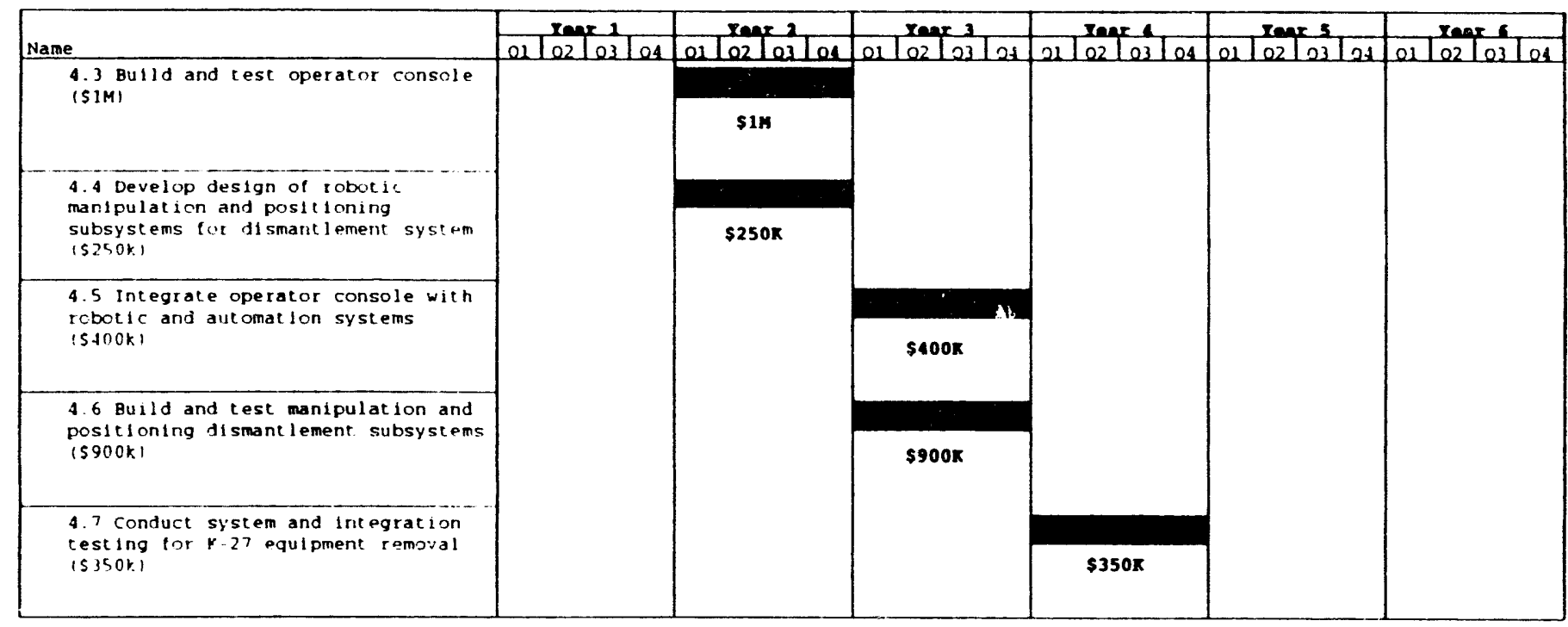




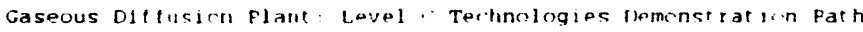

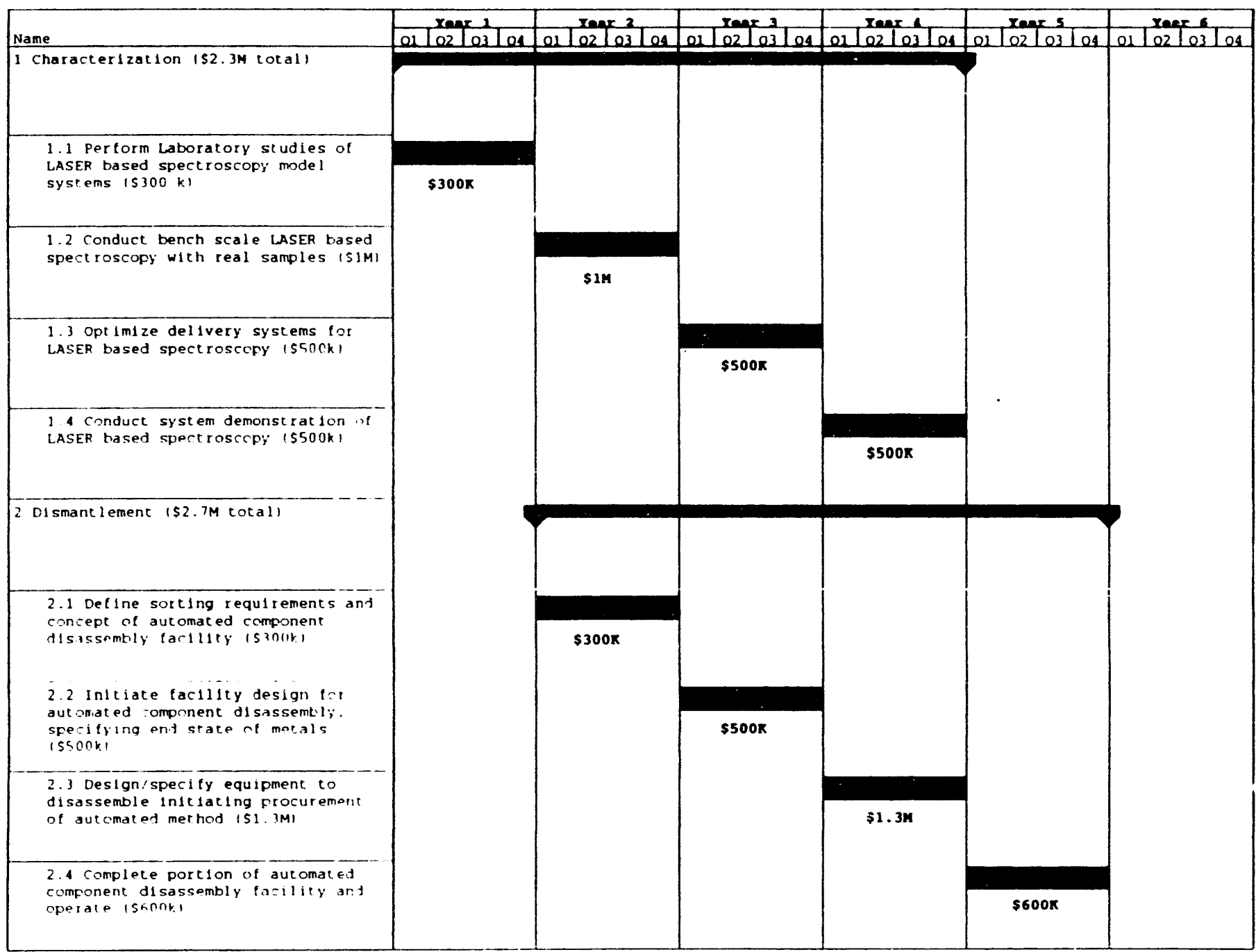


Gaseous Diffusion Plant: Level C Technologies Demonstrat ion Path

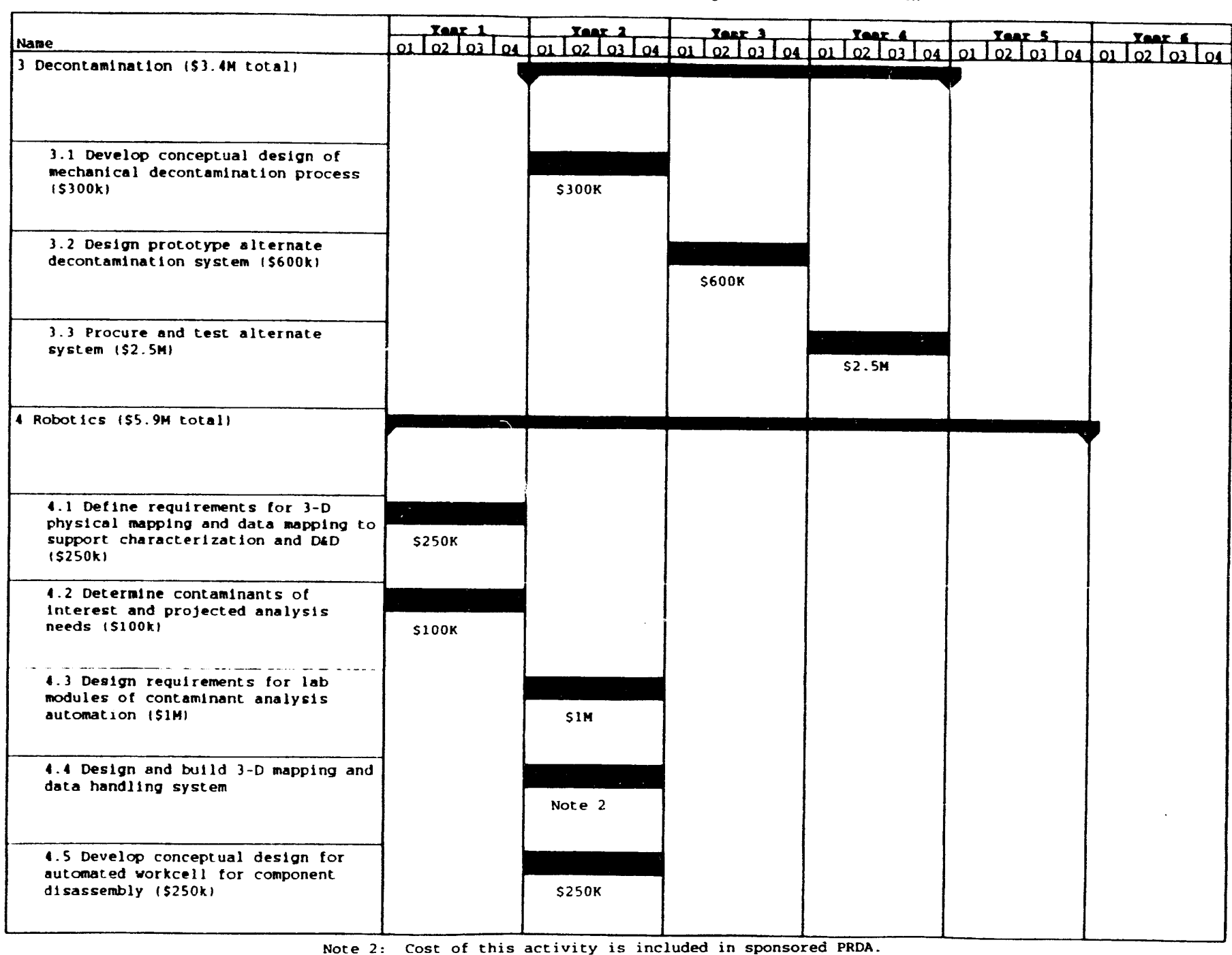


Gaseous Inffusinn flant: Level C Technclogies Dumstration Path

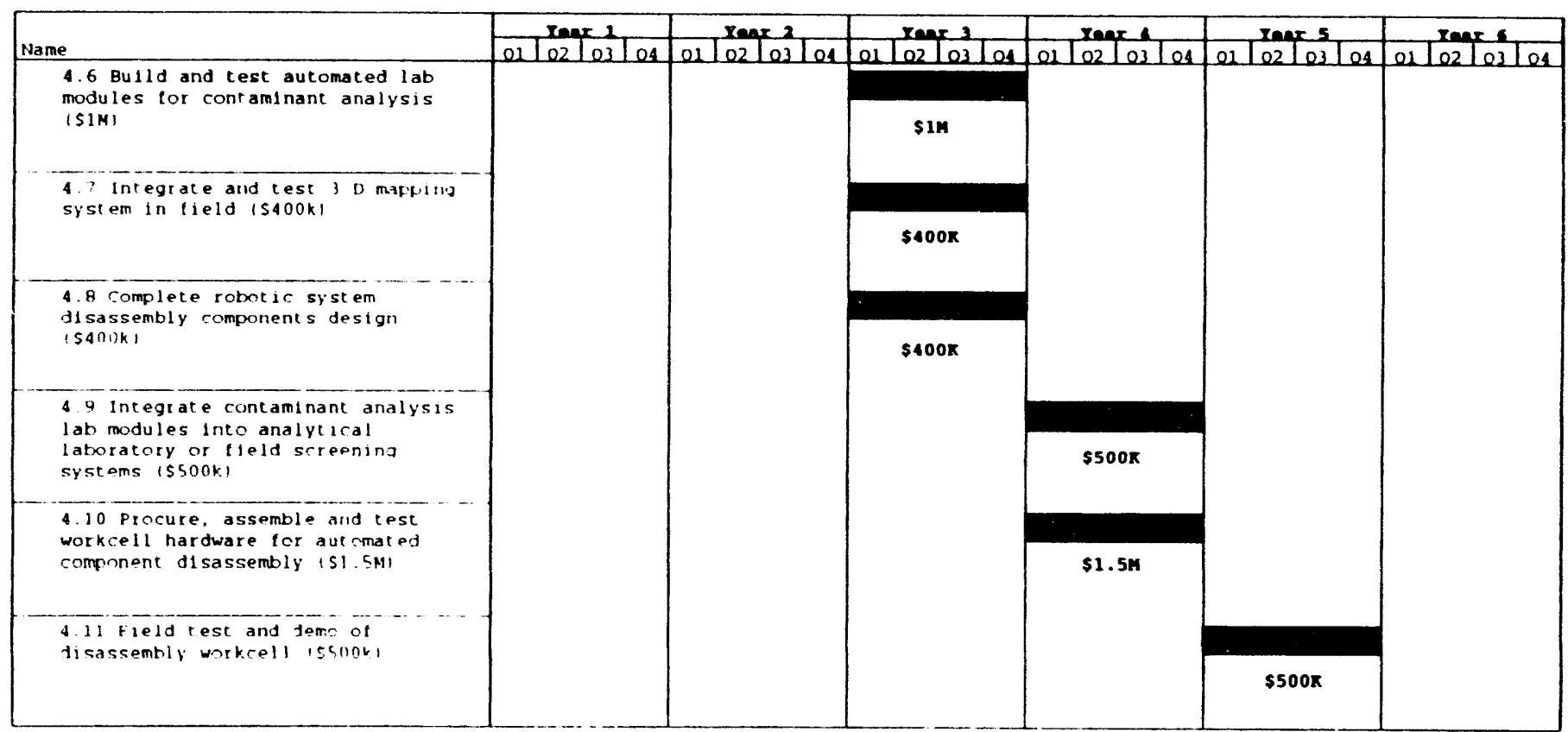


Gaseous Diffusion Plants

Process Equipment

-




\section{Highly Contaminated Equipment}

\section{Section $1 \quad$ Situation Analysis}

\section{Section 1.1 Problem Definition}

Hot cells are found throughout the DOE Complex and represent a significant problem for D\&D. Hot cells have a high-radiation environment with highly contaminated equipment. The cells are generally packed with equipment, resulting in limited space for movement, and generally have limited access. Techniques available for hot cell D\&D are cumbersome, high risk to personnel, time consuming, and are unreliable because of the high-radiation fields.

\section{Section $1.2 \quad$ Characterization}

Baseline Current baseline technologies include standard characterization methods: Technologies analysis of plant records and documentation; physical and video/remote inspection; sampling and laboratory analysis of radioactive and hazardous materials; and non-destructive assay and measurement using assay meters and counters.

Deficiencies Several deficiencies are associated with current baseline technologies for characterization. The accuracy of plant records and documentation varies. Inspections are limited by the risk of exposure and restricted access to equipment. Surveying is non-discriminatory, is limited by restricted access and the risk of worker exposure, and creates secondary waste. Because samples cannot be characterized in real time, we need to deal with the hazards and risks associated with transporting contaminated materials. The capacity of laboratories where the samples are analyzed is limited, and the analytic methods are slow and cumbersome.

The risks associated with current baseline technologies for cilaracterization include worker exposure and industrial safety issues. There are also some risks with transporting samples.

Solutions One solution to the problems associated with using current baseline technology for characterization is a viable method for a real-time, in situ characterization. The tools and methods should include mapping and discrimination capabilities and improved access capabilities for video. The methods must have remote capabilities because of the high-radiation environment of hot cells. 


\section{Section 1.3 Decontamination}

Deficiencies Several deficiencies are associated with current baseline technologies for decontamination. The methods available to us are labor intensive, time consuming, and costly, and they generate secondary waste. The efficiency of these methods is questionable. Moreover, we lack adequate reach and measurement methods for debris collection.

The risks associated with current baseline technologies for decontamination include worker exposure, not being able to adequately perform decontamination, and excess waste.

Solutions A viable method for inexpensive in situ, remote decontamination and remote debris removal with little or no sec:ondary waste generation is needed. This solution depends on remote technology capabilities.

\section{Section 1.4 Dismantlement}

Baseline Current baseline technologies for dismantlement include rotary saws, Technologies jaws-of-life, plasma arc torches, overhead cranes, master-slave manipulators, and manual removal when radiation levels permit.

Deficiencies The primary deficiencies associated with the current baseline technologies for dismantlement are worker exposure, safety hazards, secondary waste generation, limited manipulator reach and access, limited crane access, and lack of existing cranes and manipulators. Dismantlement with current technologies is a very labor intensive and time consuming process.

The risks associated with current baseline technologies for dismantlement include worker exposure and excess waste generation.

Solutions An automated remote mechanism that performs repetitive tasks while generating little or no secondary waste is an option for high-radiation environments. If lower levels of radiation can be achieved through decontamination, then manual dismantlement and entombment with no dismantlement are also options. 


\section{Section 1.5 Materials Disposition}

Baseline Current baseline technologies include burial, size reduction, and visual Technologies segregation. However, burial requires continuous surveillance and maintenance.

Deficiencies Several deficiencies characterize current baseline technologies for materials disposition. We are limited by diminishing landfill space, increasingly restrictive environmental regulations, and our inability to recycle or reuse buried waste. Size reduction is labor intensive and it produces secondary waste; contaminated materials must still be disposed of.

Solutions Segregation and volume reduction improvements as well as entombment are options. Metals reuse is another option that is being investigated under the fuel reprocessing ID.

\section{Section 1.6 Robotics and Automation}

Baseline Currently, the baseline technologies for the D\&D of equipment in Technologies high-radiation environments are limited to master-slave manipulators, cranes, crawlers, mobile platforms, and remote monitoring and surveillance.

Deficiencies The deficiencies associated with current robotics and automation baseline technologies are the lack of such technologies needed to perform in situ characterization, decontamination, and dismantlement of equipment in high-radiation areas in hot cells. The current technologies and equipment are either archaic or unreliable, or have limited access capabilities (e.g., operate at floor level only or are too big to be used in hot cells).

Solutions Reliable robotics and automation (e.g., smaller pipe crawlers, micro robotics, robotics operating further from the floor) would solve many of the problems associated with using current baseline technologies for characterization, decontamination, and dismantlement of equipment in hot cells. These systems must be able to operate in high-radiation fields, handle large pieces of equipment, be mobile and modular, and be able to support 3-D modeling and virtual reality applications.

\section{Section $1.7 \quad$ Regulation}

No unique regulations exist. Future burial regulations may require treatment of buried waste.

\begin{tabular}{ccc}
\hline G-4 & $\begin{array}{c}\text { January } 1994 \\
\text { Revision } 0\end{array}$ & $\begin{array}{c}\text { Technical Program Plan for the Transitioning. } \\
\text { Decommissioning, and Final Disposition Focus Area }\end{array}$
\end{tabular}




\section{Section 1.8 Management and Systems}

Recycling is not addressed in this ID because the fuel reprocessing ID is looking at the viability of recycling highly contaminated equipment.

\section{Section 2 Description of the Proposed Integrated I emonstration}

The ID provides an integrated solution across six technology areas. This ID does not address regulatory issues.

Industry involvement is integral to the success of the decontamination demonstration and the robotics development. Various vendors have demonstrated decontamination techniques and robotics capabilities. The experience would be used as a springboard for this ID.

The potential payback is 6.5 FTEs (greater than or equal to $\$ 1.3$ million) from future IDs (e.g., fuel-reprocessing equipment), more than $\$ 10$ million from speeding up the 324 B-cell cleanup and a similar quantity from shortening other times for D\&D of hot cells and canyons (e.g., 100 cells/canyon; cells $x$ $\$ 10$ million $=\$ 1.0$ million $)$.

Many national laboratories will be involved in this ID. INEL and PNL are recommended to lead the effort, with SNL, SRTC, and others offering expertise in robotics and sensors and, possibly, in developing decontamination solutions.

Current technologies being used in 324 B-cell have proven cumbersome, unreliable, inefficient, and time consuming. Specifically, characterization has involved, but may not have been confined to, using operational records and lab sampling techniques; removal of dust and debris has used simple mechanical systems that cause dust and contamination to become airborne, resulting in secondary contamination and filter problems. Past dismantling has used inexpensive, unreliable tools that become waste. Also, waste disposal has been very costly since the one lab sample showed hazardous constituents. All waste is considered remote-handled mixed waste.

Using current methods has led to a need for better and faster techniques in characterization, with improved accuracy and discrimination and a 3-D mapping capability. Decontamination requires improved techniques in the dry decontamination area for breached piping, vessels, and liners, improved wet decontamination techniques (e.g., faster, non-hazardous, reduced secondary waste) and in improved methods for removing dust and debris, reducing airborne particulate matter to provide a capability to get under equipment, and do so faster. Dismantling needs improved methods for reducing airborne 
particulates and improved speed and efficiency. Materials disposition needs improved segregation involving real-time characterization to improve timeliness, and improved volume-reduction technology. Reduction of secondary waste generation is an area for improvement for all D\&D functions.

This ID could be achieved in three years' time. Because of ongoing D\&D work at 324 B-cell at PNL and because of the identification oi potential equipment improvements that have resulted from the work to date, PNL is recommended for demonstration of doored hot cell equipment. INEL is recommended for the top-hatch equipment $D \& D$ demonstration due to a large number of top-hatched hot cells at that location

This dernonstration is applicable to hot cell equipment (highly contaminated in a high-radiation field); if successful, it would also be applicable to canyon equipment. Hot cells and/or canyons are found throughout the complex and, therefore, provide an opportunity for tremendous cost savings to DOE. This demonstration would also provide opportunities to industry.

The exact savings is unknown at this time. As mentioned earlier, however, $\$ 1.3$ million could be saved from the fuel-reprocessing demonstration, $\$ 10$ million from 324 B-cell cleanup and from each hot cell and canyon across the complex.

\section{Section 2.1 Activities}

This ID will consist of activities similar to those of any of the recommended D\&D IDs defined elsewhere in this document. Initially, for eact. of the major D\&D functions (characterization, decontamination, dismantling, and waste disposal) and robotics, the laboratories will work with industry to improve existing technologies for application in a hot cell environment. These improved technologies will then be applied to the problems of dust and debris removal and equipment removal in a hot cell environment. Follow-on studies and documentation will be performed as needed after each of the activities described below.

Characterization activities will support development of radiation and hazardous materials sensors, and technologies for remote capabilities. The sensor development will be performed to improve accuracy, discrimination and timing (real-time preferred, especially for segregation purposes), and to provide a 3D mapping capability (a 3D mapping capability of initial conditions will allow for segregation to start during decontamination). The remote capabilities improvements are addressed under Robotics/Automation. Characterization field implementation will be coordinated with decontamination and dismantlement activities. 
Decontamination activities will be performed to show improvements in dry and wet decontamination techniques and to show improved methods for dust and debris removal. Several technologies will be developed under the decontamination activities. Cryogenics dry decontamination will be improved ( made faster, provide more coverage, and be usable on smaller circumference piping) under an INEL lead with industry involvement. Dust and debris removal technologies and a modular filtration systems (for use with the dust and debris removal systems and the dismantling systems) will be improved (made faster, enabled to clean from under equipment, and reduce airborne dust) under PNL with other laboratories and industry input. Wet decontamination solutions will be improved (made non-hazardous, reduce secondary waste generation, made faster acting) under a PNL lead with industry involvement. Robotics and remote systems will be developed for this task under the robotics and automation task. Field demonstrations will be performed prior to integration into on-going field activities.

Dismantling activities are to demonstrate segregation and waste volume reduction technologies. Since the fuel reprocessing $\mathrm{ID}$ is to demonstrate recycling of highly contaminated equipment, recycling was not addressed in this ID. Dismantling will be performed to show capabilities for cells with doored entry and cells with top-hatch entry. The equipment decontaminated in the decontamination demonstration will be used for this demonstration.

The dismantlement development activity is for integrating the filtration system developed/improved under the decontamination development, and modification of a system being developed for BWID. Current dismantling technologies were assumed efficient for non-hatch dismantling and were not to be improved beyond filtration for this demonstration. The filtration integration is to assure the filtration system developed under the decontamination task would be applicable to the chosen dismantling technologies. It may involve some modification of the dismantling technologies to assure a common interface. The BWID system modification will piggyback off an ongoing project to deveiop a dismantling system which will operate through a hole (effectively a top hatch). The development is to provide a dismantling capability through a top hatch entry.

Materials disposition activities will be performed to demonstrate improvements to waste segregation and volume reduction. Material disposition development is planned for robotics/remote capabilities improvements addressed under robotics and automation and characterization improvements to enable in-cell segregation, which were developed under the characterization task. Specific segregation benefits to be demonstrated are being able to perform in-cell segregation in a timely manner, and being able to perform in-cell volume reduction with lowered secondary waste generation.

Technical Program Plan for the Transitioning.

Decommissioning, and Final Disposition Focus Area
January 1994

Revision 0
G.7 
The robotics and automation activities are strictly development. Robotics and automation is the development of integrated systems to be used throughout the D\&D tasks. Remote capabilities will be developed for characterization, dust and debris removal, equipment decontamination and segregation. Field testing and integration are planned in coordination with other systems for each of the D\&D functions.

\section{Section $2.2 \quad$ Deliverables}

Project activities will be documented through progress reports, cost/benefit analysis, and a final report.

- Progress reports will include information related to development and demonstration of characterization methods, robotics, and dismantlement.

- A comparative cost/benefit analysis addressing decontamination efforts will include a report on development and demonstration of a system to remove dust and debris, the development and demonstration of a dry decontamination application, and the demonstration of minimal secondary waste-generating wet decontamination application.

- A final report on the segregation and volume reduction activities for debris and equipment will detail the development and comparative costs and benefits of the demonstration of the system. The final report will address the project activities, accomplishments, lessons learned, and recommendations. 


\section{Section 2.3 Reasons for Pursuing the Proposed ID Now (versus Later)}

- The reason to pursue the proposed ID now, with higher expenditures in the first year, is because D\&D of 324 B-cell is ongoing. People are available to perform the actual demonstrations; the needed technology requirements have been identified; the potential technologies to pursue have been identified; and baselines exist for characterization, decontamination, dismantling, and materials demonstration. The baselines will provide a comparative basis for determining the benefits of the demonstrated technologies. Also, since 324 B-cell is being decontaminated, there is a potential for costsharing with EM-30 and EM-40, at least in the running of the demonstrations. Waiting to perform a similar ID on another hot cell will be more costly because the EM-30/-40 work will have been lost for comparison, and cost sharing may not be possible for actually performing the ID.

- Pursuing this ID early may also reduce later ID cost if the characterization demonstration is successful. Characterization lessons learned may also feed into later research to be tested in the other proposed IDs.

- Although 324 B-cell is driving the need to perform this ID early, INEL is also available in this time frame for performing the characterization and other demonstrations. Characterization has already been performed at $324 \mathrm{~B}$-cell.

- Pursuing this ID will also provide the D\&D program an early success. If this ID is delayed, there will be no early success for the $\mathrm{D} \& \mathrm{D}$ program because the delay will not only add the delay time, but will also add time for needed technology identification, which has been done by EM-30 and EM-40 in the B-Cell case.

- Most of the benefits will not be realized unless this ID is pursued early. 


\section{Section $3 \quad$ Benefits}

The following are the benefits of successfully completing the proposed ID:

- potential savings of approximately $\$ 20 \mathrm{M}$ associated with an ongoing D\&D project

- shared approach due to ongoing D\&D project and available manpower, training, and equipment

- visibility of immediate D\&D response

- improved techniques in characterization, debris removal, dry/wet decontamination, segregation, volume reduction, and remote/robotic dismantlement

- the D\&D ID program benefits from an early victory demonstrating D\&D techniques

- future IDs benefit from demonstrated results of this ID

- segregation techniques, volume reduction, and innovative decontamination applications result in reduced waste

This ID is applicable to other D\&D problems throughout the DOE Complex.

- Similar cost savings are applicable to the Complex-wide hot cells and process cells (potentially, $\$ 2 \mathrm{~B}$ for 100 cells).

- DOE will benefit from private industry's development of innovative decontamination applications.

- Private industry will benefit by developing and demonstrating innovative techniques.

- Successful demonstration of the ID techniques will show ine viability of using these techniques in high-radiation, confinedspace environments (e.g., hot cells, canyons, processing facilities, and reprocessing facilities). There are potentially hundreds of applicable sites.

Cost benefits associated with the proposed ID are as follows:

- cost savings of potentially $\$ 20 \mathrm{M}$ immediate payback and, potentially, \$2B Complex-wide

- low demonstration costs for a high payback 


\section{Section $4 \quad$ What Cannot Be Done Between FY 94 and FY 99}

All of the activities proposed for this ID can be completed between FY 94 and FY 99.

\section{Section $5 \quad$ Locations}

The table below lists the DOE sites with hot cell facilities, their relationships to each other, and the current justification for a D\&D ID.

\begin{tabular}{|c|c|c|c|c|}
\hline DOE Sites & $\begin{array}{c}\text { Potential } \\
\text { Commerclal } \\
\text { Sites }\end{array}$ & $\begin{array}{c}\text { Relationships } \\
\text { between } \\
\text { Sites/Functions }\end{array}$ & $\begin{array}{l}\text { Technical } \\
\text { Justification }\end{array}$ & $\begin{array}{l}\text { Financlal } \\
\text { (or Other) } \\
\text { Justiflcation }\end{array}$ \\
\hline $\begin{array}{l}\text { Hantord-PNL } \\
324 \text { B-Cell }\end{array}$ & $\begin{array}{l}\text { Industrial } \\
\text { partners }\end{array}$ & $\begin{array}{l}\text { Lead for development } \\
\text { of decontamination } \\
\text { solutions, filtration } \\
\text { system, and } \\
\text { dust/debris removal; } \\
\text { demonstration of the } \\
\text { developments, the } \\
\text { dust/debris } \\
\text { segregation system } \\
\text { and dismantlement }\end{array}$ & $\begin{array}{l}\text { Worst case for } \\
\text { dust/debris, high } \\
\text { radiation fields; } \\
\text { availability of facility, } \\
\text { manpower, and } \\
\text { equipment, potential } \\
\text { cost-sharing, ongoing } \\
\text { effort }\end{array}$ & $\begin{array}{l}\text { Shared EM-30/40 } \\
\text { costs. Piggyback to } \\
\text { an ongoing D\&D } \\
\text { activity }\end{array}$ \\
\hline $\begin{array}{l}\text { INEL-ICPP } \\
\text { WCF Cells } \\
\text { CPP- } 640 \text { Cells }\end{array}$ & & $\begin{array}{l}\text { Development } \\
\text { characterization } \\
\text { techniques, cryo- } \\
\text { decontamination, } \\
\text { robotic/remote, and } \\
\text { dismantlement; } \\
\text { demonstration of } \\
\text { characterization, dry } \\
\text { decontamination, top } \\
\text { hatch dismantlement } \\
\text { and equipment } \\
\text { segregation system }\end{array}$ & $\begin{array}{l}\text { Facilities for confined } \\
\text { space, high radiation } \\
\text { levels, and limited } \\
\text { access; availability of } \\
\text { facilities }\end{array}$ & $\begin{array}{l}\text { Some EM-40/30 } \\
\text { shared costs }\end{array}$ \\
\hline National laboratories & & $\begin{array}{l}\text { Development of } \\
\text { characterization } \\
\text { mapping, sensors, } \\
\text { and robotics }\end{array}$ & $\begin{array}{l}\text { Ongoing TTP } \\
\text { activities can be } \\
\text { modified to include } \\
\text { requests for ID }\end{array}$ & $\begin{array}{l}\text { Using existing TTP } \\
\text { programs and } \\
\text { opportunity of cost } \\
\text { sharing }\end{array}$ \\
\hline
\end{tabular}

Technical Program Plan for the Transitioning.

Decommissioning, and Final Disposition Focus Area
January 1994

Revision 0 


\section{Section 6 ID Schedule and Costs}

The following table summarizes the costs (in millions) of this ID over its entire lifespan.

\begin{tabular}{|l|c|c|c|c|c|c|c|}
\hline & Year 1 & Year 2 & Year 3 & Year 4 & Year 5 & Year 6 & Total \\
\hline Characterization & 1.125 & 1.000 & 0.125 & & & & 2.250 \\
\hline Decontamination & 0.750 & 0.625 & 0.250 & & & & 1.625 \\
\hline Dismantiement & 0.125 & 0.625 & 0.125 & & & & 0.875 \\
\hline Materials Disp. & & 0.125 & 0.375 & & & & 0.500 \\
\hline Robotics \& Auto. & 1.500 & 1.000 & 1.000 & & & & 3.500 \\
\hline Mgmt. \& Sys. & 0.330 & 0.340 & 0.830 & & & & 1.500 \\
\hline Total & 3.830 & 3.715 & 2.705 & 0.000 & 0.000 & 0.000 & 10.250 \\
\hline
\end{tabular}


Hot Cells Domonstration Path

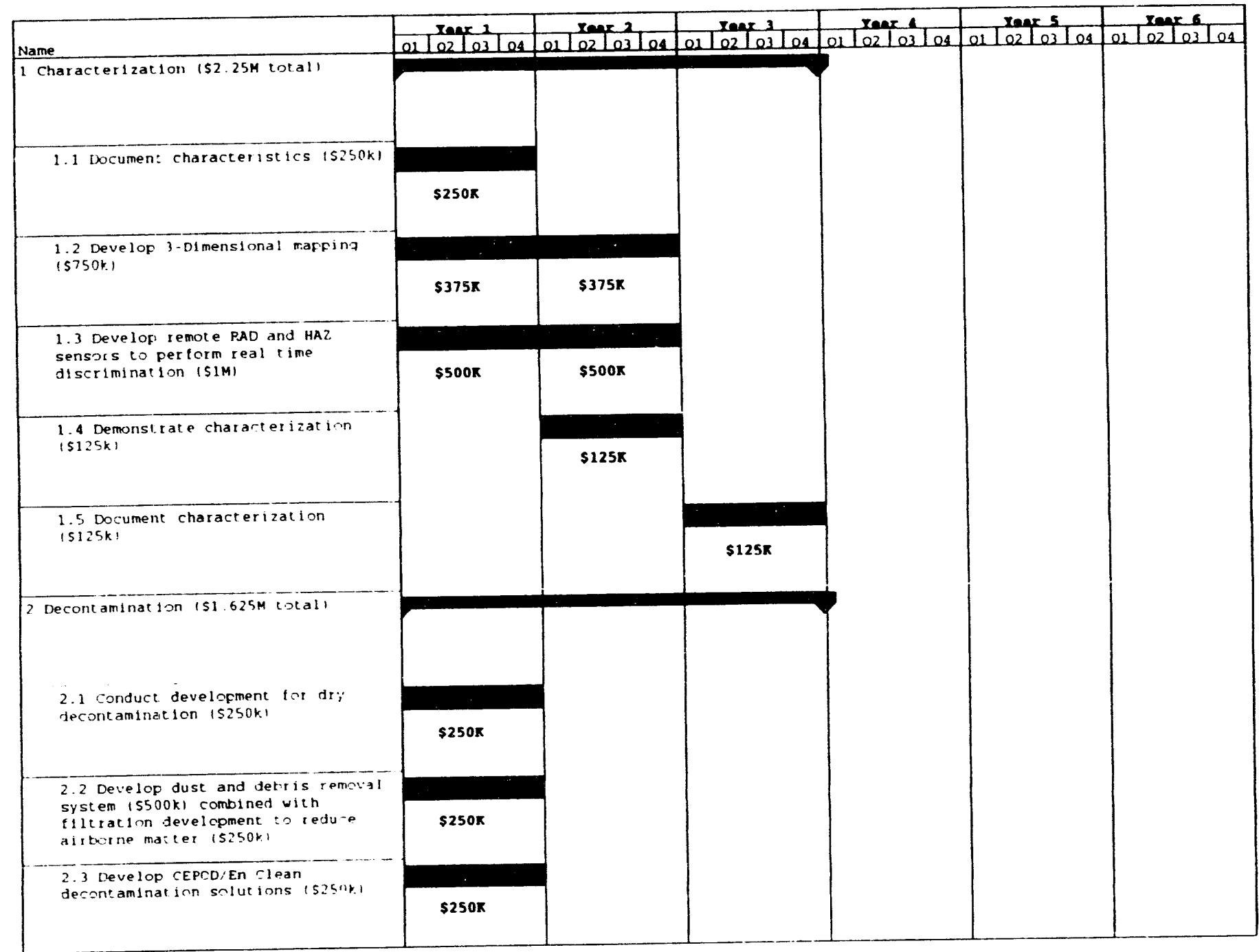




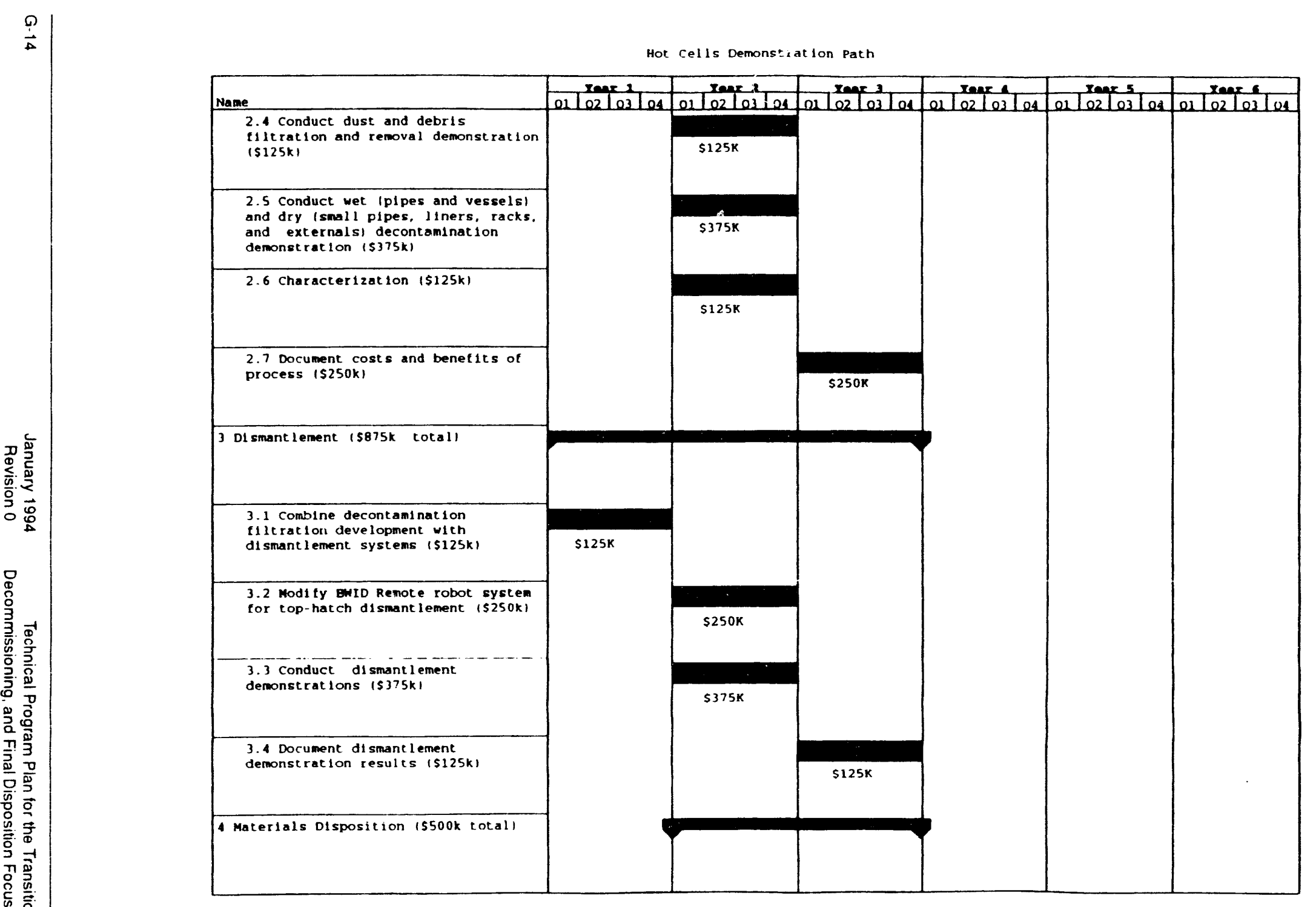


Huc rells Demonst ration patt

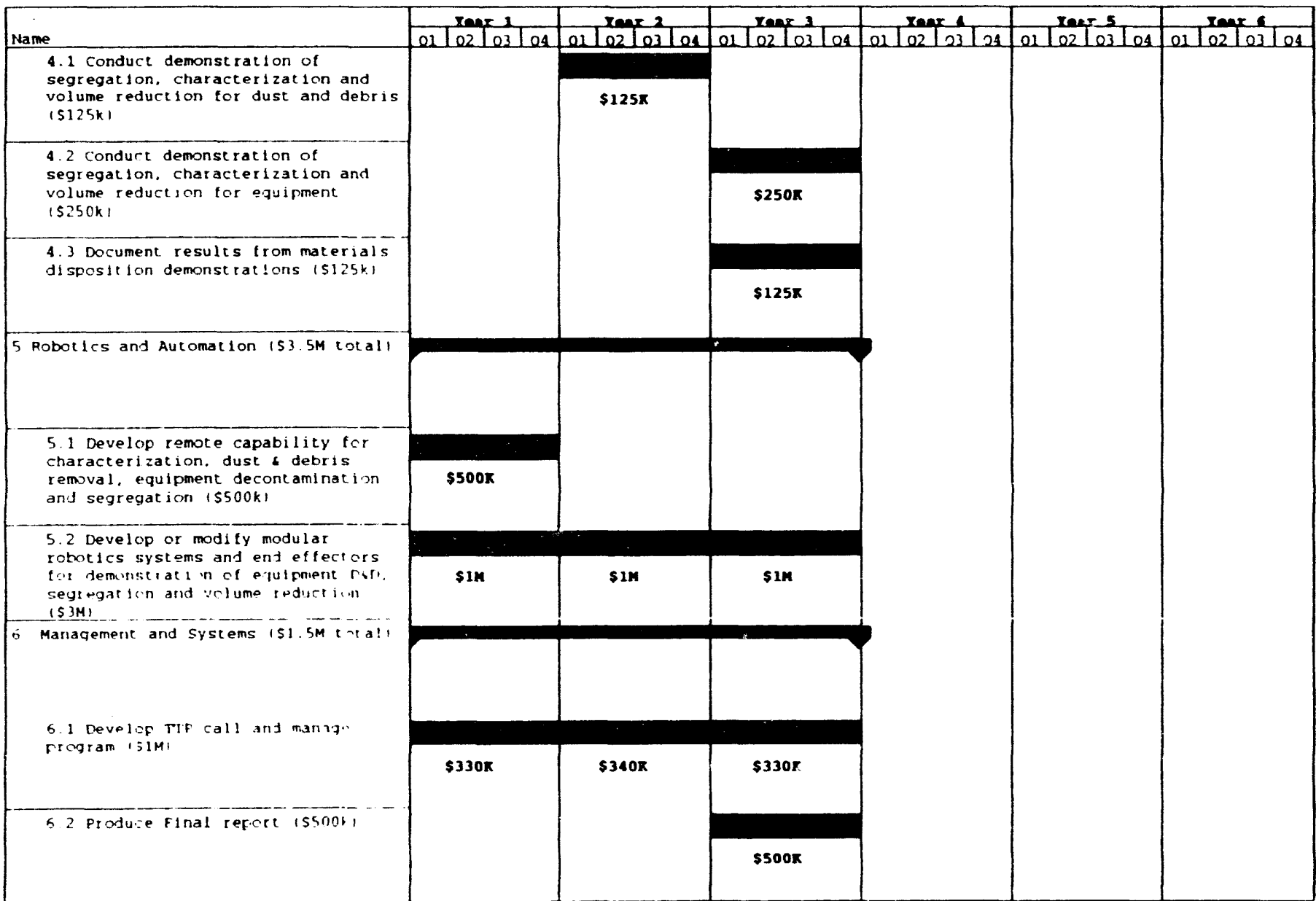


Hot Cells

Appendix G

Highly Contaminated Equipment 


\section{Appendix H}

\section{Lithium-processing Facilities}




\section{Process Equipment}

\section{Section 1 Situation Analysis}

\section{Section 1.1 Problem Definition}

Mercury-contaminated process equipment can be found in lithium processing facilities at the Department of Energy's Y-12 Plant and poses certain unique D\&D challenges. Similar types of problems exist at commercial facilities, including mercury mining and chlor-alkali facilities. Mercury is a highly toxic substance which, with excessive exposure, can lead to human and animal symptoms of heavy metal poisoning. Although relatively minor levels of mercury contamination exist at several sites within the DOE complex, addressing mercury contamination issues is a major task for the lithium processing facilities at $Y-12$. There is an estimated 7,000 tons of mercury-contaminated equipment at one $Y-12$ facility alone. Mercury contamination is a near-term issue for this Y-12 Plant facility, Building 9201-4, currently in the EM-40 Program; D\&D planning for this facility is currently underway.

\section{Section 1.2 Characterization}

Baseline

Technologies

Current baseline technologies include standard characterization methods: core and smear sampling and subsequent laboratory analysis. Because the accuracy of these methods has been proven, there has been little change over the last few years. The costs associated with baseline technologies for characterization vary depending on the installation.

Deficiencies There are several deficiencies associated with current baseline technologies for characterization. Sampling is usually non-discriminatory, is limited by restricted access and the risk of worker exposure, and creates secondary waste. In addition, the capacity of laboratories where the samples are analyzed is limited and the analytic methods are oftentimes slow and cumbersome. Excessive sampling may be required to ensure a homogeneous representation of the material.

The risks associated with current baseline technologies for characterization correspond primarily to worker exposure and industrial safety issues. There are also some risks with transporting samples. In addition, there is an uncertainty associated with defining the samples as a homogenous representation of the equipment contamination.

$\begin{array}{ccc}\text { H.2 } & \begin{array}{c}\text { January } 1994 \\ \text { Revison } 0\end{array} & \begin{array}{c}\text { Technical Program Plan for the Transitioning, } \\ \text { Decommissioning, and Final Disposition Focus Area }\end{array}\end{array}$


Solutions The most meaningful solution to the problems associated with using current baseline technology for characterization is a viable method for a real time, certifiable, field characterization. The tools and methods should include statistical sampling plans to ensure that the equipment is completely characterized. This will minimize the number of samples sent to the laboratory and secondary waste generation as well. This is the best solution because it reduces worker exposure and is more efficient; however, it depends on the design of a remote delivery system.

\section{Section 1.3 Decontamination}

Baseline Current baseline technologies for mercury decontamination rely primarily on Technologies thermal desorption (roasting). Roasting is widely used for small contamination problems. It is currently the BDAT defined by EPA for mercury treatment.

Deficiencies There are several deficiencies associated with the use of thermal desorption for decontamination: negative public perception, uncertain regulatory acceptance, and reduced worker efficiency. There are uncertainties associated with the condensing of the vaporized mercury following the roasting process. There inust be a method for inventorying the mercury contained in the equipment and assuring that all of it is recovered in the condensing process and so ensure that the equipment is clean. Moreover, there are some uncertainties about whether mercury air emissions requirements can be met during the roasting process.

In order to use thermal desorption, contaminated equipment must first be disassembled, pre-cleaned, and sized for the treatment facility. Disassembly and pre-cleaning are labor intensive, time consuming, and costly, and have yet to be proven on highly-contaminated equipment.

The risks associated with the use of thermal desorption for decontamination correspond primarily to worker exposure and the potential for an environmental insult through the release of large amounts of mercury vapors. As a result, maximized use of PPE and constant surveillance of mercury vapors are required.

Solutions The best solution to the problems associated with using the current baseline technologies for decontamination is a method for inexpensive, in situ decontamination. This will minimize the amount of mercury that must be removed by ex situ roasting and, hence, the costs associated with the roasting technology. 


\section{Section 1.4 Dismantlement}

Baseline Current baseline technologies for dismantlement include rotary saws, Technologies torches, other heat-generating cutting methods, and manual removal. Because the accuracy of these technologies has been proven there has been little change in the last 20 years.

Deficiencies The primary deficiencies associated with the current baseline technologies for dismantlement are increased mercury vapor air emissions, high worker exposure levels to vaporized mercury, safety hazards, secondary waste, the need for PPE, and the fact that it is a labor-intensive process.

The risks associated with current baseline technologies for dismantlement correspond primarily to worker exposure to toxic mercury vapors and mercury vapor air emissions.

Solutions The most meaningful solution to the problems associated with current baseline technologies for dismantlement is an automated mechanism that performs repetitive tasks with little or no secondary waste. The mechanism must be able to disassemble large pieces of equipment without vaporizing the mercury contamination and it must be movable and modular. This solution depends on the robotics technology of remote delivery systems.

\section{Section 1.5 Materials Disposition}

Baseline Current baseline technologies include burial and storage. Though by far the Technologies most expedient method, burial requires continuous surveillance and maintenance, and its viability under current and future regulations is questionable. The costs associated with baseline technologies for materials disposition by burial range from one to four dollars per pound.

Deficiencies There are several deficiencies with current baseline technologies for materials disposition. We are limited by diminishing landfill space, increasingly restrictive environmental regulations, the inability to recycle or reuse buried waste, and the spectre of material resurrection. Size reduction is expensive, is labor-intensive, and produces secondary waste; even after size reduction contaminated materials must still be disposed of.

Solutions The most meaningful solution to the problems associated with using current baseline technologies for materials disposition is a viable means to turn decontaminated scrap materials into products for controlled beneficial reuse and/or free release. This solution is dependent on the willingness and ability of DOE to ensure a market for decontaminated scrap materials.

$\begin{array}{ccc}\text { H.4 } & \begin{array}{c}\text { January } 1994 \\ \text { Revison } 0\end{array} & \begin{array}{c}\text { Technical Program Plan for the Transitioning, } \\ \text { Decommissioning, and Final Disposition Focus Area }\end{array}\end{array}$




\section{Section $1.6 \quad$ Robotics and Automation}

Baseline Currently, there are no robotic or automated baseline technologies for the Technologies decontamination of lithium process equipment.

Deficiencies The deficiencies associated with current robotics and automation baseline technologies are the lack of technologies needed to perform in situ characterization, decontamination, and dismantlement of contaminated equipment.

Solutions Sophisticated robotics and automation may solve many of the problems associated with using current baseline technologies for characterization, decontamination, and dismantlement of contaminated equipment.

\section{Section $1.7 \quad$ Regulation}

All of the approaches and solutions that we have recommended can work under the existing regulations. In order for these approaches and solutions to succeed, however, the public must be educated about, encouraged to participate in, and made aware of the benefits of recycling and the benefits of reuse. Moreover, it is meaningless to talk about recycling materials from decontaminated equipment while we lack a realistic de minimis level for free release.

\section{Section $1.8 \quad$ Management and Systems}

This demonstration is to be coordinated with the metals recycle demonstration if possible.

To be beneficial, this demonstration must be coordinated with the onset of 9201-4 facility D\&D activities, scheduled to begin in FY98. Although EM-40 is funding some technology development activities, continued integration of this demonstration with the currently funded EM-40 activities will ensure that there is no duplication of efforts and that information from both sets of activities is used by both the integrated demonstration and the EM-40 activities as applicable. 


\section{Section 2 Description of the Proposed Integrated Demonstration}

\section{Section 2.1 Qualifications}

This integrated demonstration will include the pre- and post-characterization of the lithium processing equipment for mercury contamination, the removal of the contaminant, removal of the equipment, and disposition of the mercury and equipment. The following technologies may be applicable to the removal of mercury contamination from process equipment: hot air flow through equipment; heated inert gas flow through equipment; cutting methods that do not generate mercury vapors; high-pressure flushing of equipment; induction heating of equipment; modular containment; and a mercury containment/recovery system. We expect to use existing technologies available through commercial vendors, as appropriate, and to involve commercial entities to assure commercialization of emerging technologies. The ID will produce an integrated solution to the mercury-contaminated equipment problem for implementation by the customer.

This is a field demonstration which will provide some laboratory work related to characterization and decontamination before the full demonstration can proceed. We expect that work in support of other demonstrations related to dismantlement and robotics will also provide technology applicable to this ID.

\section{Section $2.2 \quad$ Deliverables}

- characterization technologies and techniques

- mercury removal techniques

- large equipment dismantlement techniques

- mercury recycle requirements 


\section{Section 2.3 Reasons for Pursuing the Proposed ID Now}

In the Y-12 facility $9201-4$, mercury continues to be released to the environment through monitored air emissions and it has the potential for release into the surrounding soil. The EM-40 customer organization is currently pursuing the cleanup of this facility and is int : " $, \cdots: \cdots$;afer, and cheaper techniques. Personnel are available who $r n, n$, who understand the processes: this information can be $\ldots+\ldots, g$ the problem. In addition, mercury cleanup of East Fork Pop r $C_{1} \mathrm{~s}_{2}^{\prime}$, which runs through the Y-12 Plant and into the city of Oak Ridge, is in progress in order to meet CERCLA and Clean Water Act NPDES requirements. Pursuing this D\&D ID now would help in minimizing the potential for contaminating a rehabilitated area during the subsequent $D \& D$ activities.

\section{Section $3 \quad$ Benefits}

The following are the direct benefits of successfully completing the proposed ID.

- reduced mercury releases to the environment

- additional metals for recycle

- new mercury chamrarization and decontamination techniques for industrial use

The following are the $\iota$ is to EM.

- reduced worker exposure to mercury

- minimal environmental insult from mercury-contaminated equipment in the event of fire or other hazard

- increased public support for activities

- projected cost savings of $\$ 80$ million in the D\&D of $9201-4$ from estimated $50 \%$ reductions in PPE usage, lab analysis for characterization, and amount of metal processing equipment requiring ex situ treatment (thermal desorption).

The following are the benefits to the DOE Complex.

- new technology for measuring mercury inside equipment

- new technology for removing mercury from the inside of equipment

- in situ cleanup techniques for process facilities which were placed in stand-by status before decontamination 


\section{Section 4 What Cannot Be Done between FY-94 and FY-99}

- minimization of vapor emissions from the 9201-4 facility caused by activities not addressed in this demonstration

- decontamination of other buildings and/or equipment outside the $9201-4$ facility

- decontamination/dismantlement/disposal of any of the classified process equipment in the $9201-4$ facility

- recycle of recovered mercury and metals

\section{Section $5 \quad$ Locations}

The Y-12 Plant is the recommended site for this demonstration; specifically, it is proposed that the demonstration be conducted at the $9201-4$ facility. Since the majority of the mercury contamination issues reside at the Y-12 Plant facilities, the use of 9201-4 would provide an optimum demonstration of the technologies. In addition, the demonstration would be effective in addressing ancillary issues, such as regulatory approach and safeguards/security aspects, which tend to be site-specific. This information would be used in further D\&D planning activities for both the 9201-4 facility and other potential facilities.

\section{Section $6 \quad$ Assumptions}

This proposal assumes that all recyclable metals will be processed by DOE's metal recycling efforts and does not address the mechanism for recycling of the metals other than to attempt to recycle the metals generated by the demonstration itself.

Section $7 \quad$ Issues

- What is the de minimis mercury concentration limit for recycle and/or free release of mercury-contaminated metals?

- Will this process be acceptable to the public?

- Will free release of previously mercury-contaminated equipment be allowed by the regulators? 


\section{Section $8 \quad$ ID Schedule and Costs}

The following table summarizes the costs (in millions) of this ID over its entire lifespan.

\begin{tabular}{|l|c|c|c|c|c|c|c|}
\hline & Year 1 & Year 2 & Year 3 & Year 4 & Year 5 & Year 6 & Total \\
\hline Characterization & 0.440 & 0.480 & 0.480 & 0.520 & 0.400 & & 2.320 \\
\hline Decontamination & 0.160 & 0.140 & 0.500 & 0.400 & 2.400 & & 3.600 \\
\hline Dismantlement & 0.224 & 0.284 & 0.372 & 0.240 & 0.120 & & 1.240 \\
\hline Materials Disp. & 0.064 & 0.032 & 0.021 & 0.067 & 0.040 & & 0.224 \\
\hline Robotics \& Auto. & 0.267 & 2.807 & 2.792 & 2.083 & 0.453 & & 8.402 \\
\hline Mgmt. \& Sys. & 0.066 & 0.044 & 0.010 & 0.030 & 0.010 & & 0.160 \\
\hline Total & 1.221 & 3.787 & 4.175 & 3.340 & 3.423 & $\mathbf{0 . 0 0 0}$ & $\mathbf{1 5 . 9 4 6}$ \\
\hline
\end{tabular}


Lithium vemonstration Path

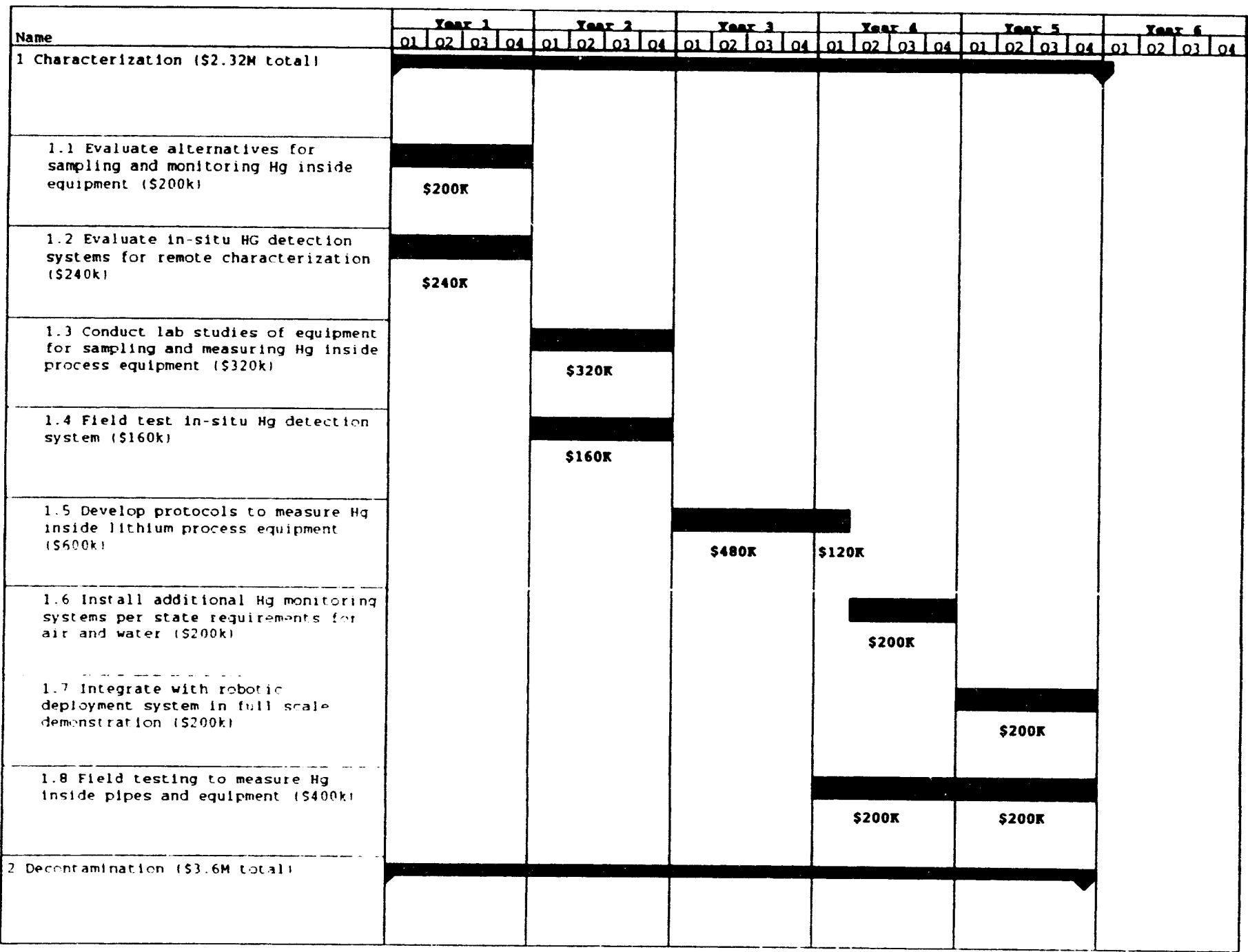


Lithlum Demonstration Path

\begin{tabular}{|c|c|c|c|c|c|c|}
\hline Name & 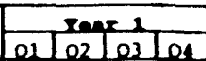 & 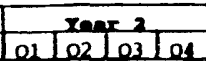 & \begin{tabular}{|l|l|l|l|}
\multicolumn{3}{|c|}{ Yane 3} \\
01 & 02 & 03 & 04 \\
\end{tabular} & 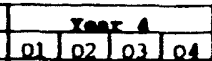 & 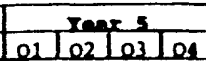 & toulour \\
\hline $\begin{array}{l}2.1 \text { Evaluate methods to } \\
\text { decont aminate } \mathrm{Hg} \text { inside pipes and } \\
\text { equipment } 152001\end{array}$ & $\$ 160 \mathrm{~K}$ & $40 \mathrm{~K}$ & & & & \\
\hline $\begin{array}{l}2.2 \text { Conduct lab studies of } \\
\text { techniques to decont aminate } \mathrm{Hg} \\
\text { Inside pipes and equipment }(5200 \mathrm{k})\end{array}$ & & $\$ 100 \mathrm{~K}$ & $100 \mathrm{~K}$ & & & \\
\hline $\begin{array}{l}2.3 \text { Devel op equipment for } \\
\text { decontaminat } 1 \text { on inside lithium } \\
\text { equipment }(5800 \mathrm{k})\end{array}$ & & & $\$ 400 K$ & $5400 \mathrm{~K}$ & & \\
\hline $\begin{array}{l}\text { 2. Conduct Fleld demonstration of } \\
\text { in-situ decontamination of inside of } \\
\text { 11thium process equipment. } 152.4 \mathrm{M} \mid\end{array}$ & & & & & $52.4 \mathrm{M}$ & \\
\hline 301 smant lement $151.24 \mathrm{M}$ total) & & & & & & \\
\hline $\begin{array}{l}\text { 3.1 Develop concept of } 11 \text { thi um } \\
\text { dismant lement system }(\$ 160 k)\end{array}$ & $\$ 128 \mathrm{~K}$ & $\$ 32 K$ & & & & \\
\hline $\begin{array}{l}\text { 3.2 Design and Initlate procurement } \\
\text { of dismant lement prototype }(5480 \mathrm{k})\end{array}$ & $596 \mathrm{~K}$ & $\$ 192 K$ & $\$ 192 \mathrm{~K}$ & & & \\
\hline $\begin{array}{l}\text { 3.3 Design and select } 5-6 \text { tooling } \\
\text { concepts }(5120 \mathrm{k})\end{array}$ & & $560 \mathrm{~K}$ & $560 \mathrm{~K}$ & & & \\
\hline $\begin{array}{l}3.1 \text { Procure and implement cest of } \\
\text { ma jor component }(\$ 280 \mathrm{k})\end{array}$ & & & $596 \mathrm{~K}$ & $5187 \mathrm{~K}$ & & \\
\hline $\begin{array}{l}3.5 \text { Develop tooling specifications } \\
\text { and procure } 2-3 \text { (580k) }\end{array}$ & & & $\$ 27 k$ & $553 \mathrm{~K}$ & & \\
\hline
\end{tabular}


Lithium Demunstration Path

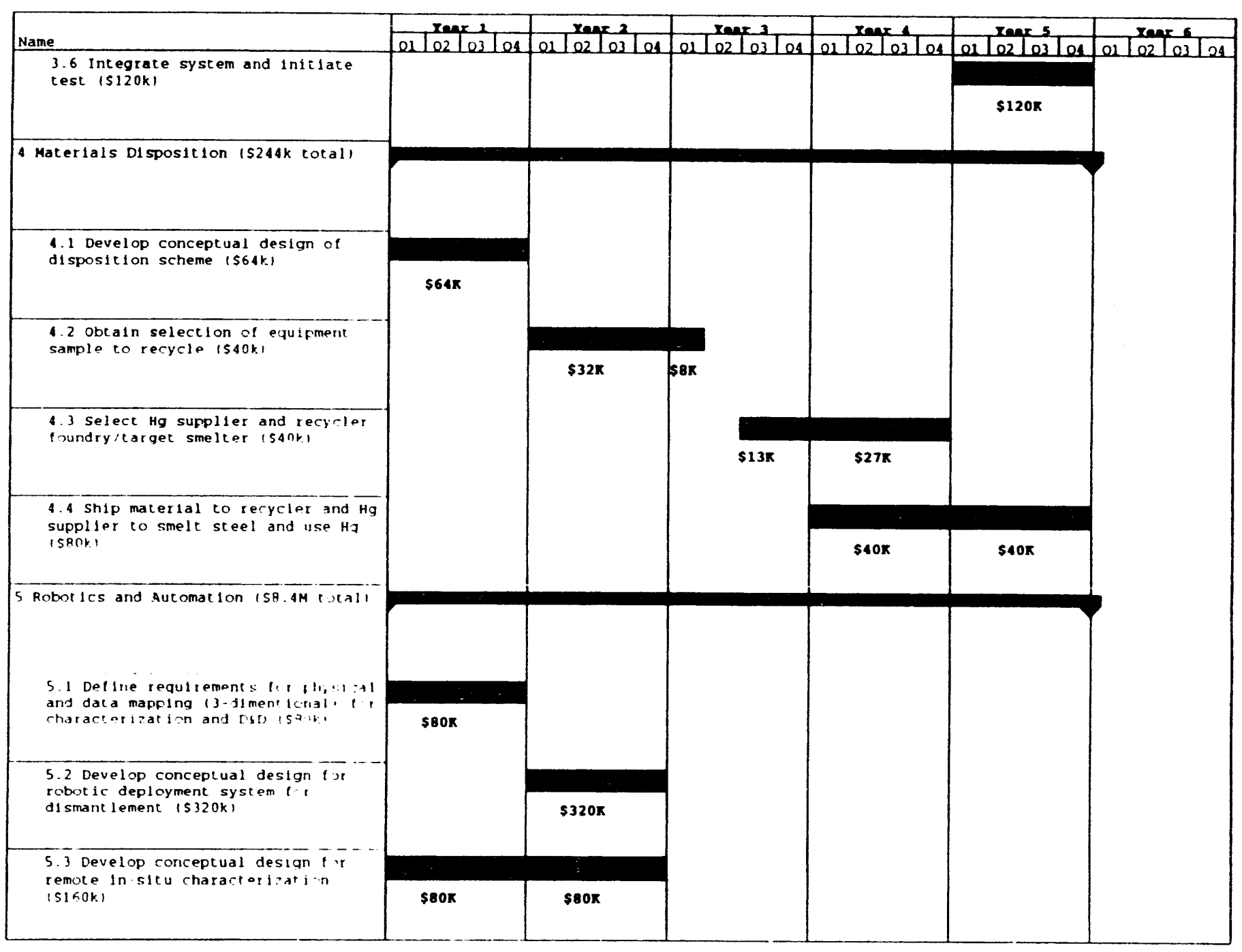


L.1 hilum Demonst rat Ion Fath

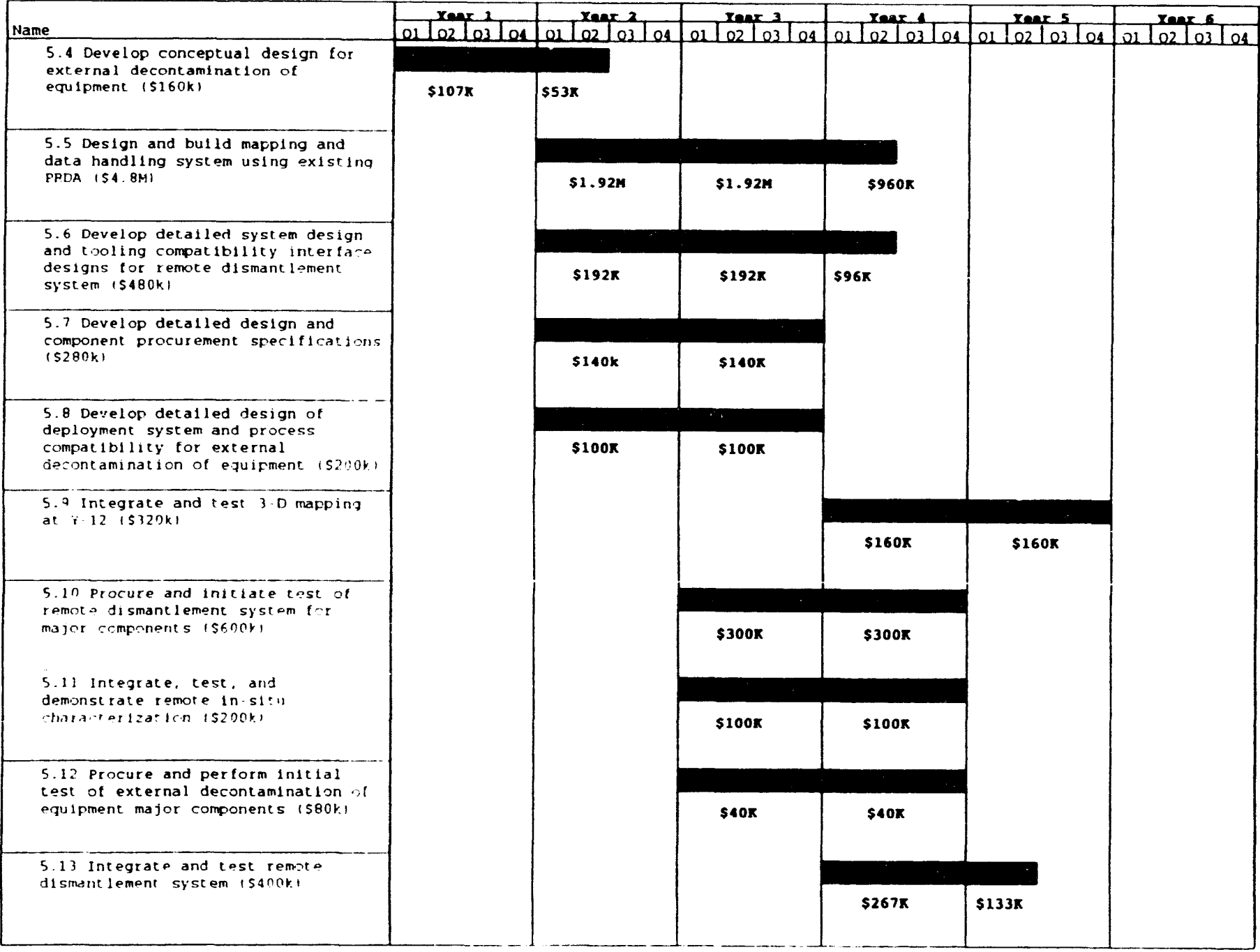




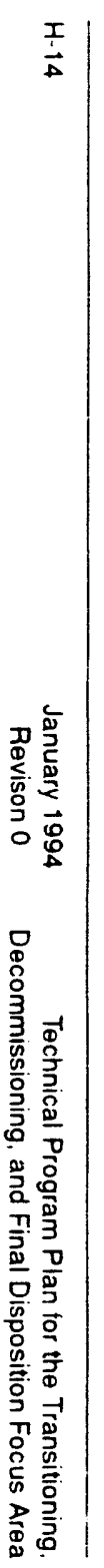

Lathum Demonst rat 1 on Fath

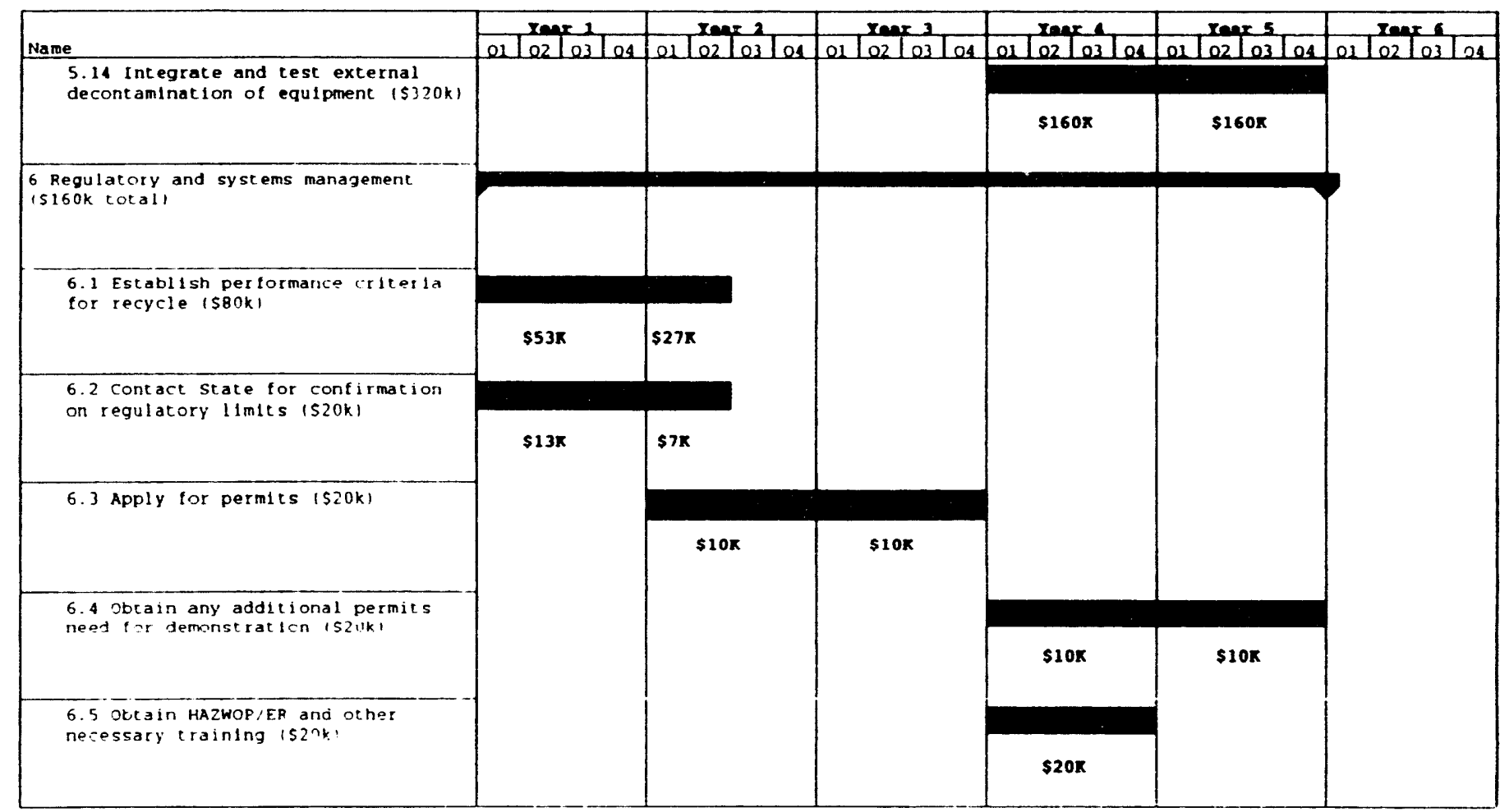




\section{Section 1 Situation Analysis}

\section{Section 1.1 Problem Definition}

Size of Problem Large quantities of scrap metal are accumulating at the various Department of Energy (DOE) installations across the country as a result of ongoing DOE programs and missions in concert with present day waste management practices. Current inventories of scrap metal contaminated with radionuclides are in the order of millions of tons, with additional quantities being generated on a regular basis. Large additions to these scrap metal inventories will occur as environmental restoration and decommissioning programs gain momentum. Exact estimates of the existing contaminated scrap metal inventories, current generation rates, and future generation rates with increased decommissioning programs throughout the entire DOE complex are not available. However, reasonable estimates are available for the sites within the control of the Oak Ridge Operations Office.

Within the Oak Ridge Reservation (ORR), around 500,000 tons of scrap metal are being stored with additional scrap generation at a rate of 1,400 ton/year. ${ }^{1}$ This rate will increase significantly with future D\&D activities. Projections indicate that 775,000 tons of scrap metal could be generated through D\&D at the K-25 site over the next ten years. Similar increases from future D\&D activities may be projected for the other ORR sites including X-10, Y-12, Fernald, Portsmouth, and Paducah. Historically, the typical make-up of the ORR scrap metal is $80-85 \%$ ferrous metal/mild steel and $10-15 \%$ aluminum, with a balance of stainless steel, copper, brass, and nickel. Significant amounts of exotic metals such as tantalum, Inconel, ${ }^{\mathrm{M}}$ and titanium are also encountered. Recent studies on scrap inventories and generation rates at other DOE sites ${ }^{2}$ indicate the following: there are 1100 tons of scrap stored at INEL; 8,800 ton/year are being generated and buried at Hanford; 150 tons/year are being generated and buried at LANL. It is likely that the above scrap inventories and scrap components are similar to those that could be expected for the other operating regions within the DOE complex.

1 H. W. Hayden, M. J. Stevenson, J. K. Bailey, J. R. Weir, W. C. Gilbert, "Contaminated Scrap Metal Management on the Oak Ridge Reservation," presented at the Environmentally Conscious Manufacturing Conference, Arlington, VA. 1 September 1993. 
Problem Locations
Using current baseline technology, it will take generations to characterize, decontaminate, and package the scrap metals for burial. Currently the schedule remains undetermined and will depend on the individual D\&D schedules for each facility. Cost estimates using current baseline technology range from one-half to five dollars per pound for burial, the lowest corresponding to DOE-site (on site) disposal, the highest to commercial disposal.

All DOE and Department of Defense (DoD) installations, domestic commercial facilities and foreign commercial and government facilities that have used nuclear materials currently have inventories of contaminated scrap metals and/or will have such inventories with future D\&D activities. It is likely that the distributions of scrap metal at various DOE sites would be similar to those described above at the ORR. Major portions of the scrap would include mild steel, aluminum alloys and copper alloys, deriving from building structural, architectural, heating, cooling and piping applications. More exotic forms of metal scrap would derive from specific process operations that were carried out at particular sites. Thus, large quantities of nickel scrap and uranium tails (in the form of UF6) are at the gaseous diffusion plants; significant quantities of stainless steel scrap are at the chemical processing facilities; scrap mercury is associated with lithium enrichment processing; specialty stainless steels and nickel-base alloys at nuclear reactor facilities; and so forth.

Much as the nature of the processing operations at individual sites will affect the particular types of metal scrap, these same operations will also affect specific types of radionuclide contaminants in the scrap, as well as the location of the contamination - on the surfaces or within the volume of the metal scrap. Volumetric tritium contamination is expected in scrap at Savannah River, LANL, Mound, Y-12, and Princeton (Tokamac fusion test reactor). Tritiated scrap can also be found in the U.K., China, Russia and France. At uranium-processing facilities, as generated, most of the scrap metal would be surface contaminated with relatively little volumetric-contaminated metal present. Uranium and associated daughter products, mainly thorium-234 and protactinium-234, are likely to be the predominant radionuclides. At those sites involved in processing enriched uranium and plutonium, off-site handling and processing of metal scrap become very complicated because of restrictions related to the handling of special nuclear material (SNM) that are imposed on the private sector by the Nuclear Regulatory Commission (NRC). In these cases, there is no de minimis or BRC concentration that is exempt from NRC regulations. NRC-licensed businesses can have up to 350 grams of SNM on site at any given time. Metal taken from the decommissioned gaseous diffusion process also has significant potential for small quantities of technetium- 99 contamination as a result of recycling uranium from spent reactor fuels, primarily from the Hanford and Savannah 
River plants. Trace quantities of transuranic elements such as plutonium-239 and neptunium-237 may also be found. Nuclear fission by-products such as cesium-137 and strontium-90 and activation products such as cobalt-60 are the primary contaminants found on process scrap generated at facilities having reactor operations.

\section{Section 1.2 Characterization}

Baseline Technologies

Current baseline technologies for scrap having surface contamination include standard characterization methods: smears, wipes, hand-held instrumentation, and statistical sampling. There has been little change in characterization methods in the last 20 years. Though reliable and proven, these methods are laborious and time consuming, and there is a substantial risk of worker exposure. The costs associated with baseline technologies for characterization vary, depending on the installation, the nature of the contaminants, and the complexity of the shapes and morphology (surface to volume ratio) of the articles of the contaminated scrap.

Deficiencies There are several deficiencies associated with current baseline technologies for characterization. The methods available to us are slow, labor intensive, and do not accommodate real-time monitoring. We have neither the tools nor the technology to accurately characterize complex shapes and forms (e.g., pipes, equipment) in situ. Technologies for reliable characterization of volumetrically contaminated scrap are not available.

The risks associated with current characterization technology are primarily worker exposure.

Solutions The most meaningful solution to the problems associated with using current technology for characterization is a viable method for real-time, in situ characterization. This is the best solutions because it reduces worker exposure and is more efficient. This solution depends on the robotics technology and/or remote delivery systems.

\section{Section 1.3 Decontamination}

Baseline Current baseline technologies include standard wet and dry surfaceTechnologies decontamination methods. Surface decontamination is effective for simple geometric shapes; however, it is less effective for complex shapes and often generates a substantial amount of waste. This waste is not only expensive to dispose of but poses serious environmental hazards and substantial risks for worker exposure. 
Deficiencies

Solutions

\section{Section 1.4 Dismantlement}

Baseline Technologies

Deficiencies

Solutions

\section{Section 1.5 Materials Disposition}

Baseline Technology labor intensive.
Serious deficiencies are associated with current baseline technologies for decontamination. The methods available are labor intensive, have the risk of personnel exposure, and often generate a tremenduus amount of waste.

The risks associated with current decontamination technology include worker exposure and excess waste.

The most meaningful solution to the problems associated using current technology for decontamination is a viable method for in situ decontamination. This is the best solution because it maximizes decontamination before dismantling and reprocessing. This solution depends on the robotics technology and/or remote delivery systems.

Current baseline technologies for dismantlement include saws, grinders, shears, and cutting torches. Although reliable, these methods create airborne contaminants, which pose exposure and other industrial safety hazards and are

The primary deficiencies associated with the current baseline technologies for dismantlement are the lack of equipment tailored to the specific application and the lack of adequate effluent containment. The risks associated with current dismantlement technologies correspond primarily to worker exposure, release of airborne contaminants, and industrial safety issues.

The most meaningful solution to the problems associated with current technologies for dismantlement is an automated mechanism that performs repetitive tasks with little or no contaminated particulate effluent. This is the best solution because it addresses the large volume of materials with minimal risk, cost, and environmental impact. The solution depends on the robotics technology of remote delivery systems.

Historically, recycling has represented a major proportion of the total domestic commercial metal production. Within the primary metals industries, significant quantities of scrap are generated through trimming operations in the production of semi-finished products such as sheet, plate, rod, bar, extrusions and forgings. Such scrap forms are routinely remelted for reprocessing and are referred to as "home" or "run-around" scrap. Depending on the particular product forms being produced, the amount of trim scrap may range from about $10 \%$ to $50 \%$ of the weight of the original material processed. Because such material does not enter the commercial scrap market, there are 
few reliable statistics indicating the total quantities that are routinely processed. Additional scrap is generated when the semi-fabricated products are processed for the manufacture of parts and components. Such operations can include trimming scrap from forming operations, machine chips, defect parts, etc. In many instances component manufacturers can easily segregate scrap materials on an alloy-by-alloy basis, which permits easier recycle (hence, premium scrap value) by either their original materials supplier or within the commercial secondary metals industry. Such material is called "prompt" or "new" scrap. Finally, "obsolete" or "old" scrap is generated when manufactured equipment is overhauled, dismantled, or scrapped.

The disposal of scrapped automobiles provides an excellent case study of the methods by which complex systems composed of numerous materials are dismantled and processed in manners to optimize the value and recycle opportunities for each of the constituent materials. Figure 1. provides a simplified flow sheet for automotive recycling operations that permit separate recovery of magnetic ferrous materials, non-magnetic copper alloys, zinc alloys, and stainless, high-grade aluminum alloys, and low-grade aluminum alloys. These processes also permit recovery of "fluff," rubber, and glass, which are not easily recycled and are disposed as solid waste. About $90 \%$ of all cars taken out of service are shredded thirough an established infrastructure for recycling, and about $75-80 \%$ of the average car $(3100 \mathrm{lb})$ is metal scrap that is recycled. ${ }^{3}$ While most landfills are composed of municipal wastes, enormous problems would arise if the present rates of recycle were not available for the $9,000,000$ cars per year being scrapped in the U.S.

3 Facts and information published by the Institute of Scrap Recycling Industries, Inc., Washington. D.C., 1993. 
Figure 1. Schematic Flow Dlagram of Automotlve Scrap Metal Recycling ${ }^{4}$

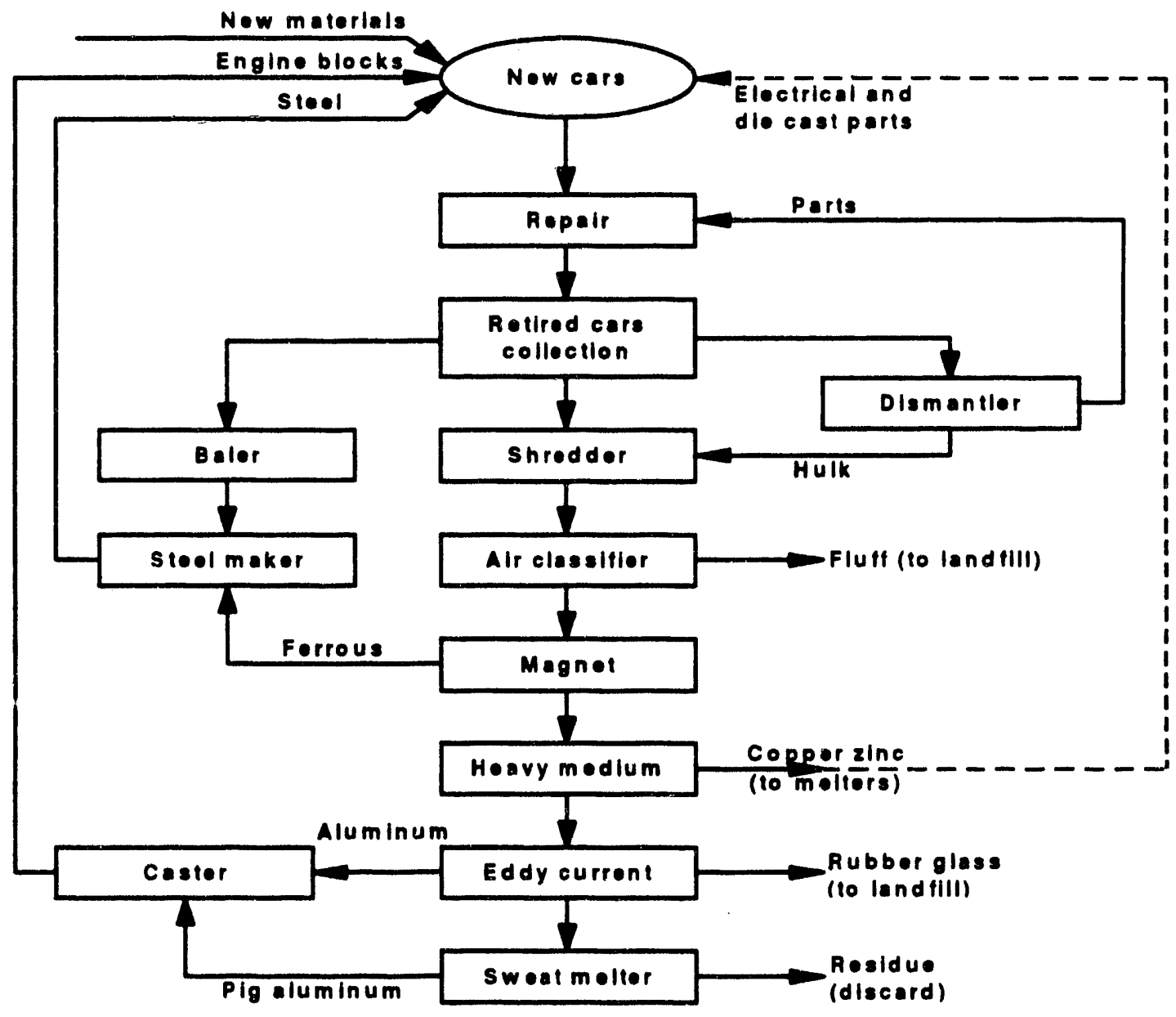

4 J. H. Van Linder, “Aluminum Recycling, Everybody's Business: Technological Challenges and Opportunities," Light Metals, pp. 675-682, TMS, Anaheim, CA (1990). 
The American Metal Market presents regular statistics on scrap usage throughout the U.S. metals industry. The following are the scrap consumption levels for $1990 .^{5}$

- Iron and Steel $\quad$. . . . . 58,400,000 MTon

- Aluminum . . . . 2,600,000 MTon

- Copper . . . . . . . 1,600,000 MTon

- Lead, Tin and Lead-Tin Alloys _ 907,000 MTon

- Zinc . . . . . . . 189,200 MTon

- Nickel . . . . . . . 33,800 MTon

Such quantities of scrap usage represents significant proportions of the total commercial production of metals in the U.S. The Institute of Scrap Recycling Industries reports recycled metals compose the following percentages of U.S. needs:

- Iron and Steel $\quad . \quad$. $\quad . \quad$. $\quad . \quad$. $45 \%$

- Copper . . . . . . . . . $43 \%$

- Aluminum . . . . . . . .

- Lead . . . . . . . . . $55 \%$

- Zinc . . . . . . . . $19 \%$

- Stainless Steel . . . . . . $\quad 50 \%$ 
For the specific case of using scrap iron and steel in steel making rather than virgin iron ore and coal, Institute of Scrap Recycling Industries (ISRI) quotes EPA studies which indicate the following savings:

- Reduced energy usage . . . . $74 \%$

- Reduced virgin materials use . . . $90 \%$

- Reduced air pollution . . . . $\quad$. $86 \%$

- Reduced water use . . . . . . . $40 \%$

- Reduced water pollution . . . . $76 \%$

- Reduced mining wastes . . . . . $97 \%$

- Reduced consumer waste generation . . $105 \%$

In the case of aluminum beverage cans, recycling requires only $5 \%$ of the energy required to produce a can from virgin raw materials. Not surprisingly with this incentive, almost $70 \%$ of the cans produced in the U.S. are now being recycled. The vital economic importance of metal scrap is demonstrated by the fact that the American Metals Market publishes quotations for numerous forms of metal scrap in several North American regions every business day of the year.

Scrap recycle is a routine, economically significant feature of the commercial metals industry. From the standpoints of resource utilization, environmental improvement (minimize land burial), energy conservation, pollution abatement, and cost minimization, metals recycle makes good sense. The same benefits would apply to recycle of the radiologically contaminated scrap metals (RSM) present at the DOE sites were it not for the serious problems associated with

- the risks and consequences from the general release of RSM

- the lack of demonstrated technologies for the removal of radiological contaminants from RSM

- the lack of an industrial infrastructure for processing RSM

- the absence of a U.S. de minimis standard for the general release of refined/processes RSM

Today, DOE surface-contamination guidelines allow the general release of process-contaminated metal scrap with less than $1,000 \mathrm{dpm} / 100 \mathrm{sq} \mathrm{cm}$ removable alpha or $5,000 \mathrm{dpm} / 100 \mathrm{sq} \mathrm{cm}$ fixed alpha from natural uranium, $\mathrm{U}-235, \mathrm{U}-238$, and associated daughter products and radionuclides with decay modes other than alpha emission (beta-gamma). Currently, there is no 
DOE guidance (nor NRC regulation) with respect to the release of metal with volumetric or bulk contamination.

In contrast to the commercial metals industry, current baseline technology for materials disposition for non-releasable metal scrap from the DOE sites include burial and long-term retrievable storage. Burial and storage require continuous surveillance and maintenance, and their viability under current and future regulations is questionable. By burying material that might otherwise be recycled, we lose valuable scrap materials and additional clean metal (e.g., as purchased new waste containers). The costs associated with baseline technologies for materials disposition by burial range from one-half to five dollars per pound. On a volumetric basis, burial costs range from $\$ 11 / \mathrm{ft}^{3}$ at the Nevada Test Site to about $\$ 50 / \mathrm{ft}^{3}$ at INEL and Hanford, to $\$ 300 / \mathrm{ft}^{3}$ at Barnwell. By burying contaminated material, we risk colliding with future regulations that may require excavation and remediation of that site.

There have been numerous investigations, studies, and assessments over the years on the prospects of recycling contaminated scrap metal. One of the earliest references is a $1951 \mathrm{AEC}^{\mathrm{Aeport}}{ }^{6}$ that investigates the hazards from commercial release of uranium-contaminated scrap metal. This was followed in 1952 by an aricle in the trade journal Iron Age that was titled, "Sale of Uranium Contaminated Scrap Metal Recommended."7 In 1991, an assessment ${ }^{8}$ was made for recycling contaminated metal waste into stainless steel canisters for placing high-level waste into repositories. In the interim period, many laboratory-scale studies and engineering-scale demonstrations were completed, and a fair amount of scrap metal has actually been processed and sold or put to use. ${ }^{9}$ The results of these studies is that uranium and plutonium contamination (as well as many of their daughter products) can be removed easily from most metals by melting under a slag with the resulting processed metal having greatly reduced contaminant levels in the range of a few parts per million or less. Extensive studies of scrap metal decontamination by melt-refining techniques have been reported by Heshmatpour, Copeland and co-workers of Oak Ridge National Laboratory. ${ }^{10,11,12}$ Various base metals (including mild steel, stainless steel,

6 H. B latz, J. H. Harley. M. Eisenbud, Investigation of the Potential Hazard in Releasing Scrap Metal Contaminated with Uranium to Commercial Channels, USAEC NY-1558 (June 1951).

7 H. Blatz, "Sale of Uranium Contaminated Scrap Recommended," Iron Age, No. 170, pp. $125-7$ (1952).

8 G. A. Reiman, Technical Assessment of Process to Enable Recycling of Low-Level Contaminated Metal Waste, INEL Information Report, EGG-MS-9879 (October 1991).

9 R. P. Whitfield, letter to distribution, Radioactive Scrap Metal Recycling (23 October 1991).

10 G. L. Copeland, R. L. Heestand, R. S. Mateer, "Volume Reduction of Low-level Contaminated Metal Waste by 
$\mathrm{Ni}, \mathrm{Al}, \mathrm{Cu}, \mathrm{Pb}, \mathrm{Sn}, \mathrm{Zn}$ and $\mathrm{Pb}-\mathrm{Sn}$ alloys contaminated with uranium) were considered in these studies. The results demonstrated that high degrees of decontamination could be achieved without a great deal of sensitivity to flux type and composition. Borosilicate and blast furnace slags with high $\mathrm{Fe}_{2} \mathrm{O}_{3}$ content were preferable for ferrous metals, $\mathrm{Cu}$ and $\mathrm{Ni}$. Low-melting $\mathrm{NaCO}_{3}-\mathrm{NaCl}-\mathrm{NaOH}$ slags were suitable for $\mathrm{Zn}, \mathrm{Pb}, \mathrm{Sn}$, and $\mathrm{Pb}-\mathrm{Sn}$ alloys, while fluoride slags were desirable for $\mathrm{Al}$. As effective as melt treatment with slags had been in decontamination, the studies also report that meaningful levels of decontamination could be achieved in melting without deliberate slag additions. Presumably this is related to normal dross formation, which occurs with metal melting operations.

Similar melt refining studies of uranium-contaminated base metals were carried out by workers at Fernald, ${ }^{13,14}$ Hanford, ${ }^{15}$ and Pacific Northwest Laboratory (PNL). ${ }^{16}$ Earlier studies at $\mathrm{ANL}^{17,18}$ demonstrated that melt refining techniques were also effective for removal of plutonium and americium contaminants from various base metals. Given the highly oxidizable nature of $\mathrm{U}, \mathrm{Pu}$ and most transuranic elements, it is likely that melt refining methods would be effective for removal of all of these elements. This would include many of the daughter products of uranium and plutonium that can be expected in contaminated scrap metal. However, daughter products of lesser oxidation potential such as technetium-99, and activation products, such as cobalt-60, cannot generally be removed by conventional pyrometallurgical processing. Alternative process technologies must be developed for decontamination of metals containing such contaminants. This is significant because the vast quantities of nickel in the GDP's (market values

Melting: Selection of Method and Conceptual Plan," ORNL/TM-6388, Oak Ridge National Laboratory, Oak Ridge, TN (1978).

11 B. Heshmatpour, G. L. Copeland, "The Effect of Slag Composition and Process Variables o.1 Decontamination of Metal Waste by Melt Refining," ORNL/TM-7501, Oak Ridge National Laboratory, Oak Ridge. TN (1981).

12 B. Heshmatpour, G. L. Copeland, "Metallurgical Aspects of Waste Metal Decontamination by Mel Refining," Nuclear and Chemical Waste Management, Voi. 2, pp. 25-31 (1981).

13 E. W. Mautz, G. G. Briggs, W. E. Shaw, J. H. Cavendish, "Uranium Decontamination of Common Metals by Smelting: A Review," NLCO-1113, National Lead Co., Cincinnati, OH (1975).

14 J. H. Cavendish, "Treatment of Metallic Wastes by Smelting," NLCO-1157, National Lead Co., Cincinnati, OH (1978).

15 G. A. Beitel, P. G. Ortiz, "Volume Reduction of Metallic Waste," RHO-SA-91, Rockwell Hanford Operations.

16 R. G. Nelson, D. R. Montgomery, "The Cladding Hull Decontamination Process: Part 2, Densification by Inductoslag Melting," PNL-3166, Pacific Northwest Laboratories, Richland, WA. (1980).

17 N. Levitz, et al., "Decontamination of Plutonium-contaminated Glove Boxes," ANL-8128, Argonne National Laboratories, Argonne, IL (1974).

18 M. G. Seitz, T. J. Gerding, M. J. Stiendler, "Decontamination of Metals Containing Plutonium and Americium," ANL-78-13, Argonne National Laboratory, Argonne, IL (1979).

Technical Program Plan for the Transitioning. Decommissioning, and Final Disposition Focus Area
January 1994

Revision 0 
in the hundred of millions of dollars) contain small amounts of Tc-99 contamination.

DOE is currently releasing some metals on a case-by-case basis following well prescribed release criteria. Recently, DOE shipped over 700,000 pounds of contaminated metal to a commercial smelter for fabrication into shielding blocks for use at other DOE sites for high-energy physics programs. DOE Oak Ridge Office (ORO) has a goal of releasing 3,000,000 pounds of metal this fiscal year via this route. In pursuit of possible applications of recycled scrap metals for controlled reuse at DOE or other fede:al sites, various groups within the DOE-EM organization are sponsoring efforts at numerous DOE and commercial sites. ${ }^{19}$ Studies are presently under way at the following DOE sites: Argonne, Hanford, Idaho, Los Alamos, Oak Ridge, Sandia and Savannah River. DOE-funded efforts are under way or planned at EPA; Sanford Cohen Associates; Scientific Ecology Group, Inc.; Manufacturing Sciences Corp.; Molten Metals Technology, Inc.; SAIC; Battelle; Columbus; Quadrex Corp.; and Grumman Aircraft.

Three PRDA programs related to RSM recycle are under consideration:

- a program with Manufacturing Sciences Corp. and Colorado School of Mines related to the decontamination of Ni RSM for removal of $\mathrm{Tc}$ and subsequent melting, alloying and fabrication of stainless steel containers for DOE use

- a program with Molten Metal Technology, Inc. to demonstrate the application of its proprietary Catalytic Extraction Processing for separation of contaminants from RSM

- a program with Scientific Ecology Group (SEG) for a full-scale demonstration of scrap met?i recycling using the SEG decontamination and melting facilities for the production of shield blocks, waste disposal containers, and other products for reuse at DOE Sites

Through EM-50, a national Technical Support Group has been established to develop a strategic plan for D\&D IDs. Within this broad effort, a subteam has been formed in the area of metals recycle. This team has drafted the present document, which recommends the metal decontamination/recycle technology program described in the next section. One of the earliest activities is the demonstration of the production of waste canisters from contaminated stainless steel for controlled reuse at the DOE sites. 
Deficiencies Several deficiencies are associated with current baseline technologies for materials disposition. We are limited by diminishing landfill space, increasingly restrictive environmental regulations, and the specter of material resurrection.

The risks associated with current materials disposition technologies include primarily environmental impact, worker exposure, and regulatory compliance. By burying contaminated material, we risk colliding with future regulations that may require excavation and remediation of that site.

Solutions The most meaningful solution to the problems associated with using current technology for materials disposition as a viable means to turn scrap into products for controlled beneficial reuse. This is the best solution because it is cost effective, environmentally sound, energy- and resource-efficient, and it saves the taxpayer money. This solution depends on the committed investment of funds from private industry and is contingent upon DOE's commitment to ensure a market for recycled materials.

\section{Section 1.6 Robotics and Automation}

Baseline Technologies

Currently, robotics and automation technologies are available but not being

Deficiencies applied to recycle of radioactively contaminated metals.

The deficiencies associated with current robotics and automation baseline technologies were described as they relate to characterization, decontamination, and dismantlement. The lack of such technologies needed to perform in situ characterization, decontamination, and dismantlement of radioactive scrap metal is a deficiency.

Solutions Robotics and automation would solve many of the problems associated with using curreni technologies for characterization, decontamination, and dismantlement of radioactive scrap metal.

\section{Section $1.7 \quad$ Regulation}

Most of the technical approaches and solutions that have been recommended can work under existing regulations. In order for these approaches and solutions to succeed, however, the public must be educated about, encouraged to participate in, and made aware of the benefits of recycling for beneficial reuse. Ultimately the full benefits of metals recycling will require the adoption of a de minimis standard permitting general release. 
Section 1.8 Management and Systems

The existing metals recycle program is in its infancy and lacks adequate coordination. DOE should establish a cooperative, coordinated effort for metals recycle throughout the Complex and explore opportunities to include DoD and private industry.

Section 2 Description of the Proposed Integrated Demonstration

\section{Section 2.1 General Concept}

The ultimate vision for processing DOE RSM involves the establishment of regional commercial recycling facilities that are convenient to the DOE sites and coordinated with the needs and specific requirements of particular sites and/or groups of sites. This plan would minimize the need for excessive long-distance transport of radioactively contaminated materials on public transportation routes. In terms of the projected needs and volumes of metal that are now available and will become available through D\&D activities, it is feasible that commercial centers could become viable for the following regions:

- Tennessee

- ORNL

- K-25

- Y-12

- Fernald

- Portsmouth

- Paducah

- South Carolina

- Savannah River

- Midwest

- ANL

- Ames

- Pacific Northwest

- INEL

- Hanford

- PNL 
- Southwest

- LANL

- LLNL

- Lawrence Berkeley Laboratory (LBL)

- Sandia

- Rocky Flats

Commercial initiatives have led to the formation of the foundations of a multi-industry RSM complex in the Oak Ridge Area. Serious discussions are reputedly underway for similar commercial developments convenient to the Savannah River and INEL sites. There are also indications of similar considerations related to numerous other DOE sites. The long-term viability of the proposed regional RSM recycle centers, hinges upon

- the development and demonstration of cost-effective decontamination processing technologies, and, more importantly,

- a long-term commitment by DOE to sustain recycling activities over a sufficient period of time to merit private organizations, making the substantial investments in facilities and personnel required to carry out these activities.

The metals recycle team of the Technical Support Group (TSG) identified numerous specific opportunities for integrated demonstrations of technologies for recycle of contaminated metal scrap at various DOE sites. These included consideration of the following contaminated metals:

- Tritium-contaminated stainless steel

- Savannah River

- LANL

- Hanford

- Uranium- and fission-product-contaminated stainless steel

- NEL

- Complex-wide

- GDP nickel contaminated with U compounds and Tc-99

- K-25

- Paducah

- Portsmouth

- Mercury

- Y-12 
- Mild steel

- Complex Wide

- Aluminum

- Complex-wide

- Precious metals

- Complex-wide

- Lead

- Complex-wide

- Uranium tails (UF6)

- K-25

- Paducah

- Portsmouth

Upon consideration of the various alternatives, the team determined that priority should be given to an integrated demonstration for the production of a variety of stainless steel waste containers for controlled reuse at DOE sites through melting feed stocks of tritium-contaminated stainless steel scrap, uranium- and fission-product-contaminated stainless steel scrap, and uranium-contaminated mild steel and nickel scrap augmented with purchased chromium. Of the various types of metal scrap, stainless steel represents the highest potential for beneficial reuse within the DOE complex.

\section{Section $2.2 \quad$ Technologies}

The proposed ID integrates demonstration activities in four technological areas: characterization, decontamination, dismantlement, and materials disposition. Characterization will acidress the chemical composition of radiological contaminants present in the materials before processing and after each processing stage of the proposed ID. Decontamination activities will involve the application of standard decontamination treatments in order to reduce surface contamination to the appropriate levels prior to further handling of the components. Dismantlement activities will be required before processing certain of the proposed stainless steel components as well as reducing the sizes of all scrap components to levels suitable for subsequent melt processing. Materials disposition activities will involve the following processing steps:

- Scrap materials will be melted using melt refining procedures designed for optimal removal of radiological contaminants.

During the melting operations, careful controls will be required to ensure that all product materials will meet AISI specifications for type 304 stainless steel. 
- Billets of the melted material will be processed using standard rolling procedures for the production of sheet material at thicknesses required for the production of the desired waste containers.

- Waste canisters and/or B-25 $5^{\mathrm{TM}}$ type boxes will be asserinuled using standard fabrication and welding techniques from the stainless steel sheet materials.

- The fabricated stainless steel waste containers will be shipped back to the DOE sites for controlled reuse at those sites.

During FY 94, it is recommended that demonstration activities be concentrated on tritiated stainless steel siug buckets, heat exchangers, and other items at Savannah River. During FY 95, additional effort should be directed to processing items at DNEL and contaminated mild steel and nickel scrap from the GDPs.

We also propose that a series of laboratory tests be carried out in parallel with the activities described above. These efforts will involve:

- completion of a detailed literature survey on published reports on decontamination of RSM

- continuation of detailed thermodynamic and kinetic evaluations of scrap metal processing options, which are currently under way in a joint effort of LANL and Carnegie-Mellon University

- experimental evaluations of advanced processing technologies based on slag/metal interactions and gas/metal interactions for removal of uranium, plutonium and transuranics, electrorefining, electrowinning, and other purification procedures for removal of difficult species such as technetium- 99 and cobalt -60

- experimental back-up to the recycle processing effort for solving problems that might arise during the course of the $\mathbb{I D}$

The success of this ID will be an important component of the DOE D\&D Program since it will establish, for the first time in this country, that radioactively contaminated metals can be economically recycled for beneficial reuse. This will establish that the metals recovered from large-scale D\&D activities can be reused and not merely buried. An intrinsic feature of this ID is the establishment of commercial consortia to join with DOE and melt stainless steel and fabricate containers for utilization by DOE. The program will be considered a success only when the stainless steel containers 
are delivered and used in DOE facilities, and the stainless steel RSM recycle industry is established.

The products of the new industry fostered by this ID will provide the DOE sites with higher quality containers than the corrodible mild steel drums that are currently in general use. Since the completion dates of the permanent DOE repositories for transuranic (TRU) and high-level wastes, as well as many of the commercial low-level waste facilities are uncertain, it is likely that DOE, other federal agencies, and private industry will require above-ground, long-term storage for these wastes. Stainless steel waste drums, which are corrosion-resistant, will perform much better than the drums that are currently used and will have a lower total life-cycle cost. Cost saving will accrue to DOE as a result of these lower life-cycle costs; DOE will also save money through the aversion of stainless steel waste disposal costs.

\section{Section $3 \quad$ Locations}

\begin{tabular}{|c|c|c|c|c|}
\hline $\begin{array}{c}\text { Potentlal RSM } \\
\text { Recycle Centers } \\
\text { DOE Sltes }\end{array}$ & $\begin{array}{l}\text { Potential } \\
\text { Commerclal } \\
\text { Sltes }\end{array}$ & $\begin{array}{l}\text { Relatlonshlps } \\
\text { between Sltes }\end{array}$ & $\begin{array}{l}\text { Technical } \\
\text { Justifleation }\end{array}$ & $\begin{array}{l}\text { Financlal } \\
\text { (or other) } \\
\text { Justlfication }\end{array}$ \\
\hline $\begin{array}{l}\text { Tenneseese } \\
\text { (ORNL, K-25, Y-12, } \\
\text { Paducah, } \\
\text { Portsmouth, Fernald) }\end{array}$ & $\begin{array}{l}\text { Commercial nuclear } \\
\text { power plants }\end{array}$ & \multirow[t]{5}{*}{$\begin{array}{l}\text { Virtually all DOE and } \\
\text { commercial sites } \\
\text { have RSM. }\end{array}$} & \multirow{5}{*}{$\begin{array}{l}\text { All DOE and } \\
\text { commercial sites } \\
\text { have similar RSM } \\
\text { problems } \\
\text { Scrap recycle efforts } \\
\text { with coordination of } \\
\text { DOE and private } \\
\text { sector actions lead } \\
\text { to optimal leverage. }\end{array}$} & \multirow{5}{*}{$\begin{array}{l}\text { Life-cycle cost } \\
\text { benefits from recycle } \\
\text { versus burial } \\
\text { Availability of RSM } \\
\text { disposal sites over } \\
\text { long-term } \\
\text { Energy savings: } \\
\text { resource utilization: } \\
\text { pollution abatement } \\
\text { and waste } \\
\text { minimization }\end{array}$} \\
\hline $\begin{array}{l}\text { South Carolina } \\
\text { (Savannah River) }\end{array}$ & $\begin{array}{l}\text { Commercial nuclear } \\
\text { power plants: } \\
\text { commercial } \\
\text { uranium chemical- } \\
\text { processing plants }\end{array}$ & & & \\
\hline $\begin{array}{l}\text { Midwest } \\
\text { (ANL, Ames) }\end{array}$ & $\begin{array}{l}\text { Commercial nuclear } \\
\text { power plants }\end{array}$ & & & \\
\hline $\begin{array}{l}\text { Pacific Northwest } \\
\text { (INEL, PNL, Hanford) }\end{array}$ & $\begin{array}{l}\text { Commercial nuclear } \\
\text { power plants; fuel- } \\
\text { reprocessing } \\
\text { plants; uranium- } \\
\text { mining and refining } \\
\text { plants }\end{array}$ & & & \\
\hline $\begin{array}{l}\text { Southwest } \\
\text { (LANL, LLNL, LBL. } \\
\text { Sandia, Rocky Flats) }\end{array}$ & $\begin{array}{l}\text { Commercial nuclear } \\
\text { power plants; } \\
\text { uranium-mi ing and } \\
\text { refining plants }\end{array}$ & & & \\
\hline
\end{tabular}




\section{Section $4 \quad$ ID Schedule and Costs}

The following table summarizes the costs (in millions) of this ID over its entire lifespan.

\begin{tabular}{|l|r|r|r|r|r|r|r|}
\hline & Year 1 & Year 2 & Year 3 & Year 4 & Year 5 & Year 6 & Total \\
\hline Partnershlp Devl. & 0.750 & 1.000 & 0.975 & 0.550 & 0.425 & & 3.700 \\
\hline Tech. Transfer & 1.320 & 1.750 & 1.840 & 1.270 & 0.820 & & 7.000 \\
\hline New Tech. Devl. & 1.170 & 1.250 & 1.250 & 0.980 & 0.650 & & 5.300 \\
\hline Total & 3.240 & 4.000 & 4.065 & 2.800 & 1.895 & $\mathbf{0 . 0 0 0}$ & $\mathbf{1 6 . 0 0 0}$ \\
\hline
\end{tabular}




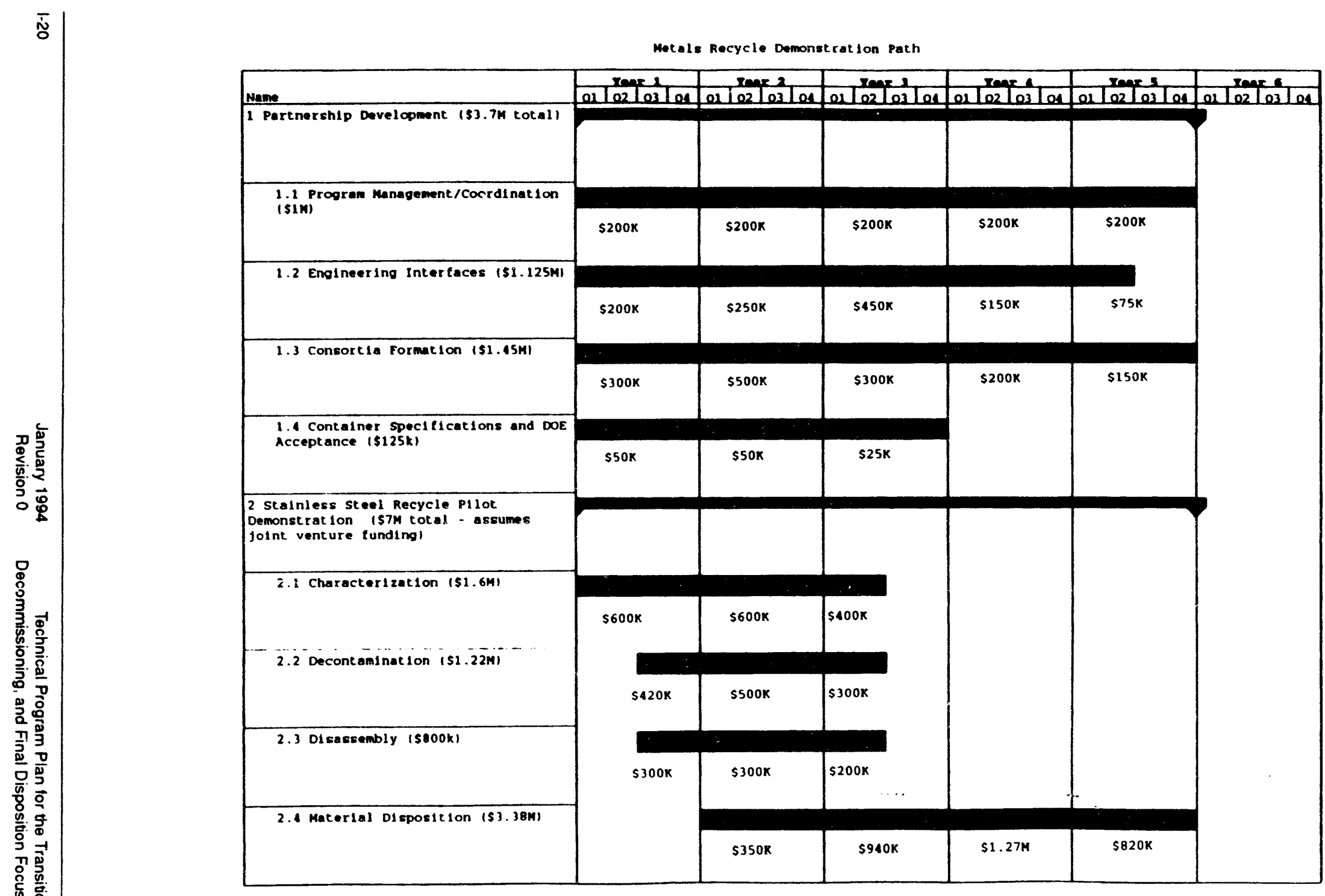


Metals Recycle Demonstration Path

\begin{tabular}{|c|c|c|c|c|c|c|}
\hline \multirow{2}{*}{$\begin{array}{l}\text { Name } \\
\text { Metels Recycle Technology } \\
\text { Demonst ration is } 5.3 \mathrm{M} \text { totall }\end{array}$} & 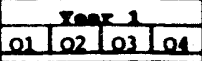 & $02\left[02 \int_{03}^{2}\right]_{01}$ & 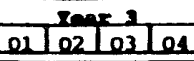 & 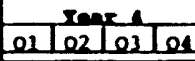 & 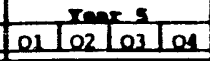 & \multirow[t]{2}{*}{ Oato2 } \\
\hline & & & & & & \\
\hline $\begin{array}{l}\text { 3.1 Theoretical Process } \\
\text { Investigation (s } 450 \text { ) }\end{array}$ & $s 200 k$ & $\$ 150 \mathrm{~K}$ & $\$ 100 \mathrm{~K}$ & & & \\
\hline \multicolumn{7}{|c|}{$\begin{array}{l}\text { 3.2 Experimental Process Development } \\
\text { Demonstrat ion - ex-situ }\end{array}$} \\
\hline \multicolumn{7}{|l|}{ 3.2.1 Nickel Recovery $(52.98 \mathrm{BH})$} \\
\hline & $\$ 600 \mathrm{~K}$ & s700K & \$850K & $\$ 580 \mathrm{~K}$ & $\$ 250 \mathrm{~K}$ & \\
\hline $\begin{array}{l}3.2 .2 \text { Motale Recovered from } \\
\text { Litthium Processing Equipment } \\
\text { (s500k) }\end{array}$ & $5200 \mathrm{~K}$ & $\$ 200 \mathrm{~K}$ & \$100k & & & \\
\hline \multirow{2}{*}{$\begin{array}{l}3.2 .3 \text { other Non-ferrous Metals } \\
\text { (\$1.37W) }\end{array}$} & & & & & & \\
\hline & \$170K & $\$ 200 \mathrm{~K}$ & $\$ 200 \mathrm{~K}$ & $\$ 400 \mathrm{~K}$ & $\$ 400 \mathrm{R}$ & \\
\hline
\end{tabular}




\section{Appendix J}

\section{Plutonium-processing Facilities}

This appendix contains two proposals. The De-inventory and Deactivation proposal begins on page J-2 and the Equipment proposal begins on page $J-20$. 


\section{De-inventory and Deactivation}

\section{Section 1 Situation Analysis}

\section{Section 1.1 Problem Definition}

Description of With the reduction of the weapons mission, virtually all of the the Problem plutonium-processing facilities throughout the DOE Complex (primarily Rocky Flats, Savannah River, Hanford, LANL, and LLNL) will require de-inventory and deactivation; the magnitude has yet to be determined. Because of their construction and functions, plutonium-processing facilities tend to be more difficult to retire. As a result of this, delays in deactivation activities do no allow for the reduction of the significant ongoing surveillance and maintenance cost. Furthermore, at sites with plutonium-processing facilities, they are generally considered the major contributor to off-site risk.

The proposed ID covers the activities associated with the deactivation of plutonium-processing facilities, such as facility characterization, high-concentration ${ }^{N} \mathrm{NM}$ liquid handling, SNM chemical stabilization, removal of SNM from inaccessible areas, and decontamination at the multi-gram level. It focuses on stabilization of facilities, cost (e.g., system maintenance, security), off-site risk reduction issues, and an operational approach.

\section{Section $1.2 \quad$ Characterization}

Baseline Current baseline technologies include standard characterization methods: Technologies non-destructive assay (NDA) gamma scans, visual observation, manual measurement, historical records, process knowledge, and inspections. Despite the excessive labor and personnel exposure associated with these methods, there has been little change over the last few years. The costs associated with baseline technologies for characterization vary depending on the installation and are contingent upon sampling, analysis, downtime, secondary waste disposal, and personnel exposure costs.

Deficiencies There are several deficiencies associated with current baseline technologies for characterization: inadequate equipment to read radiation levels in the presence of even moderate levels of background radiation; poor sample hi Jling and processing of samples; lack of adequate in situ characterization tecnniques to identify SNM from the outside of ducts and equipment; personnel hazards and containment problems when opening equipment to 
characterize for internal contamination; and lack of methods for the field identification of either the presence or absence of hazardous contaminants. Because samples cannot be characterized in real time, we need to deal with the hazards and risks associated with the transportation of contaminated materials, worker exposure, and off-site release. The capacity of laboratories where the samples are analyzed is limited and the analytic methods are slow and cumbersome. There are containment problems when opening systems to characterize internal contamination; and characterization using samples results in the generation of secondary waste. The time it takes for samples to be sent off for analysis and returned reduces the overall efficiency of D\&D operations. Less than adequate configuration control results in characterization, containment, and control difficulties and complicates the use of automation.

The risks associated with current baseline technologies for characterization C... "spond primarily to the inability to plan the work, the inability to identify areas of concern, the generation of secondary waste, and, to a lesser extent, the transportation of samples.

Solutions The most meaningful solution to the problems associated with ising current baseline technology for characterization is a viable method for a real-time, in situ characterization. The tools and methods should include mapping and discrimination capabilities, improved access capabilities for video, optical 3-D CAD capabilities, in-system probes, portable neutron systems (passive and active), automated data records, and real-time field measurement capabilities for radioactive and hazardous constituents. These solutions reduce worker exposure and are more efficient.

\section{Section 1.3 Decontamination}

Baseline Current baseline technologies include manual scrubbing for physical removal Technologies (e.g., brushes, scrapers), chemical treatment, flushes, and vacuum collection systems in ducts.

Deficiencies There are several deficiencies associated with current baseline technologies for decontamination. The methods available to us are labor intensive, time consuming, and costly, and they generate a tremendous amount of secondary (usually mixed) waste. Liquid decontamination methods are complicated by operational constraints designed to prevent criticalities.

The risks associated with current baseline technologies for decontamination correspond primarily to worker exposure and excess waste. Moreover, the lack of adequate decontamination techniques hinders the reduction of SNM levels, the reduction of public risk, and the reduction of maintenance and security costs. 
Solutions The most meaningful solutions to the problems associated with using the current baseline technologies for decontamination is a viable method for automated removal of bulk SNM liquids and particulates that will minimize secondary wastes and reach inaccessible areas. This is the best solution because it addresses the weaknesses of current baseline technologies.

\section{Section 1.4 Dismantlement}

Baseline

Technologies

Current baseline technologies for dismantlement include manual operations with small tools, pumps, tanks, etc., inside primary containers.

Deficiencies The primary deficiencies associated with the current baseline technologies for dismantlement are the amount of manual labor required and the lack of remote operating capabilities.

The risks associated with current baseline technologies for dismantlement correspond primarily to worker exposure and industrial/radiological hazards.

Solutions The most meaningful solution to the problems associated with current baseline technologies for dismantlement is the enhancement of the efficiency of manual size reduction.

\section{Section 1.5 Materials Disposition}

Baseline Current baseline technologies include standard, safe, retrievable storage Technologies methods. Safe retrievable storage requires continuous surveillance and maintenance, and its viability under current and future regulations is questionable.

Deficiencies There are several deficiencies with current baseline technologies for materials disposition. We are limited by inadequate containers for long-term storage, diminishing storage space, increasingly restrictive environmental regulations, undetermined ling-term stabilization processes, and long-term, real-time monitoring and characterization.

Solutions The most meaningful solutions to the problems associated with using current baseline technologies for materials disposition are to develop safe, long-term residue storage containers that meet DP return acceptance criteria and to develop residue treatment processes that will reduce secondary waste generation and support long-term goals for the management of national assets and waste. 


\section{Section 1.6 Robotics and Automation}

Baseline Currently, the baseline technologies for de-inventory and deactivation do not, Technologies for the most part, include robotics and automation (except for some previous applications used in duct remediation).

Deficiencies The deficiencies associated with current robotics and automation baseline technologies are the lack of such technologies needed to perform in situ characterization, decontamination, and bulk removal of ducts and piping.

Solutions Sophisticated robotics and automation would support characterization of existing facilities and more efficient removal of SNM from inaccessible areas.

\section{Section $1.7 \quad$ Regulation}

All of the approaches and solutions that we have recommended are, generally, viable under the existing regulations.

\section{Section $1.8 \quad$ Management and Systems}

There are numerous issues associated with the plutonium-facilities deactivation problem that should be addressed with systems engineering techniques. Principally, these involve options for reducing public risk, reducing the costs of maintaining deactivated facilities, and minimizing waste and residue management.

\section{Section 2 Description of the Proposed Integrated Demonstration}

The scope of this ID is the development of technologies to assist in the deactivation of plutonium-processing facilities. Principal deactivation activities include SNM consolidation, removal of plutonium contamination in the tens-of-grams range and above from process equipment, disposition of high-level liquid solutions, characterization of facilities, assessment and removal of SNM from inaccessible areas, and other activities necessary to reduce risks and operational costs. This ID includes studies, cold development, and laboratory and field activities.

This ID is focused on support of the two major transition technical goals: the reduction of facility operating costs and the reduction of off-site risk. The transition approach to achieve those goals is through the following actions: facility characterization, removal and stabilization of high SNM-concentration liquid, stabilization and consolidation of SNM, removal 
of SNM from inaccessible areas, decontamination of multi-gram plutonium contamination levels, and preparation for facility turnover for long-term surveillance or D\&D. Technology development activities targeted at support of the above transition actions will focus on the use of technology to improve efficiency and accuracy as a means of enhancing labor productivity. Selected activities will support improved worker safety during deactivation operations and improvements in long-term SNM storage methods.

The proposed plutonium deactivation ID activities have been broadly defined as laboratory-scale and field-scale activities. The location of laboratory-scale activities will be determined based on responses to requests for TTPs and/or PRDAs to perform the work defined. Because equipment development typically does not require work in safety-class facilities, the actual location in which the activities are performed will be of secondary importance to other factors in executing the activities.

For field-scale activities, on the other hand, active plutonium facility, along with an active infrastructure to perform the necessary work, is required. Certain requirements (e.g., worker qualifications, procedural compliance, safety assessment, readiness reviews, permit compliance) must be in place and applicable to the demonstration work to be performed. While some field-scale activities, such as characterization and testing of decontamination agents, may be covered under the umbrella of routine operations, activities such as sectioning of gloveboxes and size reduction will need substantially more support than the overall D\&D ID could be expected to provide. Therefore, these activities can be performed only in conjunction with ongoing deactivation activities at an applicable field site.

Overall, the Plutonium-processing Deactivation ID consists of series of activities. These activities develop specific technologies in a progressive fashion, from laboratory- to field-proven status. The series allows for input from industry, the use of national laboratory expertise, and the collective experience of site "owners"; it also provides a variety of test beds. Ultimate complete solutions are effected based on the successful completion of previous phases.

Three applicable field sites have budgeted activities in the appropriate time frame: Savannah River, Hanford, and Rocky Flats. There are some uncertainties associated with each of these sites. Given these uncertainties, the requirement that major field activities be associated with active programs, and the indefinite initiation date for field activities, the applicable field activities have been developed generically to allow their performance at any of the three sites. 
Section 2.1 Activities

The initial activity of the Plutonium-processing Equipment ID will involve the confirmation of tasks and priorities; further development of scope, success criteria, schedules, and contingencies; and initiation of system studies. This confirmation effort will be done by the D\&D Technical Support Group, with additional input from affected field sites and program offices. Along with the confirmation of management details, the system studies and some initial laboratory-scale activities will be assigned to specific entities (sites, laboratories, private companies), the interfaces with other IDs and IPs formalized, and TTP Calls and RFPs finalized. This effort will require the development of a national perspective, and assurance which all sites with plutonium-processing facilities, the national laboratories, regulators, industry, and the public will provide appropriate up-front input to technology development needs and activity criteria.

The systems studies will focus on developing the technical basis to support the activity justification, priorities, and success criteria. Initial systems analyses will evaluate the interrelationships of D\&D functions: characterization requirements, graded reduction of system requirements with reduced facility risk, and interim state criteria for surveillance or D\&D optimization. Follow-on studies will provide more detailed options analyses for waste packaging life-cycle cost and residue generation effects of D\&D. Reporting activities are discussed in the "Deliverables" section, below.

The characterization activities will support the development of sensor sensitivities in ranges of specific interest to plutonium facility deactivation and support better means of characterization both in situ and at the point of packaging. Initial activities will focus on the development of instrumentation for in-glovebox contamination ranges. Follow-on activities will concentrate on identifying methods for RCRA-constituent analysis for in situ environments developed in other IDs and suitable for use in plutonium facility deactivation. Additional activities will include the improvement of package assessment methods as well as SNM in-field evaluation techniques for equipment configurations. The field implementation of the characterization activities will be coordinated with the decontamination field activities.

The decontamination activities will seek to provide better means (and validate the approach) for more aggressive, early, and in situ decontamination, resulting in less operational cost, off-site risk, and downstream D\&D cost. Initial activities will focus on techniques to reduce contamination levels in inaccessible areas (e.g., flushing of piping, in situ decontamination of glovebox internal equipment). Subsequent activities will cover improvement of accessibility in awkward environments and handling of liquid. The activities are sequenced with complex ex situ field activities that depend on 
preceding field demonstrations of either component or similar in situ technologies, and these, in turn, depend on preceding laboratory activities.

The number of activities covered under the dismantlement, materials disposition, and robotics areas is relatively small, based on the deactivation programmatic focus. The dismantlement activities cover the application of glovebag technology to specific deactivation problems and duct remediation enhancements. The materials disposition activities support approaches to better handle deactivation-generated residues. The robotics activities support duct accessibility and 3-D mapping. Initial activities define system requirements, followed by cold and hot demonstrations. 


\section{Section $2.2 \quad$ Deliverables}

\section{General}

- technology status reports detailing the results of laboratory or cold activities to support the decisions on whether and how to proceed with field activities

- technical evaluation report detailing the results of field trials to support DQOs and the methods for meeting the objectives

- documentation for hardware, engineering, prototypes, and functional requirements

- annual reports

- strategic or management plan

- various weekly and monthly highlights, budget and project control documentation, etc.

\section{Specific}

- results of project task confirmation effort

- validation and revision of management plan

- public outreach approach

- industry participation plan

- ID/P coordination plan/protocol

- quarterly progress reports for the activity groups (i.e., characterization, decontamination, dismantlement, materials disposition, robotics)

- activity-based results

- cost/benefit and risk/benefit analyses

- recommendations

Reports will identify activity accomplishments, successes measured against established criteria, operational data, waste-generation information, and traceability of data. This information will be reported by activity and summarized on a quarterly basis. 
Section 2.3 Reasons for Pursuing the Proposed ID Now (versus Later)

- Deactivation of plutonium-processing facilities must be completed in the near future to reduce off-site risks and operational costs. In addition, these deactivations will accommodate budget cuts and free up funds for eventual D\&D.

- Regulatory and safety practices are constraining our ability to perform deactivation using previously acceptable methods.

- This process represents an opportunity to tie into and avail ourselves of other activities funded by EM-50 (e.g., IDs, IPs).

\section{Section $3 \quad$ Benefits}

The following are the direct benefits of successfully completing the proposed ID:

- assist other D\&D activities to reduce the possibility of SNM proliferation and nuclear criticality, operating costs, and problems with stakeholder involvement

- reduce internal exposure to workers

- reduce off-site risks to the public during deactivation activities

- reduce industrial hazards for workers

- demonstrate improved technology for characterization instrumentation and tools for operational cost savings

Through interaction with industry on technological development and transfer, we will be able to take advantage of current industrial developments, foster improvements to focus on our specific needs, and apply technologies developed for deactivation activities to other non-DOE remediation and cleanup activities. Following are categories of deactivation technologies that might be applicable to such activities:

- characterization instrumentation (e.g., in situ NDA scanners)

- localized containment systems that are smaller and more flexible

- decontamination processes (e.g., foams and gels for surface decontamination) 
This ID is applicable to other D\&D problems throughout the DOE Complex.

- It will support activities that are ongoing in other IDs and apply developments in those IDs to plutonium-processing facility deactivation.

- Deactivation techniques developed for gloveboxes at plutonium-processing facilities can be applied to gloveboxes used for other purposes (e.g., enriched uranium processing).

- Advances made in characterization activities for contaminated ductwork will be useful for D\&D work at other facilities.

- SNM and TRU assay activities will support and enhance waste characterization activities.

The cost benefits resulting from the technical development activities supported by the plutonium-processing facilities deactivation $" m$ will be based upon the reduction of costs and periods of the pre-D\&D surveillance and maintenance (S\&M) phase. Based on the projected plutonium-processing facility baseline operating costs, economies resulting from the implementation of these technologies would be in the range of $\$ 5$ million per year for the DOE Complex, over a 20 year period, for a total avoided cost of approximately $\$ 100$ million.

\section{Section $4 \quad$ What Cannot Be Done Between FY 94 and FY 99}

The deactivation of plutonium-processing facilities in the weapons corriplex are predominantly near-term activities. Out-year TD activities will largely be completed too late to support such activities. 


\section{Section $5 \quad$ Locations}

The table below lists the DOE and commercial sites with plutonium-contaminated facilities, their relationships to each other, and the current justification for a D\&D ID.

\begin{tabular}{|c|c|c|c|c|}
\hline DOE Sltes & $\begin{array}{c}\text { Potential } \\
\text { Commerclal } \\
\text { Sltes }\end{array}$ & $\begin{array}{l}\text { Relatlonships } \\
\text { between Sltes }\end{array}$ & $\begin{array}{l}\text { Technical } \\
\text { Justiflcation }\end{array}$ & $\begin{array}{l}\text { Financial } \\
\text { (or other) } \\
\text { Justlication }\end{array}$ \\
\hline $\begin{array}{l}\text { "Open" sites } \\
\text { (e.g., national } \\
\text { laboratories and } \\
\text { other sites capable } \\
\text { of development } \\
\text { activities) }\end{array}$ & $\begin{array}{l}\text { industrial } \\
\text { partners }\end{array}$ & $\begin{array}{l}\text { joint participation } \\
\text { with problem owners } \\
\text { to ensure that needs } \\
\text { are addressed }\end{array}$ & $\begin{array}{l}\text { need to broaden the } \\
\text { technology base }\end{array}$ & $\begin{array}{l}\text { cost-sharing } \\
\text { opportunities }\end{array}$ \\
\hline Rocky Flats & \multirow{4}{*}{$n / a$} & \multirow{4}{*}{$\begin{array}{l}\text { All sites with } \\
\text { plutonium- } \\
\text { contaminated } \\
\text { facilities will be } \\
\text { invited to participate } \\
\text { in laboratory-scale } \\
\text { activities and to } \\
\text { incorporate their site- } \\
\text { specific requirements } \\
\text { into activity } \\
\text { development. }\end{array}$} & $\begin{array}{l}\text { 1) large Pu facility } \\
\text { 2) initiating EM-60 } \\
\text { deactivation activities } \\
\text { 3) planning - current } \\
\text { work - current }\end{array}$ & \\
\hline Savannah River & & & $\begin{array}{l}\text { 1) large Pu facility } \\
\text { 2) ongoing DP } \\
\text { deactivation activities } \\
\text { 3) eventual EM- } 60 \\
\text { deactivation activities } \\
\text { 4) planning - current } \\
\text { work - current }\end{array}$ & \\
\hline LANL & & & $\begin{array}{l}\text { 1) large Pu facility } \\
\text { 2) operational status }\end{array}$ & \\
\hline Hanford & & & $\begin{array}{l}\text { 1) large Pu facility } \\
\text { 2) initiating EM-60 } \\
\text { deactivation activities } \\
\text { 3) planning - current } \\
\text { work - current }\end{array}$ & \\
\hline
\end{tabular}




\section{Assumptions}

- Plutonium-processing facilities will be open for reasonably easy access to representatives from industry and other sites throughout the DOE Complex.

- Transition and site activities will preclude use of appropriate facilities.

- Overall ID cost will not exceed \$20 million.

- Plutonium-processing Facilities ID field activities will be conducted in conjunction with operating program deactivation activities.

- Waste disposal will not be a significant project roadblock.

\section{Section 7 Issues}

- Numerous issues associated with the problem of plutonium facilities deactivation should be addressed with systems engineering techniques. These principally involve issues related to the handling, packaging, storage, and treatment of wastes generated by D\&D.

- Which disposition, disposal, and treatment options are acceptable to the public (e.g., incineration could provide very significant TRU waste reduction and affect D\&D technology and operational choices)? 


\section{Section 8 ID Schedule and Costs}

The following table summarizes the costs (in millions) of this ID over its entire lifespan.

\begin{tabular}{|l|c|c|c|c|c|c|c|}
\hline & Year 1 & Year 2 & Year 3 & Year 4 & Year 5 & Year 6 & Total \\
\hline Characterization & 0.30 & 0.80 & 0.30 & 1.20 & 0.70 & & 3.30 \\
\hline Decontamination & 0.20 & 1.00 & 4.00 & 1.50 & 1.50 & & 8.20 \\
\hline Dismantlement & & & & 1.25 & & & 1.25 \\
\hline Materials Disp. & & & 0.77 & 0.62 & 0.60 & & 1.99 \\
\hline Robotics \& Auto. & & 0.05 & 0.05 & 0.70 & 0.20 & & 1.00 \\
\hline Mgmt. \& Sys. & 0.50 & 0.25 & & & & & 0.75 \\
\hline Total & $\mathbf{1 . 0 0}$ & $\mathbf{2 . 1 0}$ & $\mathbf{5 . 1 2}$ & $\mathbf{5 . 2 7}$ & $\mathbf{3 . 0 0}$ & $\mathbf{0 . 0 0}$ & $\mathbf{1 6 . 4 9}$ \\
\hline
\end{tabular}


Plut onilum Facllit tes Deactivation Demonst ration Path

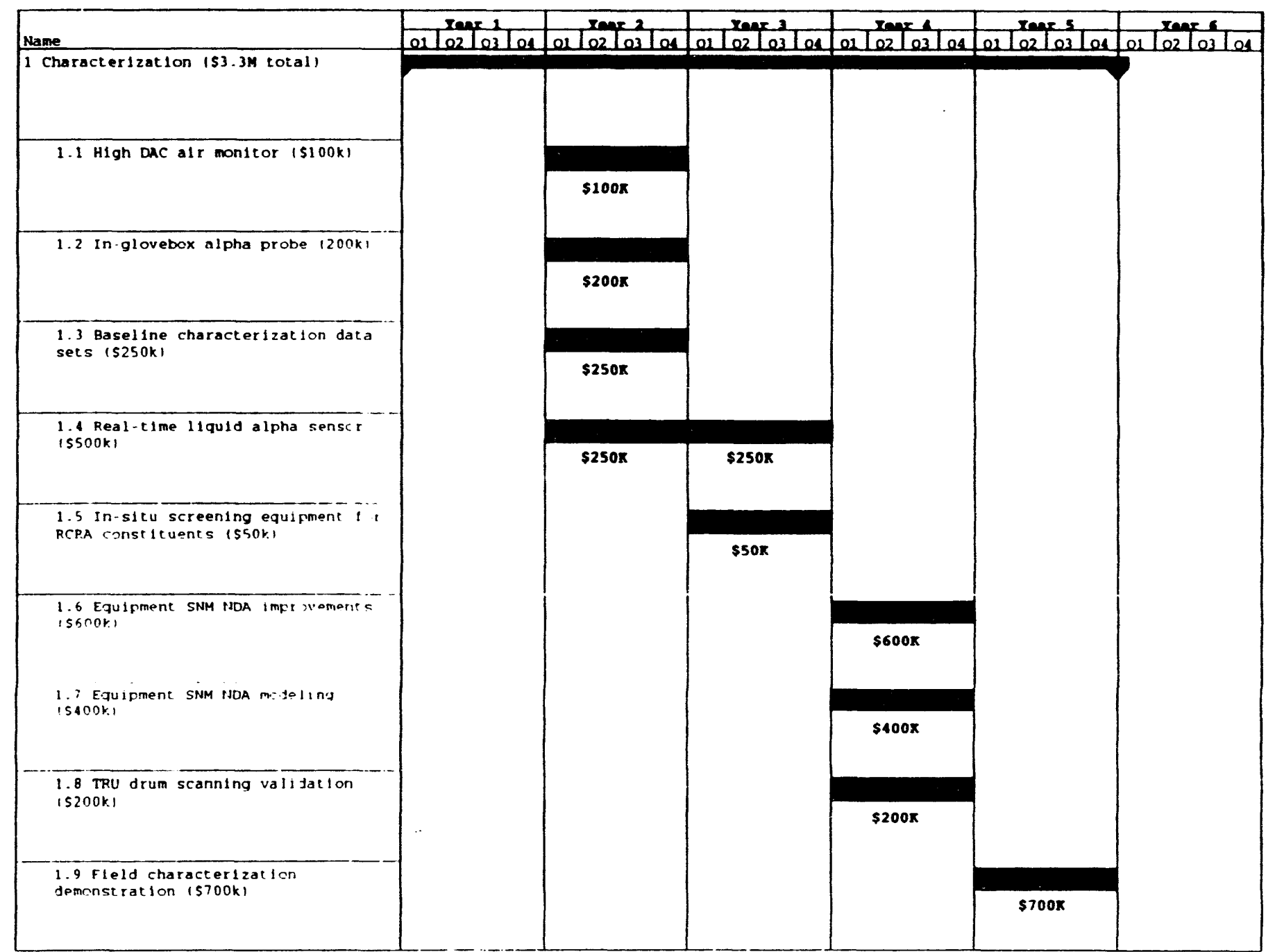


Plutonium Facilities Deactivation Demonstrat ion rath

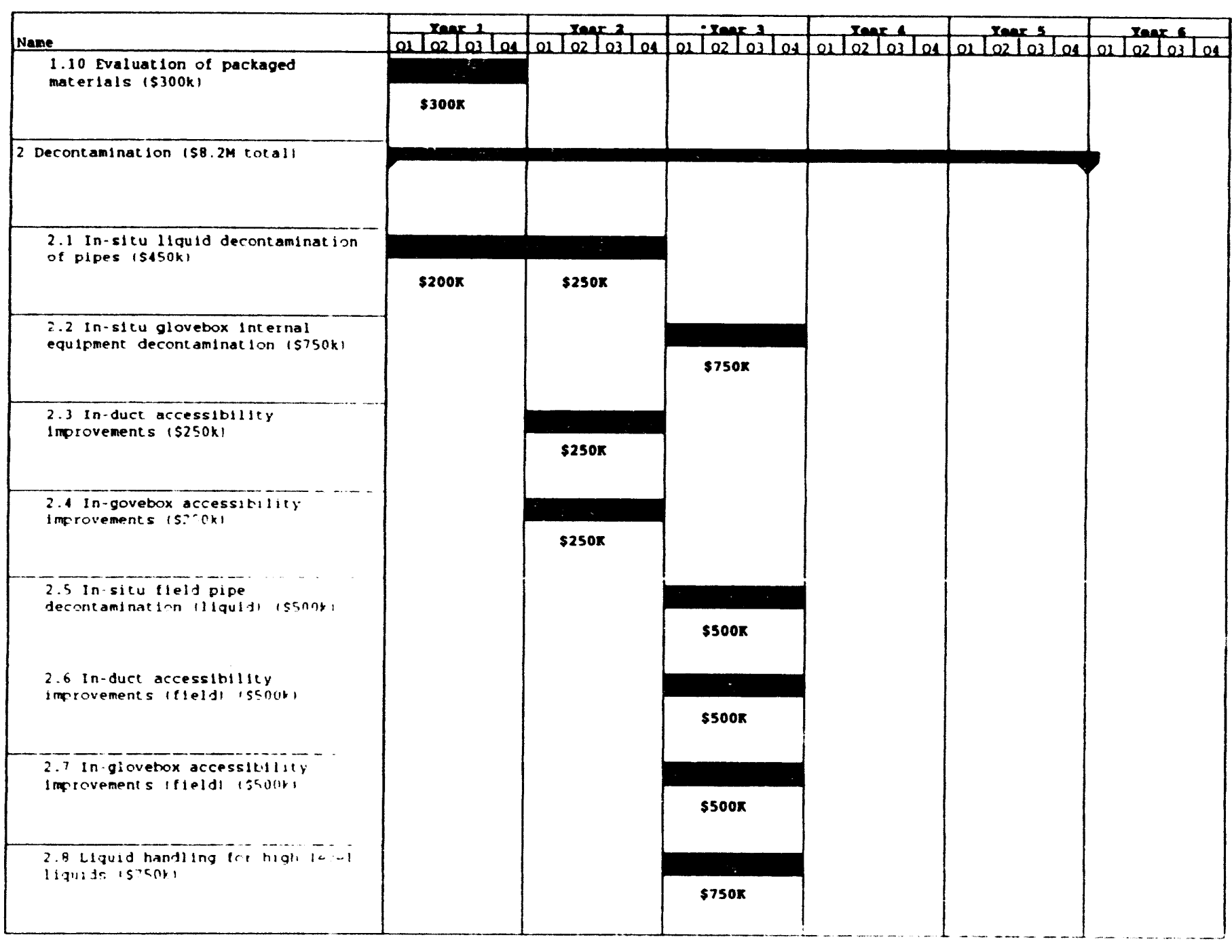


Plutchium Facilities Deactivation Demonstration path

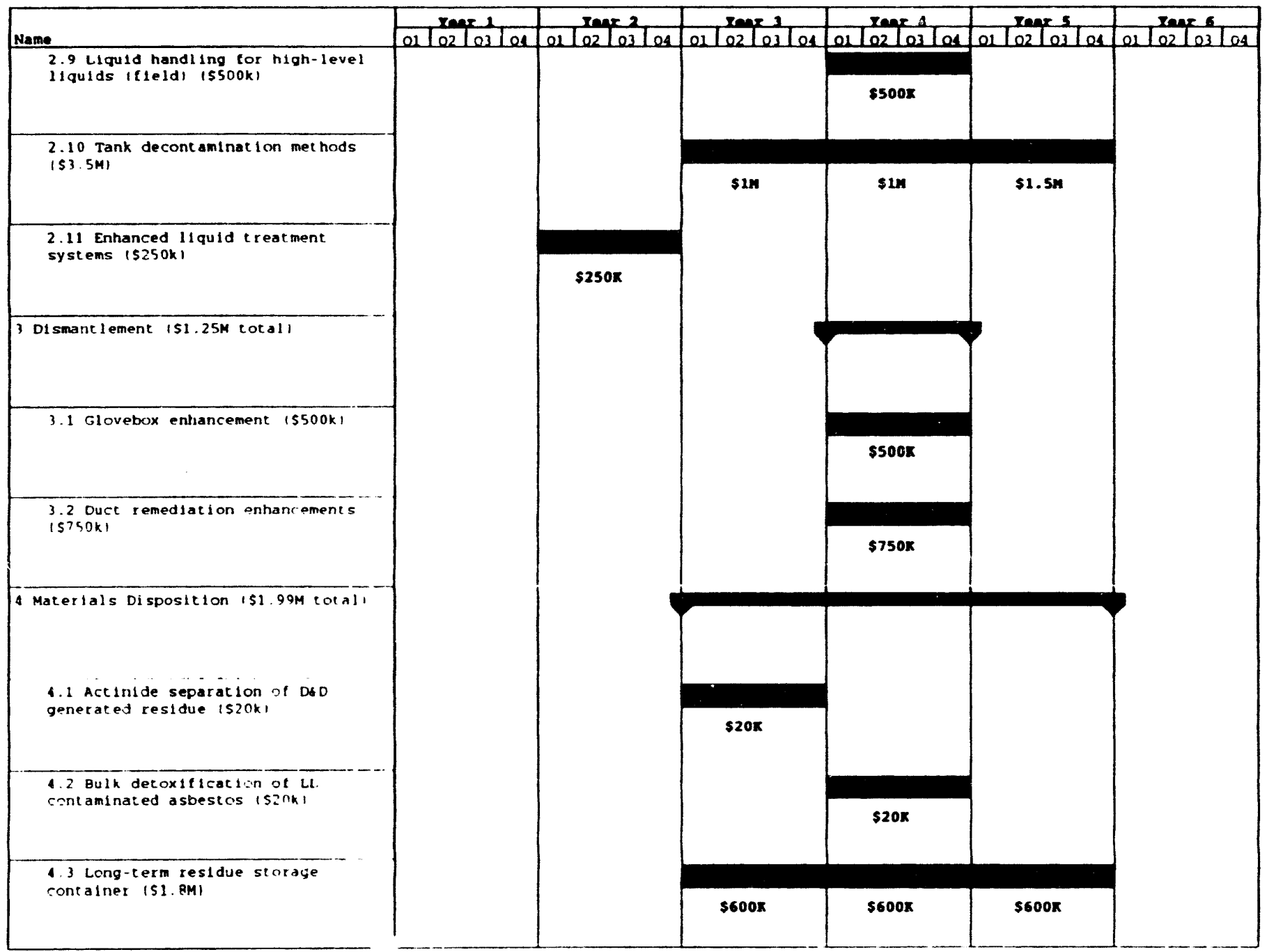




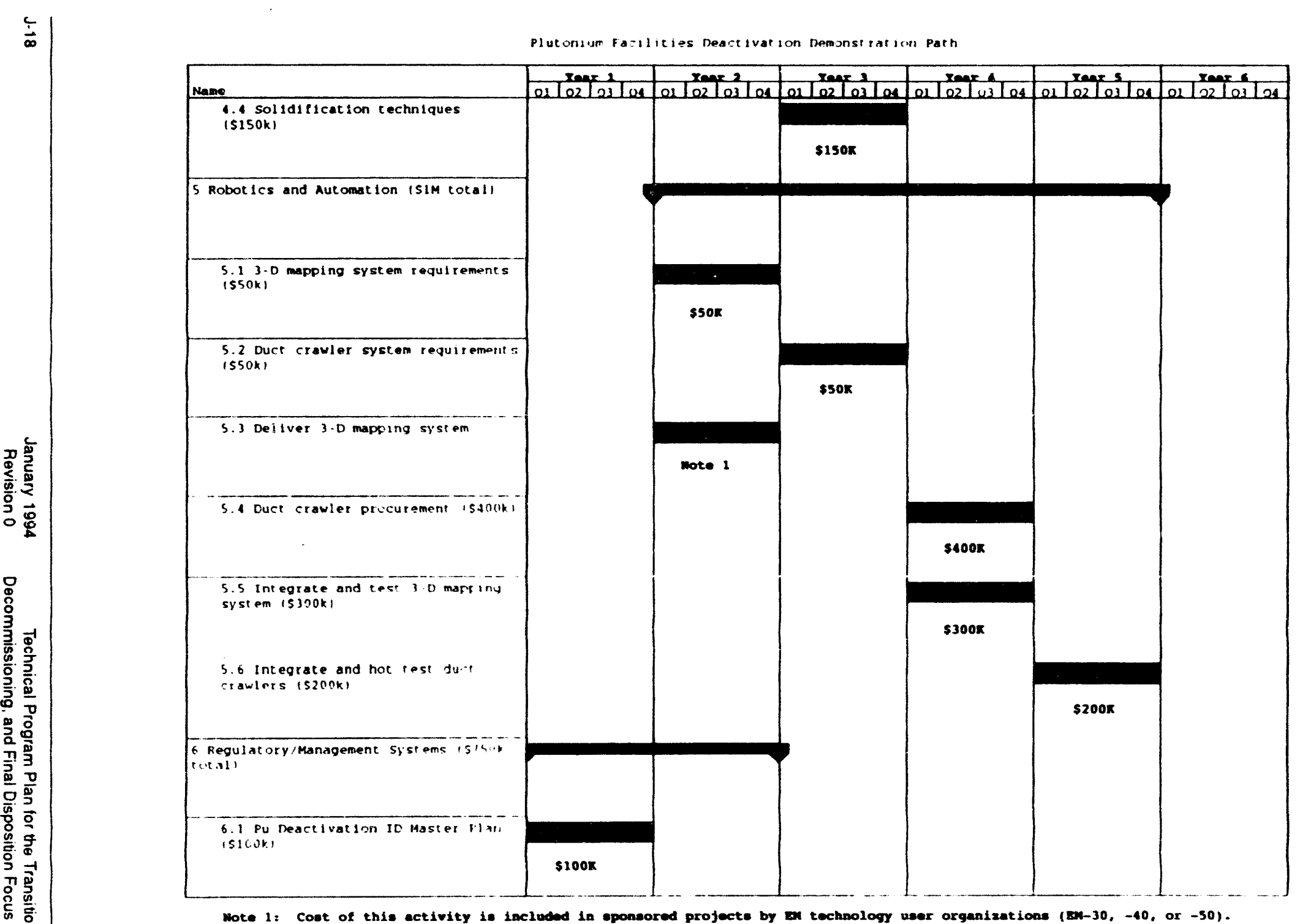


Plut onlum Facllities Deact. At ion Demonstration path

\begin{tabular}{|c|c|c|c|c|c|c|}
\hline & 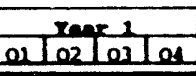 & 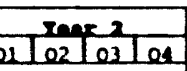 & Oeleatejtor & Feleztoila & 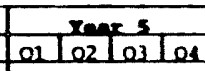 & 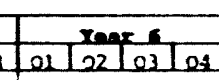 \\
\hline 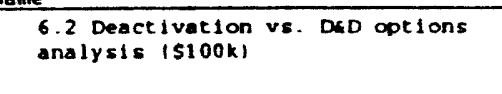 & 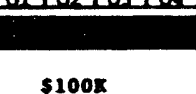 & & & & & \\
\hline 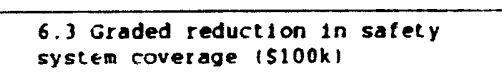 & & & & & & \\
\hline $\begin{array}{l}\text { 6.A Residue package } 11 \text { fe cycle cost } \\
\text { analysis } \mid \text { S } 100 \mathrm{k} \text { ) }\end{array}$ & & s1008 & & & & \\
\hline 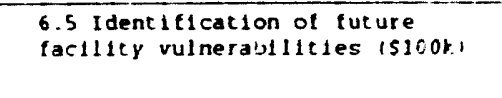 & s1000 & & & & & \\
\hline 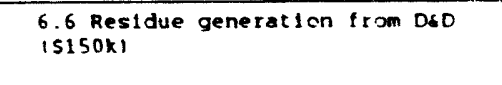 & & s150\% & & & & \\
\hline 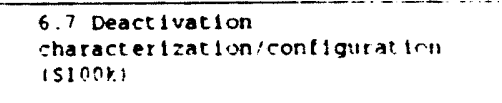 & $\$ 100 x$ & & & & & \\
\hline
\end{tabular}




\section{Equipment}

This appendix contains two proposals. The De-inventory and Deactivation proposal begins on page $J-2$.

\section{Section $9 \quad$ Situation Analysis}

\section{Section 9.1 Problem Definition}

Description of Facilities throughout the DOE Complex contain what amounts to tens of the Problem thousands of tons of plutonium-contaminated equipment, principally at Rocky Flats, Savannah River, Hanford, LANL, and LLNL. There are also a few domestic industrial sites and several overseas sites with plutonium contamination. Although less in tonnage or area than problems such as uranium or reactors, plutonium-processing facilities present relatively higher public risk in the event of release. Because of their construction and functions, plutonium-processing facilities tend to be more difficult to retire. Thus, delays to D\&D represent a significant ongoing surveillance and maintenance cost. The cost of actual D\&D is expected to be in the range of several billion dollars. Much of the resultant waste will be classified as transuranic, for which there is no permanent means of disposal at this time; intermediate or long-term waste storage costs will continue after D\&D is completed. Finally, at sites with plutonium-processing facilities, those facilities are generally considered the major contributor to off-site risk.

The proposed $\mathrm{D}$ covers the activities associated with the D\&D of plutonium facility equipment subsequent to facility deactivation. It focuses on the actual removal of equipment, waste generation and regulatory issues, a "construction project" approach, and occupational and radiological risks to workers.

\section{Section 9.2 Characterization}

Baseline Technologies

Current baseline technologies include standard characterization methods: gamma spectrometry, smears and samples, process knowledge, historical records, and inspections. Because the use of these methods has been accepted in the piecemeal D\&D projects undertaken to date, there has been little change in the technology over the last few years. The increased scope of the current DOE Complex D\&D and the attendant waste-generation issues supports the need to develop more accurate, rapid, and flexible characterization technologies. The costs associated with baseline technologies for 
Deficiencies

Solutions

\section{Section 9.3 Decontamination}

Baseline Technology characterization vary depending on the installation and are contingent upon sampling, analysis, downtime, secondary waste disposal, and personnel exposure costs. The "no characterization" option is also a baseline approach.

There are several deficiencies associated with current baseline technolngies for characterization: inadequate equipment to determine surface and airborne contamination levels in a highly contaminated environment in real time; poor handling and processing of samples; lack of adequate in situ characterization techniques to identify SNM from the outside of ducts and equipment; the hazards to personnel and the containment problems when opening equipment to characterize internal contamination; and lack of methods for field certification of the presence or absence of hazardous contaminants. Because samples cannot be characterized in real time, we must deal with the hazards and risks associated with the transportation of contaminated materials and the difficulties commercial laboratories have when faced with the task of performing analyses for hazardous chemicals on plutonium-contaminated samples. The capacity of laboratories where the samples are analyzed is limited, and the analytic methods are slow and cumbersome. In addition, characterization using samples results in the generation of secondary waste, and the time it takes for samples to be sent off for analysis and returned reduces the overall efficiency of $D \& D$ operations. Less than adequate configuration control results in characterization, containment, and control difficulties and complicates the use of automation.

The most meaningful solution to the problems associated with using current baseline technology for characterization are viable methods for a real-time, in situ characterization. The tools and methods should include mapping and discrimination capabilities, improved access capabilities for video systems, optical 3-D capabilities, in-system probes, portable neutron systems (passive and active), long-range alpha detectors (LRAD), laboratory automation, local field laboratories, and real-time field measurement capabilities for radioactive constituents. These solutions reduce worker exposure, support regulatory approval of a method for waste certification, and are more efficient because they will use automated technology.

Current baseline technologies include manual scrubbing (e.g., brushes), sprays, strippable paints, chemical treatments, and vacuum collection systems in ducts. Ex situ decontamination methods (e.g., electropolishing) have been demonstrated, but not integrated into operations. No decontamination, and disposal as-is, is also a baseline approach. 
Deficiencies There are several deficiencies associated with current baseline technologies for decontamination. The methods available are labor intensive, time consuming, and costly, and they generate a tremendous amount of secondary (often mixed) waste. They require multiple applications to obtain satisfactory decontamination. Because we currently have no means to determine the contamination levels under material that shields alpha particles (e.g., paint), the current technologies are often inaccurate and difficult to apply. The efficiency of these methods is questionable. They suffer from the inability to treat liquids generated during decontamination operations. As a result of these deficiencies, items are often sent straight to disposal without any attempt at decontamination; alternatively, lack of in situ decontamination result in greater contamination (and, therefore, greater risk to personnel) in size reduction and packaging. The risks associated with current baseline technologies for decontamination correspond primarily to worker exposure and excess waste generation.

Solutions The ideal solutions should provide viable methods for in situ decontamination of equipment, including cracks, crevices, and gasket areas. These solutions maximize decontamination before dismantling and reduce secondary waste. Additionally, better methods to decontaminate materials after breaching the system contamination boundary need to be implemented to take advantage of the economies of scale. Solutions must consider the ability to access confined areas and other spatial constraints.

\section{Section 9.4 Dismantlement}

Baseline Current baseline technologies for dismantlement include manual operations Technologies with small tools, typically using supplied air or "bubble" suits, performed in temporary, disposable containment structures.

Deficiencies The primary deficiencies associated with the current baseline technologies for dismantlement are inadequate cutting methods, high risk of internal exposure (from alpha contamination, lead, asbestos), safety hazards, secondary waste, and labor-intensive processes. Significant problems exist in controlling dust and airborne contamination.

Solutions The solutions to the problems are the enhancement of manual size reduction and selected automated mechanisms that perform repetitive tasks and generate little secondary waste. These solutions, supported by improvements in decontamination and characterization techniques, will greatly increase worker efficiency while retaining operational flexibility. The mechanisms must be versatile enough to support different spatial configurations and material inputs and should maximize size reduction with no dispersal of radiological contamination. This solution depends on 3-D scanning, the 
robotics technology of remote delivery systems, and improvement in the operability of sectioning and size reduction containment systems.

\section{Section 9.5 Materials Disposition}

Baseline Current baseline technology is the interim, monitorable storage pending final Technologies disposition at the Waste Isolation Pilot Project (WIPP) for TRU waste, and standard burial techniques for LLW. Little, if any, real reuse or recycling is actually practiced.

Deficiencies Several deficiencies characterize current baseline technologies for materials disposition. We are limited by diminishing landfill space; increasingly restrictive environmental regulations; the inability to recycle or reuse buried waste; and the need to remove, process, and redisposition previously buried wastes. The absence of definitive TRU disposal options and the constraints and uncertainties associated with land disposal restriction (LDR) contaminated material disposal and storage complicate waste processing and interim storage issues.

Solutions The most meaningful solution to the problems associated with using current baseline technologies for materials disposition is a viable means to reduce the volume and turn decontaminated scrap materials into products for controlled beneficial reuse (probably within the DOE Complex). Failing this, significant improvements to the current situation would result from the reclassification of waste materials (i.e., TRU to LLW) to allow for better management. The solutions will encompass both surface and bulk techniques.

\section{Section 9.6 Robotics and Automation}

Baseline Currenily, the baseline technologies for remote, robotic, and automated Technologies equipment is limited to duct crawlers and remote monitoring and surveillance.

Deficiencies The deficiencies associated with current robotics and automation baseline technologies are the lack of such technologies needed to perform in situ characterization, decontamination, and dismantlement of high-volume, high-contamination equipment in plutonium-processing facilities. The current technologies and equipment either have limited access capabilities or have not been applied to this problem (as in the case of D\&D support).

Solutions Sophisticated robotics and automation (e.g., smaller pipe crawlers, micro robotics) would solve many of the problems associated with using current baseline technologies for characterization, decontamination, and dismantlement of high-volume, high-contamination equipment in plutonium-processing facilities. For plutonium facilities, the principle focus 
for robotics is to avoid work in contamination-controlled areas and to reduce labor costs and worker exposure.

\section{Section 9.7 Regulation}

All of the approaches and solutions recommended in this section are, for the most part, viable under the existing regulations. Regulatory constraints could be mitigated by a technology improvement program, by joint efforts with the regulators to develop better waste/release certification methods, and by a means of supporting ARAR determination.

\section{Section 10 Description of the Proposed Integrated Demonstration}

The scope of this ID is the development of technologies to assist in the D\&D of plutonium-processing facilities' process equipment. This scope includes all equipment that makes up or is within the primary containment boundary: gloveboxes, tanks, ducts, filter plenums (Zone I only), process piping, etc. ID activities support those D\&D activities that occur throughout the removal and disposition of the contaminated equipment. This ID includes studies, cold development, and laboratory and field activities, including both Pu-239 and Pu-238 facilities.

The ID will focus on two principle areas of opportunity: the reduction of D\&D labor costs, and the reduction of the quantities of waste in the higher risk and cost classifications (i.e., TRU versus LLW). Reduction in labor costs will result from having more productive $D \& D$ workers, providing workers with the tools and information to take the correct action the first time, providing a less-contaminated environment to work in, and avoiding rework and recontamination of cleaned items.

The reduction of waste volumes from higher risk and cost classifications will proceed first with minimizing the volume of TRU-mixed, then TRU, then LL-mixed, then LLW. This plan will reduce the cost of long-term storage, packaging, handling, and disprsal. Cost reductions will be accomplished in three ways. Focusing on earlier and more accurate characterization will allow better planning and reduce the material conservatively assigned to a higher classification. Improved decontamination methods will be developed to clean up items before breaching the glovebox or system boundary; the decontamination methods used after equipment is sectioned will focus on achieving consistent, reproducible results in a routine environment. Finally, items will be certified as non-hazardous (LDR) and outside of RCRA controls as early in the process as possible. 
The proposed Plutonium-processing Equipment ID activities have been broadly defined as laboratory-scale and field-scale activities. The location of laboratory-scale activities will be determined based on responses to requests for technical task plans (TTPs) and/or professional research and development agreements (PRDAs) to perform the work defined. Because esiuipment development typically does not require work in safety-class facilities, the actual location in which the activities are performed will be of secondary importance to other factors in executing the activities.

For field-scale activities, on the other hand, a deactivated plutonium facility, along with an active infrastructure to perform the necessary work, is required. Certain requirements (e.g., worker qualifications, procedural compliance, safety assessment, readiness reviews, permit compliance) musi be in place and applicable to the demonstration work to be performed. While some field-scale activities, such as characterization and testing of decontamination agents, may be covered under the umbrella of routine operations, activities such as sectioning of gloveboxes and size reduction will need substantially more support than the overall D\&D ID could be expected to provide. Therefore, these activities can be performed only in conjunction with an active plutonium D\&D project at an applicable field site.

Overall, the Plutonium-processing Equipment ID consists of series of activities. These activities develop specific technologies in a progressive fashion, from laboratory- to field-proven status. The series allows for input from industry, the use of national laboratory expertise, and the collective experience of site "owners"; it also provides a variety of test beds. Ultimate complete solutions are effected based on the successful completion of previous phases.

Three applicable field sites have budgeted activities in the appropriate time frame: Savannah River (PuFF, HB Line), Hanford (233-S), and Rocky Flats (B/779 Pilot). There are some uncertainties associated with each of these projects. Given these uncertainties, the requirement that major field activities be associated with active projects, and that significant field activities will not be initiated until FY 96, the applicable field activities have been developed generically to allow their performance at any of the three sites.

\section{Section 10.1 Activities}

The initial activity of the Plutonium-processing Equipment ID will involve the confirmation of tasks and priorities; further development of scope, success criteria, schedules, and contingencies; and initiation of system studies and will be done in an expert workshop format. Along with the confirmation of management details, the system studies and some initial laboratory-scale activities will be assigned to specific entities (sites, laboratories, private 
companies), the interfaces with other IDs and IPs formalized, and TTP Calls and requests for proposals (RFPs) finalized. This expert workshop will have and confirm a national perspective, and it will ensure that all sites with plutonium-processing facilities, the national laboratories, regulators, industry, and the public will provide appropriate up-front input to technology development needs and activity criteria.

The systems studies focus on developing the technical basis to support the activity justification, priorities, and success criteria. A brief technology logic assessment will be conducted to confirm technologies and the extent of problems and needs. Other initial systems analyses will evaluate the interrelationships of D\&D functions: material flow, interface with facility systems, regulatory impacts, precedence of activities, and waste impacts. Follow-on studies will provide more detailed options analyses for waste segregation and minimization, packaging, and level of decontamination cost/benefit. Reporting activities are discussed in the "Deliverables" section, below.

The characterization activities support the development of sensor sensitivities in ranges of specific interest to plutonium-processing equipment D\&D and support better means of characterization both in situ and at the point of packaging. Initial activities will focus on the development of instrumentation for in-glovebox contamination ranges. Follow-on activities will concentrate on adapting methods for RCRA-constituent analysis for in situ environments developed in other IDs and suitable for use in plutonium equipment. Additional activities will include the improvement of package and drum assay. The field implementation of the characterization activities will be coordinated with the decontamination and dismantlement field activities.

The decontamination activities will seek to provide better means (and validate the approach) for more aggressive, early, and in situ decontamination, resulting in less downstream and ex situ decontamination, dismantlement, and disposition costs. Initial activities focus on techniques to reduce contamination levels in inaccessible areas (e.g., dry internal decontamination of piping, in situ decontamination of glovebox internal equipment) prior to breaching the system boundary. Subsequent activities cover improvement of accessibility in awkward environments, and $e x$ situ equipment decontamination techniques. The activities are sequenced with complex ex situ field activities which depend on preceding field demonstrations of either component or similar in situ technologies, and these, in turn, depend on preceding laboratory activities.

The dismantlement activities will focus on the improvement of personnel efficiency, based on more effective tooling and size reduction enclosure improvements. Initial activities cover dismantlement of glovebox internals and general tool development. Subsequent activities focus on demonstration 
of sectioning and size reduction facility enhancements, which will be coordinated with ex situ decontamination actions.

The muterials disposition activities will support the goal of reducing the hazardous and non-hazardous TRU and LLW volumes. They are designed not to duplicate activities covered under the metals recylce or other programs, but rather to interface with requirements, develop pre-treatments or packaging concepts, and, perhaps, provine candidate materials for the other programs' testing. Downstream activiti, also cover approaches to limited actinide separation from D\&D-generated materials, and to plutonium-contaminated asbestos.

The robotics activities crosscut support characterization, decontamination, and dismantlement activities to allow for improvement of access to constrained areas and of labor productivity. Duct accessibility, 3-D mapping, centralized size reduction, mobile decontamination and dismantlement assistance, and mobile transport improvement areas will be targeted for automated systems or robotic applications. Initial activities define system requirements, followed by cold and hot demonstrations. This set of activities will tie closely with other ID robotic programs. 


\section{Section 10.2 Deliverables}

\section{General}

- technology status reports detailing the results of laboratory or cold activities to support the decisions on whether and how to proceed with field activities

- technical evaluation report detailing the results of field trials to support DQOs, the methods for meeting the objectives, and technically defensible data to support a record of decision (ROD)

- documentation for hardware, engineering, prototypes, and functional requirements

- annual reports

- strategic or management plan

- various weekly and monthly highlights, budget and project control documentation, etc.

\section{Specific}

- results of expert workshop

- validation and revision of management plan

- public outreach approach

- industry participation plan

- ID/IP coordination plan/protocol

- quarterly progress reports for the activity groups (i.e., characterization, decontamination, dismantlement, materials disposition, robotics)

- activity-based results

- cost/benefit and risk/benefit analyses

- recommendations

Reports will identify activity accomplishments, successes measured against established criteria, operational data, waste-generation information, and traceability of data. This information will be reported by activity and summarized on a quarterly basis.

\begin{tabular}{cc}
\hline J-28 January 1994 \\
Revision 0
\end{tabular}


Section 10.3 Reasons for Pursuing the Proposed ID Now (versus Later)

- Regulatory and safety practices are constraining our ability to perform D\&D using previously acceptable methods.

- Substantial portions of these activities will support facility deactivation, which is in progress and which will continue past 1999.

- We anticipate overall plutonium facilities' D\&D activities to increase significantly beginning in FY 98.

- This process represents an opportunity to tie into and avail ourselves of other activities funded by EM-50 (e.g., IDs, IPs).

\section{Section $11 \quad$ Benefits}

The following are the direct benefits of successfully completing the proposed ID:

- assist other D\&D activities to reduce the possibility of SNM proliferation and nuclear criticality, operating costs, and stakeholder involvement problems

- reduce internal exposure to workers

- reduce off-site risks to the public during D\&D activities

- reduce industrial hazards for workers

- reduce high-level (TRU) wastes and ensure that those high-level wastes that are generated are in a compact, transportable, and disposable form

- demonstrate improved technology for characterization instrumentation and tools for operational and materials disposition cost savings

- recycle stainless steel for beneficial reuse by DOE 
Through interaction with industry on technological development and transfer, we will be able to take advantage of current industrial developments, foster improvements to focus on our specific needs, and apply technologies developed for D\&D activities to other non-DOE remediation and cleanup activities. Following are categories of D\&D technologies that might be applicable to such activities:

- characterization instrumentation (e.g., TRU waste monitors)

- dismantlement tooling that is smaller and more flexible

- decontamination processes (e.g., foams, gels, and dry methods for surface decontamination)

- robotic and automated systems

This ID is applicable to other D\&D problems throughout the DOE Complex.

- It will support activities that are ongoing in other IDs and apply developments in those IDs to other D\&D applications.

- D\&D techniques developed for gloveboxes at plutoniumprocessing facilities can be applied to gloveboxes used for other purposes (e.g., enriched uranium processing).

- Advances made in characterization and removal activities for contaminated ductwork will be useful for D\&D work at other facilities.

- SNM and TRU assay activities will support and enhance waste characterization activities.

Data collected under this program will support the ongoing D\&D planning effort.

- estimates of recycle/reuse potential for D\&D-generated materials

- refinements of D\&D methods

- waste volume forecasts (supporting waste storage requirements)

- baseline project criteria 
Section 12 What Cannot Be Done Between FY 94 and FY 99

We lack the technology to

- decontaminate whole or large portions of gloveboxes in a single process and

- "shred" whole gloveboxes and thereby avoid manual dismantlement and size-reduction activities.

Without this technology, these methods will be unavailable to us in the given time frame.

\section{Section $13 \quad$ Locations}

The table below lists the DOE and commercial sites with plutonium-contaminated facilities, their relationships to each other, and the current justification for a D\&D ID.

\begin{tabular}{|c|c|c|c|c|}
\hline DOE Sltes & $\begin{array}{l}\text { Potential } \\
\text { Commerclal } \\
\text { Sites }\end{array}$ & $\begin{array}{l}\text { Relationships } \\
\text { between Sites }\end{array}$ & $\begin{array}{l}\text { Technical } \\
\text { Justlfication }\end{array}$ & $\begin{array}{l}\text { Financial } \\
\text { (or other) } \\
\text { Justiflcation }\end{array}$ \\
\hline $\begin{array}{l}\text { "Open" sites } \\
\text { (e.g., national } \\
\text { laboratories and other } \\
\text { sites capable of } \\
\text { development } \\
\text { activities) }\end{array}$ & $\begin{array}{l}\text { industrial } \\
\text { pätners }\end{array}$ & $\begin{array}{l}\text { joint participation with } \\
\text { problem owners to } \\
\text { ensure that needs are } \\
\text { addressed }\end{array}$ & $\begin{array}{l}\text { need to broaden the } \\
\text { technology base }\end{array}$ & $\begin{array}{l}\text { cost-sharing } \\
\text { opportunities }\end{array}$ \\
\hline Rocky Flats & \multirow{4}{*}{$\begin{array}{c}\text { none } \\
\text { identified }\end{array}$} & \multirow{4}{*}{$\begin{array}{l}\text { All sites with plutonium- } \\
\text { contaminated facilities } \\
\text { will be invited to } \\
\text { participate in } \\
\text { laboratory-scale } \\
\text { activities and to } \\
\text { incorporate their site- } \\
\text { specific requirements } \\
\text { into activity } \\
\text { development. }\end{array}$} & $\begin{array}{l}\text { 1) large Pu facility } \\
\text { 2) initiating EM-40 } \\
\text { D\&D activities } \\
\text { 3) planning - FY } 95 \\
\text { work - FY } 97\end{array}$ & \\
\hline Savannah River & & & $\begin{array}{l}\text { 1) large Pu facility } \\
\text { 2) ongoing DP } \\
\text { D\&D activities } \\
\text { 3) initiating EM-40 } \\
\text { D\&D activities }\end{array}$ & \\
\hline LANL. & & & $\begin{array}{l}\text { 1) large Pu facility } \\
\text { 2) eventual EM-40 } \\
\text { D\&D activities }\end{array}$ & \\
\hline Hanford & & & $\begin{array}{l}\text { 1) large Pu facility } \\
\text { 2) initiating EM-40 } \\
\text { D\&D activities }\end{array}$ & \\
\hline
\end{tabular}




\section{Section 14 Assumptions}

- Plutonium-processing facilities will be open for reasonably easy access to representatives from industry and other sites throughout the DOE Complex.

- There will be no investment in the metals-refining infrastructure.

- There will be no licensed production smelter available before FY 99.

- There will be no ci minimis standard before FY 97.

- Transition and site activities will not preclude the use of appropriate facilities.

- The overall cost of the ID should not exceed $\$ 20$ million.

- Plutonium-processing Facilities ID activities will be conducted in conjunction with an operating program D\&D project.

- Waste disposal will not be a significant project roadblock.

\section{Section 15 Issues}

- Numerous issues associated with the problem of plutonium facilities equipment should be addressed with systems engineering techniques. These principally involve issues related to the handling, packaging, storage, and treatment of wastes generated by $D \& D$.

- Which disposition, disposal, and treatment options are acceptable to the public? 


\section{Section 16 ID Schedule and Costs}

The following table summarizes the costs (in millions) of this ID over its entire lifespan.

\begin{tabular}{|l|c|c|c|c|c|c|c|}
\hline & Year 1 & Year 2 & Year 3 & Year 4 & Year 5 & Year 6 & Total \\
\hline Characterization & 0.20 & 0.67 & 0.77 & 0.65 & 0.20 & & 2.49 \\
\hline Decontamination & & 0.45 & 1.30 & 2.00 & 1.75 & & 5.50 \\
\hline Dismantlement & & 0.45 & 1.75 & 1.25 & 1.00 & & 4.45 \\
\hline Materials Disp. & 0.02 & 0.04 & 0.02 & 0.07 & 0.02 & & 0.17 \\
\hline Robotics \& Auto. & 0.02 & 0.15 & 1.30 & 1.20 & & & 2.67 \\
\hline Mgmt. \& Sys. & 0.90 & 0.35 & 0.20 & & & & 1.45 \\
\hline Total & 1.14 & 2.11 & 5.34 & 5.17 & 2.97 & 0.00 & 16.73 \\
\hline
\end{tabular}




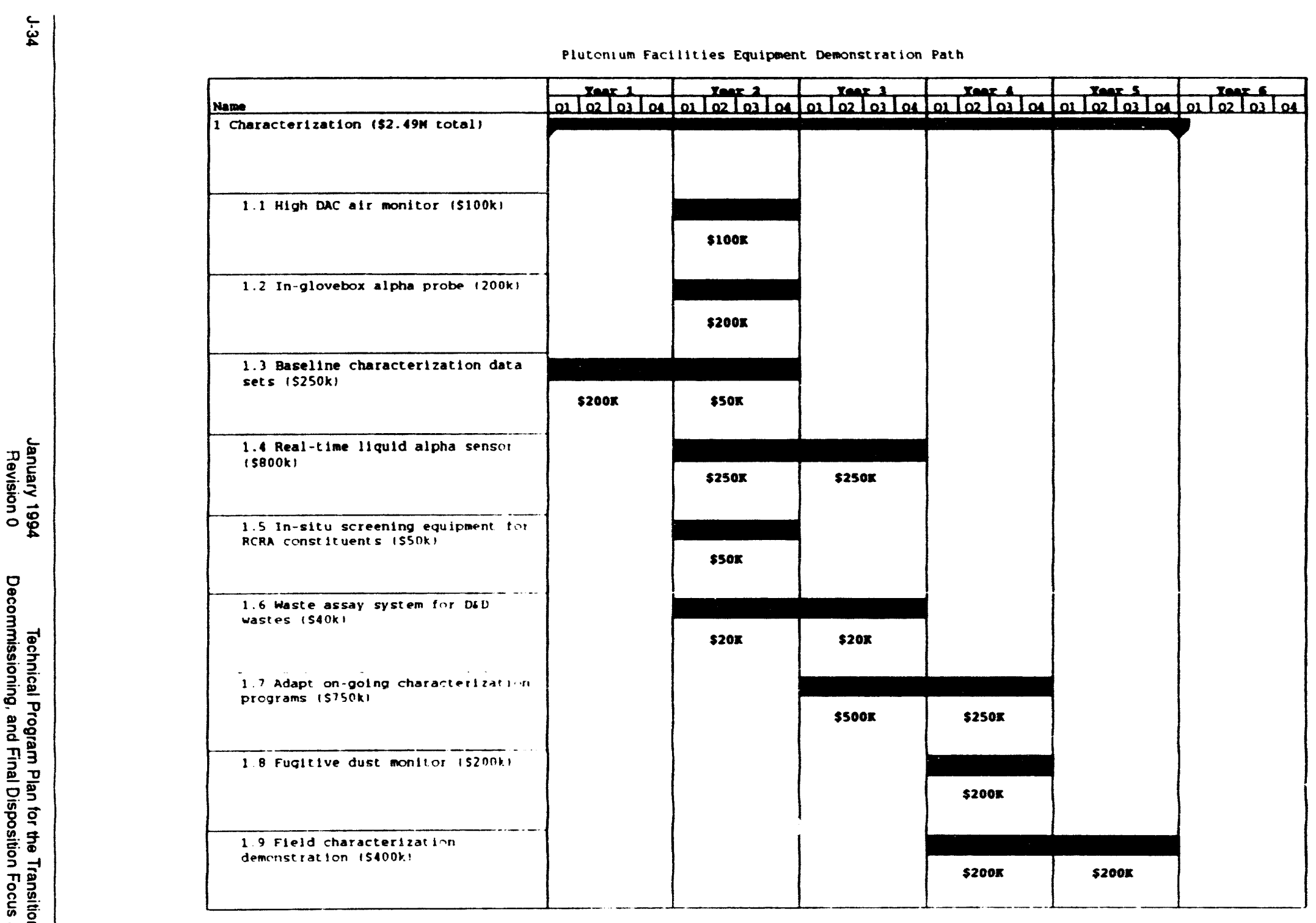


Plut onium Facilitles Equipment Demonstraticn Path

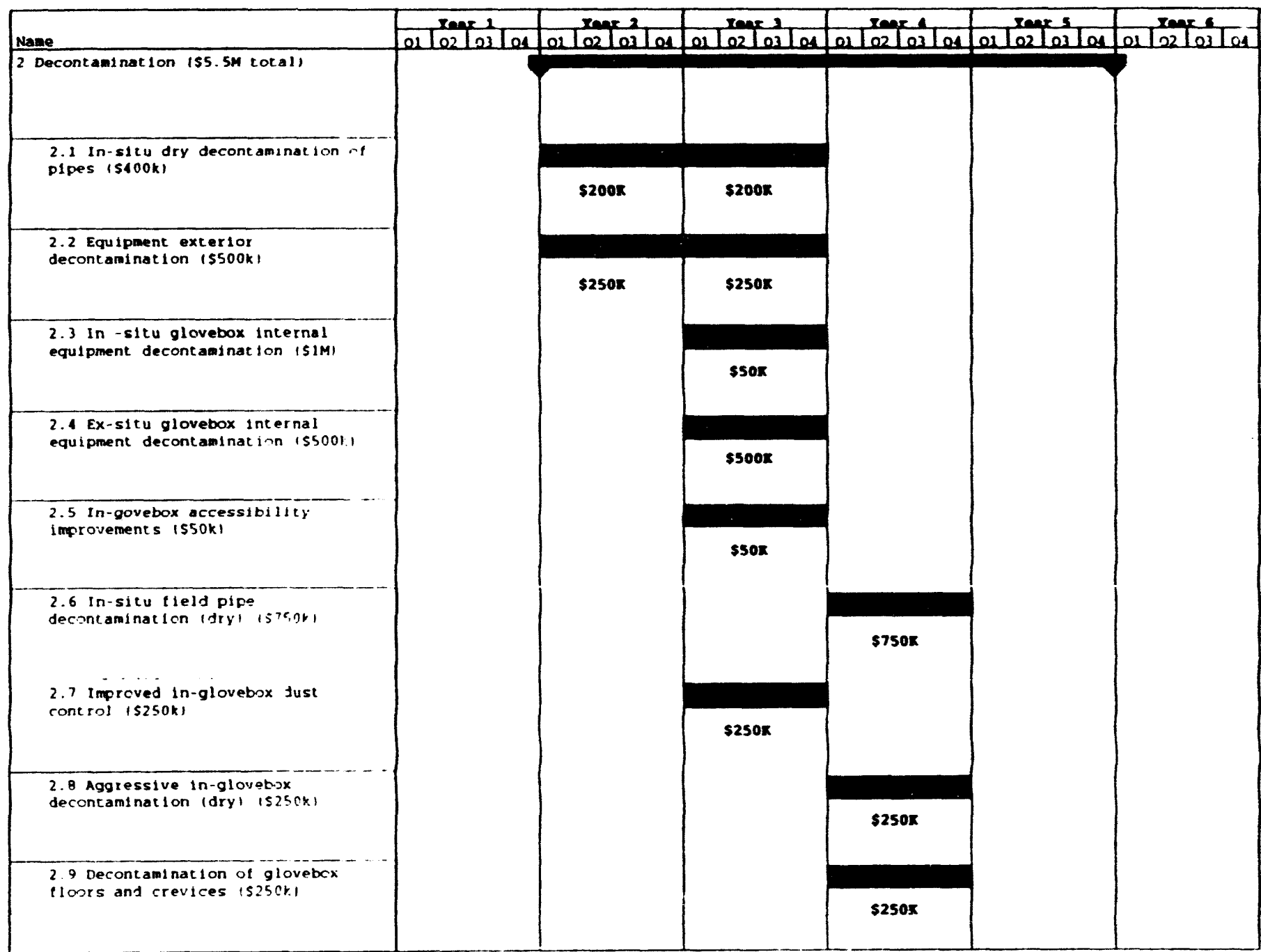




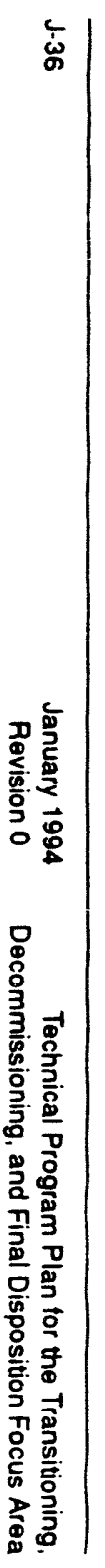

Plutciliun Facilities Equipment Demonst ration Path

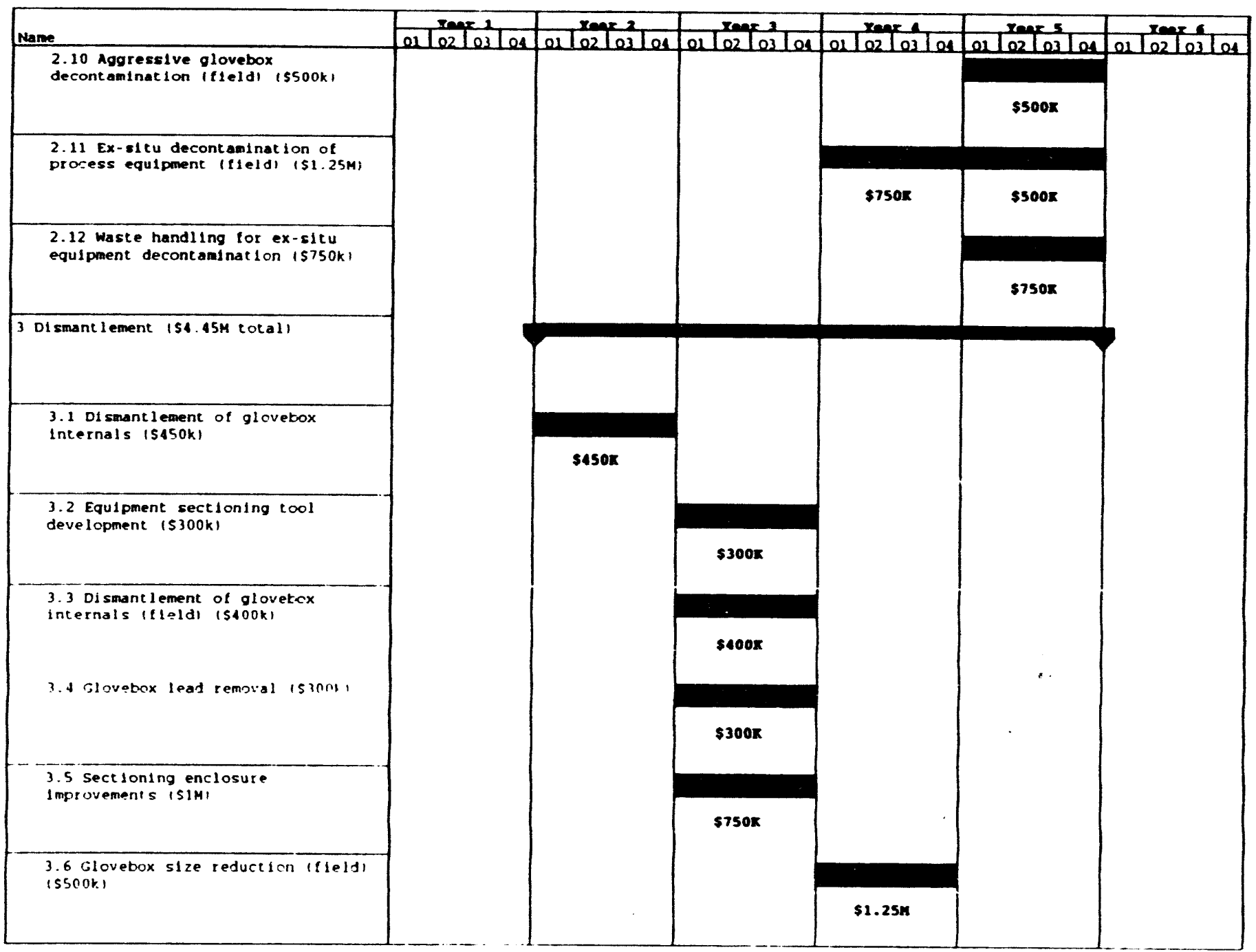


Plutchium facillelies Equipment Demonstration path

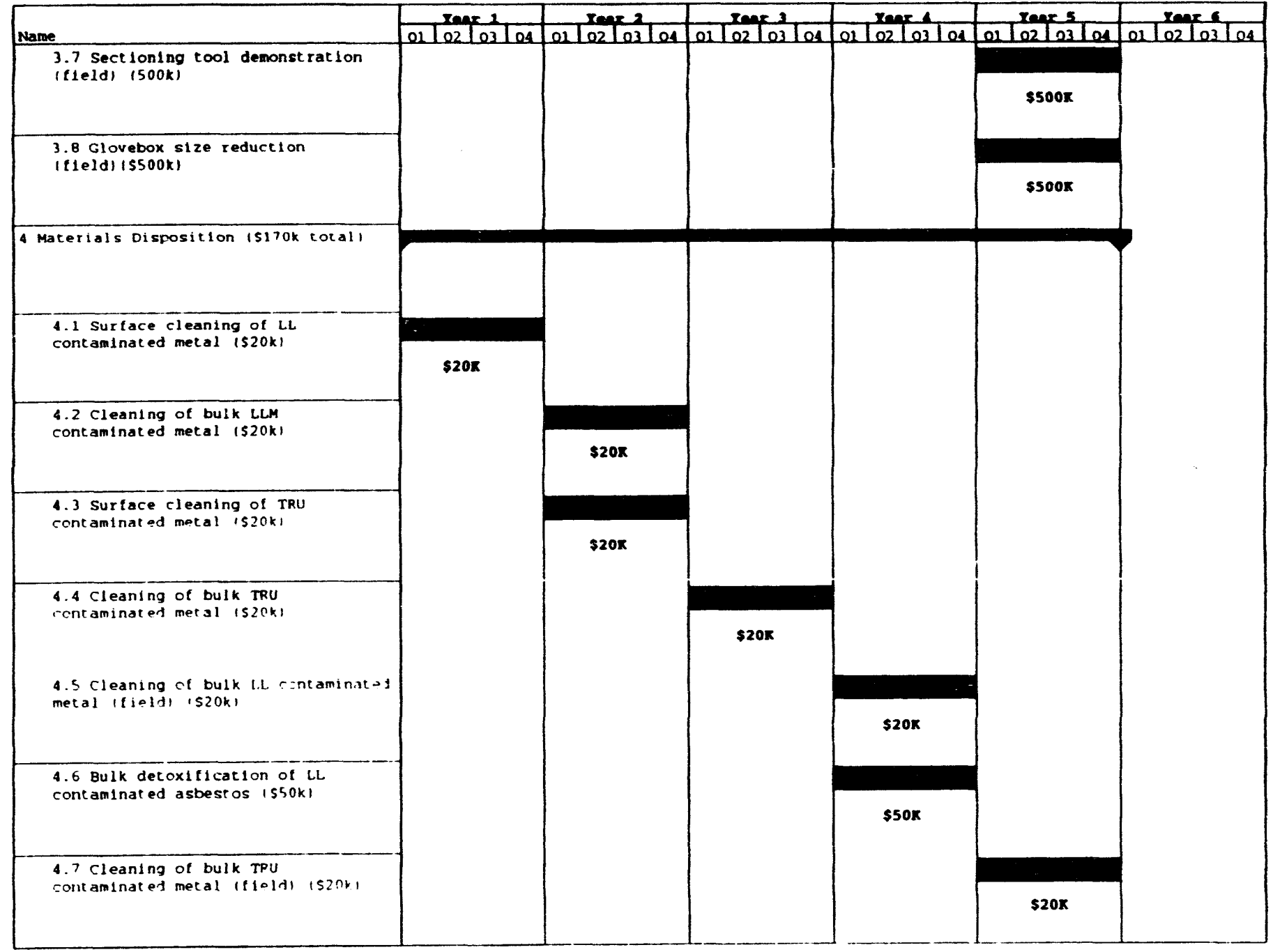




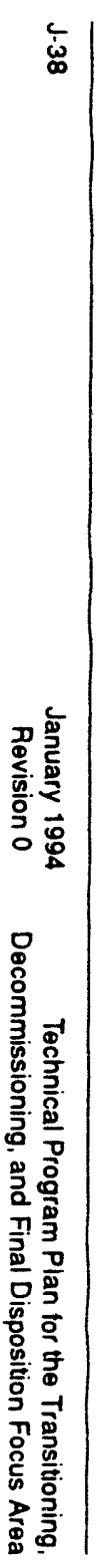

Plutentum Facsittes Equiprene Denonscration Pach

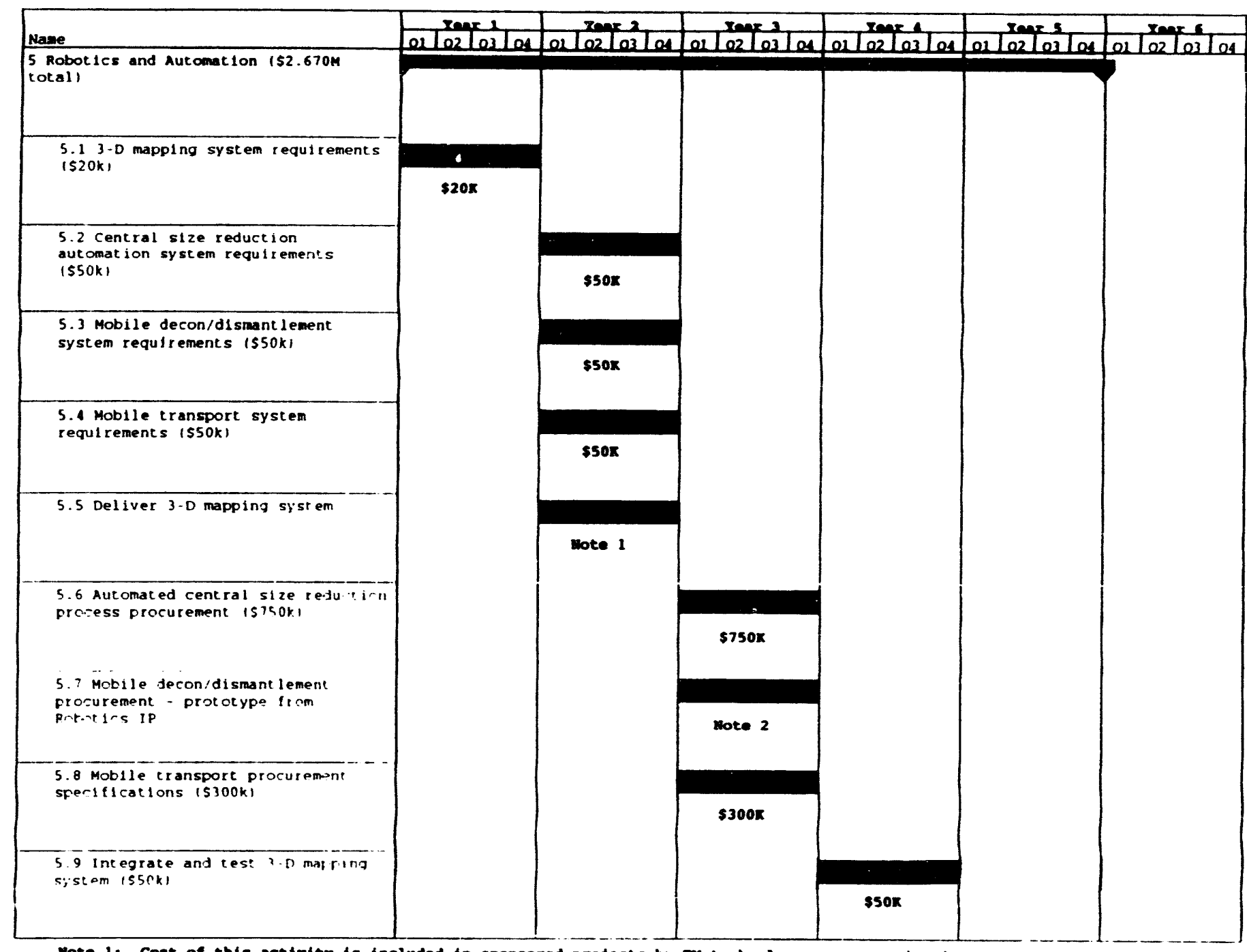

Wote 1: coet of this activity if included in aponsored projects by mechnology ueer organizetions (Ex-30, -40, or -50). 
Plutonium Facilities Equipment Des,onstration Path

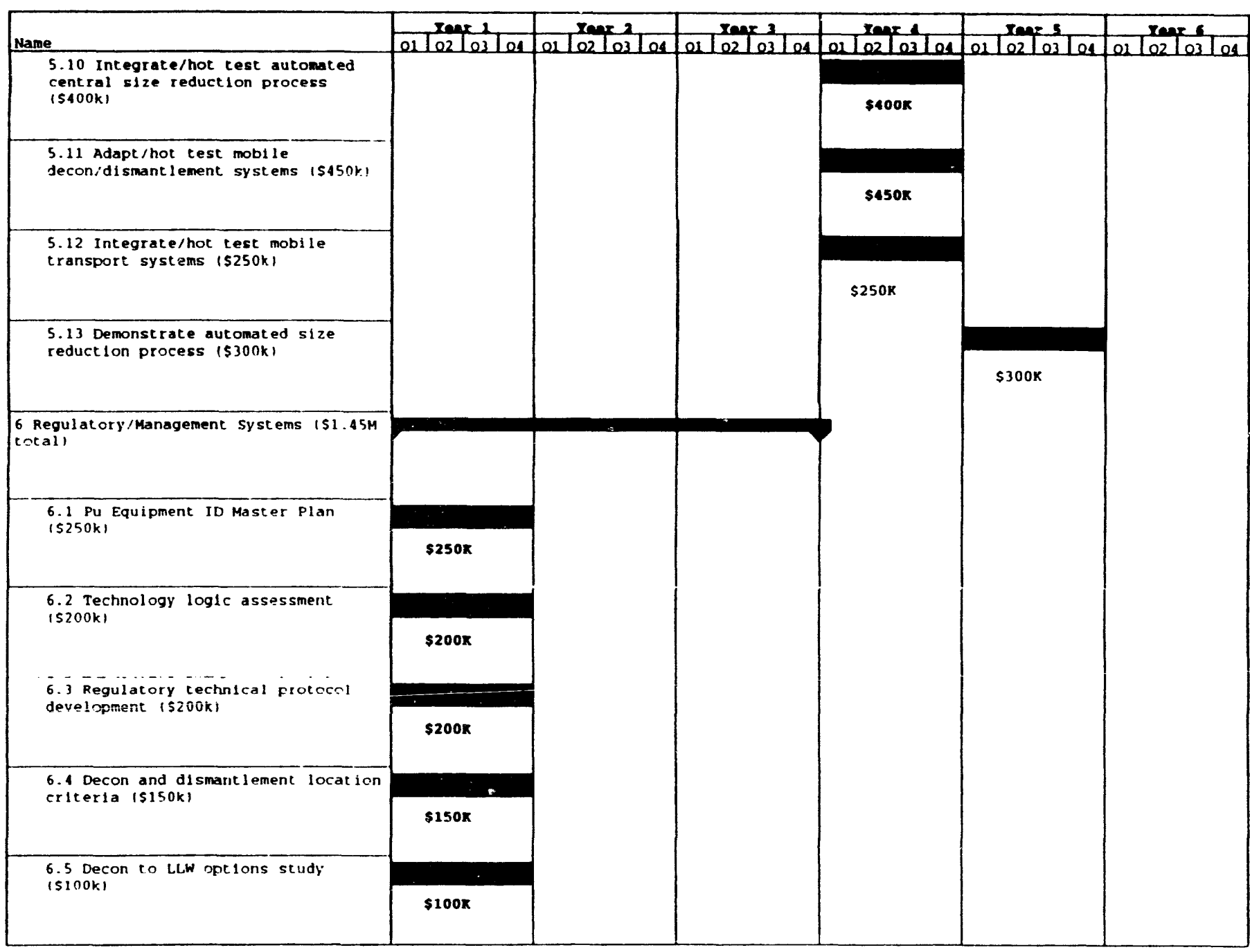




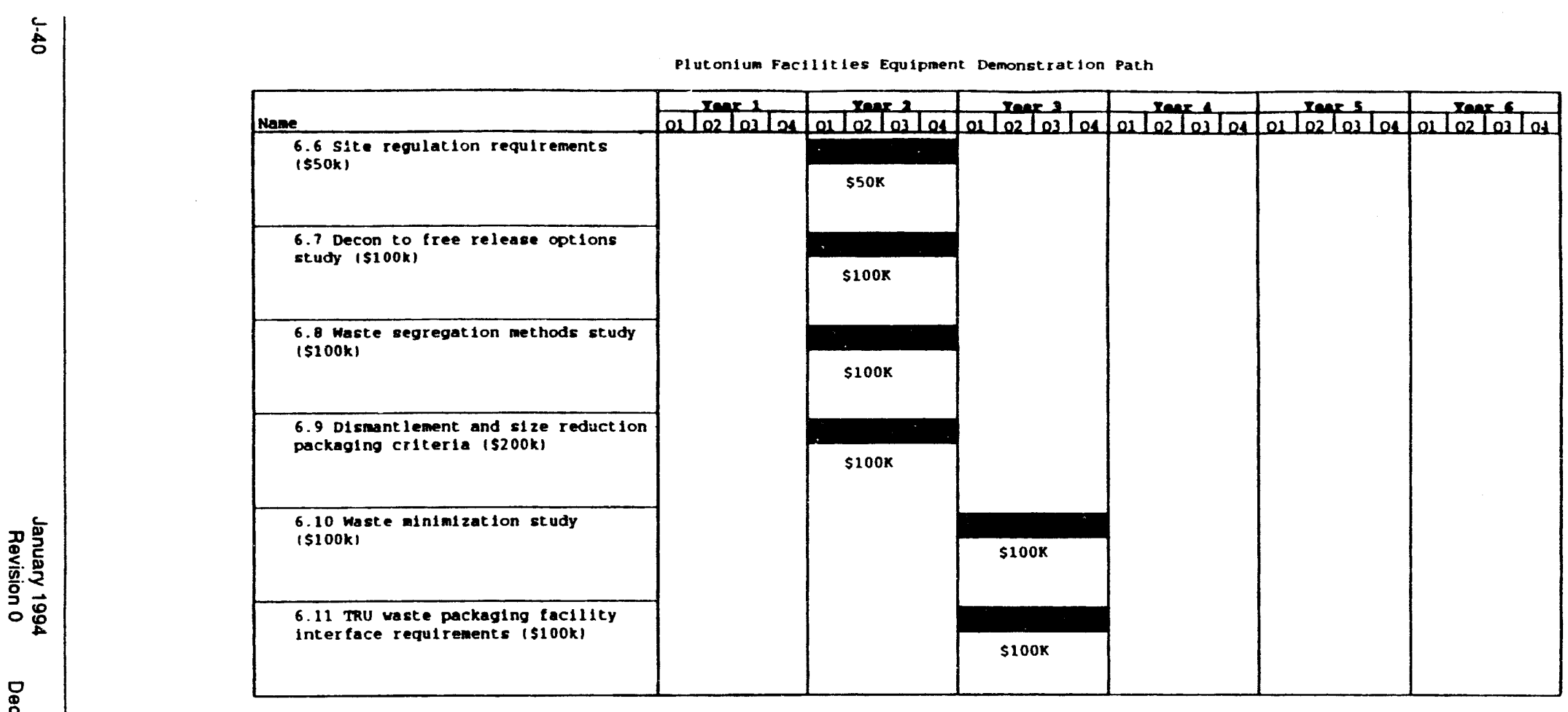




\section{Vessel and Core Components}

\section{Section $1 \quad$ Situation Analysis}

\section{Section 1.1 Problem Definition}

Size of the Nuclear reactor sites around the world pose a multitude of challenges to D\&D: Problem auxiliary systems, piping, ventilation systems, fuel storage basins, biological shields, and reactor structure and core components. Many sites, including universities and major DOE sites, have activated metal reactor vessel and core components. This specific problem presents the most difficult challenge and requires the most innovative technologies during the dismantlement of reactor sites.

Currently, the cleanup schedule remains undetermined and will depend on the D\&D schedules for each facility. Costs for vessel and core component D\&D may exceed hundreds of millions of dollars, if separate dismantlement systems are designed and fabricated for each reactor requiring D\&D.

This ID does not address graphite production reactors D\&D, nor does it address those instances where a reactor vessel and internals may be removed and shipped intact to a burial site.

\section{Section 1.2 Characterization}

Baseline Current baseline technologies include standard radiological and materials Technologies characterization methods in conjunction with the use of process knowledge (e.g., flux maps, special core loadings, operating history, power production). Though high-radiation fields can limit the accuracy of measurement set-modeling of the various parameters, they can assist in characterizing these heterogeneous structures.

Deficiencies Several deficiencies are associated with current baseline technologies for characterization. Current technologies have limited capabilities to accurately measure high-radiation fields, discern the location of the radiation, and separate surface-transferable versus bulk-activated components.

The risks associated with current baseline technologies for characterization include worker exposure and industrial safety issues. There are also risks associated with the release of radiological contaminants. 
Solutions The only solution envisioned to characterize highly irradiated components is to design a sampling system to extract a small portion of the component (i.e., drilling and collecting the removed material for ex situ analysis). The results can then be used to extrapolate total doses for the entire component to be removed. Total dose numbers will be accurate enough to design shielding requirements for removal and handling operations as well as for storage, packaging, and transportation. The system will be as compact as possible to access confined areas.

\section{Section 1.3 Decontamination}

Baseline Technologies

Decontamination of neutron-activated vessel and core components is necessary only for the purpose of limiting loose contamination in the work place during handling operations. Secondary systems (e.g., water or air filtration) supporting the dismantlement activity can generate loose contamination during the maintenance activities (e.g., filter changes) and will necessarily require decontamination operations. Baseline decontamination technologies are adequate but must be adapted to be remotely performed.

Deficiencies The baseline technologies are not generally "remotized."

Solutions Handling systems and support activities must be maintained remotely. A means to change HEPA filters or operate systems without hands-on activities will be addressed.

\section{Section 1.4 Dismantlement}

Baseline Current baseline technologies for dismantlement include long-reach Technologies manipulation and various cutting techniques to separate and remove core components and vessels. Because the adequacy of these technologies has been proven in various combinations at several sites, there has been little change in the last several years.

Deficiencies The primary deficiency associated with the current baseline technologies for dismantlement is high exposure levels. Regulations on workers' exposure reductions have now made it necessary to develop the technologies which will allow the work to be done without subjecting individuals to radiation exposure. The level of baseline technology is not adequate to preclude some "hands-on" activities. Other deficiencies include safety hazards, secondary waste generation, and labor-intensive processes. 
Solutions The most meaningful solution to the problems associated with current baseline technologies for dismantlement is to design a size-reduction system that involves robotic-tooling delivery systems and new tooling for cutting and handling. Ideally, a machine will be provided with long-reach manipulation capability. The end effectors should be remotely interchangeable, incorporate miniaturization and modular technology, employ advanced cutting techniques (e.g., plasma, water-jets, lasers), and should include a dexterous manipulator with 3-D viewing capabilities. This equipment may be designed to be adapted to the existing facility's lifting equipment, must be remotely maintainable, and must be reliable.

Consideration must be given to smoke generation and control if lasers or torches are used outside of a water-shielded environment. If underwater cutting is done, maintenance of proper water chemistry and a system to retrieve fines from demolition activities must be developed. These solutions depends on the robotics technology of remote delivery systems.

\section{Section 1.5 Materials Disposition}

Baseline The current baseline technology for size-reduced irradiated component Technologies materials disposition is packaging in shipping containers and disposing at a burial site for LLW.

Deficiencies There are several deficiencies with current materials disposition by land burial. We are limited by diminishing landfill space and increasingly restrictive environmental regulations. Transportation of highly activated material to burial sites is limited to small, lightweight loads because of shielding requirements for public transportation.

Solutions There is no known alternative to land burial of highly irradiated material. The only known solution to the problems associated with using current baseline technologies for materials disposition is to remove and transport activated materials and to standardize and simplify shielded transportation and disposal systems. With early planning we may be able to employ self-shielding concepts or use other contaminated recycled materials for shielding. 


\section{Section 1.6 Robotics and Automation}

Baseline

Technologies

Deficiencies

Solutions

\section{Section $1.7 \quad$ Regulation}

All of the approaches and solutions that we have recommended can be accomplished under the existing regulations. Regulations governing shipment of high-radiation loads will limit load size. Current restrictions on radiation levels of packages on public highways would require so much shielding that the payload (vessel and components) shipped would be but a small percentage of the total weight of the transportation system. A more efficient means to ship heavy payloads (e.g., with escorts, special routing, 24-hour travel) needs to be developed. In addition, other modes of transportation (e.g., rail, barges) should be investigated for their relative efficiency.

\section{Section $1.8 \quad$ Management and Systems}

We do not coordinate our efforts or communicate lessons learned well enough. Because of the lack of coordination and communication, each site, facility, and program is often forced to act (i.e., make decisions, initiate actions) on its own. This lack of coordination and communication also fosters the poor use of resources and a poor public opinion of our work. 
The proposed D\&D IDs represent an opportunity to develop a national program that can provide solutions to numerous situations, with little or no duplication of effort. Specifically, DOE management should provide a coordinated D\&D program for vessel and core components that will be efficient and effective. Once achieved, the program will represent a national consensus with approval from all stakeholders.

This ID will also require a strong systems management team to coordinate the many diverse activities associated with assembling, testing, and demonstrating a complex system. Technological contributors and participants include several DOE sites, various industries, and universities.

\section{Section 2 Description of Proposed Integrated Demonstration}

This ID will use an integrated approach to dismantlement of research reactor vessels and will develop technologies that may be applied to D\&D of fuel storage ponds, hot cells, fuel-reprocessing canyons, and commercial power reactors. We will assemble a remotely operated system to remove samples for characterization; decontaminate air and water through filtration systems; and dismantle internals and vessels with robotic, computer-aided cutting systems. Wherever practical, we will use and adapt existing technologies that have been successfully proven in the field.

Because a number of different end effectors will perform different functions at the end of the boom, the design must provide for quick changes of end effectors. Equipment for mapping of complex internals, component samplecollecting, and cutting will all be mounted on the end of the computer-guided delivery system. We will develop end effectors capable of complex movements to reach around, down, and through to perform their required functions. Low-maintenance, low-waste volume filtration systems will be coupled with the cutting system to collect dismantlement debris.

We will address the issues associated with the transportation of materials with high gamma dose rates to land burial sites, and we will involve a number of DOE, university, and industrial sites. We will investigate both regulatory avenues and design technology limitation. The ID will incorporate ongoing development projects and will foster the adaptation and enhancement of existing commercial equipment. 
Specifically, this ID addresses the following:

- D\&D of metal research reactor vessels and internals by size reduction and packaging;

- remote, robotic dismantlement and disassembly technologies (e.g., cutting end effectors, three-dimensional mapping for characterization);

- redesigned containment and filtration systems for air, water, and particulates; and

- an integrated dismantlement system that could be adapted to a wide variety of facilities other than reactors.

This ID will involve laboratory and field development of new technologies, modification and adaptation of existing technologies, systems integration, demonstration testing, and implementation of a project funded by EM-40.

\section{Section $2.1 \quad$ Deliverables}

The ultimate deliverable of this ID is a remotely operated research reactor dismantlement system for mapping coordinates of components, followed by computer-guided size reduction and removal of components and vessel or containment shell segments. The system's design features will also allow for the dismantlement of specific, overhead-access hot cells, fuel-processing canyons, fuel storage ponds, commercial power reactors, and other facilities.

To enhance technology transfer both within DOE and between DOE and the private sector, accomplishments and status will be reported annually.

\section{Section 2.2 Reasons for Pursuing the Proposed ID Now}

Although there are no known regulatory drivers for the D\&D of currently deactivated research reactor vessels and core components, public opinion concerning letting deactivated reactors sit or the sheer weight of the benefits may call for timely implementation of this ID. This ID will ultimately deliver a generic, remote dismantlement system with numerous technology applications for DOE and industry. Once completed, this system (and any other systems it spawns) will eliminate the costly practice of designing and building specific application systems for one-time use.

Argonne National Laboratory is currently dismantling the EBWR reactor vessel and plans to start dismantlement of the CP-5 reactor vessel in FY 96-97, followed by the Juggernaut reactor, 2-4 years later. With such near-term needs and obvious advantages for university, industry, and EM-40 involvement and 
cost sharing, the reactors ID could be used to demonstrate and work out all the mechanisms required to implement and bring an ID sponsored by EM-50 to successful fruition on an EM-40 project in the near future.

\section{Section $3 \quad$ Benefits}

- Direct benefits

- reduced worker exposure

- reduced secondary waste

- reduced environmental threat

- heavy involvement with industry

- Bencíits to DOE Complex

- improved public perception

- enhanced technology transfer

- shared technology between sites and problem areas

- shared costs to achieve common goals

- joint EM-60, -40, and -50 funding

- industry investment and cost sharing

- university investment

- applicability to other sites

- hot cells

- fuel storage pools

- fuel reprocessing canyons

- Benefits to industry and the national economy

- profit from building and selling systems to dismantle reactors

- reduced utilities costs to dismantle U.S. commercial power reactors by using DOE-developed technology

- technology adapted to handle toxic materials in manufacturing, to handle underwater demolition, or to handle rescue operations

- reduced costs by cost sharing among university research reactors 


\section{Section $4 \quad$ What Cannot be Done between FY 94 and FY 99}

- Items that are important to the demonstration but are beyond the scope of the proposal

- demonstration of technologies for more than one type of reactor

- demonstration of all cutting technologies selected (only one will be tested)

- Total automatic 3-D mapping of core component location coordinates and produ tion of software to automatically guide cutting tools to plan the most efficient sequence

- Laser (high-power) cutting delivery systems should be included but are beyond the limits of current technology. 


\section{Section $5 \quad$ Location}

The table below lists DOE sites with reactors, grouped according to their relationship to characterization and decontamination, dismantlement, robotics, and management and systems.

\begin{tabular}{|c|c|c|c|c|}
\hline DOE Sltes & $\begin{array}{l}\text { Potentlal } \\
\text { Commercial } \\
\text { Sttes }\end{array}$ & $\begin{array}{c}\text { Relationships } \\
\text { botween } \\
\text { Sltes }\end{array}$ & $\begin{array}{l}\text { Technical } \\
\text { Justilication }\end{array}$ & $\begin{array}{l}\text { Financlal } \\
\text { (or Other) } \\
\text { Justiflcation }\end{array}$ \\
\hline $\begin{array}{l}\text { Charactorization } \\
\text { and } \\
\text { Decontamination } \\
\text { Hanford, ETEC, } \\
\text { LANL. SRP }\end{array}$ & $\begin{array}{l}\text { Many reactors in the } \\
\text { U.S. }\end{array}$ & $\begin{array}{l}\text { All have some D\&D } \\
\text { experience }\end{array}$ & $\begin{array}{l}\text { 1) Some D\&D ex- } \\
\text { perience } \\
\text { 2) More effective } \\
\text { evaluation from } \\
\text { user/maintenance } \\
\text { perspective }\end{array}$ & \\
\hline $\begin{array}{l}\text { Diemantiement } \\
\text { ANL-E, INEL, } \\
\text { ORNL, SRP }\end{array}$ & $\begin{array}{l}\text { Many sites in the } \\
\text { U.S. and abroad }\end{array}$ & $\begin{array}{l}\text { ANL-E - active } \\
\text { reactor D\&D program } \\
\text { others - no plans } \\
\text { for the near term }\end{array}$ & $\begin{array}{l}\text { the designated sites } \\
\text { all have deactivated } \\
\text { research reactors }\end{array}$ & $\begin{array}{l}\text { ANL-E has EM-40 } \\
\text { funded reactor } \\
\text { dismantlement } \\
\text { program in near } \\
\text { term (FY 97) }\end{array}$ \\
\hline $\begin{array}{l}\text { Robotices/Syatems } \\
\text { Integration } \\
\text { SRP, ETEC, INEL. } \\
\text { ORNL, ANL-E, and } \\
\text { current TTP work } \\
\text { sites }\end{array}$ & $\begin{array}{l}\text { Several commercial } \\
\text { suppliers }\end{array}$ & $\begin{array}{l}\text { All sites have had } \\
\text { reactor facilities: } \\
\text { ETEC - D\&D } \\
\text { complete } \\
\text { ANL - active } \\
\text { others - not started }\end{array}$ & $\begin{array}{l}\text { 1) Savannah River } \\
\text { and ETEC have } \\
\text { personnel experi- } \\
\text { enced in reactor } \\
\text { D\&D } \\
\text { 2) ETEC ISI business } \\
\text { experience ap. } \\
\text { plicable to remote } \\
\text { systems }\end{array}$ & $\begin{array}{l}\text { For mock-up cold } \\
\text { tests, the following } \\
\text { sites have capital } \\
\text { facilities with the } \\
\text { required attributes: } \\
\text { INEL } \\
\text { EGCR at ORNL } \\
\text { ETEC }\end{array}$ \\
\hline $\begin{array}{l}\text { Mansegement and } \\
\text { Systems } \\
\text { all involved sites } \\
\text { (ORNL. ANL-E. } \\
\text { ETEC, INEL) }\end{array}$ & $\begin{array}{l}\text { Many sites in the } \\
\text { U.S. and abroad }\end{array}$ & $\begin{array}{l}\text { Reactor D\&D } \\
\text { experience and/or } \\
\text { reactors requiring } \\
\text { D\&D }\end{array}$ & $\begin{array}{l}\text { Reactor D\&D } \\
\text { experience and/or } \\
\text { reactors requiring } \\
\text { D\&D }\end{array}$ & $\begin{array}{l}\text { ANi has scheduled } \\
\text { D\&D for the near } \\
\text { future; ETEC has } \\
\text { recently completed } \\
\text { several }\end{array}$ \\
\hline
\end{tabular}


Section $6 \quad$ Issues

The following are the primary issues associated with reactor core and vessel dismantlement.

- Do either the benefits or public opinion outweigh the lack of regulatory drivers when deciding whether to implement this ID now?

- Can current Department of Transportation (DOT) regulations for transportation of radioactive waste be waived or modified for special cases (e.g., reactor component shipments) to allow more elicient movement of material to burial and storage sites?

\section{Section 7 ID Schedule and Costs}

The following table summarizes the costs (in millions) of this ID over its entire lifespan.

\begin{tabular}{|l|c|c|c|c|c|c|c|}
\hline & Year 1 & Year 2 & Year 3 & Year 4 & Year 5 & Year 6 & Total \\
\hline Characterization & 0.125 & 0.300 & & & & & 0.425 \\
\hline Decontamination & 0.100 & 0.125 & 0.025 & & & & 0.250 \\
\hline Dismantiement & 0.500 & 1.250 & 1.875 & 2.375 & 1.500 & & 7.500 \\
\hline Materials Disp. & & & 0.050 & 0.050 & & & 0.100 \\
\hline Robotics \& Auto. & 0.300 & 0.850 & 2.350 & 1.500 & 1.500 & & 6.500 \\
\hline Mgmt. \& Sys. & 0.475 & 0.375 & 0.125 & 0.125 & 0.125 & & 1.225 \\
\hline Total & 1.500 & 2.900 & 4.425 & 4.050 & 3.125 & 0.000 & $\mathbf{1 6 . 0 0 0}$ \\
\hline
\end{tabular}




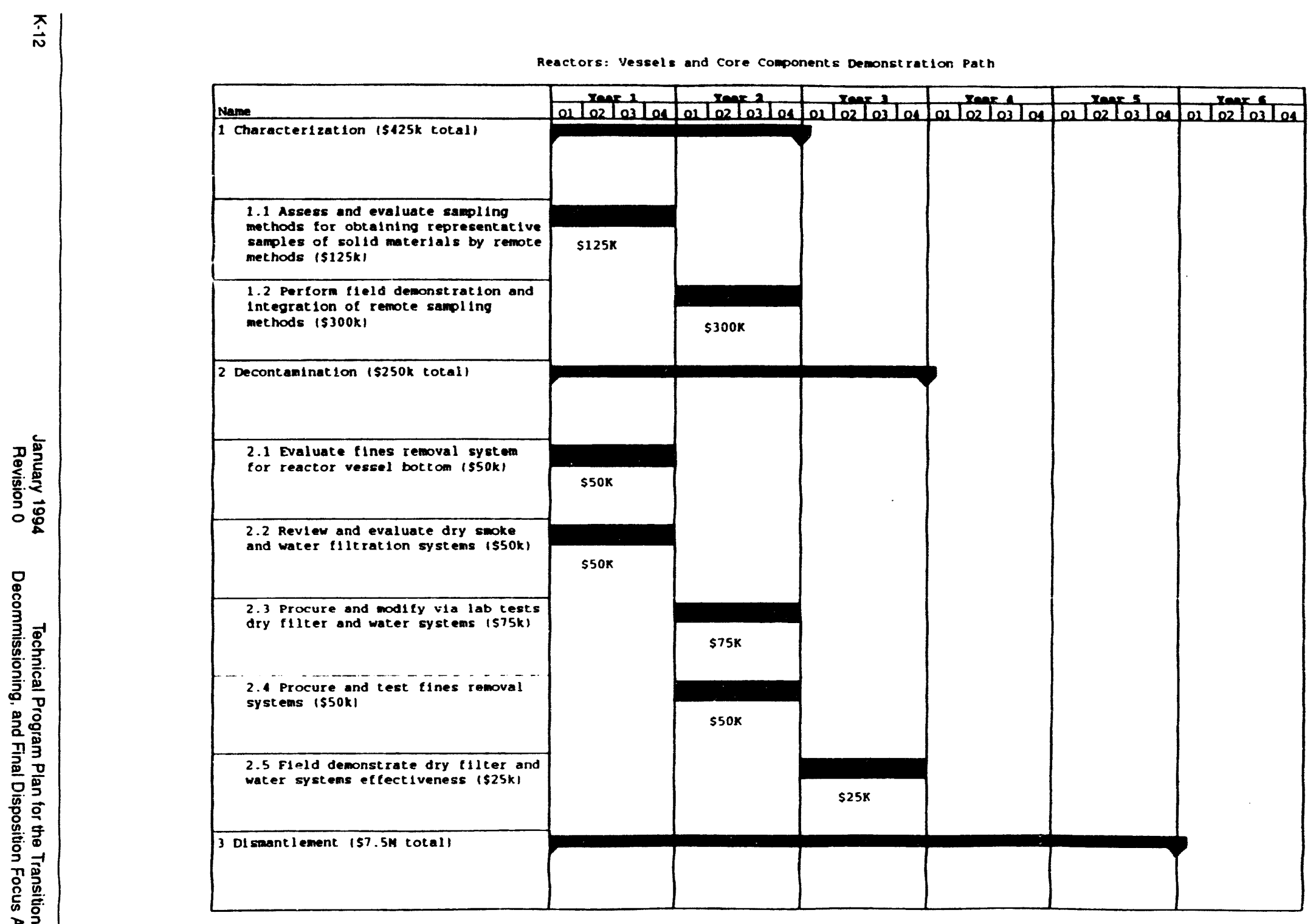


Reactors: Vessels and Core Components Demonst rat ion Fath

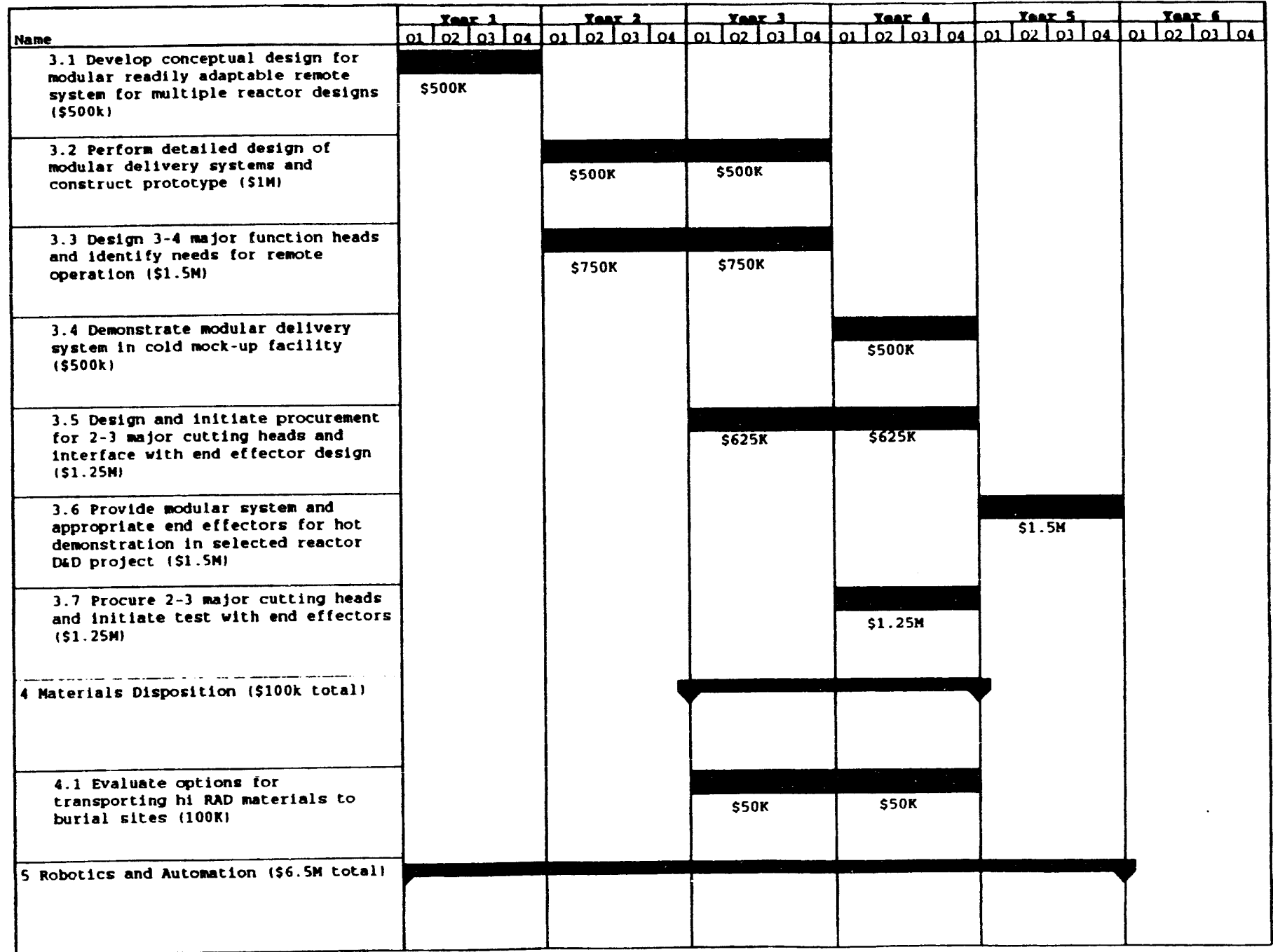




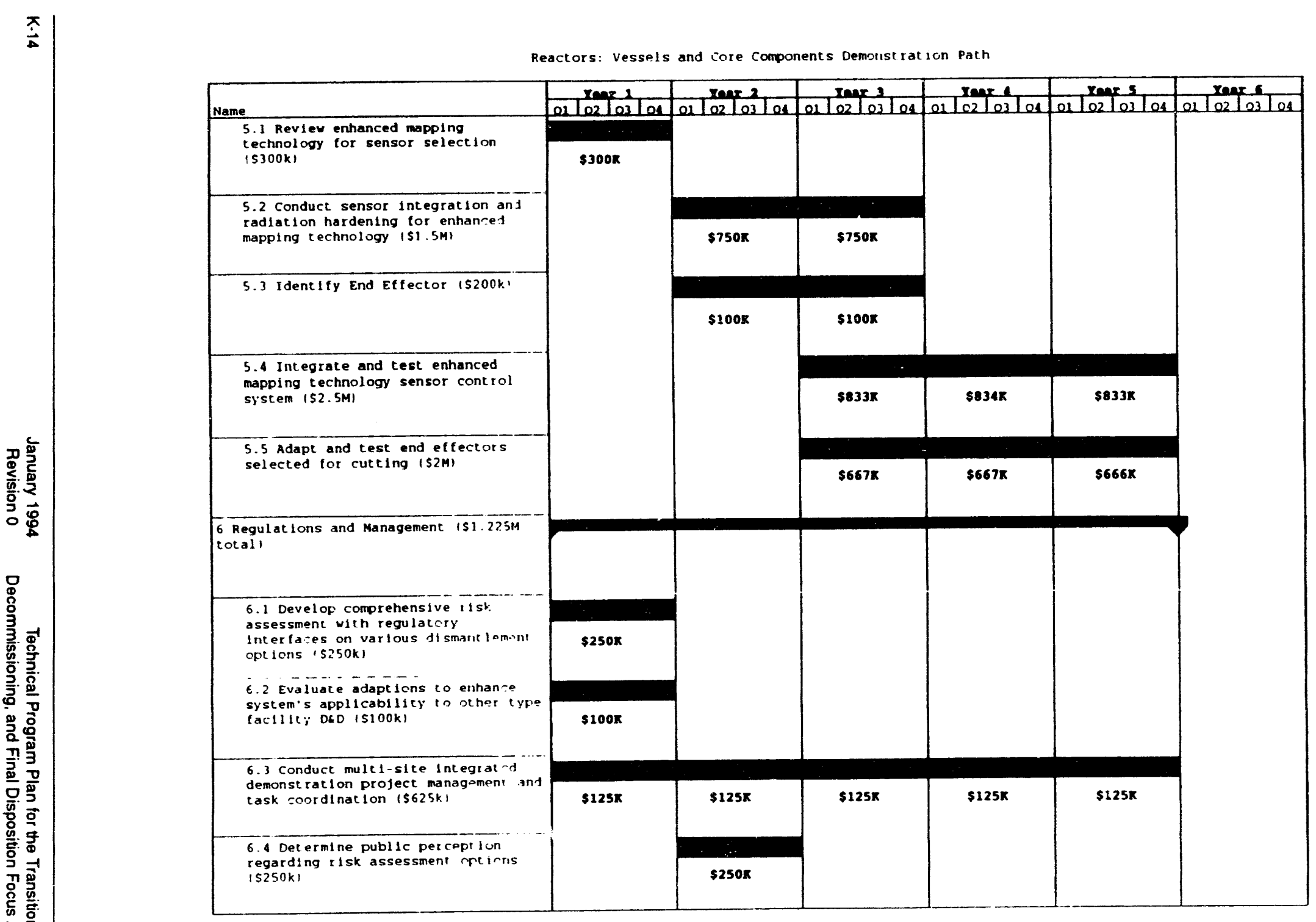




\section{Appendix L}

\section{Uranium-processing Facilities}

This appendix contains two proposals. The Uranium Process Systems proposal begins on page L-2 and the Asbestos and Transite proposal begins on page $L-24$. 


\section{Uranium Process Systems}

This appendix contains two proposals. The Uranium Process Systems proposal begins on page L-2 and the Asbestos and Transite proposal begins on page $L-24$.

\section{Section 1 Situation Analysis}

\section{Section 1.1 Problem Definition}

Size of the The scope of the proposed Uranium Process Systems ID includes equipment, Problem piping, control systems, ducts, vessels, utilities, and related components once used in processing uranium-containing materials. It excludes consideration of irradiated fuel and TRU-contaminated systems. Only depleted and low enrichment uranium-contaminated systems are included.

As detailed in the Locations section of this appendix (page L-15), numerous DOE and commercial sites have facilities housing uranium-processing systems and components. Within the DOE Complex, these areas contain a total of approximately 4.5 million square feet of floor space, with miles of process piping and duct work as well as numerous process components. The cost to D\&D the uranium-processing system within the DOE Complex could - depending on the approach, technologies selected, and waste burial costs - exceed $\$ 5$ billion.

Problem The DOE sites that have equipment contaminated with uranium include Locations Fernald, Oak Ridge, INEL, Savannah River, LANL, Rocky Flats, and Hanford. In addition, many commercial and foreign sites have equipment contaminated with uranium. Uranium contamination is ubiquitous at most of these sites primarily because, in the past, uranium has been managed less strictly than have other radioactive materials.

\section{Section $1.2 \quad$ Characterization}

Baseline Baseline characterization technologies rely heavily upon knowledge of the Technologies process in use (or that was used), an extensive sampling program to ensure proper characterization of all process sectors, and off-site laboratory analysis of the collected samples. These activities are augmented by direct observation and inspection, limited field screening, and limited use of close support field laboratories. The cost of characterization may account for as much as $20 \%$ of the total $D \& D$ budget. 
Deficiencies The deficiencies with the baseline technologies are amplified by the shear magnitude of the D\&D effort. The miles of process pipe and duct work as well as the innumerable process components must be characterized both inside and out. Such an effort - particularly that required to sample piping, ductwork, and components internally - will be extremely time consuming and labor intensive. Also, characterization efforts may generate airborne contaminants and result in exposure to direct radiation. These concerns will only increase when systems are opened in order to perform internal characterization. Following shipment of the samples to off-site laboratories, scheduling problems can still crop up because of the bottlenecks at the laboratories.

The risks associated with baseline characterization technologies can be classified as either direct or indirect. The direct risks, associated with the characterization effort itself, include the generation of airborne contaminants, the increased potential for worker exposure, and the risk of industrial accidents resulting from the need to access elevated piping, ductwork, components, or to gain internal access to a process component. The indirect risks, resulting from the deficiencies of the characterization technologies, include significant budget overruns caused by protracted scheduling delays.

Solutions The most meaningful solution to the problems associated with using current baseline technologies for characterization is a viable method for real-time, in situ characterization. This solution reduces worker exposure by reducing handling. This solution would address the identified deficiencies and satisfactorily eliminate - or at least minimize - the identified risks. This solution may also benefit from the integration of in situ measurement and robotic or remote sampling, which would also reduce the risk of industriai accidents.

Real-time in situ will be the main area investigated. An alternative approach - which will also be evaluated - involves the coupling of remote/automated sampling capabilities with field laboratory capabilities (i.e., on-site field screening and near real-time field analysis). Both approaches would improve productivity, reduce costs, reduce the risk of personnel exposure and industrial accidents, and reduce the risk of D\&D schedule delays caused by lost samples or bottlenecks at off-site laboratories.

\section{Section 1.3 Decontamination}

Baseline Baseline decontamination technologies are, for the most part, highly Technologies structured janitorial services: wiping, washing, chemical cleaning, physical surface removal, vacuuming, etc. Because the effectiveness of these methods has been proven, they have seen little change or innovation in the last decade. 
The costs associated with decontamination of uranium-processing systems and equipment across the DOE Complex may be as high as $40 \%$ of all D\&D costs. Using only baseline technologies, we may never have enough money to perform all of the required work.

Deficiencies Decontamination is effective for simple geometric shapes and can be redone, if necessary. However, it is less effective for complex shapes, is extremely labor intensive, and generates a substantial amount of secondary waste, which is not only expensive to dispose of but requires additional processing before disposal.

Another deficiency is that components having weld seams, joints, crevices, pits, and similar surface irregularities are not easily decontaminated, even with very aggressive decontamination techniques. As a result of this deficiency, repeated decontaminations may be required. Each repeated application will add to the generation of secondary wastes, scheduling delays, and cost.

The direct risks associated with the baseline decontamination technologies are the generation of airborne contaminants, the potential for personnel radiation exposure as a result of working in the immediate proximity of the contaminated material, and the potential for industrial accidents resulting from working on elevated process components and handling potentially hazardous chemicals. Another direct risk is the potential for spills or the accidental release of a decontamination fluid. The indirect risk of budget overruns exists because of the potential for repeated decontamination applications, which would extend the overall D\&D schedule and generate additional quantities of secondary waste.

Solutions

The preferred decontamination technology would achieve the following goals:

- eliminate the physical, hands-on approach to decontamination

- minimize the generation of secondary waste

- eliminate the use of chemical decontamination solutions that can leak, spill, and require the installation of radioactive waste-processing systems

- eliminate the problems related to the decontamination of weld seams, pits, crevices, etc.

- reduce the volume of resulting waste products

- minimize the potential for the decontamination process itself to adversely affect the overall D\&D schedule 
One process that provides such decontamination capabilities involves metal melting coupled with a catalytic extraction process (CEP), or the addition of "getters" with other additives that force/draw the radioactive materials to the slag phase. Such process will be generally referred to as metal melt decontamination processes.

The integration of robotics into the decontamination process to replace either in situ or ex situ, hands-on, and repetitive decontamination activities will also greatly reduce the risk of accidental personnel exposure and injuries; moreover, the use of modular containment systems will prevent the spread of contaminants.

In the D\&D of a facility contaminated with radioactive and/or hazardous materials, a major objective is to minimize the direct interaction of $D \& D$ personnel with the contaminated materials. Because D\&D personnel can not be totally eliminated from the contaminated work area, they are issued personnel protection equipment (PPE) to protect them from hazardous contaminants. The design of the PPE has a negative effect on productivity (e.g., suits are heavy, awkward, uncomfortably hot), so this ID will encompass efforts to find better designs or to improve the design of the current suits with the intent of increasing productivity and reducing the amount of time required for personnel to dress out in PPE.

\section{Section 1.4 Dismantlement}

Baseline Current baseline technologies for dismantlement include manual and Technologies hydraulic tools used to cut and shear process equipment: high-pressure water jets, saws, laser cutters, and plasma and acetylene torches. Because the effectiveness of these methods has been proven, there has been little change and few innovative applications developed in the past several years. These methods are versatile and easy to control and there is a substantial knowledge base to support them; however, these methods generate secondary wastes, require manual intervention/operation, and expose workers to mechanical hazards as well as airborne and volatile contaminants.

The costs associated with dismantlement of uranium-processing systems and equipment across the DOE Complex may be as high as $40 \%$ of all D\&D costs. Using only baseline technologies, we may never have enough money to perform all of the required work.

Deficiencies There are several deficiencies associated with current baseline technologies for dismantlement. The methods available are labor intensive and subject workers to the risk of exposure to contaminants and industrial hazards. In addition, possible accidental releases would endanger both the public and the environment. 
Solutions The most meaningful solution to the problems associated with using current baseline technologies for dismantlement is a viable method for in situ/ex situ dismantlement and size reduction using robotics and automation. Of particular interest are tools/robotics that will handle massive equipment. This is the best solution because it improves worker safety, increases productive work hours, and reduces the chance of exposure/release.

Note: There are fewer restrictions on the dismantlement of equipment that has been decontaminated than on equipment that has not been decontaminated.

\section{Section 1.5 Materials Disposition}

Baseline Technologies

Current baseline technologies include "box and bury," decontamination for controlled recycle and reuse, and decontamination for free release. Because the efficacy of "box and bury" has been proven, there has been little improvement or innovation in the last decade. Though by far the most expedient methods, both burial and storage require continuous surveillance and maintenance, and their viability under current and future regulations is questionable. By burying materials that might otherwise be recycled, we lose valuable materials and introduce clean metals (e.g., waste containers) to the waste stream. Moreover, buried waste may ultimately need to be retrieved and cross-country transportation of wastes is neither reasonable nor politically acceptable. The costs associatud with baseline technologies for materials disposition by burial may be as high as $20 \%$ of all D\&D costs.

Deficiencies The current baseline technology for materials disposition has several deficiencies. We are limited by diminishing landfill space, increasingly restrictive environmental regulations, and lack established regulatory guidance on acceptable limits of residual activity that would permit either the controlled release (e.g., limited to use within the DOE Complex) or free release (BRC).

The risks associated with current materials disposition technologies include environmental impact, worker exposure, regulatory compliance, and possible materials resurrection. 
Solutions The most meaningful solution to the problems associated with using current technologies for materials disposition is to minimize the quantity of waste materials requiring disposal so as to reduce the associated risks accordingly. This objective will require the establishment of regulations that would define BRC limits. Such regulations would allow the free release of clean material for commercial reuse. A second release limit could also be defined to permit the controlled beneficial reuse of materials found to have very low levels of radioactive contaminants. This is the best solution because it is cost effective, environmentally sound, and energy and resource efficient. This solution depends on the committed investment of funds from private industry and is contingent upon DOE's commitment to ensure a market for recycled materials, once such regulations are established.

\section{Section 1.6 Robotics and Automation}

Baseline Currently, there are few - if any - baseline technologies for D\&D of Technologies uranium-processing systems and equipment that include robotics and automation.

Deficiencies The deficiencies associated with current robotics and automation baseline technologies are the lack of robotic equipment and automated machinery that could be used to perform in situlex situ characterization, decontamination, and dismantlement of contaminated uranium-processing systems and equipment.

Solutions Robotics and automation would solve many of the problems associated with using current baseline technologies for characterization, decontamination, and dismantlement of contaminated uranium-processing systems and equipment. Most importantly, robotics and automation would reduce or eliminate the need for personnel to perform hazardous duties.

We expect that this ID will use the dual-arm robot currently under development by OTD's RTDP. We will also seek suitable commercial robots as alternatives. 


\section{Section 1.7 Regulation}

DOE must hasten its efforts in the establishment of BRC/acceptable levels of residual activity for uncontrolled release. Data accumulated during the D\&D ID on achievable levels of residual activity could be used to support the establishment of such a value.

As an interim solution, DOE could use values recommended in the draft FEMP ROD (due April 1997) for acceptable levels of residual activity. The established objective of minimizing the quantity of waste required to be sent to a low-level, radioactive waste disposal facility cannot be achieved unless such values are determined. These values should be based on risk-based analysis, lowest levels of detectability, and effectiveness of existing decontamination techniques.

All of the approaches and solutions that we have recommended (except a free release criteria) can work under existing regulations. A database for ARARs and an analysis of implications and effects on D\&D operations would be particularly useful.

In order for these approaches and solutions to succeed with the least amount of negative impact, the public must be informed about, encouraged to participate in, and made aware of the advantages of recycling for beneficial reuse. Unfortunately, it is meaningless to talk about recycling contaminated materials for beneficial reuse while we lack a realistic criteria either for free release or controlled reuse.

\section{Section 1.8 Management and Systems}

To date, the application of D\&D to uranium-processing systems has been limited to small projects generally costing less than $\$ 25$ million. These efforts were of a relatively modest scale in comparison to the multi-billion dollar D\&D efforts currently faced by DOE. Therefore, these smaller, earlier D\&D efforts could not justify the extensive improvement programs presently being proposed under this and related IDs because the cost for any earlier development programs could not have been recovered.

The D\&D ID defined here would be pursued using a systems approach that will combine concepts from the six technology areas to form a single, effective approach to solving the problems related to the D\&D of uranium-processing systems.

In the discussion, above, of the six technology areas, a recurrent theme is the existing commercial technologies must be enhanced or improved to achieve a more efficient and cost-effective D\&D program. Exploiting the 
relationships between commercial technologies could produce the needed enhancements, provide an integrated system of enhanced capabilities to support one or more technology areas, and lead to a meaningful cost payback. For example, if we combine the metal remelt process with a container fabrication process, we can decontaminate and recycle while we reduce costs (no new containers but salvageable materials). By using such processes, we can reduce the volume and create more manageable forms (e.g., melt pipes down to ingots) and thereby reduce the cost of disposing of the contaminated metal. In addition, processes such as metal remelt eliminate the problems associated with the decontamination and verification of residual levels of contaminants associated with components having a complex shape. 


\section{Section 2}

\section{Description of the Proposed Integrated Demonstration}

The objective of this proposed ID is to develop the most effective approach for the D\&D of uranium-processing systems through the systematic integration of the D\&D technologies selected from the six technology areas. Uranium-processing systems include equipment, piping, control systems, ducts, vessels, utilities, and related components that were once used to process uranium-containing materials, excluding irradiated fuel and TRU-contaminated materials. The selection of the preferred technologies (which are to be improvements and enhancements to proven approaches rather than research and development) will be achieved through a comparative technical and economic evaluation of viable alternative processes or concepts. The bases for these comparative evaluations will be data and performance information collected from field demonstrations.

\section{Section $2.1 \quad$ Summary}

For characterization, the emphasis will be on funding real-time, in situ analytical capabilities. Currently, demonstration efforts are planned first for the laboratory, then for the field. Characterization capabilities will be sought to support remedial action activities and to characterize both inorganic and organic hazardous materials, as well as radioactive contaminants.

The decontamination phase of the ID will evaluate the baseline physical (i.e., hands-on) approach to decontamination against several newer decontamination technologies. The application of these newer decontamination technologies will be evaluated as in situ and ex situ processes. In addition, there will be an evaluation of portable modular containments intended to prevent the spread of contamination. Most of the decontamination evaluations would be performed directly as field demonstrations, while initial laboratory demonstrations would be performed only if the technology under cvaluation is in a developmental stage.

The application of robotics is being evaluated for several technology areas in an attempt to reduce the risks to D\&D personnel from hazardous materials and industrial accidents. Increases in labor efficiency will also be realized because the need for personnel to dress out in anti- $\mathrm{C}$ clothing will be reduced because robotic devices can be operated from clean areas. Robotics technology will be considered for the placement and operation of in situ analysis equipment, light and heavy dismantlement activities, decontamination, and remote surveillance.

Dismantlement will evaluate dust control and the size reduction of large equipment, in addition to the above robotics applications. 
Materials disposition alternatives will center on technologies to minimize the volume of waste requiring disposal (including secondary waste) and maximizing the quantity of material suitable for recycle. Concepts to be addressed include simultaneous metal remelt/decontamination, volume reduction/super compaction, and waste container fabrication using recycled metal. In the metal remelt process, the radioactive contaminants can be selectively separated from the bulk of the product ingot through the addition of "getters" or a catalytic process. A risk-based criteria for metal release will also be addressed as part of this technology evaluation.

A systems engineering approach will be used for the development of the detailed ID plan, for the evaluation of the performance of the various demonstrations, and for the selection of a preferred combination of technologies that minimize costs and comply with applicable local, state, and federal regulations.

In addition to the above, development of processes such as CEP or other metal remelt processes can achieve the decontamination of metals while simultaneously producing commercially viable products, thereby addressing the recycle objective.

Furthermore, all applicable CERCLA, RCRA, and DOE regulations must be addressed before the D\&D ID can be initiated. This review should include planning, obtaining permits, etc. Performing the $\mathrm{ID}$ at a site where D\&D is under way would likely speed the permitting process. Delays in the completion of the review would most likely result in a corresponding delay in the start of the ID.

Many of the technologies currently under evaluation and development that are applicable to this ID involve private industry. The following are some of the Stage-3 and Stage-4 technologies in existing PRDA contracts:

- dry-ice blasting

- high-pressure washing (for cutting and cleaning)

- dry-abrasive impingement

- liquid abrasive systems

- recyclable chelating solvents

- laser decontamination of process metals

- CEP

- recycle and reuse of radioactively contaminated scrap metal

- rapid surface sampling 
- portable sensors for hazardous wastes

- three-dimensional integrated characterization

- advanced worker protection system

- selective/sorptive protective clothing

We will be able to involve private industry through PRDAs and no-cost RFPs.

A primary objective of this D\&D ID is to reduce costs through enhancements or new technologies, such as the following.

- Integrate robotics/automation to significantly increase the productivity of D\&D personnel by approximately 2.5 hours per shift to 5.5 hours by reducing the time required to dress out in Anti-C clothing (some operators will be moved away from the work area).

- Improve effectiveness of the decontamination processes to enhance the probability of recycle for beneficial reuse and to reduce or eliminate secondary waste.

- Reduce the generation of secondary waste.

- Reduce the volume of wastes requiring disposal.

- Obtain real-time characterization results to rapidly and correctly determine the effectiveness of the decontamination process.

- Reduce the number of samples submitted to laboratories for chemical/radiological analysis.

- Obtain data to support the establishment of restricted reuse and free release criteria.

All reasonable available technologies in each area will be tested side-by-side to evaluate the merits of each. We expect that the successful completion of this ID will produce a system of enhanced or new technologies that provide complete D\&D capability, from characterization through materials disposition, with related support in the areas of robotics, automation, and regulation. To ensure cost effectiveness for the DOE Complex, the system(s) we envision will support a broad range of applications. 


\section{Section $2.2 \quad$ Deliverables}

- improved system of technologies for the D\&D of uranium-processing systems

- real-time characterization technologies for uranium (radiological)

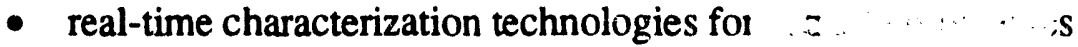

- real-time characterization technologies for ha ardors inorganics (lead, mercury, chromium)

- remote/robotic deliver of characterization devices

- automated/robotic system for in situ decontamination

- methodology for efficient size reduction of large equipment

- remote video system for observation

- reusable, portable, modular containment system

- large-scale demonstration of metal recycle/reuse (metal remelt)

- field data for multiple, in situ decontamination technologies

- field data for multiple, ex situ decontamination technologies

- compendi applicable regulation and their effect on operatior

- documentaw of of the extent of the problem throughout the DOE Complex and a plan for identifying requirements from and transferring technologies $: 0$ applicable sites

Section 2.3 Reasons for Pursuing the Proposed ID Now (versus Later)

- FEMP compliance agreement deadline; CERCLA ROD date is April 1997

- opportunity to integrate with FEMP Treatability Testing

- timely availability of improved technology for pending Rocky Flats D\&D 
Section $3 \quad$ Benefits

- cost savings of $\$ 500$ - 900 million during EM-40 implementation

- reduced worker exposure to radionuclides and hazardous chemicals

- reduced risk of injury from industrial accidents

- schedule reduction for EM-40 work resulting from more efficient practices

- minimal environmental impact through minimized waste and reduced disposal volume

- conservation of resources through recycle/reuse

- support of more accurate characterization at reduced costs

- minimal risks of off-site expcisure through more thorough characterization and improved containment practices

- improved public perception because of DOE focus on investment in improved operation and cost savings initiatives

- established basis for a recycle industry

- technologies and practices that can be transferred to other DOE and commercial problems and applications

- reduced airborne contaminants, resulting in less secondary waste and exposures

\section{Section $4 \quad$ What Cannot Be Done between FY 94 and FY 99}

We believe that all of the items important to the demonstration could be completed between FY 94 and FY 99. Incremental improvements in needed technologies can be integrated easily into the demonstration. However, a lack of success with real-time characterization could push the availability of some technologies beyond 1999. Opportunities for additional improvements in technologies will likely be identified during the course of the demonstration. 


\section{Section $5 \quad$ Locations}

There are several DOE and commercial sites that have contaminated uranium-processing systems. The various sites had different processes; however, each site had processes involving uranium-containing materials, either in a non-irradiated form or separated from fission products.

\section{Section 5.1 DOE Sites}

\section{Fernald}

Fernald is a representative site because contamination and equipment are somewhat similar at all the sites. Fernald has a variety of contaminants in addition to uranium and it exhibits a variety of uranium-compound contaminants.

The consent agreement at Fernald mandates the earliest clean-up of all of the DOE sites. EM-40's customer at Fernald is supportive of using the site as a test bed. The local community and regional politics at Fernald require a high profile from DOE technology development and demonstration. EM-40 D\&D at Fernald is scheduled to begin in FY 94, with a potential EM-50 tie-in.

- FFCA compliance date set for April 1997 (CERCLA ROD)

- treatability study plan usable for permitting requirements

- dismantlement of buildings to begin in FY 94

- able to take advantage of EM-40 activities to leverage costs

- D\&D funding in EM-40 ADS's

\section{Rocky Flats}

Rocky Flats facilities are also representative of the problems. Initial treatability work at Rocky Flats will begin in the 1994-1999 time frame

- recently designated EM-60 site

- major D\&D planning will begin in FY 95

- not FFCA-driven at this time

- Fernald experiences expected to be directly applicable 


\section{Hanford}

- D\&D of uranium-processing facility (fuel fabrication and $\mathrm{UO}_{3}$ plant) is currently a low priority

- D\&D scheduled to begin after 2001

INEL

- SMC D\&D scheduled to start in 2004

- still in production

\section{Savannah River}

- uranium-processing facility (target fabrication and $\mathrm{UO}_{3}$ plant) still in operational standby

- D\&D not scheduled

\section{Oak Ridge}

- Y-12 still operational

- D\&D scheduled to begin after 2001 (not all uranium-processing systems have been scheduled for D\&D)

\section{LANL}

- D\&D of uranium-processing systems currently underway

- primarily laboratory-scale facilities 


\section{Section 5.2 Commercial Sites}

\section{RMI}

- limited process equipment

- D\&D imminent

\section{Aero Jet (Jonesboro, TN)}

- currently operational

\section{Carolina Metals}

- currently operational

\section{NMI}

- currently operational

\section{Sequoia Fuels}

- currently operational

commercial reactor fuel fabrication facilities

- currently operational

\section{FUSRAP}

- various 


\section{Section 6 Assumptions}

- All potential commercial participants must have relevant backgrounds and/or demonstrated capabilities to be eligible for qualification in ID procurement.

- Laboratory demonstrations include all testing and related efforts to support a field demonstration that includes only on-site demonstrations (i.e., no final field readying).

- Costs for the ciemonstrations do not include costs from funded tie-in activities such as PRDAs and TTPs from other programs.

- Disposal costs are estimated at the current NTS rate of approximately $\$ 10.00$ per cubic foot. Future actual costs will most likely fall between $\$ 100.00$ and $\$ 200.00$ per cubic foot for LLW.

- Any savings resulting from not sending recyclables to burial may be offset by costs associated with on-site segregation of materials and other recycling process costs, resulting in a nonet savings for recycling. Life-cycle costing associated with disposal costs (above) will also affect this assumption.

\section{Section $7 \quad$ Issues}

- Does the ID definition include the final demonstration of the integrated system as a whole or as a sum-of-the-parts analysis? 


\section{Section 8 ID Schedule and Costs}

The following table summarizes the costs (in millions) of this ID over its entire lifespan.

\begin{tabular}{|l|c|c|c|c|c|c|c|}
\hline & Year 1 & Year 2 & Year 3 & Year 4 & Year 5 & Year 6 & Total \\
\hline Characterization & 0.70 & 1.30 & 1.00 & 0.40 & & & 3.40 \\
\hline Decontamination & 1.70 & 0.90 & 0.50 & & & & 3.10 \\
\hline Dismantlement & & 0.50 & 1.80 & 0.30 & & & 2.60 \\
\hline Materials Disp. & & 0.40 & 0.20 & 0.10 & & & 0.70 \\
\hline Robotics \& Auto. & & & 0.90 & & & & 0.90 \\
\hline Mgmt. \& Sys. & 1.00 & 1.00 & 2.70 & 3.50 & & & 8.20 \\
\hline Total & 3.40 & 4.10 & 7.10 & 4.30 & 0.00 & 0.00 & 18.90 \\
\hline
\end{tabular}


Uianium nrozassing Systems Demonsitarion Path

\begin{tabular}{|c|c|c|c|c|c|c|}
\hline Name & 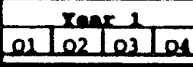 & os reyes & 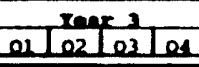 & Tences & 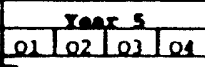 & 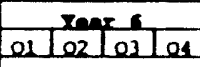 \\
\hline 1 Characterization 153.49 totall & & & & & & \\
\hline $\begin{array}{l}\text { 1.1 Lab demo of tour real-time in } \\
\text { stu Radionucilde with exsting } \\
\text { PRDAs and the EM-SO IP (SIM) }\end{array}$ & $\$ \$ 00 \mathrm{x}$ & $\$ 500 \pi$ & & & & \\
\hline $\begin{array}{l}1.2 \text { Lab Demo of four real-time Haz } \\
\text { Inorganics with existing PRDAs and } \\
\text { EM-50 IP ISIM! }\end{array}$ & & \$500R & $\$ 500 \pi$ & & & \\
\hline $\begin{array}{l}\text { 1.3 Field demo of two real time in } \\
\text { situ Haz Inorganics with existing } \\
\text { PRDAs is } 300 \mathrm{k} \text { l }\end{array}$ & & & $\$ 200 \pi$ & $\$ 100 \mathrm{~K}$ & & \\
\hline $\begin{array}{l}\text { 1.4 Lab demo of four real-time } \mathrm{Haz} \\
\text { organtes with existing PRDAs and } \\
\text { EM-50 if } 15500 \mathrm{k})\end{array}$ & $\$ 200 \pi$ & $\$ 300 \pi$ & & & & \\
\hline $\begin{array}{l}\text { 1.5 Fleld demo of two real-time in } \\
\text { sttu Rodionuclides with existing } \\
\text { PRDAs is } 300 \mathrm{k} \text { l }\end{array}$ & & & $\$ 200 \pi$ & $\$ 100 \pi$ & & \\
\hline $\begin{array}{l}\text { 1.6 Fleld deme of two Haz organirs } \\
\text { with existing PROAs is inghi }\end{array}$ & & & & & & \\
\hline 2 Dl smant lement $152.6 \mathrm{M} \mathrm{torall}$ & & & & & & \\
\hline $\begin{array}{l}2.1 \text { Fleld Demo - size Reduction } \\
\text { issook }\end{array}$ & & $\$ 500 \pi$ & & & & \\
\hline $\begin{array}{l}2.2 \text { Fleld Demo Rncotis } \\
\text { Dismant lement } 15300 \mathrm{k} \text { ) }\end{array}$ & & & $\$ 300 \pi$ & & & \\
\hline
\end{tabular}


Uranium-processing Systems Demenstration Path

\begin{tabular}{|c|c|c|c|c|c|c|}
\hline Name & \begin{tabular}{|l|l|l|l|l|}
\multicolumn{3}{|c|}{ Tagr 1} \\
01 & 02 & 03 & 04 \\
\end{tabular} & \begin{tabular}{|l|l|l|l|}
\multicolumn{3}{|c|}{ rage 2} \\
01 & 02 & 03 & 04 \\
\end{tabular} & 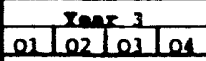 & 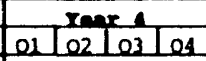 & 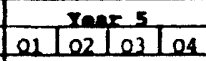 & \begin{tabular}{|l|l|l|l|}
\multicolumn{4}{|c|}{ Tane 6} \\
01 & 02 & 03 & 04 \\
\end{tabular} \\
\hline $\begin{array}{l}2.3 \text { Lab Demo - Robot 1C DI smant lement } \\
\text { of large pay load ( } 51.5 \mathrm{M} \text { ) }\end{array}$ & & & $\$ 1.5 \mathrm{n}$ & & & \\
\hline $\begin{array}{l}\text { 2.4 Field Demo - Rob. Dismant lement } \\
\text { of large paylodd } 15300 \mathrm{k} \text { ) }\end{array}$ & & & & $\$ 300 \mathrm{~K}$ & & \\
\hline 3 Decontamination $153.1 \mathrm{M}$ totall & & & & & & ${ }^{\circ}$ \\
\hline $\begin{array}{l}\text { 3.1 Field Demo - Ex Situ, Physical } \\
\text { Decontaminate. (s700k) }\end{array}$ & $5700 x$ & & & & & \\
\hline $\begin{array}{l}3.2 \text { Lab Demo - strippable Coatings } \\
\text { (s300k) }\end{array}$ & $\$ 300 \pi$ & & & & & \\
\hline $\begin{array}{l}\text { 3.3 Field Deme - In situ Surtace } \\
\text { Derontaminat } 1 \text { on (s700k) }\end{array}$ & \$700K & & & & & \\
\hline 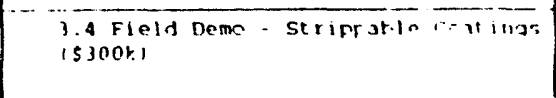 & & $\$ 300 \mathrm{x}$ & & & & - \\
\hline 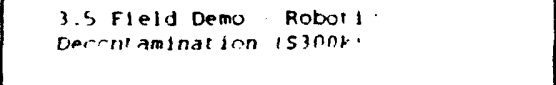 & & $\$ 300 x$ & & & & \\
\hline $\begin{array}{l}3.6 \text { Fleld Demo-solution Basat } \\
\text { Decontamination } 15500 \text {. }\end{array}$ & & $\$ 300 x$ & $\$ 200 x$ & & & \\
\hline $\begin{array}{l}3.7 \text { Fleld Demo-Portatile Modulat } \\
\text { Cort } 31 \text { nimant } 15300 k .1\end{array}$ & & & $\$ 300 \mathrm{x}$ & & & \\
\hline
\end{tabular}




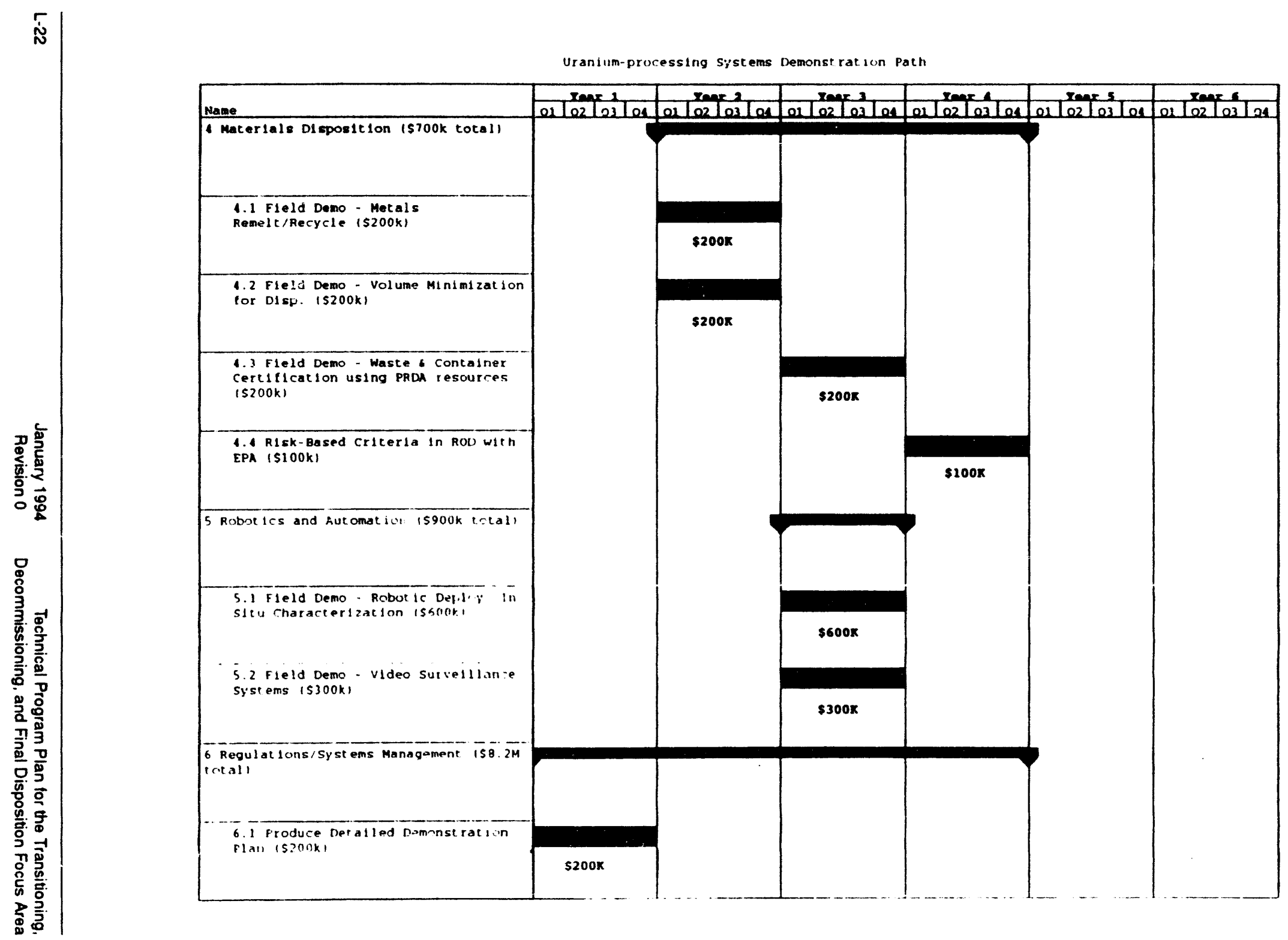


Uranium-prozessing Systems Demonstrat i on Par.h

\begin{tabular}{|c|c|c|c|c|c|c|}
\hline Name & $020_{02}^{\text {Tanc } 1}$ & 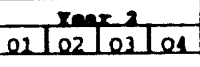 & 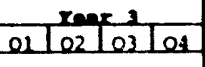 & 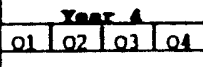 & \begin{tabular}{|c|c|c|}
0102 & 03 & 04 \\
\end{tabular} & 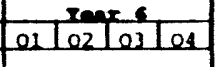 \\
\hline $\begin{array}{l}6.2 \text { Develop Compendium of Applicable } \\
\text { DED regulations isiooki }\end{array}$ & $\$ 100 \mathrm{x}$ & & & & & \\
\hline $\begin{array}{l}\text { 6.3 Define conplex-wide problem } \\
\text { is } 200 \mathrm{k} \text { i }\end{array}$ & $\$ 200 \mathrm{x}$ & & & & & \\
\hline $\begin{array}{l}\text { 6.4 Develop strategy for accessing } \\
\text { Indust ry's technologies }\end{array}$ & Mote 1 & & & & & \\
\hline $\begin{array}{l}\text { 6.5 Mapping syster for } \\
\text { characterization data }\end{array}$ & & note 1 & & & & \\
\hline $\begin{array}{l}\text { 6.6 Systems Analysts of } \\
\text { Demonstration Results } 15200 \mathrm{k} \text { ) }\end{array}$ & & & $\$ 200 x$ & & & \\
\hline $\begin{array}{l}\text { 6.7 Full-scale Implementation of ID } \\
\text { system (52M) }\end{array}$ & & & & s2n & & \\
\hline 6.8 site Support Tasks $155.5 \mathrm{M}$ ) & & & & & & \\
\hline & $\$ 500 \mathrm{x}$ & \$1M & $\$ 2.5 n$ & $\$ 1.5 \mathrm{M}$ & & \\
\hline
\end{tabular}

Wote 1: Cost of this activity is included in sponsored projects by en technology user organizations iEn-30, -40 , or -50 ). 


\section{Asbestos and Transite}

This appendix contains two proposals. The Uranium Process Systems proposal begins on page $L-2$.

\section{Section $9 \quad$ Situation Analysis}

\section{Section 9.1 Problem Definition}

Size of the Using current baseline technologies, it will take decades to remove all of the Problem asbestos and transite at DOE sites. Currently, the schedule remains undetermined and will depend on the individual decontamination and decommissioning schedules for each facility. Costs for asbestos/transite D\&D have yet to be determined and will depend on a system-wide evaluation of the scope of the problem.

Problem All DOE sites, many domestic commercial sites, and many foreign sites have Locations asbestos/transite contamination, and some also have radiological contamination. The problem is particularly pervasive in DOE buildings awaiting D\&D that were built before 1970 .

\section{Section 9.2 Characterization}

Baseline Current baseline technologies include standard characterization methods: Technologies physical observation, visual inspection for friability, and manual sampling for laboratory analysis. Though characterization for asbestos is not tremendously expensive, the presence of other hazardous constituents often adds to the cost.

Deficiencies There are several deficiencies associated with the current baseline technologies for characterization. Though the accuracy of laboratory analysis has been proven, the physical removal of samples for analysis is labor intensive, time consuming, and disrupts schedules. Bottlenecks at analytical laboratories and the difficulties associated with analysis and certification of characterizations in the field represent opportunities for technical development. The subjectivity of visual ratings for friability is also a problem.

The risks associated with current baseline technologies for characterization correspond primarily to inhalation exposure for workers.

Solutions The most meaningful solution to the problem associated with using current baseline technologies for characterization is a viable method for real-time, in 
situ characterization. This is the best solution because it reduces worker exposure by reducing handling. This solution eliminates risks associated with transportation and is more efficient than current methods, so that schedules and budgets can be maintained. This solution may also benefit from integration of robotic or remote sampling and in situ measurement.

\section{Section 9.3 Decontamination}

Baseline Current baseline technologies for the removal of asbestos and transite consist Technologies of standard "contain, ventilate, spray, remove, and bag" methods. There are, however, no baseline technologies for decontaminating asbestos/transite that contains radiological or hazardous contaminants/constituents.

Deficiencies There are no baseline technologies for decontaminating asbestos/transite that contains radiological or biological contaminants/constituents.

Solutions The most meaningful solution to the problem associated with the lack of current baseline technologies for decontamination is to devise a viable method for in situlex situ decontamination of contaminated asbestos/transite. This solution will reduce the amount of waste that must be dispositioned as low-level radiological waste, thereby reducing the costs associated with disposal and the overloading of burial sites.

\section{Section 9.4 Dismantlement}

Baseline Current baseline technologies include standard "contain, ventilate, spray, Technologies remove, and bag" methods. Because the effectiveness of these methods has been proven, there has reen little change or innovation in the past several years. Since these are primarily manual methods, they are versatile, easy to control, and there is a substantial knowledge base to support them.

Deficiencies There are several deficiencies associated with current baseline technologies for dismantlement. The methods available to us are very labor intensive and subject workers to the risk of exposure to airborne asbestos, radioactive contaminants, and industrial hazards. Current dismantlement methods generate very large amounts of secondary waste (e.g., contaminated plastic, dust supression fluids, protective clothing). 
Solutions

The most meaningful solutions to the problems associated with using current baseline technologies for dismantlement are the use of a viable method for in situ dismantlement using robotics and automation (including remote video), improved glove bag operations, or improvements to in situ stabilization. There is also a need to develop an alternative to dust and fiber suppression fluids which generate a mixed asbestos/hazardous waste stream that is difficult to deal with. These are the best solutions because they reduce or eliminate exposure for workers and supervisors, use less material for containment (i.e., less secondary waste), and reduce waste treatment needs.

\section{Section 9.5 Materials Disposition}

Baseline Technologies

Current baseline technologies for the disposition of asbestos/transite consists of standard "bag, box, and bury" methods. Because the efficacy of "box and bury" has been proven, there has been little improvement or innovation in this method in the last decade. Though by far the most expedient method, both burial and storage require continuous surveillance and maintenance, and their viability under current and future regulations is questionable. Moreover, buried waste may ultimately need to be retrieved and cross-country transportation of wastes is neither reasonable nor politically acceptable. The costs associated with baseline technologies for materials disposition by burial will be extremely high.

Deficiencies There are several deficiencies associated with current baseline technologies for materials disposition. We are limited by diminishing landfill space, increasingly restrictive environmental regulations, and the possibility of materials resurrection.

The risks associated with current materials disposition technologies correspond primarily to environmental impact, worker exposure, and regulatory compliance.

Solutions The most meaningful solutions to the problems associated with using cirrent technologies for materials disposition are viable means to dispose of the materials as non-radioactive, destroy the asbestos fibers and dispose of them as non-asbestos, or recycle for beneficial reuse. These are the best solutions because they are cost effective, environmentally sound, energy and resource efficient, and they save the taxpayer money. These solutions depend on the committed investment of funds for a demonstration of destruction technologies and are contingent upon DOE's commitment to assure a market for the recycled materials. 


\section{Section 9.6 Robotics and Automation}

Baseline Currently, there are few - if any - baseline technologies for D\&D of Technologies asbestos and transite which include robotics and automation.

Deficiencies The deficiencies associated with current robotics and automation baseline technologies are the lack of such technologies needed to perform in situ/ex situ characterization, decontamination, and dismantlement of asbestos and transite.

Solutions

Robotics and automation would solve many of the problems associated with using current baseline technologies for the characterization, decontamination, and dismantlement of asbestos and transite. Most importantly, robotics and automation would reduce or eliminate the need for personnel to perform hazardous duties.

\section{Section 9.7 Regulation}

All of the approaches and solutions that we have recommended can work under existing regulations; however, we lack a free release criteria for decontaminated materials. A database for ARARs and an analysis of implications and impacts which include the criteria stipulated in CERCLA RODs would be particularly useful, as would a means to integrate OSHA and DOE radiation protection requirements.

In order for these approaches ind solutions to succeed with the least amount of negative impact, the public must be educated about, encouraged to participate in, and made aware of the advantages of recycling for beneficial reuse. Unfortunately, it is meaningless to talk about recycling decontaminated materials for beneficial reuse while we lack a realistic BRC level for free release.

\section{Section $9.8 \quad$ Management and Systems}

From the perspective of management and systems, the most beneficial contribution to solving the problems associated with the D\&D of asbestos and transite would be a DOE Complex-wide assessment of the size and the scope of the problems. Such a study would foster greater understanding of the scope and scale of the problems and help justify investments in the more tangible, technical solutions. 
Section 10 Description of the Proposed Integrated Demonstration

The objective of this proposed ID is to develop the most effective approach for the $D \& D$ of asbestos-containing/transite materials through the systematic integration of the D\&D technologies selected from the six technology areas. The selection of the preferred technologies (which are to be improvements and enhancements to proven approaches rather than the product of new research and development efforts) will be achieved through a comparative technical and economic evaluation of viable alternative processes or concepts. The bases for these comparative evaluations will be data and performance information collected from field demonstrations.

The recommended ID seeks recent technology developments across all the technology areas and does not limit the scope of the demonstration to only one or two technology areas. All reasonable available technologies in each area will be tested side-by-side to fully evaluate the merits of each. It is envisioned that successful completion of this ID will produce a family or system of enhanced or new technologies which provides a complete D\&D capability from characterization through materials disposition, with related support in the area of robotics and automation as well as the regulatory area. The envisioned system(s) will include a robustness that supports a broad band of applicability to ensure cost effectiveness for the Complex.

The development of a field laboratory with appropriate capabilities will reduce the potential for any adverse impact on the D\&D schedule associated with delays resulting from bottlenecks at off-site analytical laboratories as well as samples being delayed or lost while in transit to the laboratory. A strict, consistent, and objective analytical test could be included for the determination of friability.

The decontamination of asbestos insulation is not considered a viable program to pursue at this time. However, should asbestos fiber destruction be used (a process to be evaluated under materials disposition), then decontamination of the by-product materials using standard treatment technologies may be viable. This option will be revisited following completion of the materials disposition phase.

Decontamination of transite presents an additional challenge in that many of the processes available to decontaminate transite would also accelerate its deterioration, which would, in turn, result in the release of transite's asbestos component. Decontamination using vacuuming will be evaluated. Other decontamination methods to be evaluated include crushing and "soil washing," chemical leaching, blasting with $\mathrm{CO}_{2}$ ice pellets or water jets, and low-pressure steam. 
Improved dismantlement techniques which wil' achieve the following are to be pursued:

- a pipe/asbestos cutting process or procedure which fuses the asbestos in the area of the cut (e.g., laser cutting);

- robotics to reduce costs, improve productivity, and greatly reduce the risk of industrial accidents and to reduce the health risks to dismantlement personnel;

- the removal of pipe insulation withciut the use of a standard containment system;

- stabilization of friable asbestos;

- in situ fiber destruction

The emphasis of this proposed ID is not disposal but conversion and reuse of two basic waste materials. In the case of asbestos, there are available both chemical and thermal processes for the destruction of the asbestos fiber. If non-radioactive, this by-product could be used in roadbeds or similar applications. If trace quantities of contaminants are present, the by-product material could be used as fill or a construction material in concrete disposal units or as silica source feed to a vitrification process. As for transite, the only option that may not be viable is the destruction of the asbestos fiber since the presence of concrete might interfere with the process (unless used as feed to a vitrification process).

Due to the magnitude of the asbestos and transite D\&D problem within the DOE Complex, robotics and automation technology will be incorporated into the ID. Capabilities and objectives to be pursued for this technology include:

- removal of personnel from areas presenting industrial hazards;

- reduction of exposure of personnel to hazardous materials;

- increased productivity;

- remote pipe cutting and removal;

- removal of asbestos from pipes; and

- removal of transite.

Two regulatory issues must be resolved in order to ensure a cost-effective $D \& D$ program can be developed for asbestos and transite materials within the DOE Complex. 
The first issue relates to acceptable levels of residual activity (BRC). Currently, such levels have not been defined. Should the asbestos component of the ACM be destroyed and radiologically decontaminated, this material could not be reused as construction fill material or in road beds unless such values are established. The only alternative is disposal; however, the costs and environmental impact of disposal make it an undesirable option. Data accumulated during the ID on achievable levels of residual activity could be used to support the establishment of BRC levels in the draft FEMP ROD (due April 1997) for acceptable and achievable levels of residual activity.

The second issue relates to transite which is classified as non-friable. Transite could, however, become friable during dismantling due to cracking and other causes. Since deterioration of the transite increases the propensity for fiber release, it may be necessary at that time to re-classify the transite as friable. A standard, uniformly accepted method for establishing asbestos friability in transite does not exist and should be developed.

The basic objectives of this ID can be achieved by coupling commercially-developed technologies from different areas to provide a complete process. For example, coupling robotic pipe cutting and asbestos removal with a process that destroys asbestos fiber and with a process to remove radioactive contaminants can achieve higher field productivity, reduce costs (e.g., eliminate all the costs associated with hazardous waste disposal while producing a usable by-product), and reduce worker exposure to health and safety risks.

Many of the technologies currently under evaluation and development that are applicable to this ID involve private industry. For example:

- chemical and thermal asbestos fiber destruction;

- $\mathrm{ABCOV}$ technology (proprietary);

- crusning and chemical leaching;

- foam cleaning;

- mechanical removal;

- $\mathrm{CO}_{2}$ ice blasting; and

- strippable paints and coatings. 


\section{Section 10.1 Deliverables}

- improved system of technologies for the D\&D of asbestos, transite, and $\mathrm{ACMs}$

- real-time characterization technologies

- remote/robotic pipe segmenting and asbestos removal (with and without traditional containment)

- remote/robotic transite removal

- remote video system for observation

- functional technology for the destruction of asbestos fiber

- recommended technologies for the removal of radioactive material in residue remaining following the destruction of asbestos

- data to be used in the development of BRC limits for materials remaining following the destruction of asbestos fibers

- standardized, uniformly accepted method for establishing asbestos friability in transite

- innovative uses for asbestos, transite, and ACMs

\section{Section 10.2 Reasons for Pursuing the Proposed ID Now (versus Later)}

- FEMP compliance agreement deadline; CERCLA ROD date is April 1997

- opportunity to integrate with FEMP Treatability Testing 


\section{Section $11 \quad$ Benefits}

- more efficient and safer techniques for asbestos removal

- demonstrated reduced exposure to work force and the public

- a means to remove or eliminate land burial (i.e., land resource conservation)

- convert hazardous material to a usable, recyclable material

- all sites involved will be cleaner and safer

- technology applicability would be worldwide

- cost savings to DOE

- schedule reduction due to more efficient practices

- supports more accurate characterization at reduced costs

\section{Section 12 What Cannot Be Done between FY 94 and FY 99}

It was concluded that all items comprising the asbestos/transite ID could be completed in 36 months and, therefore, the ID could be accornplished well before FY 99. Should incremental improvements in technologivs be needed, sufficient time exists in the FY 94 - FY 99 time frame to accept modifications to the overall ID. However, lack of success with real-time characterization could push availability of this technology beyond FY 99. 


\section{Section $13 \quad$ Locations}

Most DOE and many commercial sites have asbestos/transite contamination. Every effort will be made to use the most appropriate DOE site for demonstration of each technology area; however, emphasis will be placed on sites conducting D\&D tests.

\begin{tabular}{|c|c|c|c|c|}
\hline DOE Sites & $\begin{array}{l}\text { Potentlal } \\
\text { Commerclal } \\
\text { Sites }\end{array}$ & $\begin{array}{l}\text { Relatlonships } \\
\text { between Sites }\end{array}$ & $\begin{array}{c}\text { Technical } \\
\text { Justification }\end{array}$ & $\begin{array}{c}\text { Financlal } \\
\text { (or other) } \\
\text { Justiflcation }\end{array}$ \\
\hline $\begin{array}{l}\text { FEMP } \\
\text { Rocky Flats } \\
\text { Hanford } \\
\text { Savannah River } \\
\text { INEL } \\
\text { LANL } \\
\text { Sandia } \\
\text { Oak Ridge } \\
\text { PANTEX }\end{array}$ & $\begin{array}{l}\text { any older } \\
\text { commercial } \\
\text { production } \\
\text { site, especially } \\
\text { if more than } 25 \\
\text { years old }\end{array}$ & $\begin{array}{l}\text { all sites have } \\
\text { asbestos and transite } \\
\text { some sites have } \\
\text { radiological } \\
\text { contamination of the } \\
\text { ACMs }\end{array}$ & $\begin{array}{l}\text { any site would make a } \\
\text { good demonstration } \\
\text { site for general } \\
\text { techniques } \\
\text { need to select a site in } \\
\text { or entering the D\&D } \\
\text { mode }\end{array}$ & $\begin{array}{l}\text { consent agreement at } \\
\text { FEMP and, possibly, } \\
\text { at Rocky Flats } \\
\text { mandate an earlier } \\
\text { clean up } \\
\text { good potential cost } \\
\text { savings due to size of } \\
\text { problem and current } \\
\text { baseline methods } \\
\text { EM-40 customer at } \\
\text { FEMP is supporter of } \\
\text { site as a test bed }\end{array}$ \\
\hline
\end{tabular}

\section{Section 13.1 DOE Sites}

\section{Fernald}

- FFCA compliance date set for April 1997 (CERCLA ROD)

- treatability study plan usable for permitting requirements

- dismantlement of buildings to begin in FY 94

- able to take advantage of EM-40 activities to leverage costs

- D\&D funding in EM-40 ADS's 


\section{Rocky Flats}

- recently designated EM-60 site

- major D\&D planning will begin in FY 95

- not FFCA-driven dt this time

- Fernald experiences expected to be directly applicable

\section{Hanford}

- D\&D of facility is currently a low priority

- D\&D scheduled to begin after 2001

\section{INEL}

- D\&D scheduled to start after 2001

\section{Savannah River}

- facility still in operational standby

- D\&D not scheduled

\section{Oak Ridge}

- K-25 awaiting D\&D

- Y-12 still operational

\section{LANL}

- D\&D of some facilities currently underway

- primarily laboratory-scale facilities 


\section{Section 13.2 Commercial Sites}

It is expected that many, or at least most, of the older commercial facilities contain asbestos and/or transite; however, some may have already instituted a replacement program for one or both of these materials. Therefore, a survey would be required to state with some degree of certainty the current scope of this problem in the commercial sector.

\section{Section 14 ID Schedule and Costs}

The following table summarizes the costs (in millions) of this ID over its entire lifespan.

\begin{tabular}{|l|c|c|c|c|c|c|c|}
\hline & Year 1 & Year 2 & Year 3 & Year 4 & Year 5 & Year 6 & Total \\
\hline Characterization & & 0.20 & 0.10 & & & & 0.30 \\
\hline Decontamination & & & & & & & 0.00 \\
\hline Dismantlement & 2.00 & 1.50 & 0.50 & & & & 4.00 \\
\hline Materials Disp. & 2.50 & 1.00 & 0.20 & & & & 3.70 \\
\hline Robotics \& Auto. & & 0.30 & & & & & 0.30 \\
\hline Mgmt. \& Sys. & 0.50 & 0.80 & 0.60 & & & & 1.90 \\
\hline Total & 5.00 & 3.80 & 1.40 & 0.00 & 0.00 & 0.00 & 10.20 \\
\hline
\end{tabular}


Astestos and Tiansite Demonstration Path

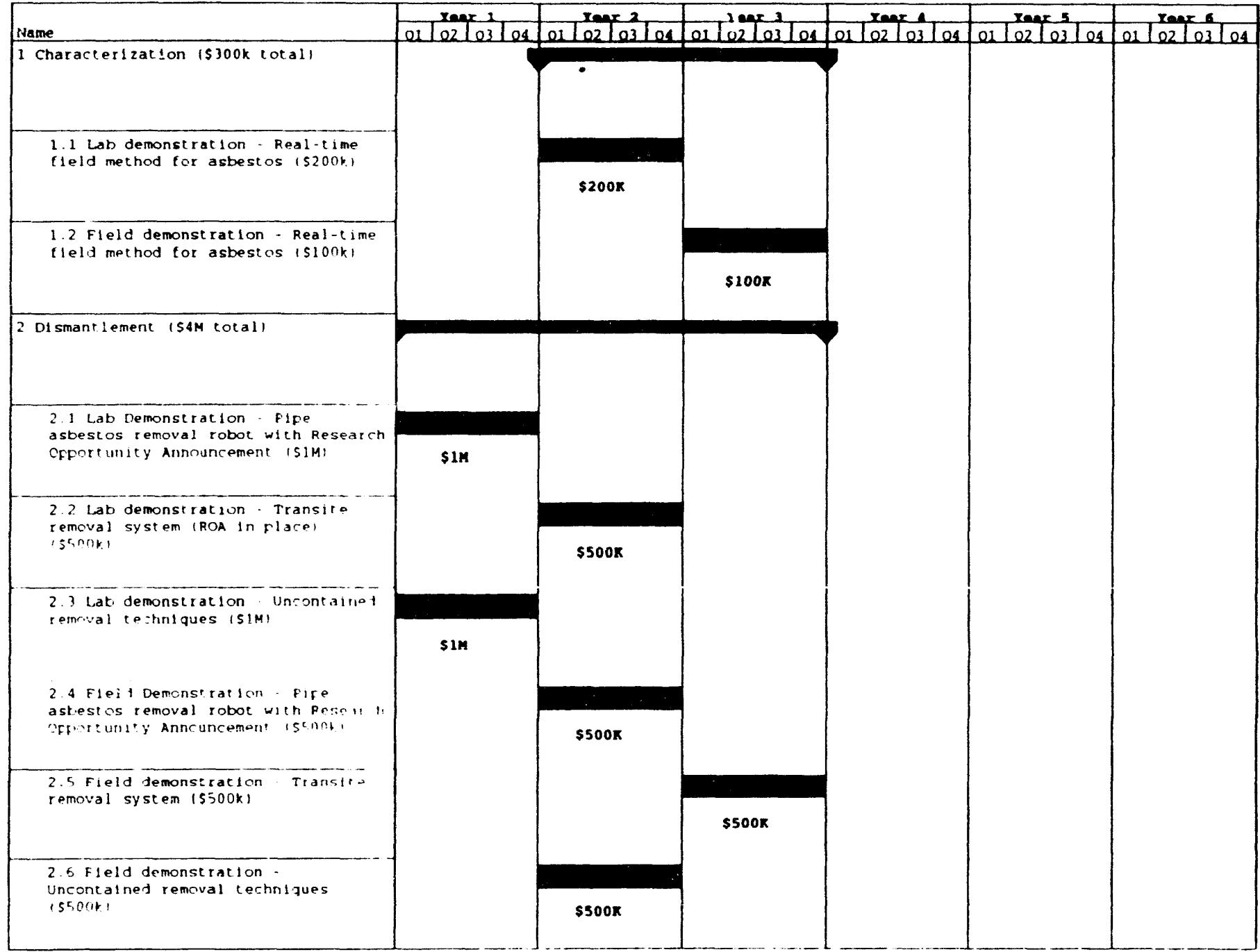




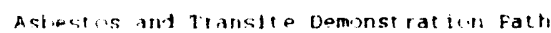

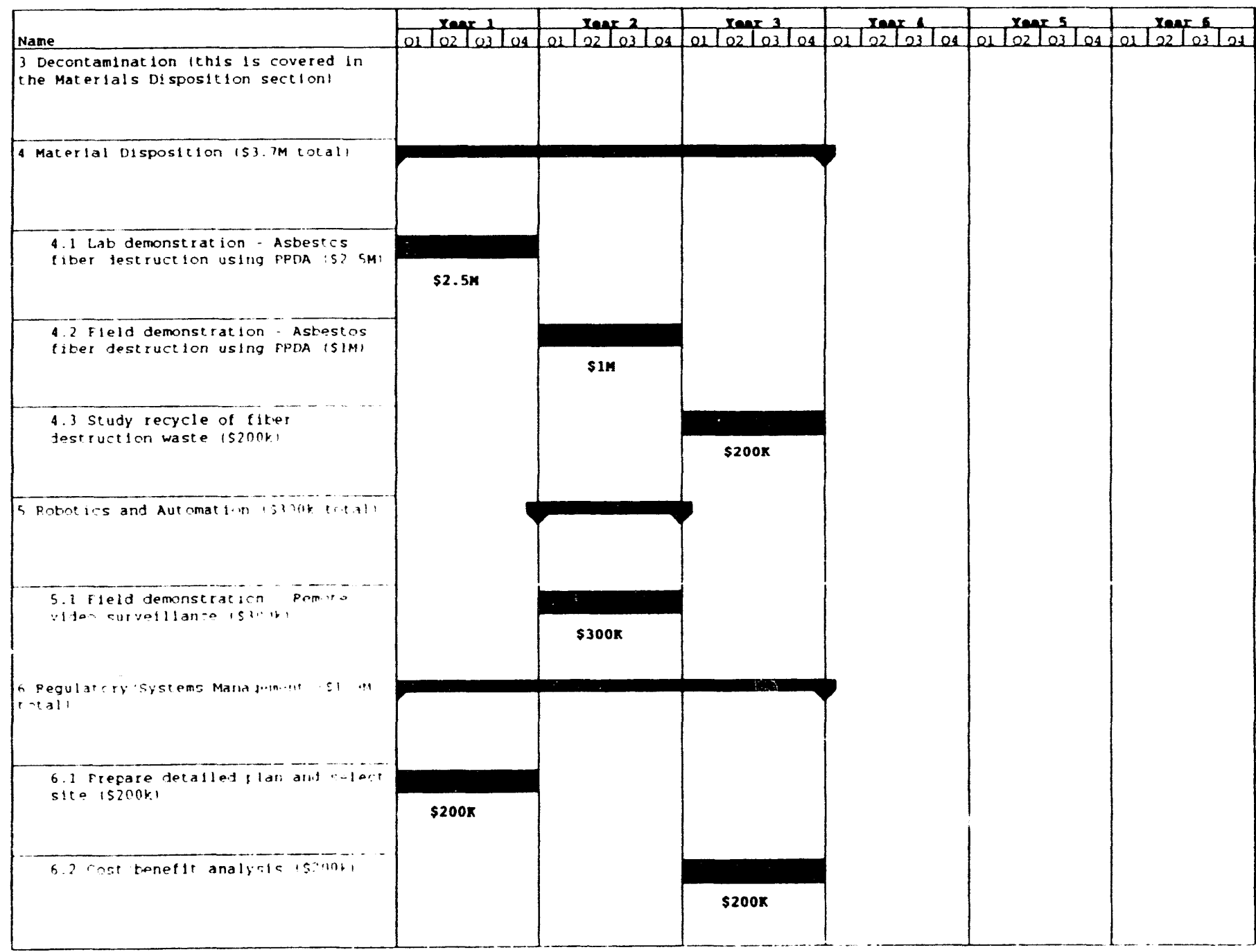




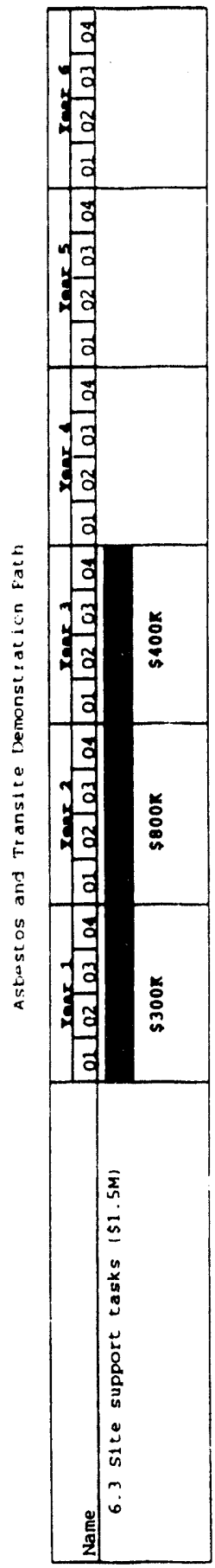


Glossary

Technical Program Plan for the Transitioning,

Decommissioning, and Final Disposition Focus Area
January 1994

Revision 0 

ALARA
as low as reasonably achievable
ANL
Argonne National Laboratory
BEC
below environmental concern
BRC
below regulatory concern
$\mathrm{CAD}$
computer-aided design
CEP
catalytic extraction process
CERCLA
Comprehensive Environmental Response, Compensation, and Liability Act
$D \& D$
decontamination and decommissioning
DF
decontamination factor
DoD
Department of Defense
DOE
Department of Energy
DOT
Department of Transportation
DT\&E
demonstration, testing, and evaluation
DP
Defense Programs
$\mathrm{EH}$
Environment and Health
EM
Environmental Restoration and Waste Management
EPA
Environmental Protection Agency
EPRI
Electric Power Research Institute
ER
Environmental Restoration
ES\&H
environment, safety, and health
ETEC
Energy Technology Engineering Center
FEMP
Fernald Environmental Management $F$ jject 
FFA

FFCA

FUSRAP

GDP

HEPA

ID

IDC

INEL

IP

ISRI

LANL

LBL

LDR

LL

LLNL

LLW

LRAD

MOU

NASA

NDA

NEPA

NTS

NRC
Federal Facility Agreement

Federal Facilities Compliance Agreement

Formerly Utilized Sites Remedial Action Program

gaseous diffusion plant

high-efficiency particulate air (filter)

integrated demonstration

Integrated Demonstration Coordinator

Idaho National Engineering Laboratory

integrated program

Institute of Scrap Recycling Industries

Los Alamos National Laboratory

Lawrence Berkeley Laboratory

land disposal restriction

low level

Lawrence Livermore National Laboratory

low-level waste

long-range alpha detector

Memorandum of Understanding

National Aeronautics and Space Administration

nondestructive assay

National Environmental Policy Act

Nevada Test Site

Nuclear Regulatory Commission 
ORNL

ORO

ORR

OSHA

OTD

PCB

PI

PNL

PPE

PRDA

R\&D

RCRA

RDDT\&E

RFP

ROD

RSM

RTDP

S\&M

SEG

SNM

TCLP

TD
Oak Ridge National Laboratory

Oak Ridge Office (of DOE)

Oak Ridge Reservation

Occupational Safety and Health Act

Office of Technology Development

polychlorinated biphenyl

principal investigator

Pacific Northwest Laboratory

personnel protection equipment

professional research and development agreement

Research and Development

Resource Conservation and Recovery Act

Research, Development, Demonstration, Testing, and Evaluation

request for proposal

Record of Decision

radiologically contaminated scrap metal

Robotics Technology Development Program

surveillance and maintenance

Scientific Ecology Group

strategic nuclear material

toxicity characteristic leaching procedure

technical development 
TPM

TPO

TRU

TSCA

TSG

TTP

WAC

WIPP
Technical Program Manager

Technical Program Officer

transuranic (waste)

Toxic Substance Control Act

Technical Support Group

technical task plan

waste acceptance criteria

Waste Isolation Pilot Plant 
$+\sqrt{2}-$
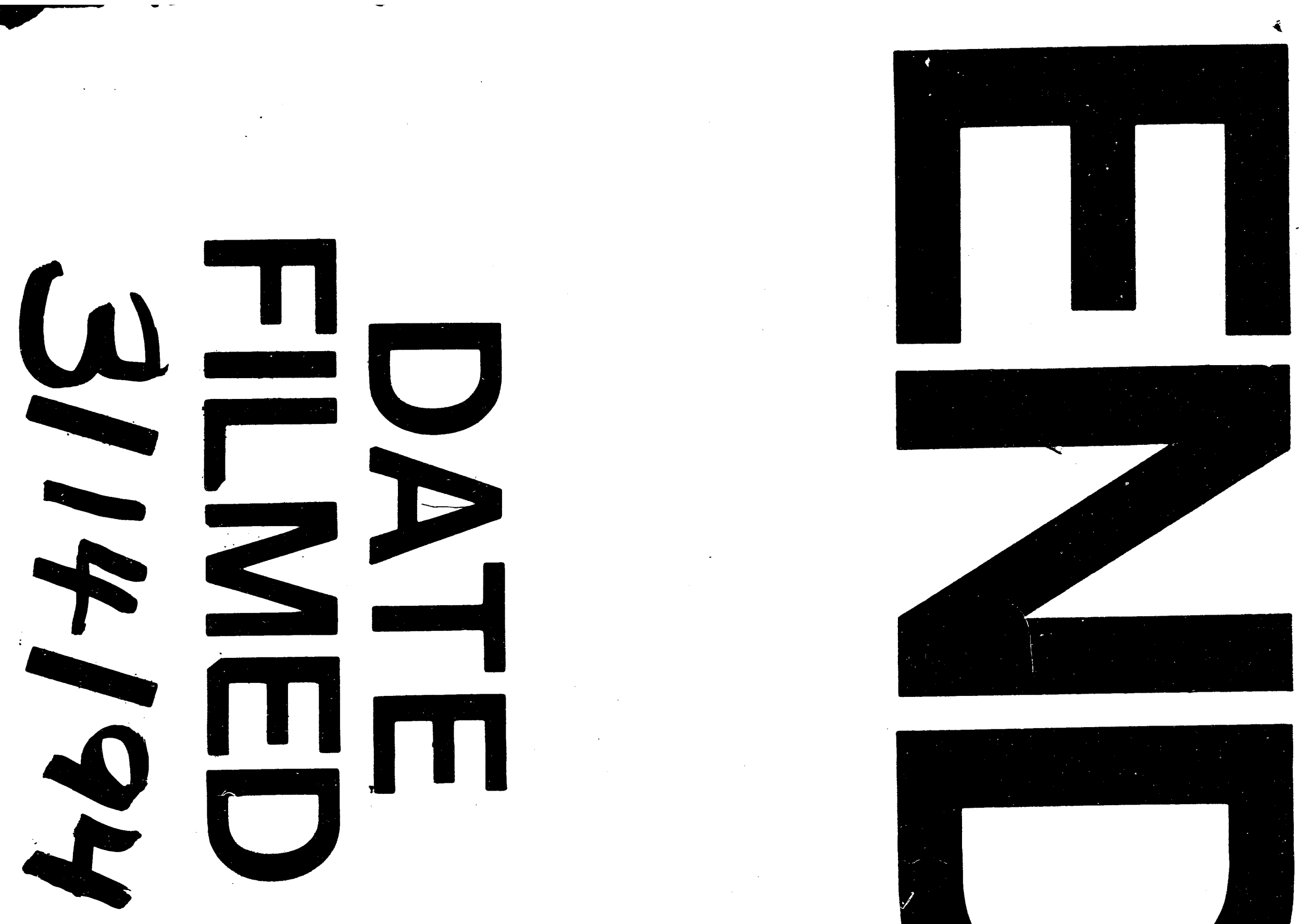

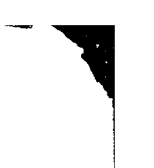
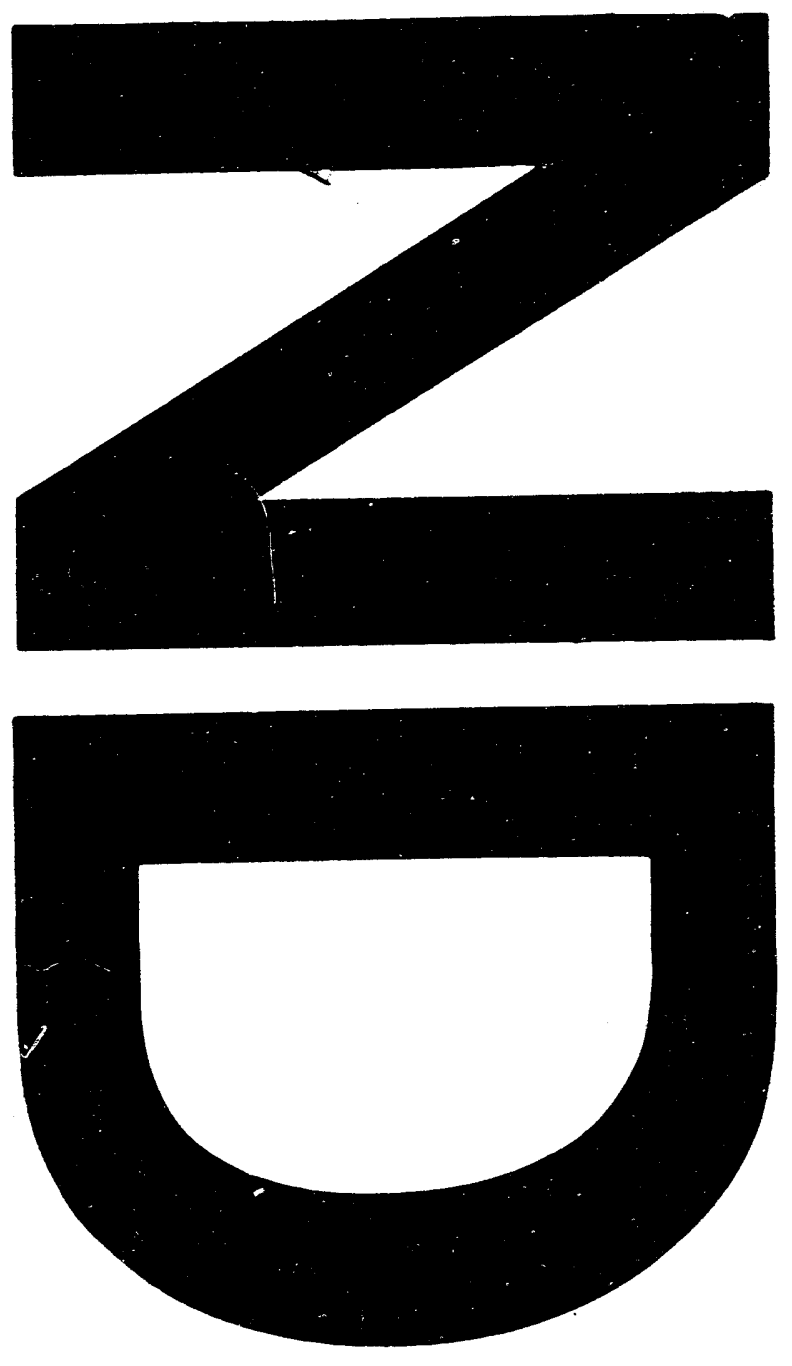
